\title{
Geomorphic Landform Design as an Alternative for Conventional Valley Fill Surface Mine Reclamation: Assessing Conceptual Design, Groundwater Modeling, and Contaminant Desorption
}

\author{
Nathan C. DePriest
}

Follow this and additional works at: https://researchrepository.wvu.edu/etd

\footnotetext{
Recommended Citation

DePriest, Nathan C., "Geomorphic Landform Design as an Alternative for Conventional Valley Fill Surface Mine Reclamation: Assessing Conceptual Design, Groundwater Modeling, and Contaminant Desorption" (2015). Graduate Theses, Dissertations, and Problem Reports. 5477.

https://researchrepository.wvu.edu/etd/5477

This Dissertation is protected by copyright and/or related rights. It has been brought to you by the The Research Repository @ WVU with permission from the rights-holder(s). You are free to use this Dissertation in any way that is permitted by the copyright and related rights legislation that applies to your use. For other uses you must obtain permission from the rights-holder(s) directly, unless additional rights are indicated by a Creative Commons license in the record and/ or on the work itself. This Dissertation has been accepted for inclusion in WVU Graduate Theses, Dissertations, and Problem Reports collection by an authorized administrator of The Research Repository @ WVU. For more information, please contact researchrepository@mail.wvu.edu.
} 
Geomorphic Landform Design as an Alternative for Conventional Valley Fill Surface Mine Reclamation: Assessing Conceptual Design, Groundwater Modeling, and Contaminant Desortion

\author{
Nathan C. DePriest
}

\begin{abstract}
Dissertation submitted
to the Benjamin M. Statler College of Engineering and Mineral Resources at West Virginia University
in partial fulfillment of the requirements for the degree of
Doctor of Philosophy in Civil and Environmental Engineering

\author{
Leslie C. Hopkinson, Ph.D., Co-Chair \\ John D. Quaranta, Ph.D., Co-Chair \\ Hema J. Siriwardane, Ph.D. \\ Joe Donovan, Ph.D. \\ Vladislav Kecojevic, Ph.D. \\ Department of Civil and Environmental Engineering
}

\title{
Morgantown, West Virginia
} 2015

Keywords: surface mining, geomorphic, Appalachia, reclamation, groundwater, modeling, desorption, selenium

Copyright 2015 Nathan C. DePriest 


\begin{abstract}
Assessing Geomorphic Landform Design as an Alternative for Conventional Valley Fill Surface Mine Reclamation

Nathan C. DePriest
\end{abstract}

This research aimed to evaluate the potential of applying geomorphic landform design (GLD) principles to valley fill reclamation, specifically in southern West Virginia, central Appalachia, USA. When constructing reclaimed landforms, GLD aims to mimic the geomorphology of reference landforms that are stable and in erosive and hydrologic equilibrium. Challenges with the technique have been identified related to use in central Appalachia. Reference landform design values vary by location and need to be quantified at a local scale for site-specific design. Due to the steep slopes of existing valleys, constructing engineered landforms that naturally blend in with the surrounding environment may not ensure stability. Less steep, more stable slopes of geomorphic landforms could create greater stream disturbance to maintain fill volumes. Potential benefits of GLD with respect to groundwater movement and contaminant desorption have also not been quantified. This research presents three major objectives to assess geomorphic landform design in central Appalachia: 1) define the geomorphic characteristics of mature landform reference sites in southern West Virginia; 2) quantify the issues associated with implementing geomorphic reclamation on a field scale at an existing valley fill; and, 3) compare models of groundwater movement and desorption of selenium in reclamation alternatives for a southern WV surface mine. Geomorphic properties of drainage length and drainage density for mature landforms in central Appalachia were $408 \mathrm{ft}$ and $62 \mathrm{ft} / \mathrm{ac}$, respectively. Slopes were steep (>20\%), aspects were well distributed in all directions, vegetation was predominately dense core forest, and ephemeral channel heads developed where erosive surface processes created concentrated flow and sediment transport. Potential issues associated with implementing GLD in central Appalachia with respect to landform stability, stable channel mitigation, and mass balance were confirmed. No geomorphic design was able to satisfy all three criteria when the permitted area of impact was maintained. Expanding the area of impact beyond permit boundaries promoted more success in meeting design criteria, but did not comply with reclamation regulations governing excess spoil placement and constructed hillslopes. A quantitative comparison of the groundwater movement and selenium desorption between alternative reclamation designs confirmed potential benefits to geomorphic reclamation. Selenium desorption was reduced by $23-39 \%$ in geomorphic fills and was attributed to improved groundwater movement. Geomorphic reclaimed landforms exhibited 23-45\% lower infiltration volumes, $12-63 \%$ lower groundwater discharge volumes, and approximately $50 \%$ shorter groundwater residence times. These findings will be used to provide recommendations to government agencies and the surface mining industry on the practicality of implementing geomorphic reclamation as an alternative to conventional valley fill reclamation in central Appalachia. 


\section{TABLE OF CONTENTS}

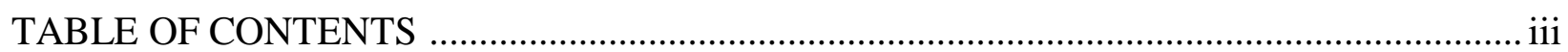

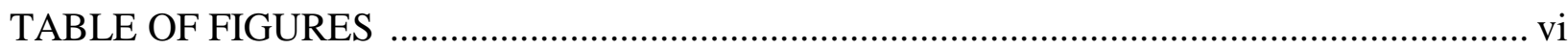

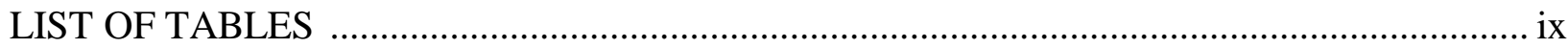

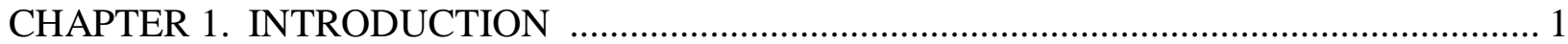

1.1. Research Motivation and Problem Statement ................................................................ 1

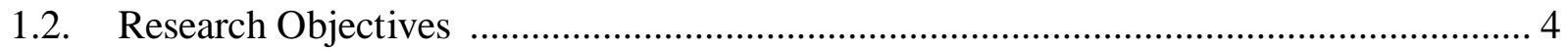

1.3. Contributions to the Body of Knowledge ………..................................................... 4

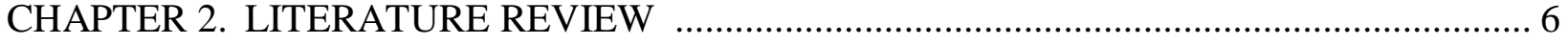

2.1. Conventional and alternative surface mine reclamation .................................................. 6

2.1.1. Conventional reclamation techniques in central Appalachia .................................... 6

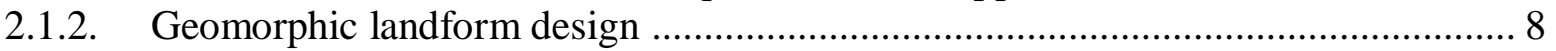

2.2. Channel heads and basin geomorphology ............................................................. 12

2.3. Groundwater and contaminant modeling ……….................................................... 15

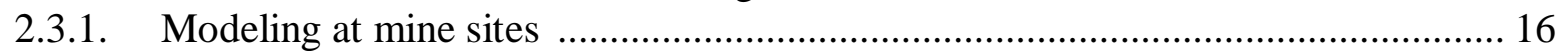

2.3.2. Groundwater modeling at Appalachian mine sites ............................................. 20

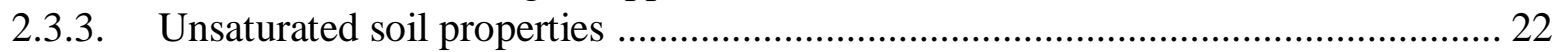

2.3.4. Desorption of selenium .............................................................................. 24

CHAPTER 3. GEOMORPHIC CHARACTERISTICS OF MATURE LANDFORMS IN

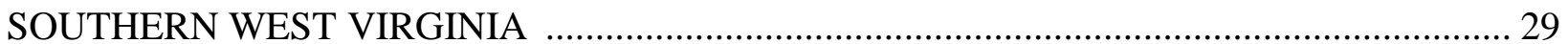

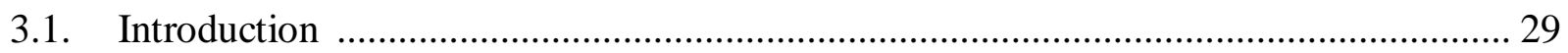

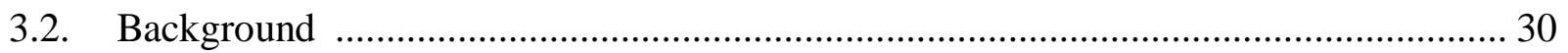

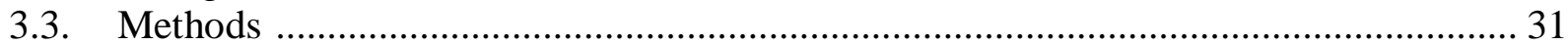

3.3.1. Reference landform site selection .................................................................... 31

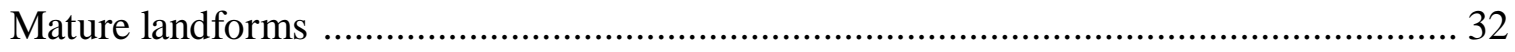

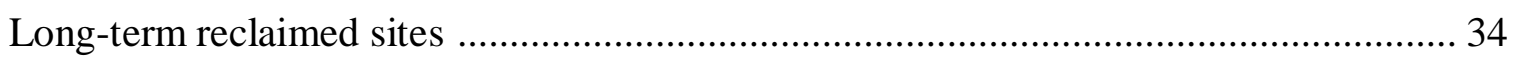

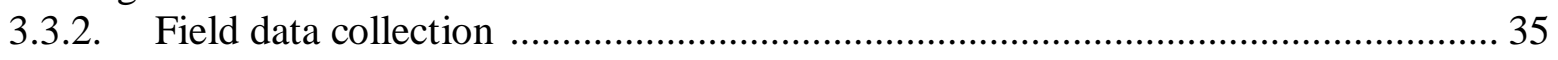

3.3.3. Geomorphic design criteria ………………................................................. 36

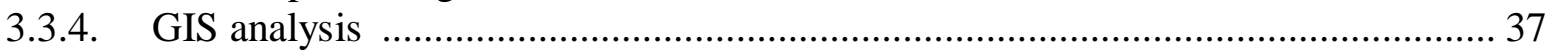

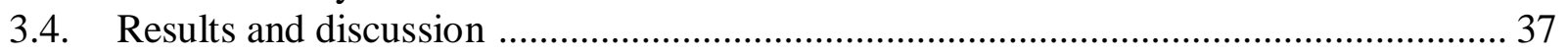

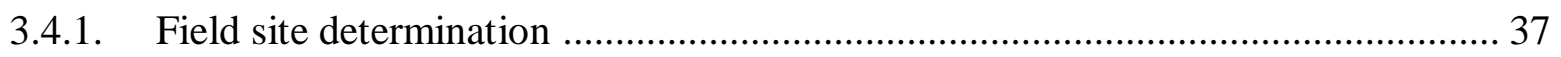

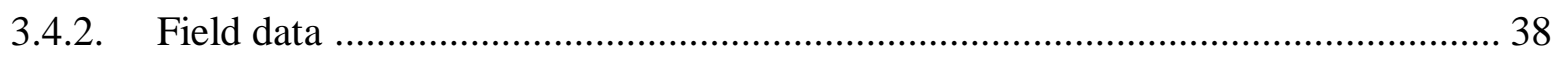

3.4.3. Geomorphic design criteria ...................................................................... 40

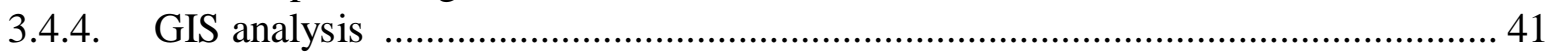

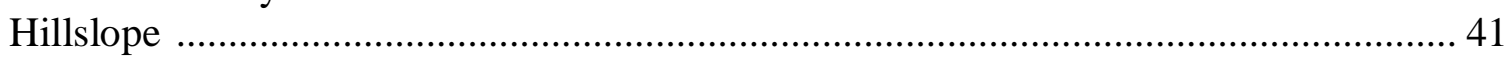

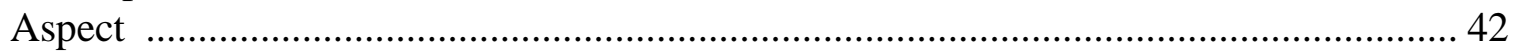

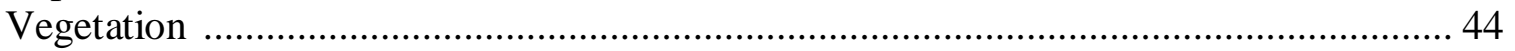

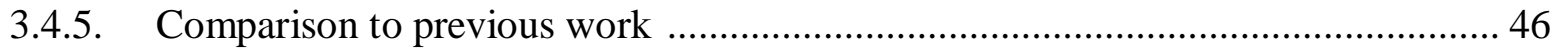

3.5. Conclusions and recommendations ........................................................................ 46

CHAPTER 4. QUANTIFYING THE ISSUES ASSOCIATED WITH IMPLEMENTING

GEOMORPHIC RECLAMTION IN CENTRAL APPALACHIA ……................................. 48

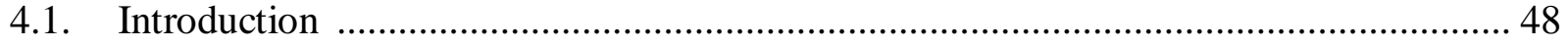

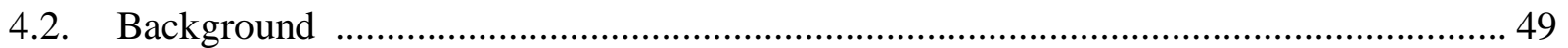

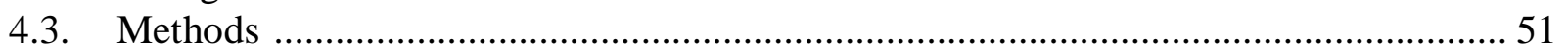

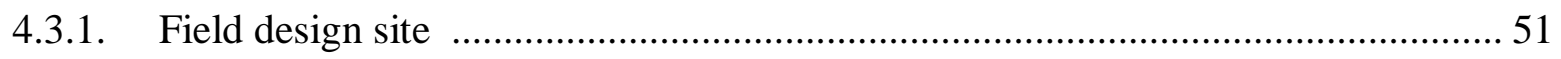


4.3.2. Design of geomorphic reclamation landforms ................................................... 52

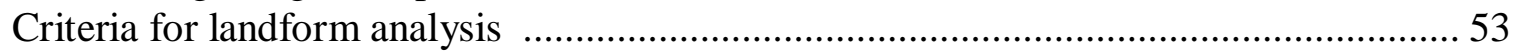

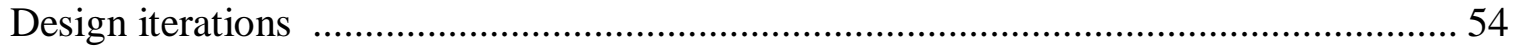

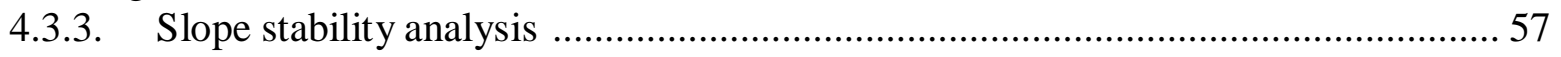

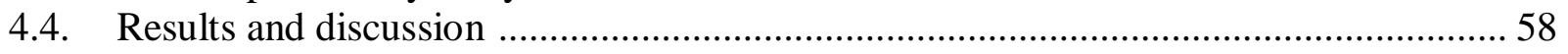

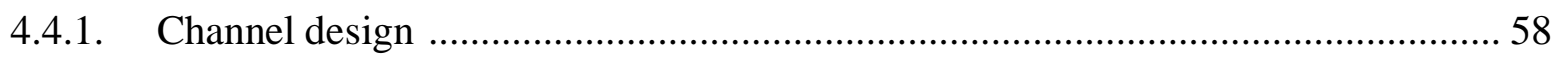

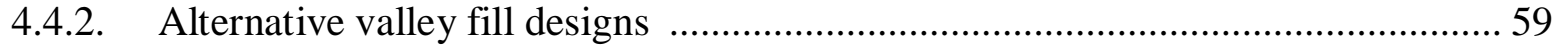

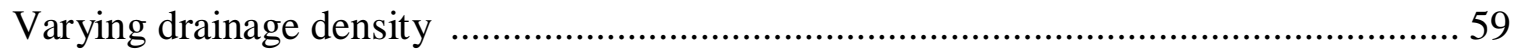

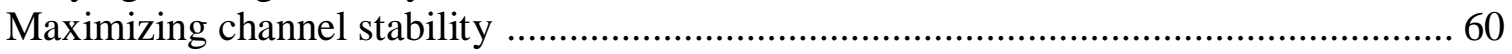

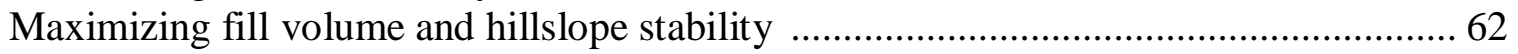

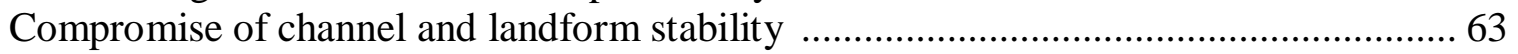

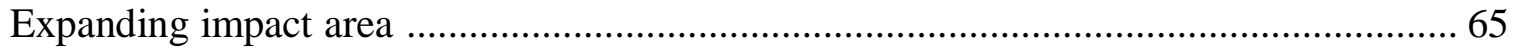

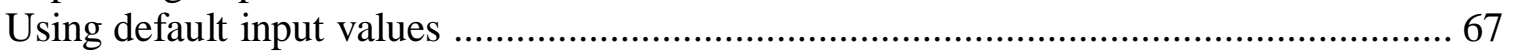

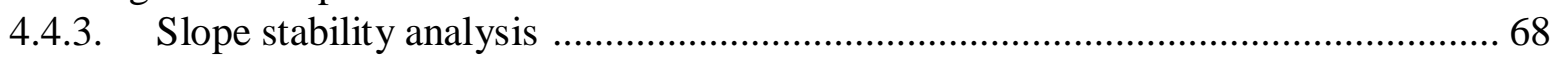

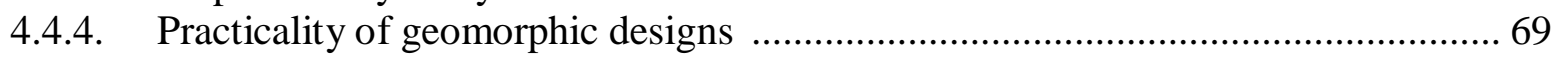

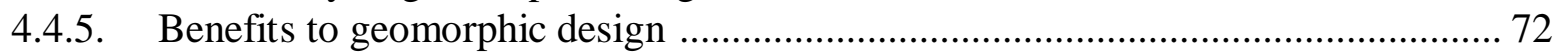

4.5. Conclusions and recommendations ........................................................................ 73

CHAPTER 5. GROUNDWATER MODELING AND SELENIUM DESORPTION COMPARISON OF GEOMORPHIC AND CONVENTIONAL VALLEY FILL

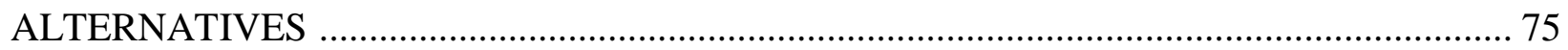

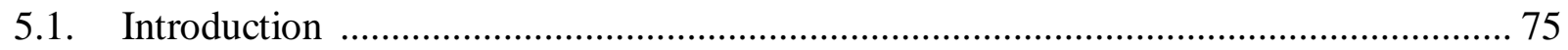

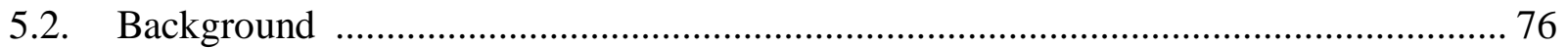

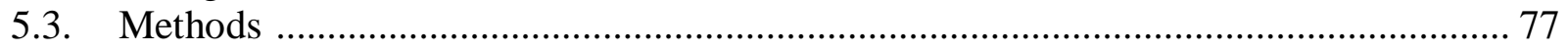

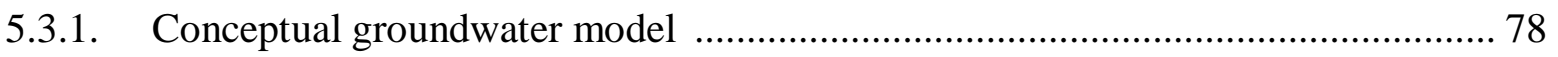

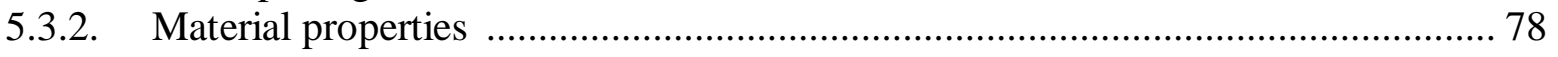

5.3.3. Numerical groundwater model ………………............................................ 82

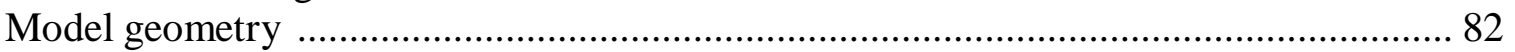

Boundary conditions - two-dimensional groundwater models ........................................ 83

Boundary conditions - three-dimensional groundwater models ..................................... 85

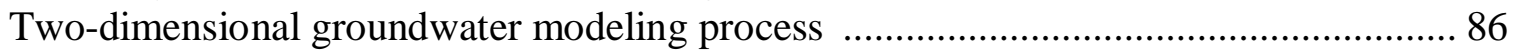

Three-dimensional groundwater modeling process ………........................................... 87

Groundwater flow path tracking ............................................................................... 87

Normalization and comparison of groundwater results ................................................. 90

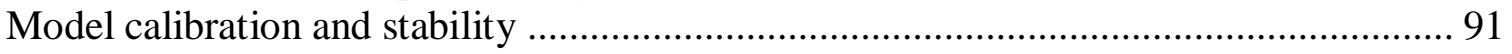

5.3.4. Selenium desorption calculation ……………..................................................... 92

Step 1: Laboratory testing of unsaturated selenium desorption ...................................... 92

Step 2: Combining selenium laboratory desorption data and two-dimensional

groundwater results .................................................................................................... 94

Step 3: Combining selenium laboratory desorption data and three-dimensional groundwater results .............................................................................................. 96

Step 4: Normalizing and comparing selenium desorption results ................................... 97

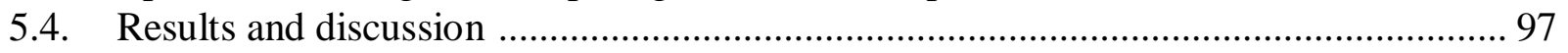

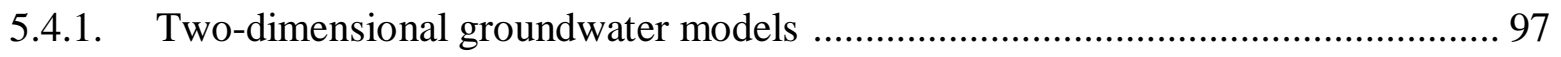

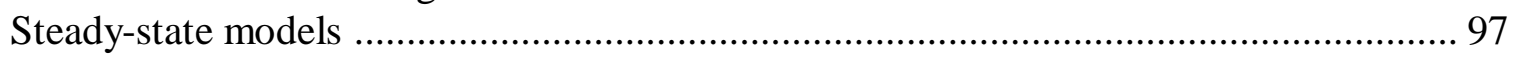

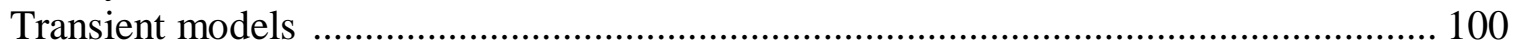

5.4.2. Three-dimensional groundwater models ............................................................ 104 
5.4.3. Groundwater model calibration and stability .................................................... 107

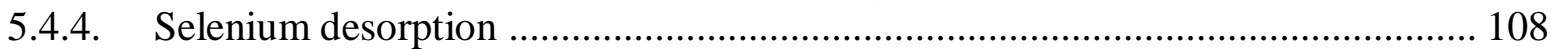

Two-dimensional calculation for desorbed Se mass ................................................. 108

Three-dimensional calculation for desorbed Se mass ............................................. 111

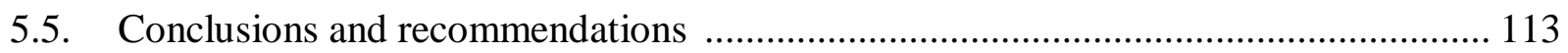

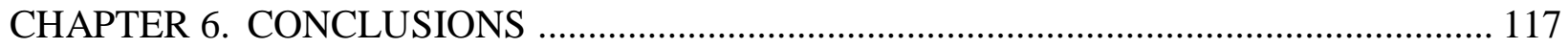

6.1. Objective 1: Quantify characteristics of mature landforms in West Virginia ............. 117

6.2. Objective 2: Quantify the issues associated with implementing geomorphic reclamation in central Appalachia ................................................................................................ 118 6.3. Objective 3: Compare groundwater and selenium transport modeling of geomorphic and conventional valley fill alternatives .............................................................................. 119

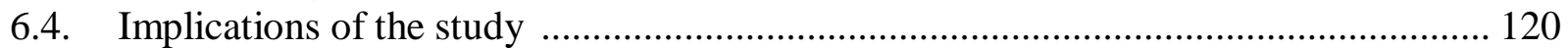

6.5. Limitations of the study and future research recommendations ................................. 121

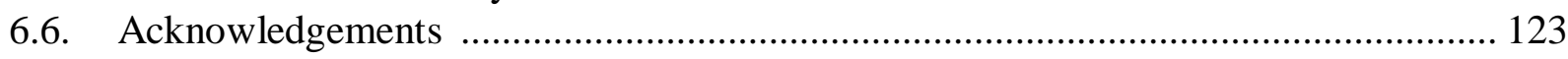

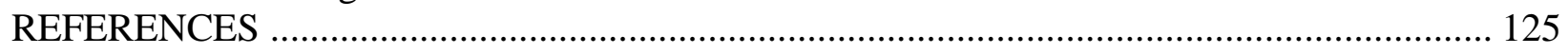

APPENDIX A. REFERENCE LANDFORM SELECTION ………………..................... 137

APPENDIX B. REFERENCE LANDFORM CHARACTERISTICS ..................................... 145

APPENDIX C. GROUNDWATER MODELING AND SELENIUM DESORPTION

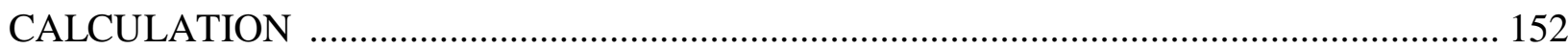




\section{TABLE OF FIGURES}

Figure 1.1. Location of research design site and extent of valley fills in West Virginia, USA ...... 2

Figure 3.1. Evaluation procedure guiding field site selection ................................................ 32

Figure 3.2. Location of reference landforms sites relative to design site for generation of geomorphic landforms

Figure 3.3. Channel heads and erosion sites at reference landforms: (a) Twin Falls State Park; (b)

Cabwaylingo State Forest; and, (c) Summersville, WV long-term reclaimed site ..................... 39

Figure 3.4. Slope distributions for reference landforms: (a) Twin Falls State Park; (b)

Cabwaylingo State Forest; and, (c) Summersville, WV long-term reclaimed site

Figure 3.5. Aspect distributions for reference watersheds: (a) Twin Falls State Park; (b)

Cabwaylingo State Forest; and, (c) Summersville, WV long-term reclaimed site

Figure 3.6. Vegetation distribution of reference landforms: (a) Twin Falls State Park; (b)

Cabwaylingo State Forest; and, (c) Summersville, WV long-term reclaimed site 45

Figure 3.7. Vegetation at (a) long-term reclaimed site; and, (b) mature landform site

Figure 4.1. VF1 and VF2 locations on (a) original contours; and, (b) conventional reclamation contours

Figure 4.2. Natural Regrade design process for generating geomorphic landforms: (a) Given an existing topography; (b) User defines landform boundary and creates a polyline which satisfies geomorphic input parameters from which to generate a stream; (c) Software generates a stream and corresponding ridges and valleys; (d) Software triangulates and contours geomorphic landform that ties into surrounding topography....

Figure 4.3. Expanded impact area of VF1 compared to the original valley fill footprint ............ 56

Figure 4.4. Geomorphic designs for VF1 with varying drainage density: (a) low drainage density (Design 1); (b) target drainage density (Design 2); and, (c) high drainage density (Design 3) .... 60 Figure 4.5. Geomorphic designs for VF2 with varying drainage density: (a) low drainage density (Design 4); (b) target drainage density (Design 5); and, (c) high drainage density (Design 6) .... 60 Figure 4.6. Geomorphic designs in permitted with maximum channel stability for (a) valley fill 1 (Design 7); and, (b) valley fill 2 (Design 8)....

Figure 4.7. Centerline profiles of geomorphic designs for valley fill 1 compared to original and conventional reclaimed topography

Figure 4.8. Geomorphic designs in permitted with maximum fill volume and hillslope stability

for (a) valley fill 1 (Design 9); and, (b) valley fill 2 (Design 10)..

Figure 4.9. Geomorphic designs for VF1 in permitted area with (a) stable channel at bankfull flow (Design 11); (b) stable channel at flood prone flow (Design 12); and, (c) stable channel at flood prone flow and high drainage density (Design 13)...

Figure 4.10. Slope distribution of (a) pre-mined topography; (b) conventional reclamation; (c) geomorphic design 12; and, (d) geomorphic design 16.

Figure 4.11. Geomorphic designs for VF1 in expanded area with (a) preserved channel (Design 14); (b) stable channel at bankfull flow (Design 15); and, (c) stable channel at flood prone flow (Design 16).

Figure 4.12. Geomorphic design for VF1 using software's default input values (Design 17)..... 68 Figure 4.13. Aspect distribution of (a) pre-mined topography; (b) conventional reclamation; (c) geomorphic design 12; and, (d) geomorphic design 16. 73

Figure 5.1. Conceptual groundwater model of valley fill 78 
Figure 5.2. Soil-water characteristic curve for mine spoil developed from Fredlund and Xing (1994) equation and Torres (2011) curve fitting parameters. Volumetric water content $(\theta)$ versus

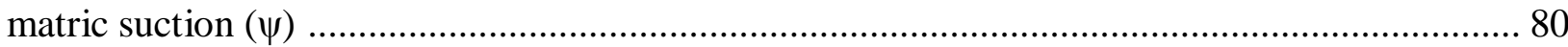
Figure 5.3. Unsaturated permeability function for mine spoil estimated according to Fredlund et al. (1994). Soil hydraulic conductivity (k) versus matric suction $(\psi)$ 81

Figure 5.4. Contours used for geometry of two-dimensional and three-dimensional models with location of two-dimensional profile slice for (a) original valley; (b) conventional valley fill reclamation; and, (c) geomorphic design

Figure 5.5. Two-dimensional profiles along centerline slice for original valley, conventional valley fill reclamation, and geomorphic design

Figure 5.6. Groundwater boundary conditions applied to two-dimensional profiles of conventional and geomorphic fills

Figure 5.7. Groundwater boundary conditions applied (as shown in plan view) to threedimensional models of (a) conventional fill, and (b) geomorphic fill. Infiltration boundary conditions (as a percentage of precipitation) applied on the XY plane; review boundary conditions applied on the XZ plane (into page) 86

Figure 5.8. Geometry of fill area affected by an individual flow path "i": a) coordinates and total area $\left(\mathrm{A}_{\mathrm{i}}\right)$ affected by flow path of interest with respect to adjacent flow paths; b) geometry of left portion of area affected by flow path of interest $\left(\mathrm{A}_{\mathrm{i}, \mathrm{i}-1}\right)$; and, $\left.\mathrm{c}\right)$ geometry of right portion of area

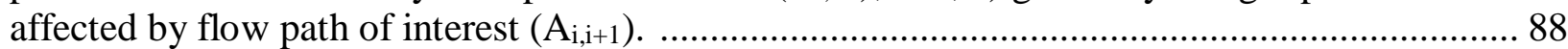
Figure 5.9. Concentration of selenium in leachate of duplicate unsaturated column tests ......... 94 Figure 5.10. Steady-state groundwater flow paths and hydraulic head for conventional fill and geomorphic fill with $10 \%$ stream infiltration. Both models are unsaturated, homogeneous, and isotropic

Figure 5.11. Normalized percent change of two-dimensional, steady-state groundwater results from conventional fill to geomorphic fill with stream infiltration rate varying from $0 \%$ to $55 \%$ of precipitation: volume of infiltrating water $\left(\mathrm{V}_{\mathrm{i}}\right)$, flow rate at toe $\left(\mathrm{Q}_{\mathrm{t}}\right)$, and degree of saturation $(\mathrm{S})$.

Figure 5.12. Difference in infiltration volume $\left(\mathrm{V}_{\mathrm{i}}\right)$ and discharge volume $\left(\mathrm{V}_{0}\right)$ among twodimensional models of reclamation alternatives. Region above $\mathrm{x}$-axis represents infiltration greater than discharge; region below $\mathrm{x}$-axis represents infiltration less than discharge ............ 103 Figure 5.13. Cumulative fraction of fill volume contacted by discharging water over time in twodimensional models of reclamation alternatives ....

Figure 5.14. Pore pressure distribution in three-dimensional models of reclamation alternatives: (a) conventional fill; and, (b) geomorphic fill. Lightest shade in distribution corresponds to positive pore pressure (location of groundwater table) 105

Figure 5.15. Cumulative fraction of three-dimensional fill volume contacted by discharging water over time in fill alternatives Figure 5.16. Normalized desorption of selenium from individual passes of water assuming passes occur in succession in two-dimensional models of reclamation alternatives .......................... 110 Figure 5.17. Cumulative normalized desorbed selenium from consecutive passes of water in twodimensional models.

Figure 5.18. Normalized desorption of selenium from individual passes of water assuming passes occur in succession in three-dimensional models of reclamation alternatives. 112 Figure 5.19. Cumulative normalized desorbed selenium from consecutive passes of water in three-dimensional models or reclamation alternatives 
Figure B.1. Channel beds at channel heads and mouth of Dixon watershed................... 148

Figure B.2. Channel beds at channel heads in Jackson watershed ......................... 149

Figure B.3. Channel beds at channel heads and mouth of Wiley watershed................... 150

Figure B.4. Mouth (looking upstream) of Dixon and Wiley watersheds.................. 150

Figure B.5. Photos of erosion sites at Summersville valley fills .......................... 150

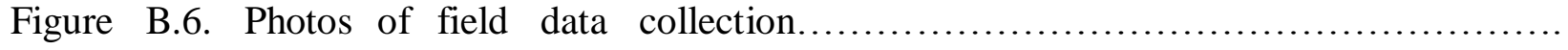

Figure C.1. Two-dimensional particle tracking of groundwater flow paths over time for conventional fill............................................................... 157

Figure C.2. Two-dimensional particle tracking of groundwater flow paths over time for

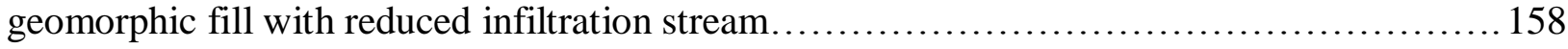




\section{LIST OF TABLES}

Table 3.1. Description, justification, and resources for decision matrix for mature landforms (Regional Evaluation Phase)....

Table 3.2. Description, justification, and resources for decision matrix for mature landforms

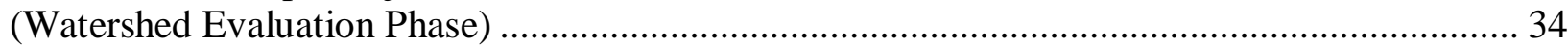

Table 3.3. Description, justification, and resources for evaluation matrix for long-term reclaimed

sites (Regional Evaluation Phase) ............................................................................... 35

Table 3.4. Description, justification, and resources for decision matrix for long -term reclaimed sites (Watershed Evaluation Phase) .................................................................................. 35

Table 3.5. Mean slope $\left(\mathrm{S}_{\mathrm{c}}\right)$, width $(\mathrm{B})$, median particle size $\left(\mathrm{D}_{50}\right)$ and drainage length $\left(\mathrm{L}_{\mathrm{D}}\right)$ at channel head locations or erosion sites of reference landforms. Standard deviation of each mean

value is reported in parentheses ........................................................................................ 39

Table 3.6. Reference landform watershed characteristics $\left(\mathrm{S}_{\mathrm{L}}=\right.$ mean hillslope, $\mathrm{DD}=$ drainage

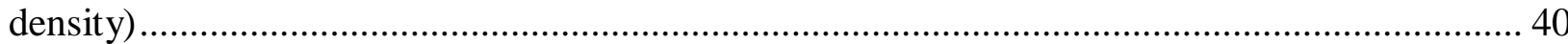

Table 3.7. Drainage densities calculated from varying stream lengths. Starting with the NHD streams first, the streams delineated from field mapped sites were added, and then the streams from GIS mapped sites were added. ...................................................................... 41

Table 3.8. Percent by area of each slope range for each reference landform............................ 41

Table 3.9. Distribution of aspect for reference landform landforms .......................................... 43

Table 3.10. Percent by area coverage of vegetation types for each reference landform.............. 44

Table 4.1. Summary of geomorphic valley fill design iterations ........................................... 57

Table 4.2. Characteristics of landforms developed to investigate drainage density (DD): ratio of design fill volume to conventional fill volume $\left(\mathrm{V}_{\mathrm{GLD}} / \mathrm{V}_{\mathrm{CV}}\right)$. Three designs created for each valley

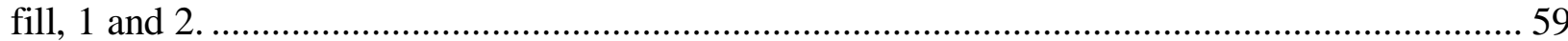

Table 4.3. Characteristics of landforms developed to maximize channel stability: range in channel slopes $\left(\mathrm{S}_{\mathrm{c}}\right)$, maximum shear stress at bankfull $\left(\tau_{\mathrm{b}}\right)$, maximum shear stress at flood prone $\left(\tau_{\mathrm{f}}\right)$, percent of unstable hillslopes by area $(>50 \%)\left(\mathrm{P}_{\mathrm{HS}}\right)$, ratio of design fill volume to conventional fill volume $\left(\mathrm{V}_{\mathrm{GLD}} / \mathrm{V}_{\mathrm{CV}}\right)$. One design was created for each valley fill, 1 and $2 \ldots . . . .61$ Table 4.4. Characteristics of landforms developed to maximize fill volume and hillslope stability: range in channel slopes $\left(S_{c}\right)$, maximum shear stress at bankfull $\left(\tau_{b}\right)$, maximum shear stress at flood prone $\left(\tau_{\mathrm{f}}\right)$, percent of unstable hillslopes $(>50 \%)\left(\mathrm{P}_{\mathrm{HS}}\right)$, ratio of design fill volume to conventional fill volume $\left(\mathrm{V}_{\mathrm{GLD}} / \mathrm{V}_{\mathrm{CV}}\right)$. One design created for each valley fill, 1 and $2 . \ldots \ldots \ldots \ldots . . . .62$ Table 4.5. Characteristics of landforms developed to compromise stability and fill volume for VF1: range in channel slopes $\left(S_{c}\right)$, maximum shear stress at bankfull $\left(\tau_{b}\right)$, maximum shear stress at flood prone $\left(\tau_{\mathrm{f}}\right)$, percent of unstable hillslopes $(>50 \%)\left(\mathrm{P}_{\mathrm{HS}}\right)$, ratio of design fill volume to conventional fill volume $\left(\mathrm{V}_{\mathrm{GLD}} / \mathrm{V}_{\mathrm{CV}}\right)$. $\mathrm{BF}=$ bankfull, $\mathrm{FP}=$ floodprone, $\mathrm{DD}=$ drainage density.

Designs were completed for three cases of channel stability.....

Table 4.6. Characteristics of landforms developed with an expanded impact area for VF1: range in channel slopes $\left(\mathrm{S}_{\mathrm{c}}\right)$, maximum shear stress at bankfull $\left(\tau_{\mathrm{b}}\right)$, maximum shear stress at flood prone $\left(\tau_{\mathrm{f}}\right)$, percent of unstable hillslopes $(>50 \%)\left(\mathrm{P}_{\mathrm{HS}}\right)$, ratio of design fill volume to conventional fill volume $\left(\mathrm{V}_{\mathrm{GLD}} / \mathrm{V}_{\mathrm{CV}}\right)$. $\mathrm{BF}$ =bankfull, $\mathrm{FP}=$ floodprone. Designs were completed for three cases of channel stability. 66 Table 4.7. Characteristics of landforms developed using default software parameters for VF1: range in channel slopes $\left(S_{c}\right)$, maximum shear stress at bankfull $\left(\tau_{b}\right)$, maximum shear stress at 
flood prone $\left(\tau_{\mathrm{f}}\right)$, percent of unstable hillslopes $(>50 \%)\left(\mathrm{P}_{\mathrm{HS}}\right)$, ratio of design fill volume to conventional fill volume $\left(\mathrm{V}_{\mathrm{GLD}} / \mathrm{V}_{\mathrm{CV}}\right)$.

Table 4.8. Distribution of slope ranges between 50-60\% grade and minimum Factor of Safety for

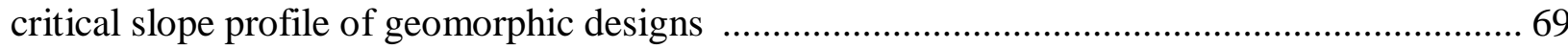

Table 4.9. Analysis of design criteria for geomorphic designs for VF1. ............................... 70

Table 5.1. Expected and range of values for fill material properties ....................................... 79 Table 5.2. Percent of mobile Se desorbed from individual consecutive infiltrations through an unsaturated sandstone soil column.

Table 5.3. Mass, volume, and Se properties of two-dimensional models of reclamation alternatives using column leaching lab data

Table 5.4. Mass, volume, and Se properties of three-dimensional models of reclamation alternatives using column leaching lab data

Table 5.5. Steady-state results for conventional and geomorphic fills: volume of infiltrating water $\left(\mathrm{V}_{\mathrm{i}}\right)$, degree of saturation $(\mathrm{S})$, flow rate at toe $\left(\mathrm{Q}_{\mathrm{t}}\right)$, and total volume of water in fill $\left(\mathrm{V}_{\mathrm{w}}\right)$. Models conditions varied as follows: saturated (Sat), unsaturated (US), isotropic (I), anisotropic (A), stream infiltration rate (Infil) from $0 \%$ to $50 \%$ of total precipitation rate or equal to uncovered infiltration rate

Table 5.6. Two-dimensional transient groundwater modeling results for the conventional fill and geomorphic fill with or without a stream under unsaturated isotropic conditions: volume of infiltrating water $\left(\mathrm{V}_{\mathrm{i}}\right)$, flow rate at toe $\left(\mathrm{Q}_{\mathrm{t}}\right)$, cumulative volume of water that has discharged through toe $\left(\mathrm{V}_{\mathrm{o}}\right)$, total volume of water in fill $\left(\mathrm{V}_{\mathrm{w}}\right)$, degree of saturation $(\mathrm{S})$, and difference in infiltration and discharge volumes $\left(\mathrm{V}_{\mathrm{i}}-\mathrm{V}_{\mathrm{o}}\right)$.

Table 5.7. Normalized percent change in two-dimensional groundwater modeling results from conventional fill to geomorphic fills: volume of infiltrating water $\left(\mathrm{V}_{\mathrm{i}}\right)$, flow rate at toe $\left(\mathrm{Q}_{\mathrm{t}}\right)$, cumulative volume of water that has discharged through toe $\left(\mathrm{V}_{\mathrm{o}}\right)$, total volume of water in fill $\left(\mathrm{V}_{\mathrm{w}}\right)$, and difference in infiltration and discharge volumes $\left(\mathrm{V}_{\mathrm{i}}-\mathrm{V}_{\mathrm{o}}\right)$.

Table 5.8. Normalized percent change in three-dimensional transient groundwater modeling results from conventional fill to geomorphic fill: volume of infiltrating water $\left(\mathrm{V}_{\mathrm{i}}\right)$, instantaneous flow rate at toe $\left(\mathrm{Q}_{\mathrm{t}}\right)$, cumulative volume of water that has discharged through toe $\left(\mathrm{V}_{\mathrm{o}}\right)$, total volume of water in fill $\left(\mathrm{V}_{\mathrm{w}}\right)$, and difference in infiltration and discharge volumes $\left(\mathrm{V}_{\mathrm{i}}-\mathrm{V}_{\mathrm{o}}\right)$.... 106 Table 5.9. Percent change in normalized selenium desorption in two-dimensional model of geomorphic fill with stream compared to conventional fill as a result of consecutive passes of water, both individually and cumulatively

Table 5.10. Percent change in normalized selenium desorption in three-dimensional model of geomorphic fill compared to conventional fill as a result of consecutive passes of water, both individually and cumulatively

Table A.1. Regional evaluation matrix for Twin Falls State Park.............................137

Table A.2. Regional evaluation for Cabwaylingo State Forest. .......................................... 138

Table A.3. Regional evaluation for East Lynn Lake Wildlife Management Area .................... 139

Table A.4. Regional evaluation for Laurel Lake Wildlife Management Area ......................... 140

Table A.5. Regional evaluation for R.D. Bailey Lake ......................................................... 141

Table A.6. Regional evaluation for Beech Fork State Park. ................................................ 141

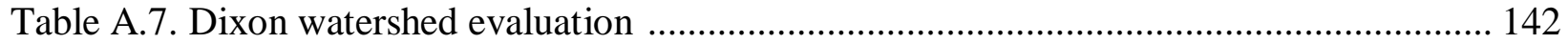

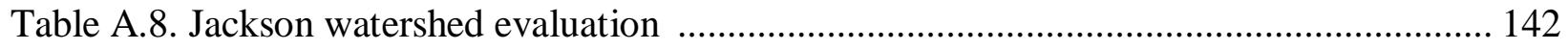

Table A.9. Wiley watershed evaluation ...................................................................... 142 
Table A.10. Regional evaluation for Summersville long-term reclaimed site

Table A.11. Watershed evaluation for northwest facing valley fill in Summersville, WV. ...... 143

Table A.12. Watershed evaluation for southwest facing valley fill in Summersville, WV. ...... 144

Table A.13. Watershed evaluation for northeast facing valley fill in Summersville, WV. ....... 144

Table A.14. Watershed evaluation for southeast facing valley fill in Summersville, WV. ....... 144

Table B.1. Site properties - Dixon watershed. .................................................................. 145

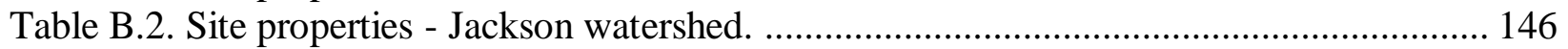

Table B.3. Site properties - Wiley watershed. .................................................................. 146

Table B.4. Critical grain size distribution for pebble count collection sites ........................... 147

Table C.1. Review of soil properties relevant to groundwater modeling based on literature: saturated hydraulic conductivity $\left(\mathrm{K}_{\mathrm{sat}}\right)$, anisotropy ration $\left(\mathrm{K}_{\mathrm{H}} / \mathrm{K}_{\mathrm{V}}\right)$, and porosity (n) .............. 152 Table C.2. Review of soil properties relevant to selenium transport modeling based on literature, lab testing, and surface mine permit file: bulk density $(\rho)$, selenium starting concentration $\left(\mathrm{C}_{0}\right)$, and selenium distribution coefficient $\left(\mathrm{Se} \mathrm{K}_{\mathrm{d}}\right)$. 153

Table C.3. Review of boundary conditions based on precipitation, infiltration percentages, and infiltration capacities from literature: annual precipitation rate $(\mathrm{P})$, percentage of precipitation attributed to infiltration $\left(\mathrm{I}_{\mathrm{P}}\right)$, and infiltration rate based on capacity $\left(\mathrm{I}_{\mathrm{C}}\right)$ 154 Table C.4. Two-dimensional steady-state models for each fill with varying model conditions: saturated (Sat), unsaturated (US), isotropic (I), anisotropic (A), and stream infiltration rate (Infil) from $0 \%$ to $50 \%$ of total precipitation rate or equal to uncovered infiltration rate 155 Table C.5. Two-dimensional transient groundwater models for each fill type considering unsaturated and isotropic soils and infiltration ranging from $0 \%$ to $55 \%$ of precipitation 155 Table C.6. Two-dimensional groundwater particle tracking in conventional fill and geomorphic fill with $10 \%$ infiltration stream. Vs = additional percentage of fill volume contacted by discharging water 156 Table C.7. Three-dimensional groundwater particle tracking in conventional fill and geomorphic fill. $\mathrm{Vs}=$ additional percentage of fill volume contacted by discharging water 159 


\section{CHAPTER 1. INTRODUCTION}

\subsection{Research Motivation and Problem Statement}

Surface mining of coal is a dominant cause of landuse change in central Appalachia (Townsend et al, 2009). The surface mining process consists of removing overburden from the tops of mountains to expose coal seams. The bulk of mined rock (referred to as overburden or spoil) is placed on the mined surface while excess spoil is placed in valleys fills outside of the mined area (USEPA, 2011). Typical valley fill reclamation in West Virginia must meet the following specifications set by the West Virginia Department of Environmental Protection (WVDEP): i) long-term static factor of safety of 1.5 or greater; ii) maximum 2:1 slopes with 20 -ft wide benches every 50 vertical feet; iii) a rock core (minimum width of $16 \mathrm{ft}$ ); and, iv) properly designed drainage for 100-yr, 24-hr rain event (WVDEP, 1993; WVDEP, 1999). While successful in short-term stability, concerns remain related to long-term stability (Bell et al., 1989; Michael et al., 2010). In addition, current surface mine reclamation techniques have been unsuccessful in compensating for lost stream length and forested areas in headwater systems, which has resulted in altered watershed hydrology and impaired water quality below fills (Palmer et al., 2010; Bernhardt and Palmer, 2011). Over 2,300 valley fills have been permitted in WV (Figure 1.1) with an estimated buried stream length of over 1,200 miles (USEPA, 2011). Little is known about the large-scale and long-term hydrologic consequences (both in water quantity and quality) of existing mountaintop mining reclamation practices (Miller and Zégre, 2014). In addition, the engineered slopes on valley fill faces do not accurately mimic the geomorphology of the pre-mined topography. 


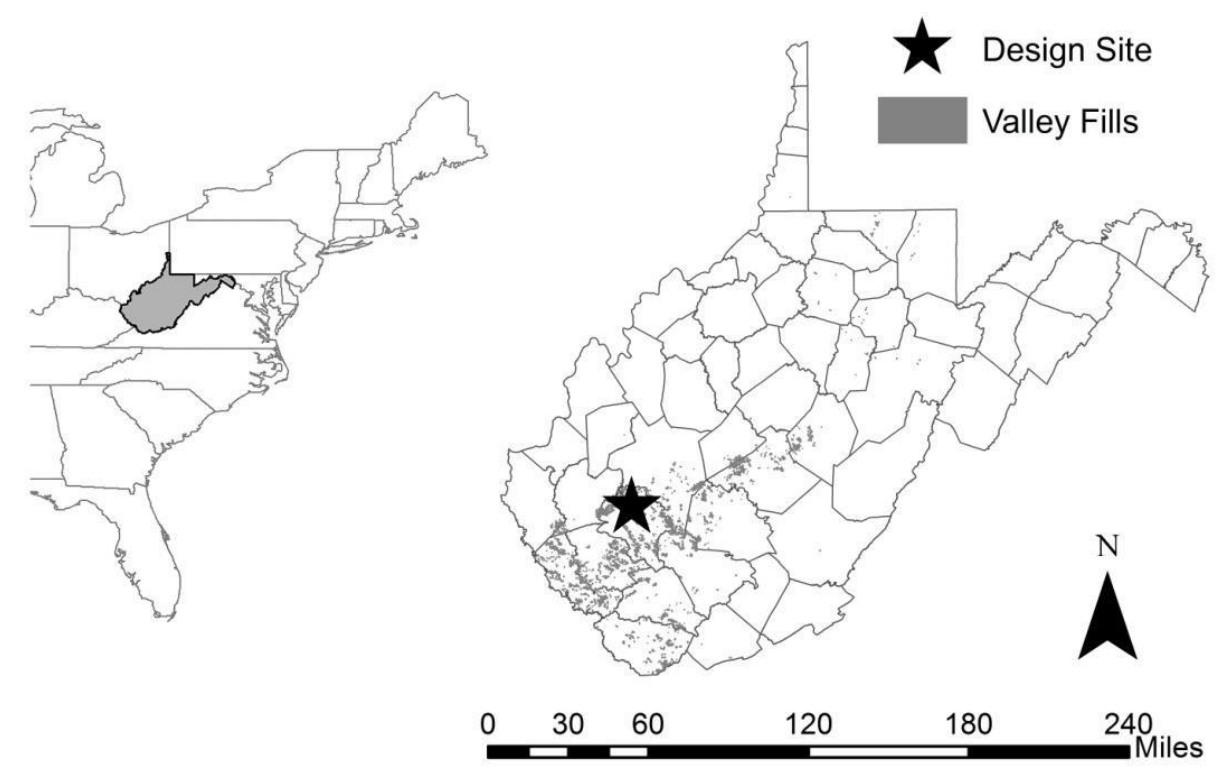

Figure 1.1. Location of research design site and extent of valley fills in West Virginia, USA.

The issues associated with the existing reclamation techniques in central Appalachia have prompted an analysis of alternative reclamation methods, including geomorphic landform design (GLD) (e.g. Michael et al., 2010; Sears et al., 2013; Sears et al., 2014; Russell et al., 2014). GLD incorporates geomorphology of mature reference landforms into reclamation designs to develop a balance between erosive and resistive forces, resulting in a system in equilibrium with low erosion rates (Schor and Gray, 2007). If compared to conventional reclamation design, GLD aims to produce landforms that are more aesthetically pleasing and natural looking, reduce longterm maintenance, require fewer artificial elements, support long-term stability, and improve water quality (Toy and Chuse, 2005). GLD is becoming more widely accepted by the scientific and regulatory community as an alternative method for reclaiming disturbed landforms (Nicolau, 2003), and there has been interest by United States federal agencies such as the U.S. Office of Surface Mining, Reclamation and Enforcement (OSMRE) in implementing it throughout the country (e.g. OSMRE Geomorphic Forum, 2009 and 2014). The majority of application of geomorphic reclamation to date has been in the southwestern U.S. (e.g. Measels and Bugosh, 2007; Bugosh, 2009; Robson et al., 2009). Additional geomorphic reclamation projects have been completed outside of the U.S. (e.g. Martin-Duque et al., 1998; Evans and Willgoose, 2000; Martin-Moreno et al., 2008; Martin-Duque et al., 2010). 
Many challenges have been documented that must be addressed prior to the use of geomorphic reclamation principles in central Appalachia, USA. Quantifying the reference values for geomorphic design criteria in central Appalachia on a local scale is necessary for accurate sitespecific design of geomorphic landforms (Sears et al., 2014). Soil types, vegetation, and precipitation differences among different geographic areas within the U.S. all have an effect on drainage length and drainage density, the controlling factors in geomorphic landform design. Michael et al. (2010) documented potential issues regarding the stability and impact of implementing geomorphic design principles in central Appalachia. Due to the steep slopes of central Appalachian landforms, reclaimed landforms constructed to naturally blend in with the surrounding environment may not be stable. Shallower, more stable slopes of geomorphic landforms could create greater stream disturbance to maintain fill volumes. Conceptual geomorphic designs are necessary to quantify these potential issues and assess the practicality of implementing geomorphic landform design in central Appalachia. Conceptual geomorphic designs have been completed in central Appalachia on a large scale (>200 acres) (Sears et al., 2013, 2014), but smaller scale conceptual geomorphic designs (for individual valley fills, 10-20 acres) are necessary to address site-specific concerns and investigate the issues associated with implementing geomorphic reclamation on the scale at which pilot construction projects would be constructed.

An expected potential benefit to geomorphic reclamation that has not been investigated is reduced groundwater infiltration through increased surface runoff and reclaimed surface hydrology. Reduced infiltration through geomorphic slope design could increase slope stability and reduce desorption of contaminants (particularly selenium). The destruction of headwater streams could be mitigated by designing a landform that creates new streams on the reclaimed surface. The potential benefits to GLD with respect to stream mitigation, groundwater movement, and contaminant desorption have not been sufficiently investigated. Comprehensive groundwater and selenium desorption models are necessary to quantify these potential benefits. This research will investigate if future surface mine sites in central Appalachia can be designed and reclaimed with improved stream channel designs, surface and groundwater hydrology, and selenium desorption, while maintaining mineral recovery and fill volumes, by incorporating geomorphic landform design principles. 


\subsection{Research Objectives}

The overall goal of this project was to investigate the implementation of geomorphic landform design (GLD) for surface mine reclamation in central Appalachia. To assess GLD in central Appalachia, the following objectives were completed:

1. Defined the geomorphic characteristics of mature reference landforms in central Appalachia.

2. Quantified the issues associated with implementing geomorphic reclamation on the scale of an individual valley fill.

3. Compared groundwater movement and selenium desorption in conventional and geomorphic reclamation alternatives for a southern West Virginia surface mine to quantify potential benefits to geomorphic reclamation.

The completion of objectives 1, 2, and 3 are documented in chapters 3, 4, and 5, respectively.

\subsection{Contributions to the Body of Knowledge}

The following contributions to the body of knowledge resulted from this research:

1) A compiled dataset of geomorphic properties of undisturbed landforms in central Appalachia, including drainage lengths, drainage densities, slopes, aspects, vegetation, and headwater channel properties. These data can be used to generate and compare future geomorphic landform designs in central Appalachia.

2) A series of conceptual geomorphic designs that quantify the potential issues associated with GLD with respect to landform stability, channel mitigation, and material volumes. Conceptual designs can provide recommendations on the practicality of implementing a small scale geomorphic design as an alternative to a conventional valley fill, as well as insight into what compromises must be made.

3) A quantitative comparison of the groundwater movement and desorption of selenium between reclamations accomplished through traditional techniques and those applying geomorphic landform design principles. Quantified benefits of geomorphic landform 
design with respect to groundwater and selenium loads may be used when determining the practicality of applying geomorphic principles compared to the potential drawbacks.

These findings will be used to provide recommendations on the practicality of implementing geomorphic reclamation as an alternative to conventional valley fill reclamation in central Appalachia. 


\section{CHAPTER 2. LITERATURE REVIEW}

Previous work involving the aspects of this research was reviewed to determine how this research relates, compares, and supplements the body of work available on these subjects. This consisted of reviewing work on conventional and alternative surface mine reclamation techniques, geomorphology of undisturbed basins, and groundwater and contaminant modeling of reclaimed landforms.

\subsection{Conventional and alternative surface mine reclamation}

\subsubsection{Conventional reclamation techniques in central Appalachia}

Regulated reclamation of surface mining began with the passing of Surface Mining Control and Reclamation Act (SMCRA) of 1977. Studies by Bell et al. (1989) and Zipper et al. (1989a, 1989b) discussed the implementation of SMCRA and the subsequent effects and responses of surface mining in central Appalachia. Prior to SMCRA, mine overburden was handled in a "shoot-and-shove" technique. This method consisted of shoving overburden downhill as mining followed the coal seam outcrop around the mountainside. This technique led to landslides, revegetation problems, and acid mine drainage. With the implementation of SMCRA, reclamation was required to return mined land to "approximate original contour," or AOC. AOC consisted of backfilling overburden against a highwall to eliminate the highwall face and recreate the landform's original contour. Bell et al. (1989) found that slope failures were a common occurrence in AOC backfills. Major factors contributing to slope failure were steep $\left(>30^{\circ}\right)$ slopes, high pore pressures from seepage into the fill, and the toe of the fill being placed beyond the mining bench. High soil erosion rates also occurred as a result of steep slopes, lack of vegetation, and high silt contents. AOC reclamation also resulted in reclaimed landforms with minimal economic value.

After these issues associated with AOC had been documented, landforms were then reclaimed using the "variance" allowance in SMCRA (Zipper et al., 1989b). Variance allowed for not recreating the landform to "approximate original contour" if the reclamation improved the watershed by producing land suitable for economic or public use, such as residential, commercial, industrial, agricultural, or recreational. The use of variance created reclaimed 
landforms with large, relatively flat areas at the top with fills extending into the valley below. Zipper et al. (1989b) found variances to be more beneficial than AOC with respect to the following factors: environmental impacts (increased stability and reduced erosion), post-mining land use (economic value provided by the flattened top), cost (more efficient mine operation and reclamation construction), and aesthetics (no exposed highwalls or barren outslopes).

Over the past 30 years, surface mining has become the dominant cause of land use change in central Appalachia (Sayler, 2008). The amount of active surface mining in the Appalachian Plateau of eastern West Virginia was highest directly following the implementation of SMCRA and has remained constant and/or decreased since. In southern West Virginia as of 2009, the amount of surface mining had actually steadily increased (as much as threefold in some counties) (Townsend et al., 2009). This increase in surface mining activity and the use of AOC variance for reclamation has been accompanied by scrutiny of the consequences of these. Over 2,300 valley fills have been permitted in WV with an estimated buried stream length of over 1,900 kilometers (USEPA, 2011). Ferrari et al. (2009) stated that watershed hydrology can be greatly affected by the change in land cover associated with surface mine reclamation. They found that, for a given return interval storm, peak flows increased linearly with increasing percentage of watershed area affected by surface mining and reclamation. Also, larger rates of increase were expected for lower return intervals. Infiltration rates were as much as an order of magnitude lower in watersheds disturbed by mining and reclamation than in undisturbed watersheds (Negley and Eshleman, 2006). Palmer et al. (2010) stated that reclamation practices buried headwater streams, which caused loss of stream ecosystems, biodiversity, and water quality.

Current reclamation has been unsuccessful in compensating for lost stream habitat and degraded water quality. Streams below valley fills in central Appalachian had increased pH, electrical conductivity, and total dissolved solids. Metals such as Mn, Fe, Al, and Se were more concentrated in stream sediments. Bernhardt and Palmer (2011) found that reclamation resulted in loss of headwater streams, loss and homogenization of forest soils, altered watershed hydrology, and decreased water quality below fills. Little is known about the large scale and long-term hydrologic consequences (both in water quantity and quality) of existing mountaintop mining reclamation practices (Miller and Zégre, 2014). Zipper et al. (2011) stated that large forested areas have been lost, with pre-mining forests being replaced by dominantly herbaceous 
plant species. These pre-mining forested areas provided benefits to the ecosystem, such as carbon storage, water quality protection, and plant and fauna habitat that are not being supported by herbaceous vegetation.

\subsubsection{Geomorphic landform design}

Nicolau (2003) reviewed current trends and future possibilities in the techniques applied to surface mine reclamation. Two approaches were reviewed: i) reclaimed landforms designed with the intent of exporting the smallest possible amount of runoff and sediments to off-site water bodies; and ii) reclaimed landforms designed with the intent of maximizing the viability of the reclaimed landform itself. The first approach, consistent with AOC variance, was most common. This approach created geotechnically stable, but not ecologically viable, landforms. The first objectives were stability and erosion, with little concern given to integration of stream channels into a functional drainage basin. These reclaimed channels were controlled by engineering construction, whereas natural channels were controlled by water and sediment discharges. The second approach was more concerned with imitating the geomorphology of natural landforms by incorporating their slopes, channels, and drainage patterns. Nicolau (2003) suggested that this method, termed "geomorphic landform design" (GLD), has become more widely accepted by the scientific community as the appropriate method for reclaiming disturbed landforms.

Toy and Chuse (2005) provided an overview of GLD principles. In nature, an approximate steady-state or dynamic equilibrium exists in basins. Changes in geomorphology occur slowly, but disturbances to a basin can disrupt the equilibrium and cause the geomorphology to change at an accelerated rate, then requiring a very long time for the landform to return to a steady-state. The goal of geomorphic reclamation is to reconstruct landforms as close to the equilibrium as possible to reduce the effect of geomorphic processes. A ten step process for geomorphic reclamation was given: i) site characterization; ii) reclamation planning and engineering; iii) material management; iv) topographic reconstruction; v) replacement of topsoil or soil substitute; vi) surface manipulation; vii) addition of soil amendments; viii) revegetation; iv) irrigation; and, $\mathrm{x})$ site monitoring and maintenance.

Geomorphic reclamation attempts to replicate channel geomorphology from pre-disturbed conditions or from nearby undisturbed basins. Toy and Chuse (2005) suggested the four most 
important drainage-basin characteristics to consider in topographic reconstruction were as follows: i) drainage-basin relief; ii) drainage-basin area; iii) drainage density; and, iv) drainage pattern. Increasing drainage-basin relief (elevation difference between watershed boundary and watershed outlet) increased runoff, erosion, and sediment yield. As drainage-basin area increased, stream length, runoff, discharge, and sediment discharge increased. Increasing drainage density (total stream length per watershed area) increased mean annual flood magnitude and sediment yield, and decreased overland-flow length of hillslopes.

The first step of the reclamation design process is locating the main channel (Toy and Chuse, 2005). Drainage networks can then be created using dendritic patterns with appropriate drainage densities. The plan view of a dendritic pattern resembles veins of a leaf, with smaller headwaters forming the tributaries that contribute to the main channel. Longitudinal channel profiles should be concave with no abrupt changes in gradient. Hillslopes are preferred to be low gradient, short, and concave. The reclaimed landscape must merge with surrounding undisturbed basins to prevent degradation of undisturbed and reclaimed lands.

A specific approach to geomorphic reclamation was developed by Nicholas Bugosh, resulting in the Natural Regrade with GeoFluv ${ }^{\mathrm{TM}}$ (Carlson Software Inc. and Bugosh, 2005) software method (Eckels and Bugosh, 2010). This approach uses a dendritic drainage pattern and concave longitudinal profiles to generate geomorphic landforms. Required inputs are drainage density, upland channel reach length, drainage length, elevation of local drainage point, slope of the channel at that point, and information on local rainfall and runoff events. After a project area boundary is defined, the main channel is drawn, and additional channels are drawn to satisfy the drainage density and drainage length requirements, a landform is generated that satisfies the basic principles of the geomorphic reclamation approach. This initial design must be iterated to satisfy the cut/fill requirements of the reclamation site (Eckels and Bugosh, 2010).

The majority of application of geomorphic reclamation to date, specifically those applications implementing the GeoFluv ${ }^{\mathrm{TM}}$ method have been in the southwestern U.S. (e.g. Measels and Bugosh, 2007; Bugosh, 2009; Robson et al., 2009). Additional geomorphic reclamation projects have been completed outside of the U.S. (e.g. Martin-Duque et al., 1998; Evans and Willgoose, 2000; Martin-Moreno et al., 2008; Martin-Duque et al., 2010). Measels and Bugosh (2007) 
implemented a 40 hectare geomorphic design at an open pit dragline mine in southwest Wyoming, USA. Mass balance was the highest priority in the reclamation design. Geomorphic reclamation expanded the acreage that could be covered with the same material volume and minimized earthwork by splitting the area into two separate drainage areas contributing to two different main channels. Additional tributaries were necessary to satisfy drainage density design criteria. It was expected that the addition of sub-ridges and sub-valleys made the landform more stable during large storm events due to dispersed runoff.

Bugosh (2009) documented the performance of geomorphic reclamation at two open pit mines in New Mexico, USA. Monitoring of two sites over 6-7 years revealed minimal erosion after large storm events, improved water quality as compared to native lands, and the necessity of complex landforms in varying moisture harvesting and sunlight exposures for successful revegetation. Robson et al. (2009) compared post-mining topography designs using both GLD and conventional techniques. Cost analysis of reclamation alternatives presented a cost savings of $44 \%$ for the geomorphic reclamation as compared to the conventional reclamation through advantages in design, permitting, construction, and maintenance.

Martin-Moreno et al. (2008) defined geomorphic criteria and proposed geomorphic landform designs for ecological restoration of kaolin mines in Spain. Geomorphic principles were necessary in reclamation because easily erodible materials prevented establishment of soils and vegetation and resulted in sediment yield to the drainage network. The proposed design included concave slopes to reduce runoff and erosion, surficial deposits and topsoil based on the original surficial geology, and systems for flow control and sediment storage. Martin-Duque et al. (2010) monitored a quarry highwall in Spain that had been reclaimed using a geomorphic model by Martin-Duque et al (1998). The geomorphic model did not reproduce the original topography, but allowed the quarry face to evolve naturally, and the concave-convex slope profiles supported soil formation and functional ecosystem establishment. Backwasting from the reclaimed highwall filled the trench at the toe more quickly than expected, resulting in runoff and sedimentation remaining on the slope. The model performed well in two-dimensions, but a threedimensional drainage approach with multiple watersheds was recommended for a successful design. 
Application of the geomorphic approach to reclamation in the central Appalachian region of the United States has recently begun to be investigated (e.g. Michael et al., 2010; Sears et al., 2013; Russell et al., 2014; Sears et al., 2014). Michael et al. (2010) discussed the challenges associated with applying geomorphic reclamation to surface mining in the steep slope topography indicative of central Appalachia. They suggested that the principles of landform grading and stream restoration associated with geomorphic reclamation have potential for success in central Appalachia, but the following concerns were documented: i) aspects of geomorphic reclamation do not coincide with Federal SMCRA regulations such as broad plateaus, lack of curvilinear shapes, and drainage control systems; ii) shallower, more stable slopes of geomorphic landforms could create greater stream disturbance to maintain fill volumes; iii) cost increases in initial construction could discourage industry collaboration; iv) more complex and time-consuming earthwork could delay reclamation completion; and, v) due to the steep slopes of central Appalachian landforms, constructing artificial landforms that naturally blend in with the surrounding environment may not necessarily ensure stability.

Sears et al. (2013) performed an experimental study on a geomorphic reclamation for a southern West Virginia, USA surface mine. Carlson's Natural Regrade (2013, Maysville, KY), which uses the GeoFluv ${ }^{\mathrm{TM}}$ method, was used to generate a large ( 100 hectare) geomorphic design. Six subwatersheds within the entire study site watershed were defined, and a geomorphic landform was generated for each. Input parameters were left as the default values in Natural Regrade, which were indicative of southwestern United States geomorphology. Default input values, while not suggested as appropriate, were used because values for the geomorphic properties of central Appalachia were not yet known. The geomorphic design protected $400 \mathrm{~m}$ of the permitted area's original stream length, as well as generated almost $10 \mathrm{~km}$ of new type A and type C (Rosgen, 1994) stream channels. Russell et al. (2014) investigated the slope stability of the same experimental geomorphic landform compared to conventional reclamation using twodimensional profiles. The factors of safety for the geomorphic landform profile (2.04-3.49) were higher than those for the conventional valley fill profile (1.25-1.67). This increase in slope stability was attributed to shallower slopes and lower pore-water pressure buildup in the geomorphic landform. Critical unstable slope profiles, however, existed and must be analyzed independent of the geomorphic design software. Sears et al. (2014) incorporated regional 
geomorphic landform parameters to large geomorphic designs and compared them to previous designs that used default geomorphic criteria. Designs illustrated the importance of obtaining field-measured, site-specific values for the geomorphic design criteria of drainage length and drainage density. Initial work in investigating geomorphic reclamation in central Appalachia has provided a sound base for continuing studies to determine its applicability and performance as compared to existing conventional reclamation techniques.

\subsection{Channel heads and basin geomorphology}

Geomorphic landform design uses a reference landform approach. Designs are generated using the geomorphic characteristics of steady-state reference landforms, in which driving and resisting forces are balanced (Toy and Chuse, 2005). The area of most concern when quantifying the geomorphology of these landforms is the "channel head." The first widely accepted definition of the channel head came from Montgomery and Dietrich (1988), who defined it as the point closest to the drainage divide that exhibited evidence of channelized morphology. Dietrich and Dunne (1993) defined the channel head as "the upstream boundary of concentrated water flow and sediment transport between definable banks". A "definable bank" was defined as a morphological feature that existed independent of flow. The upstream stream bed was recognizable through wash marks, small bedforms, an armored surface, or signs of sediment transport. Dietrich and Dunne (1993) also defined the channel head as an incision into the ground surface that would remain as a morphological feature in the absence of flow. Using this constant channel head location can create reproducible values of drainage density. Channel heads can either form at a distinct step or headcut, or gradually. Dietrich and Dunne (1993) stated that it is important to understand where the channel head is located and how its position may change over time. The distance from the channel head to the drainage divide sets average hillslope length and controls drainage density.

Dietrich and Dunne (1993) investigated hundreds of channel heads through the coastal mountains of the western United States. Slopes were generally less than 45 degrees with dense vegetation. In some cases, $30 \%$ of channel heads occurred at large steps with the remaining majority occurring gradually or at small steps. For a given basin, an inverse relationship was found between drainage area and valley slope. However, the relationship was not as clear over a 
broad range of basins. Dietrich and Dunne (1993) stated that a broad range of slopes was necessary to define a relationship between drainage area and valley slope. The closer the channel head was to the drainage divide, the greater the drainage density. The distance between channels, as well as the drainage length, was approximately the inverse of the drainage density. Channel heads were formed by overland flow, seepage erosion, mass failure, or tunnel scour. Previous research assumed the channel head to occur at the transition between convex and concave slopes, but channel heads were predominantly found downslope of that transition point. Montgomery and Dietrich (1988) stated that the area required to support a channel (source drainage area) should increase in drier areas. Source area and drainage density should also increase with increasing slope.

Over the past 30 years, several researchers have investigated the channel head, its relationship to landform geomorphic characteristics, and its effect on a landform's channel network. These studies have also focused on the most effective means for determining the location of the channel head for accurate measures of landform hydrology. Mark (1983) compared channel networks in northeastern Kentucky defined in the field with those defined using maps. Identification of firstorder streams from topographic maps consisted of mapping channels as far upstream as cusps in the contour lines existed. In the field, channels were defined as a permanent trench or trough showing evidence of scour by channelized flow and bounded by banks sloped toward the channel bottom. The strongest correlation between map-based and field measures existed with respect to stream slopes. Only about half of the channel length mapped in the field, however, could be predicted using map based measures.

Montgomery and Dietrch (1989) mapped channel heads and investigated the relationship between channel heads and drainage areas. The channel head was defined as either "the upslope limit of erosion and concentration of flow between steepened banks" or as "the headcut closest to the drainage divide." The study site was a basin near San Francisco, CA with slopes ranging from 15 to 40 degrees and a Mediterranean climate. Source area was defined as the contributing area to a channel head. Source-basin length was defined as the distance from the drainage divide to the channel head. Abrupt channel heads formed at steep headcuts, while gradual channel heads formed where saturated overland flow and evidence of sediment transport occurred. Gradual channel heads were difficult to define because they lacked a distinctive headcut and definable 
banks. Many channel heads were approximately 1-m wide. An inverse relationship was found between source area and valley slope. Drainage density was estimated adequately as the inverse of the mean source-basin length.

Montgomery and Dietrich (1992) investigated landscape response to changes in climate and/or land use. A similarity was found between the geometry of drainage basins and the smaller basins contained within them. Studies in the coastal mountain ranges of the western United States showed an inverse relationship between drainage area contributing to a channel and valley slope. They then tested the hypothesis of using a threshold value for drainage area contributing to a channel head. The majority of channel heads were found to lie within the variance of the position calculated using a threshold drainage area value.

Building upon the work of Montgomery and Dietrich (1988, 1989, 1992), researchers have continued to investigate the most effective way to determine the location of the channel head (e.g. Vogt et al., 2003; Benda et al., 2005; Hancock and Evans, 2005). These studies all completed field surveys of stream networks and used GIS analyses to verify the following previous findings of research regarding channels heads: i) an inverse relationship between source area and slope, and ii) that channel heads are located downslope of the transition from unstable convex slopes to stable concave slopes. Heine et al. (2004) investigated several different methods for determining channel head location and recommended that the best method for determination of channel head location (other than field surveying) is using a varying source area from multiple linear regression of landform properties of each channel head location. Other findings have been that analyzing aerial photography is not sufficient for mapping headwater channels (James et al., 2006), and that USGS's National Hydrography Dataset (NHD) (USGS, 2003a) under represents headwater channel length (Heine et al., 2004).

The majority of work related to mapping headwater channels has been performed in the western United States, with limited work the author's knowledge being performed in Appalachia (e.g. Wiley et al., 2001). One study by Buckley et al. (2013) investigated geomorphic properties (specifically those needed as geomorphic landform design parameters) of undisturbed landforms of southern West Virginia. This study found that properties such as slope, drainage length, and drainage density were much different in the steep basins of central Appalachia than the existing 
values for the western United States. This work provided an initial set of data on geomorphic properties specific to central Appalachia and southern West Virginia. For the most part, however, data on the geomorphic properties of landforms in central Appalachia, the region of interest in this research, are lacking (Sears et al., 2014). While perennial and intermittent channels have received the majority of study in the central Appalachians (e.g. Paybins, 2003; Svec et al., 2005; Fritz et al., 2008), limited work has investigated ephemeral streams (e.g. Villines, 2013). Ephemeral channels, unlike intermittent and perennial channels, are not easily discernable from seasonal groundwater depth, as ephemeral channels only flow in response to rainfall and always lie above the water table (Langbein and Iseri, 1960). Ephemeral channels are of particular concern in central Appalachia because they are not accounted for in headwater stream burial and are similar to the type of channel that would be constructed on a reclaimed landform. Overall, the body of work on channel heads and headwater stream network geomorphology relationships suggests that, for a given area, stream networks can be accurately derived through a sufficient amount of field surveying and supplementary GIS analysis.

\subsection{Groundwater and contaminant modeling}

The previous work completed in groundwater and contaminant modeling provides insight into the necessary steps of the modeling process and the most effective tools to use for a given application. Brixel et al. (2012) gave an overview of the general issues associated with modeling groundwater and contaminants at a mine site. Site characterization can be completed through geological/geophysical surveys, geotechnical investigations, hydrologic analyses, and hydrogeologic investigations. The main objective of these investigations is to determine hydraulic conductivity, transmissivity, and preferential flow paths. Rate of seepage is a function of permeability, moisture content, and rate of consolidation. Historical records of groundwater table depth, groundwater quality, surface water flows/quality, phreatic levels in embankments, and seepage flow rates should be collected. The objectives of seepage modeling should be to predict the future volumetric flow of seepage during operation, to predict the future contaminant transport to the ecosystem during operation and post-closure, and to predict the reduction in groundwater from alternative seepage mitigation strategies. A conceptual model (a simplified representation of the features of the physical system and its behavior) must be developed before numerical modeling. The conceptual model should be simple but no simpler than to accurately 
describe the physical situation and should include the key components of the system (covers, liners, embankments, aquifers, faults, dikes, soil/rock layers, groundwater balance, recharge/discharge, and a conceptualization of contaminant transport). The mathematical model needs to be calibrated to existing, pre-mining conditions based on field data. Once parametric numerical modeling begins, it is suggested to model many cases since predictive models cannot be calibrated. The cases can include most likely conditions, upper bound conditions, and extreme worst case scenarios. The development of the model should be properly documented in a report that includes sections on numerical code selection, model domain and boundaries, sources and sinks, calibration methods and sensitivity analyses, model limitations, and key findings. The basic components of the groundwater model should include bedrock of low permeability, colluvial/alluvial soils of higher permeability, a groundwater table located somewhere in the more permeable soils, the tailings facility itself that increases in size over time, and a waterway to which groundwater discharges.

\subsubsection{Modeling at mine sites}

Studies focused on modeling groundwater flow and contaminant transport at active and reclaimed mine sites have used both finite-difference numerical models (e.g. Peterson et al., 2004; Mao et al., 2006; Ataie-Ashtiani, 2007; Wels et al., 2012) and finite element models (e.g. Fredlund et al., 1998; Chapuis and Aubertin, 2001; Abdelghani et al., 2009). Peterson et al. (2004) focused on two-dimensional groundwater and contaminant modeling at a uranium oreprocessing site in Utah, USA. Most of the inflow to groundwater was from discharge from bedrock aquifers. The conceptual model did not account for recharge through the ground surface due to lack of data at the site and uncertainties in modeling. The modeling tool used was SEAWAT, a finite-difference numerical code developed by the United States Geological Survey (USGS) that simulates three-dimensional variable-density groundwater flow with multi-species solute and heat transport. SEAWAT combines MODFLOW (USGS's modular finite-difference groundwater flow model) and MT3DMS (USGS's modular finite-difference model for advection, dispersion, and chemical reactions of dissolved contaminants in groundwater systems). MT3DMS allowed the user to simulate multiple contaminant reactions and transport at once. A uniform grid spacing of $10 \mathrm{~m}$ was used. The model was set at a large enough depth to ensure that boundary conditions had little to no effect on historical release of tailings fluids. 
Basin fill material hydraulic conductivity ranged from 28 to $62 \mathrm{~m} /$ day. Boundary conditions consisted of prescribed head and prescribed flow. Evapotranspiration was assumed to occur uniformly in the top five layers. Steady-state flow simulations were conducted because data suggested the local groundwater system was reaching a state of equilibrium. Simulations were first run at pre-operation conditions, then at current conditions by adding system outflow and tailings seepage. Hydraulic conductivity was obtained from site data. All other properties were taken from literature or from trial-and-error calibration. Discharge from the model was divided almost equally between evapotranspiration and river outflow. Transient simulations were also performed with initial conditions taken from the steady-state simulation. Steady-state models indicated that the majority of contaminated groundwater (particularly saline water) was produced by dissolution of evaporitic bedrock. Transient models suggested that contaminated groundwater also resulted from seepage through tailings during and after facility operation.

Mao et al. (2006) focused on modeling contaminant transport by simultaneously considering variable density flow and complex contaminant reactive processes. Modeling was completed using PHWAT (USGS's three-dimensional finite-difference model for multi-component reactive transport in variable-density groundwater flow), which combines SEAWAT and PHREEQC-2 (USGS's three-dimensional finite-difference model for low-temperature geochemical reactions). Simulated results were compared to monitoring results of column and tank flume propagation experiments. Groundwater flow depended on volumetric porosity, fluid density, volumetric flow rate from sinks and sources, time, and specific discharge. Specific discharge depended on permeability, fluid dynamic viscosity, fluid pore-pressure, gravitational acceleration, and depth. Contaminant transport depended on the hydrodynamic dispersion coefficient, fluid velocity, total aqueous component concentration, and rate of production/decay. Equilibrium and kinetic reactions were modeled simultaneously. Considering these processes simultaneously was necessary to reproduce simulated results that matched the experimental contaminant breakthrough curves. Due to numerical instability, PHWAT could only be used for small difference ranges in fluid density. Numerical instability developed with an increased Rayleigh number (ratio between buoyancy-driven forces and stabilizing forces caused by diffusion and dispersion). This study focused only on cation exchange reactions, so additional research was 
suggested to confirm the appropriateness of PHWAT for modeling other biogeochemical reactions and transport.

Wels et al. (2012) focused on modeling groundwater flow at a uranium mine site in Australia. The geology of the site consisted of meta-sedimentary and meta-volcanic rocks. The majority of contaminants in groundwater were reported through the toe of the fill from seepage and shallow groundwater discharge. Previous studies showed that only $10 \%$ of rainfall became groundwater in this humid climate, while other studies showed that as much as $50-60 \%$ of rainfall became groundwater. Numerical modeling was completed using MODFLOW with the Layer Property Flow (LPF) package and the Preconditioned Conjugate Gradient 2 (PCG2) solver. MODFLOW was run transiently in monthly time steps between August 2010 and November 2011. A uniform grid spacing of $25 \mathrm{~m}$ was used. For recharge, total rainfall for the wet season was estimated from a rain gauge. The rain needed to wet the unsaturated zone was subtracted from the total rainfall to calculate net rainfall, which was then multiplied by a percentage to get the rate of infiltrating water. Shallow creeks, engineered drains, and ground seepage locations were represented by drain nodes in the top two layers. The model was calibrated using estimates of horizontal and vertical hydraulic conductivity, specific storage, and specific yield. Recharge and aquifer properties were adjusted to fit simulated water levels to observed levels. The model was limited by the assumptions made, which included using a fixed percentage of rainfall for infiltration, discretizing into only six layers, and using an equivalent porous media to model fractured soil. Inflow to the groundwater system was highest in open pits due to hydraulic connection to highly permeable zones. Groundwater discharge and groundwater levels were highest in the wet season.

Studies implementing finite element models have considered saturated and unsaturated groundwater flow and contaminant transport. Chapuis and Aubertin (2001) focused on unsaturated and saturated seepage, specifically through dikes in a steady-state. Modeling was completed with SEEP/W, a finite element package used to solve two-dimensional groundwater problems for steady, unsteady, saturated, and unsaturated conditions. For unsaturated modeling, materials were defined using the soil-water characteristic curve (volumetric water content versus soil suction) and permeability function (hydraulic conductivity versus soil suction) developed within the software. Initial models only investigated saturated conditions in the dike. SEEP/W was determined to be adequate for this type of study, but it was advised to analyze each 
modeling case for appropriateness of the code. SEEP/W did not directly provide the position of the seepage face, so it was determined manually from the numerical solution. Seepage flow rate and water table position were higher than that calculated from approximate methods. An investigation of unsaturated seepage was suggested to fully define the flow within the slope.

Abdelghani et al. (2009) performed numerical simulations of variably-saturated water flow and contaminant transport through mining wastes using the HydroGeosphere code. HydroGeosphere is a three-dimensional control volume finite element model used to simulate variably-saturated subsurface flow and advective-dispersive mass transport in fractured or non-fractured media. Transient and partially saturated water flow conditions were used to compute flow discharge. No particular contaminant was modeled, only the transport of any contaminant solely through advection (migration by water flow response to hydraulic gradient) and dispersion (migration due to a concentration gradient and water tortuosity). The advection-dispersion equation was taken from Freeze and Cherry (1979) and depended on concentration, time, specific discharge, effective diffusion coefficient, and porosity. The model had a lower limit of $200 \mathrm{~m}$ below the pit base and left and right limits at $-400 \mathrm{~m}$ and $+400 \mathrm{~m}$. Material hydraulic characteristics of porosity, air entry value, saturated hydraulic conductivity, and residual volumetric water content were taken from previous studies. Effective diffusion coefficient was determined from the free water diffusion coefficient and tortuosity to define contaminant advection. Mechanical dispersion was defined using longitudinal and transverse dispersivities. Results showed that contaminant migration was slowest at early simulation times and was greater in the direction of the regional gradient. Over time, contaminant migration became more significant with depth due to precipitation effects. Variable recharge was also modeled by using one day of precipitation followed by two days without precipitation for each month over a two year period. In this case, the variation of degree of saturation and suction was more pronounced. 


\subsubsection{Groundwater modeling at Appalachian mine sites}

Groundwater flow at reclaimed surface coal mine sites in Appalachia has also been studied. Hawkins and Aljoe (1992) performed aquifer tests on a surface coal mine spoil fill in Upshur County, West Virginia, USA to determine hydrologic characteristics. The study site was a 3.2 hectare spoil zone with flat to gentle slopes and gently dipping $(<2 \%)$ pit floor. The spoil consisted of gray sandstone and dark gray to black shale, present in both blocky fragments and smaller material. Permeability was highly spatially variable. Fifteen wells were used for monitoring and permeability slug tests. The presence of conduits was apparent when the groundwater system was stressed during aquifer tests. In these transient conditions, psuedokarstic flow was prominent; groundwater was stored and flowed mainly through rock fractures and intergranular permeability played a minor role. Under steady-state flow conditions, porous media flow governed. Hydraulic conductivity ranged from $2.1 \times 10^{-7}$ to $1.3 \times 10^{-4} \mathrm{~m} / \mathrm{s}$. Velocity of groundwater through the spoil ranged from $1.2 \times 10^{-5}$ to $4.9 \times 10^{-5} \mathrm{~m} / \mathrm{s}$. Groundwater velocity was dependent on the degree of fracture interconnection and the permeability of intergranular materials. The hydraulic properties on the same spoil fill site were further analyzed by Maher and Donovan (2005). Aquifers responded to slug tests in three ways: conventional single response, rapid single response, and double response (rapid response followed by slow response). Statistical distributions of storativity, hydraulic conductivity, and transmissivity were all bi-modal, with distinctly high and low modes. The double modes were attributed to differences between the high void zone and the porous-medium zone present in mine spoil. Hydraulic conductivity and transmissivity exhibited log-normal distributions. The bi-modal upper and lower mean hydraulic conductivity were $10^{-3.3} \mathrm{~m} / \mathrm{s}$ and $10^{-5.3} \mathrm{~m} / \mathrm{s}$, respectively. The bimodal upper and lower mean transmissivity were $10^{-2.9} \mathrm{~m}^{2} / \mathrm{s}$ and $10^{-5.1} \mathrm{~m}^{2} / \mathrm{s}$, respectively. The bimodal upper and lower mean storativity were $10^{-2}$ and $10^{-4.7}$, respectively.

Hawkins (1995) performed aquifer testing and monitoring at five reclaimed surface mines in the northern Appalachian Plateau. Lithology consisted of coals, shales, siltstones, sandstones, claystones, and limestones. Topographic relief greater than $100 \mathrm{~m}$ was common. Groundwater wells were tested and monitored to determine hydrologic properties. Mean hydraulic conductivity of mined aquifers was $3.75 \times 10^{-5} \mathrm{~m} / \mathrm{s}$. Mean hydraulic conductivity of unmined aquifers was two orders of magnitude lower than in mined aquifers $\left(3.69 \times 10^{-7} \mathrm{~m} / \mathrm{s}\right)$. 
Groundwater depths were $44 \%$ to $71 \%$ deeper in disturbed strata than in undisturbed strata. High hydraulic properties were caused by rock fragmentation and increased spoil age. Sandstones had widely spaced fractures, and aquifers consisting mainly of sandstones exhibited higher hydraulic properties. Hydraulic properties of spoil fills in the Appalachia Plateau were expanded upon by Hawkins (2004) by monitoring over 120 wells at 18 sites in West Virginia, Pennsylvania, Kentucky, and Ohio, USA. Hydraulic conductivity ranged over seven orders of magnitude with a nonnormal distribution and mean of $1.7 \times 10^{-5} \mathrm{~m} / \mathrm{s}$. Sites between 31 to 100 years old exhibited lower hydraulic conductivities than those both newer or older than that age range. Mean saturated spoil thickness was $2.2 \mathrm{~m}, 19 \%$ of total spoil thickness. Increased saturated thickness was related to increased spoil thickness, increased sandstone content, shallower pit floor dip, and decreased distance from the highwall. Steep pit floors caused water to migrate to the pit floor and flow toward the toe through that pathway. The equations developed to predict saturated thickness based on aquifer properties were most valid with the spoil fill was less than 5 years old.

Hawkins (1994) modeled steady-state conditions for the coal mine spoil aquifer characterized by Hawkins and Aljoe (1992) using MODFLOW. The following assumptions were made: porousmedium type flow in steady-state conditions, relatively constant hydraulic conductivity throughout spoil, outflow through a known discharge point, and recharge mainly from adjacent unmined areas. The stratum underlying the spoil was simulated using a confining layer with insignificant leakage. The model domain was a 180 × 240 grid consisting of two layers of uniform $15 \mathrm{~m}^{2}$ grid cells. Initial spoil and highwall hydraulic conductivity were 0.227 and 0.0386 $\mathrm{m} / \mathrm{d}$, respectively; increasing permeability to a higher value resulted in drying of grid cells. Recharge was $10 \%$ of mean annual precipitation. Groundwater entered the spoil mainly through fractures in the exposed highwall. Permeability of the spoil at outslope cells was increased to 3 $\mathrm{m} / \mathrm{d}$ and highwall permeability was increased to $0.386 \mathrm{~m} / \mathrm{d}$ to calibrate the steady-state model to a known outflow. The calibrated steady-state model was not able to simulate transient conditions with psuedokarstic hydrologic characteristics and heterogeneity. The magnitude and location of anisotropies must be well known for MODFLOW to potentially model transient conditions for the site of interest. 


\subsubsection{Unsaturated soil properties}

When performing groundwater and contaminant modeling of reclaimed landforms, it is essential to accurately estimate the hydraulic properties of unsaturated soils (Pham, 2005). Unsaturated soil properties allow for modeling in transient and unsaturated-saturated conditions, which are more indicative of what happens in the field. Fredlund et al. (2012) extensively investigated the theory, behavior, and application of unsaturated soil properties and flow. Rate of groundwater flow depends on soil hydraulic conductivity and water storage capacity. Darcy's Law is valid for unsaturated flow only if water content remains constant. When water content varies with altered matric suction (the difference between air pressure and pore pressure), flow is governed by the soil-water characteristic curve (SWCC). The SWCC is the most important unsaturated soil property function and is used to analyze seepage, shear strength, volume change, air flow, and heat flow in unsaturated soils. Soil suction ranges from 0 to $10^{6} \mathrm{kPa}$. The key transition points of the SWCC are the air-entry value (AEV) and residual suction. At suctions above the air-entry value, flow is governed by the saturated hydraulic conductivity. Soil has the highest permeability when it is saturated, and decreases once the AEV is exceeded. Beyond the residual suction, liquid flow ceases and vapor flow governs. The relationship between flow and suction beyond the residual suction is not well known (Fredlund et al., 2012).

Directly measuring the SWCC in the laboratory is costly and time intensive. Several methods exist for estimating the SWCC through empirical equations developed by applying fitting parameters to existing SWCC data (e.g. Gardner, 1958; Brooks and Corey, 1964; Mualem, 1976; van Genuchten, 1980; Vereecken et al., 1989; Fredlund and Xing, 1994; Fredlund et al., 2002). Fredlund and Xing (1994) developed an empirical equation for the SWCC based on volumetric water content, saturated volumetric content, soil suction, suction at which residual water content occurs, and three fitting parameters $\left(\mathrm{a}_{\mathrm{f}}, \mathrm{n}_{\mathrm{f}}, \mathrm{m}_{\mathrm{f}}\right)$. The equation was valid for all soils tested. Fredlund and Xing's (1994) equation for the SWCC, along with saturated soil hydraulic conductivity $\left(\mathrm{K}_{\text {sat }}\right)$, can be used to estimate the permeability function (soil hydraulic conductivity versus matric suction) (Fredlund et al., 1994).

Fitting parameters for the Fredlund and Xing (1994) equation can be estimated from soil grain size data (e.g. Zapata, 1999; Chin et al., 2010; Torres, 2011). Zapata (1999) analyzed 70 plastic 
and 120 nonplastic granular soils. For nonplastic soils, fitting parameters were correlated to the particle diameter corresponding to $60 \%$ passing $\left(\mathrm{D}_{60}\right)$. The equation was valid for soils with $\mathrm{D}_{60}$ between $0.1 \mathrm{~mm}$ and $1.0 \mathrm{~mm}$. Fitting parameters for plastic soils were related to the percent of soil passing a No. 200 sieve $\left(\mathrm{w}_{\mathrm{p}}\right)$ and the soil plasticity index (PI). This equation was valid for $\mathrm{w}_{\mathrm{p}}$ *PI ( $\mathrm{w}_{\mathrm{p}}$ multiplied by PI) values between 0.1 and 50. Chin et al. (2010) analyzed 31 coarsegrained soils and related fitting parameters to $\mathrm{D}_{50}$ and an additional adjustable variable. For the 31 coarse grained soils analyzed, $\mathrm{D}_{50}$ ranged from $0.19 \mathrm{~mm}$ to $0.76 \mathrm{~mm}$. Torres (2011) analyzed approximately 4,500 granular soils and related fitting parameters to $\mathrm{D}_{10}$.

Fredlund et al. (2012) applied the SWCC to solve unsaturated groundwater flow problems. In steady-state groundwater flow, permeability was spatially variable due to heterogeneity of soil or water profile. Permeability varied depending on matric suction and could be modeled as heterogeneous-isotropic $\left(\mathrm{K}_{\mathrm{x}}=\mathrm{K}_{\mathrm{y}}\right)$, heterogeneous-anisotropic (ratio $\mathrm{K}_{\mathrm{x}}: \mathrm{K}_{\mathrm{y}}$ constant at any point), or continuously variable (ratio $\mathrm{K}_{\mathrm{x}}: \mathrm{K}_{\mathrm{y}}$ not constant). Volume of water remained constant, so water storage parameters were not necessary. Transient analysis required use of the water storage function; volume of water in the model changed over time through a net moisture flux at the ground surface. This flux was strongly influenced by the unsaturated zone. In one-dimensional models, a flux boundary was represented by constant infiltration less than the saturated hydraulic conductivity of the soil. Hydraulic conductivity was equal to the saturated hydraulic conductivity for the first model iteration. Two-dimensional models used finite element method to discretize the domain into nodes and elements. Smaller or larger elements were advantageous at different areas of the domain; more discrete elements were necessary at entry and exit of phreatic surface. Hydraulic head or flux boundary conditions were required at boundary nodal points. Hydraulic head gradients and flow rates at nodes were computed by averaging quantities from all elements surrounding the node. Steeper permeability functions required a higher number of iterations to solve. Finer discretization in element size and time steps allowed for rapid convergence.

Unsaturated flow was prominent while matric suction was maintained in the material. Sustained rainfall was required over a considerable amount of time and intensity for matric suction to be eliminated. Long-term matric suction was maintained when steady rainfall was one or more orders of magnitude less than saturated hydraulic conductivity $\left(\mathrm{K}_{\mathrm{sat}}\right)$. Matric suction decreased when infiltration was less than $\mathrm{K}_{\mathrm{sat}}$, but did not disappear; when infiltration was equal to or 
greater than $\mathrm{K}_{\text {sat }}$, matric suctions could be eliminated with depth. Varying initial soil moisture conditions could significantly influence rainfall infiltration and pore-pressure profiles. As AEV increased, infiltration depth increased, gradient of pore-pressure in the transition zone decreased, and pore-pressure gradient varied from approximately horizontal to zero. Movement of the wetting front was slower in soils with higher water storage due to lower AEV. As $\mathrm{K}_{\text {sat }}$ increased, rate of downward movement of the wetting front increased. Once the SWCC and $\mathrm{K}_{\text {sat }}$ of materials was known, the time required for dissipation of negative pore-pressure could be modeled. If matric suction required more time to dissipate than duration of heavy rainfall, matric suction profiles would be taken into account in slope design. If results showed that negative pore-pressures could not be maintained, it was important to assume zero matric suction (saturated conditions). According to Fredlund et al. (2012), application of numerical modeling of rainfall infiltration has not significantly influenced engineering design, and the use of matric suction in slope design has not received general acceptance as routine practice.

An example determination of unsaturated soil property functions was presented by Fredlund et al. (1998) for a mine tailings site in Papua, New Guinea. The SoilVision (SoilVision Systems Ltd., Saskatoon, Saskatchewan) database was used to estimate the SWCC data points from the mine tailings grain size distribution and soil classification. The van Genuchten (1980) equation was used to fit the predicted points to a curve. The developed SWCC, along with a value for saturated hydraulic conductivity of $1.1 \times 10^{-5} \mathrm{~m} / \mathrm{s}$, was then used to produce a curve for hydraulic conductivity versus soil suction. A steady-state analysis was modeled with the SEEP/W package of the finite element model GeoStudio (Geo-Slope International, Calgary, Alberta) to determine the location of the water table. A drought was then simulated in a transient analysis. Model results were compared to field measurements and confirmed that estimating the soil property functions through the developed method was effective.

\subsubsection{Desorption of selenium}

A contaminant of particular concern when investigating the interaction between groundwater flow and contaminant transport in central Appalachia is selenium (Se), a naturally occurring element in the coal seams and surrounding strata of southern West Virginia (Vesper et al., 2008). Vesper et al. (2008) tested the Se concentration of approximately 300 samples from cores 
extracted from the Kanawha Formation in Boone County, WV, USA. One hundred nine samples fell below the detection limit of $2 \mathrm{mg} / \mathrm{kg}$. The highest mean Se concentrations were found in coals $(3.13 \mathrm{mg} / \mathrm{kg})$ and carboliths $(3.48 \mathrm{mg} / \mathrm{kg})$. Shales $(0.56 \mathrm{mg} / \mathrm{kg})$ and mudstones $(0.54$ $\mathrm{mg} / \mathrm{kg})$ had lower mean concentrations of Se, with sandstones $(0.51 \mathrm{mg} / \mathrm{kg})$ having the lowest mean concentration. Se concentration in non-coal samples increased with reduced distance from the coal seam, and highest concentration in non-coal samples occurred within $0.5 \mathrm{~m}$ of the coal seam. Ten samples more than two meters from the coal seam had Se concentrations above the detection limit. Maximum Se concentrations found in shale, mudstone, and sandstone were 5.36, 11.9 , and $4.48 \mathrm{mg} / \mathrm{kg}$, respectively. The Se species of selenite $\left(\mathrm{Se}^{\mathrm{IV}} \mathrm{O}_{3}{ }^{2-}\right)$ and selenate $\left(\mathrm{Se}^{\mathrm{IV}} \mathrm{O}_{2}{ }^{4-}\right)$ are soluble and have been shown to occur in coal overburden of southern WV (Vesper et al., 2008; Pumure et al., 2010; Ziemkiewicz et al, 2011). Selenite exhibits a stronger bond to solid surfaces; selenate is more mobile due to looser bonding with solid surfaces (Elrashidi et al., 1987, 1989). Both selenite and selenate are more mobile in alkaline conditions than in acidic conditions (Balistrieri and Chao, 1987, 1990; Blaylock et al., 1995).

Selenium is a water quality concern because it can be toxic in excessive concentrations (Swaine, 1990; Frankenberger and Engberg, 1998). For WV coal mines, selenium discharges must meet the chronic aquatic life standard of $5 \mu \mathrm{g} / \mathrm{L}$ (USEPA, 1999); updated criteria for lentic and lotic freshwater systems of $1.2 \mu \mathrm{g} / \mathrm{L}$ and $3.1 \mu \mathrm{g} / \mathrm{L}$, respectively, are currently under review (USEPA, 2015). Many surface mines and tailings facilities have selenium discharges in excess of this standard and require post-construction treatment due to the leaching of Se from mine spoil (USEPA, 2005, 2011).

The most important soil property in quantifying the relationship of a contaminant between soil solid and aqueous phases (adsorption/desorption) is the distribution coefficient $\left(\mathrm{K}_{\mathrm{d}}\right)$, given by equation 2.1 (Freeze and Cherry, 1979).

The distribution coefficient quantifies how a contaminant partitions between liquid and solid phases at equilibrium between phases, assuming the reactions occur quickly and are reversible. If a contaminant exists in the liquid phase, its migration is retarded by transfer to the solid phase. If 
the contaminant does not exist in the liquid phase, contaminant in the solid phase is partitioned back to the liquid phase due to lower-concentration liquid being flushed through the contaminated solid zone. Over time and without reintroducing water with contaminant concentration, contaminants are eventually completely desorbed and flushed from the system. The transport of a contaminant while in the liquid phase is governed by average linear velocity of groundwater.

Research has focused on quantifying and describing the adsorption and desorption of Se from various materials, including cements (e.g. Rudin, 1996; Johnson et al., 2000; Baur and Johnson, 2003) and soils (Sheppard and Thibault, 1990; Zhang and Sparks, 1990; Kaplan and Serne, 1995). The majority of studies have focused on Se adsorption to these materials. Baur and Johnson (2003) found that sorption of Se onto cement minerals reached equilibrium quickly, with $25-80 \%$ uptake of Se from solution. $\mathrm{K}_{\mathrm{d}}$ values for selenite and selenate were $380 \mathrm{~L} / \mathrm{kg}$ and 2,060 L/kg, respectively. Johnson et al. (2000) obtained experimental Se $\mathrm{K}_{d}$ values for cement formulations ranging from $350-930 \mathrm{~L} / \mathrm{kg}$ during adsorption phases and from $820-1,100 \mathrm{~L} / \mathrm{kg}$ during desorption phases. Sorption data typically followed a linear isotherm. Rudin (1996) investigated the leaching of Se from these same cement formulations to define desorption kinetics over time. Leachates were sampled over 90 days; the cumulative percentage of Se released from cement formulations at the end of sampling ranged from 0.03-1.4\% of total Se. Kaplan and Serne (1995) found that sorption of Se to sands was very low $\left(\mathrm{K}_{d}=0.78 \mathrm{~L} / \mathrm{kg}\right)$. Adsorption onto geologic materials was not expected to play a major role in Se mobility. Sheppard and Thibault (1990) presented the following mean values for $\mathrm{K}_{\mathrm{d}}$ for different soil types: sand $=150 \mathrm{~L} / \mathrm{kg}$, silt $=500 \mathrm{~L} / \mathrm{kg}$, clay $=740 \mathrm{~L} / \mathrm{kg}$, organic $=1,800 \mathrm{~L} / \mathrm{kg}$. Zhang and Sparks (1990) used pressure-jump relaxation to determine the mechanisms and kinetics of Se sorption on goethite. Adsorption occurred primarily under acidic conditions and was much higher than the rate of desorption. A two step process was proposed as the mechanism for Se adsorption onto goethite. Se first reacted with outer surfaces to form outer-sphere complexes, followed by Se anion exchange with water to form inner-sphere complexes.

Limited studies have investigated the leaching of Se specifically from materials associated with coal mining. Wang et al. (2007) assessed the leaching of Se from coal fly ash, a byproduct of coal combustion which is often disposed of in landfills or impoundments. Coal fly ash samples 
with Se concentrations ranging from 4.60-45.6 mg/kg were collected from power plants that burned bituminous and subbituminous coal. For bituminous coal fly ashes, $\mathrm{pH}$ was the most important factor in Se leaching; 50-70\% of Se was leached as $\mathrm{pH}$ approached 12. Adsorption and desorption processes controlled Se leaching and followed a linear Langmuir isotherm. Very little leaching of Se from subbituminous coal fly ashes was attributed to high calcium content. Sharmasarkar and Vance (2002) investigated the sorption of Se species using multiple isotherm models and related Se sorption to soil properties. Ten soil samples from Powder River Basin, Wyoming, USA were equilibrated with Se treatments, centrifuged, and filtered. Freundlich isotherms provided the best fit of Se adsorption data and produced $\mathrm{K}_{\mathrm{d}}$ values ranging from 7-657 $\mathrm{L} / \mathrm{kg}$ for selenite and 5-85 L/kg for selenate. Linear isotherms suggested that surface mine sites subjected to sorption were never saturated. Se mobility was dependent on total Se available and species type.

Due to the lengthy process associated with natural rock dissolution (Sparks, 1989), Roy (2005) and Pumure et al. (2009) implemented accelerated methods of extracting Se from rocks associated with surface coal mining. Roy (2005) found that approximately $25-35 \%$ of total Se in mine overburden was mobile through chemical extraction. Sandstone and shale units exhibited low Se concentrations and were not expected to be the cause of high Se concentration in mine discharge water. Pumure et al. (2009) utilized ultrasound extraction to determine the amount of mobile Se in coal associated rock samples. Three rock samples (one sandstone and two claystones) were extracted from a mountain within the surface coal mining region of Boone and Kanawha Counties, West Virginia, USA. Ultrasound energy was applied to pulverized rock samples to simulate natural weathering. A process of ultrasonicating samples for five minutes and centrifuging them for 20 minutes was repeated 17 times. The rate of release of Se was not dependent on initial concentration but was dependent on rock type; sandstone contained the lowest Se concentration but exhibited the most rapid release of Se. The percentage of available Se extracted from each sample (sandstone, claystone 1, claystone 2) ranged from 75-99\%, 14$35 \%$, and 9.0-14\%, respectively. An additional study by Pumure et al. (2010) found that 35\% and $38 \%$ of total Se in shale samples from a southern WV surface mine were extractable by similar ultransonic methods. 
Ziemkiewicz et al. (2011) assessed the natural leaching of Se from coal tailings and mine spoil. Coarse tailings (size ranging from $0.075 \mathrm{~mm}$ to $11 \mathrm{~mm}$ ) were collected form a southern West Virginia coal preparation plant. Both untreated and treated samples were prepared and rinsed over a 96 week period; leachate samples were collected throughout and tested for Se concentration. The soil analyzed had an initial Se concentration of $1.55 \mathrm{mg} / \mathrm{kg}$. Based on the findings of Roy (2005), 25-35\% of the total Se was considered mobile. Untreated samples had an initial leachate concentration of $5.9 \pm 3.5 \mu \mathrm{g} / \mathrm{L}$. The rate of release of Se was $0.06 \%$ per day and was modeled by first order kinetics. By the end of the test, $35.1 \%$ of the mobile Se had been leached. Samples treated with iron oxyhydroxide had an initial leachate concentration of $0.7 \pm$ $0.4 \mu \mathrm{g} / \mathrm{L}$. By the end of the test, $11.6 \%$ of the extractable Se had been leached. Cumulative percentage of leached Se increased steadily for both samples and at a higher rate for the untreated sample. Extrapolated data scaled up to field conditions predicted that almost 12 years would be needed to remove $90 \%$ of the mobile Se; 4.7 years were needed for natural attenuation of Se to $5 \mu \mathrm{g} / \mathrm{L}$. Mean Se $\mathrm{K}_{\mathrm{d}}$ of coarse coal tailings was $530 \mathrm{~L} / \mathrm{kg}$. 


\section{CHAPTER 3. GEOMORPHIC CHARACTERISTICS OF MATURE LANDFORMS IN SOUTHERN WEST VIRGINIA}

\subsection{Introduction}

Geomorphic landform design uses a reference landform approach by replicating channel geomorphology from pre-disturbed conditions or from nearby undisturbed basins. Initial design is controlled by watershed geomorphology characteristics such as drainage-basin relief, drainage-basin area, drainage density, and drainage pattern (Toy and Chuse, 2005). The reference landform approach requires quantifying the geomorphic properties of mature, undisturbed landforms as critical design parameters for the generation of new, artificial geomorphic landforms. The values for geomorphic design criteria are much different in central Appalachia than in the southwestern U.S. (where geomorphic reclamation has been successful), and quantifying them on a local scale is necessary for accurate site-specific design of geomorphic landforms (Sears et al., 2014). Little research has been completed on quantifying the critical geomorphic properties of undisturbed headwater basins in central Appalachia (e.g. Wiley et al., 2001; Buckley et al., 2013). Properties of headwater channels are important because they are the channels which are buried in conventional reclamation and attempted to be mitigated in geomorphic reclamation. A more comprehensive analysis of the geomorphic properties of reference landforms is required before accurate geomorphic designs can be completed in central Appalachia. The overall goal of this portion of research was to define the properties of geomorphic landforms in central Appalachia, so that these properties could be used as reference values to complete geomorphic designs and inform future geomorphic reclamation in central Appalachia. A dataset of geomorphic properties can be used as the basis for future geomorphic designs or to supplement any future research on the geomorphic properties of Appalachian landforms. To define these properties, the following tasks were completed:

1. Defined a reference landform for design and used the definition to determine appropriate sites for field data collection.

2. Collected necessary data from field sites to define landform properties.

3. Complimented field data with a spatial analysis to determine critical geomorphic design criteria. 


\subsection{Background}

A mature landform can be described as "stable" or "undisturbed" landform. In a mature landform, erosive forces cause a landform to become naturally stable over a long period of time (Ollier, 1967). Effective landforming involves designing surfaces in which erosive forces are minimized (Schor and Gray, 2007). Designing a new landform in a way in which it is already naturally stable by mimicking the geomorphology of a mature landform would be advantageous. Ideally, a landform consisting of unconsolidated materials and in erosive equilibrium would be used as a reference for a reclaimed landform condition. As it is difficult to find entire watersheds of this type in central Appalachia, mature landforms within the region are the most appropriate and available sites for reference landform investigation. Mature landforms in headwater valleys are the type of landforms typically filled/disturbed during surface mine reclamation in Appalachia, and specifically the type of landform being disturbed at the study site in this research. To find a mature, stable, and undisturbed reference landform, a site must be found that has a minimal level of disturbance through land use, a history of stability, and a long amount of time (several decades) since major disturbance. The area of most concern when quantifying the geomorphology of landforms is the "channel head." Montgomery and Dietrich (1988) defined the channel head as the location nearest to the drainage divide where channeled morphology occurred. Henkle et al. (2011) added that channel heads represented the location exhibiting concentrated flow and sediment transport. Locating channel head locations is critical in calculating drainage density (stream length/watershed area) because the National Hydrography Dataset (NHD) (USGS, 2003a) under represents headwater stream length (Heine et al., 2004).

The majority of work done with mapping headwater channel heads has been performed in the western United States (e.g. Montgomery and Foufoula-Georgiou, 1993; Vogt et al., 2003; Benda et al., 2005; Hancock and Evans, 2005; McNamara et al., 2005; Henkle et al., 2011) or midAtlantic (Julian et al., 2012). These studies investigated the effects of slope and drainage area on channel head location, using slope-area relationships to perform large scale mapping of stream networks and investigate how they evolve over time. The main intent of the research discussed in this chapter, however, was not to establish large-scale mapping methods but to establish values for drainage length and drainage density specific to central Appalachia. Limited studies have collected geomorphic data in southern West Virginia (Wiley et al., 2001; Buckley et al., 2013). 
Central Appalachian headwater channel studies have investigated perennial and intermittent streams (e.g. Paybins, 2003; Svec et al., 2005; Fritz et al., 2008), but limited work has investigated ephemeral streams (e.g. Villines, 2013). Ephemeral channels are of particular concern in central Appalachia because they are not accounted for in headwater stream burial and are similar to the type of channel that would be constructed on a reclaimed landform. For the most part, data on the geomorphic properties of landforms in central Appalachia, the region of interest in this research, are lacking (Sears et al., 2014).

In addition to mature, undisturbed landforms, long-term reclaimed sites can be used to quantify the geomorphic properties of landforms as they evolve over time. A "long-term reclaimed" site is a surface mine site that has been reclaimed, but enough time has passed for the landform to evolve and for erosive characteristics to be evident. In this research, the purpose of the long-term reclaimed site was to quantify erosive features, such as gullies, rills, and deflection of trees that eventually result in mature, stable landforms.

\subsection{Methods}

\subsubsection{Reference landform site selection}

To determine field sites for data collection, criteria for mature landforms and long-term reclaimed sites were defined. The decision procedure consisted of four phases (Figure 3.1). While the decision procedure was the same for both types of sites, the evaluation tools varied to match the needs of the specific landform type. First, sites were evaluated at a regional scale. Then, the regions were evaluated at the individual watershed scale to make a final decision on the watersheds from which field data would be collected. Evaluation criteria were scored on a scale of 1 to 5 . Weights were given to each property according to importance. 


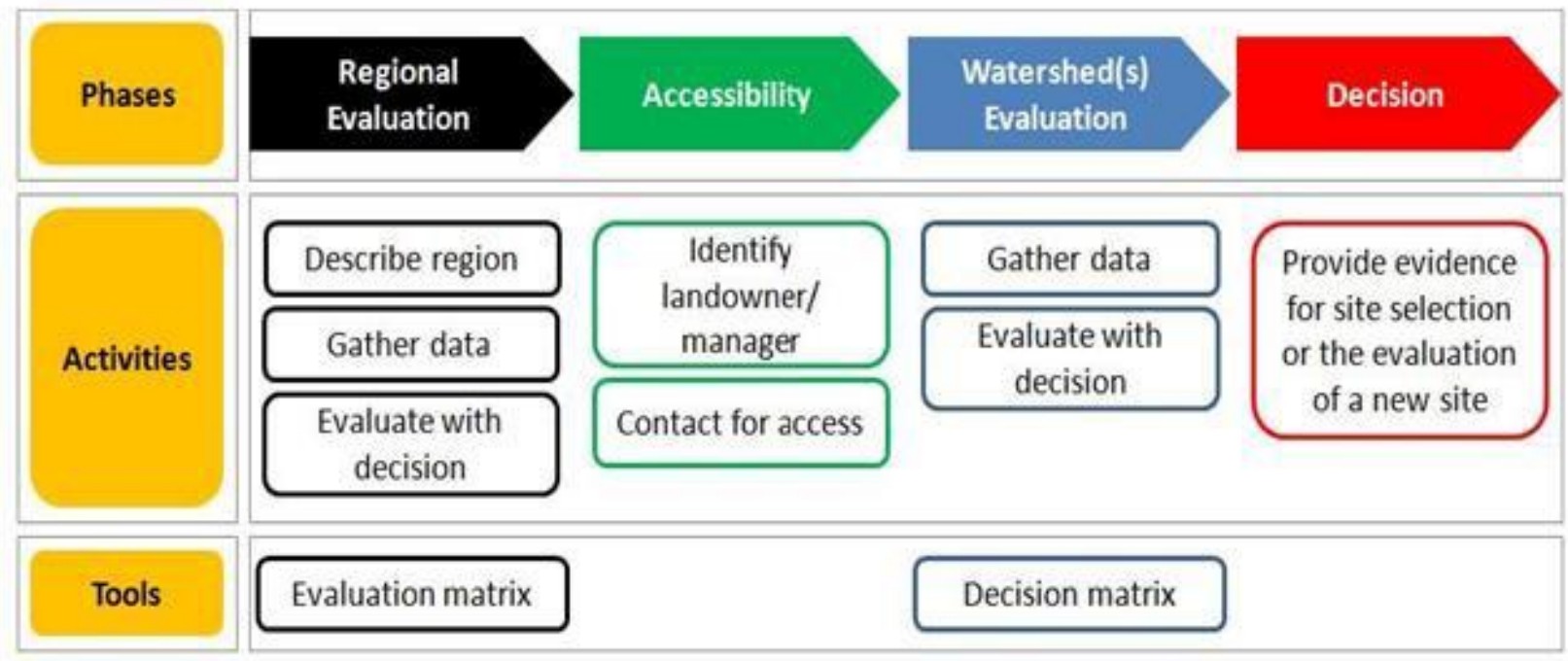

Figure 3.1. Evaluation procedure guiding field site selection.

$\underline{\text { Mature landforms }}$

For mature landforms, properties included in the regional evaluation were landuse, topography, history, GIS data availability, and access potential (Table 3.1). A score of 60 out of a possible 75 points was required in the regional evaluation to proceed to the watershed evaluation. The threshold score was taken from scoring $80 \%$ (4 out of 5) on each property. This $80 \%$ threshold was used for all evaluation matrices, at both the regional and watershed scales. Next, a decision matrix was developed to analyze reference landform potential of specific watersheds within regions with adequate scores from the regional evaluation (Table 3.2). Properties included in the watershed evaluation were accessibility, watershed size, streams/channels, vegetation, and history. A score of 84 out of a possible 105 points was required in the watershed evaluation phase to proceed to field data collection. The six regions and three watersheds evaluated in this study are documented in Appendix A. 
Table 3.1. Description, justification, and resources for decision matrix for mature landforms (Regional Evaluation Phase).

\begin{tabular}{|c|c|c|c|}
\hline Property & Weight & Description and Justification & Resources \\
\hline Landuse & 1 & $\begin{array}{l}\text { For the mature sites, we are targeting mature forests native to the } \\
\text { southern } W V \text { region. } \\
\text { All sites will be located in rural locations of southern } W V \text {, so this property } \\
\text { is given a low weight of } 1 .\end{array}$ & $\begin{array}{l}\text { - Aerial photography (provided by } \\
\text { WVGIS Technical Center) }\end{array}$ \\
\hline Topography & 1 & $\begin{array}{l}\text { For the mature sites, we are targeting unaltered topography characteristic } \\
\text { to the southern WV region, characterized by steep slopes and valleys. } \\
\text { The number of peaks per area will be evaluated and compared to the area } \\
\text { near the site under construction. } \\
\text { All sites will be located in southern WV, so this property is given a low } \\
\text { weight of } 1 \text {. }\end{array}$ & $\begin{array}{l}\text { - Digital Elevation Models (USGS) } \\
\text { (provided by WVGIS Technical } \\
\text { Center) }\end{array}$ \\
\hline History & 3 & $\begin{array}{l}\text { Defining exactly how disturbed a landform has been in its history by } \\
\text { defining land use, type of disturbance, and timing of disturbance, } \\
\text { management history. } \\
\text { Historical information is important to understand the degree of human } \\
\text { impact, so this property was given a medium weight of } 3 \text {. }\end{array}$ & $\begin{array}{l}\text { - Published reports } \\
\text { - Discussion with land managers and } \\
\text { owners }\end{array}$ \\
\hline $\begin{array}{l}\text { GIS data } \\
\text { availability }\end{array}$ & 5 & $\begin{array}{l}\text { GIS data must be available to complete the analysis of the selected } \\
\text { watershed. } \\
\text { The weight of } 5 \text { was selected as this is a critical property. Without } \\
\text { available data, calculation of reference landform properties will not be } \\
\text { possible. }\end{array}$ & - WV GIS Data Clearinghouse \\
\hline $\begin{array}{l}\text { Access } \\
\text { potential }\end{array}$ & 5 & $\begin{array}{l}\text { Measure of potential for access. Public land is scored highly. } \\
\text { The weight of } 5 \text { was selected as this is a critical property. Without access } \\
\text { permission, field data collection is impossible. }\end{array}$ & - Discussion with land managers \\
\hline
\end{tabular}

Note: 1 = Poor, 5 = Excellent

Score of $60 / 75$ is adequate for further consideration 
Table 3.2. Description, justification, and resources for decision matrix for mature landforms (Watershed Evaluation Phase).

\begin{tabular}{|c|c|c|c|}
\hline Property & Weight & Description and Justification & Resources \\
\hline Accessibility & 5 & $\begin{array}{l}\text { While minimal disturbance is ideal, access roads are needed to get access } \\
\text { to the watersheds of interest. } \\
\text { The weight of } 5 \text { was selected as this is a critical property. Without access, } \\
\text { field data collection is impossible. }\end{array}$ & $\begin{array}{l}\text { - Discussion with land managers and } \\
\text { owners }\end{array}$ \\
\hline $\begin{array}{l}\text { Watershed } \\
\text { Size }\end{array}$ & 5 & $\begin{array}{l}\text { The target watershed size is } 1 \mathrm{~km}^{2} \text {. The target watershed size corresponds } \\
\text { to the watershed that contains the valley fill of interest. } \\
\text { The weight of } 5 \text { was selected as this is a critical property. A specific } \\
\text { watershed size in necessary to complete a GLD design for the conventional } \\
\text { valley fill of interest. }\end{array}$ & $\begin{array}{l}\text { - Digital Elevation Models (USGS) } \\
\text { (provided by WVGIS Technical } \\
\text { Center) }\end{array}$ \\
\hline $\begin{array}{l}\text { Streams / } \\
\text { Channels }\end{array}$ & 5 & $\begin{array}{l}\text { We are targeting sites with minimal modification to channel planform and } \\
\text { cross-section (e.g. straightening, hardening) } \\
\text { The weight of } 5 \text { was selected as this is a critical property. Quantifying } \\
\text { mature, stable channels in equilibrium is an important goal in field work. }\end{array}$ & $\begin{array}{l}\text { - Aerial photography (provided by } \\
\text { WVGIS Technical Center) } \\
\text { - Discussion with land managers and } \\
\text { owners } \\
\text { - On-site evaluation }\end{array}$ \\
\hline Vegetation & 3 & $\begin{array}{l}\text { We are targeting mature forests with thick cover. (No evidence of recent } \\
\text { timbering or agricultural activities). } \\
\text { The weight of } 3 \text { was selected as this is a property of secondary importance. } \\
\text { Sites that have reached this level of evaluation should have these } \\
\text { vegetation characteristics at the regional scale. }\end{array}$ & $\begin{array}{l}\text { - Aerial photography (provided by } \\
\text { WVGIS Technical Center) } \\
\text { - Discussion with land managers and } \\
\text { owners } \\
\text { - On-site evaluation }\end{array}$ \\
\hline History & 3 & $\begin{array}{l}\text { We are targeting minimal development beyond the forested condition. } \\
\text { Disturbance from roads is expected, but disturbance from other human } \\
\text { impacts should be minimal. } \\
\text { The weight of } 3 \text { was selected as this is a property of secondary importance. } \\
\text { Sites that have reached this level of evaluation should have these landuse } \\
\text { characteristics at the regional scale. }\end{array}$ & $\begin{array}{l}\text { - Aerial photography (provided by } \\
\text { WVGIS Technical Center) } \\
\text { - Discussion with land managers and } \\
\text { owners } \\
\text { - On-site evaluation }\end{array}$ \\
\hline
\end{tabular}

\section{$\underline{\text { Long-term reclaimed sites }}$}

For long-term reclaimed sites, evaluation properties at a regional scale were reclaimed landuse, history, GIS data availability, and access potential (Table 3.3). A score of 64 out of a possible 80 points was required in the regional evaluation to proceed to the watershed evaluation phase.

Properties of the watershed evaluation phase included accessibility, watershed size, vegetation, and history (Table 3.4). A score of 56 out of a possible 70 points was required in the watershed evaluation phase to proceed to field data collection. The region and four watersheds evaluated in this study are documented in Appendix A. 
Table 3.3. Description, justification, and resources for evaluation matrix for long-term reclaimed sites (Regional Evaluation Phase).

\begin{tabular}{|c|c|c|c|}
\hline Property & Weight & Description and Justification & Resources \\
\hline $\begin{array}{l}\text { Reclaimed } \\
\text { Landuse }\end{array}$ & 3 & $\begin{array}{l}\text { Postmining landuse of woodland or agriculture is preferred. } \\
\text { Residential or public landuse with substantial development is not } \\
\text { preferred. } \\
\text { The weight of } 3 \text { was selected as this is a property of secondary } \\
\text { importance. It is desired to quantify natural erosive features rather } \\
\text { than those accelerated by human impact. }\end{array}$ & - Permit information \\
\hline History & 3 & $\begin{array}{l}\text { The age of fill and history of management must be evaluated. We } \\
\text { are targeting sites that have completed bond release. } \\
\text { If available, information on the stability of the fill will be reviewed. } \\
\text { The weight of } 3 \text { was selected as this is a property of secondary } \\
\text { importance. Older sites will have more erosive features and be } \\
\text { closer to equilibrium than newer sites. }\end{array}$ & $\begin{array}{l}\text { - OSM report of long-term stability of valley fills } \\
\text { (OSM, 2002) } \\
\text { - OSM valley fills construction/inspection } \\
\text { history }\end{array}$ \\
\hline $\begin{array}{l}\text { GIS data } \\
\text { availability }\end{array}$ & 5 & $\begin{array}{l}\text { GIS data must be available to complete the analysis of the selected } \\
\text { location. } \\
\text { The weight of } 5 \text { was selected as this is a critical property. Without } \\
\text { available data, calculation of reference landform properties will not } \\
\text { be possible. }\end{array}$ & - WV GIS Data Clearinghouse \\
\hline $\begin{array}{l}\text { Access } \\
\text { potential }\end{array}$ & 5 & $\begin{array}{l}\text { Measure of potential for access. } \\
\text { The weight of } 5 \text { was selected as this is a critical property. Without } \\
\text { access permission, field data collection is impossible. }\end{array}$ & - Discussion with land managers and owners \\
\hline
\end{tabular}

Note: 1 = Poor, 5 = Excellent

Score of $64 / 80$ is adequate for further consideration

Table 3.4. Description, justification, and resources for decision matrix for long -term reclaimed sites (Watershed Evaluation Phase).

\begin{tabular}{|c|c|c|c|}
\hline Property & Weight & Description and Justification & Resources \\
\hline Accessibility & 5 & $\begin{array}{l}\text { While minimal disturbance is ideal, access roads are needed to } \\
\text { get access to the watersheds of interest. } \\
\text { The weight of } 5 \text { was selected as this is a critical property. Without } \\
\text { access, field data collection is impossible. }\end{array}$ & - Discussion with land managers and owners \\
\hline $\begin{array}{l}\text { Watershed } \\
\text { Size }\end{array}$ & 5 & $\begin{array}{l}\text { The target watershed size is } 1 \mathrm{~km}^{2} \text {. The target watershed size } \\
\text { corresponds to the watershed containing the valley fill of interest. } \\
\text { The weight of } 5 \text { was selected as this is a critical property. A } \\
\text { specific watershed size in necessary to complete a GLD design } \\
\text { for the conventional valley fill of interest. }\end{array}$ & $\begin{array}{l}\text { - Digital Elevation Models (USGS) (provided by } \\
\text { WVGIS Technical Center) }\end{array}$ \\
\hline Vegetation & 3 & $\begin{array}{l}\text { We are targeting landforms with established vegetation. Sites } \\
\text { with more mature vegetation will be rated highly. } \\
\text { The weight of } 3 \text { was selected as this is a property of secondary } \\
\text { importance. Established vegetation is a design consideration. }\end{array}$ & $\begin{array}{l}\text { - Aerial photography (provided by WVGIS } \\
\text { Technical Center) } \\
\text { - Discussion with land managers and owners }\end{array}$ \\
\hline History & 1 & $\begin{array}{l}\text { The management history will be evaluated. We are targeting } \\
\text { minimal development beyond a vegetated condition. } \\
\text { Reclaimed landuse will have already been evaluated on a } \\
\text { regional scale, so this criterion is given a low weight of } 1 \text {. }\end{array}$ & $\begin{array}{l}\text { - Published reports } \\
\text { - Discussion with land managers and owners }\end{array}$ \\
\hline
\end{tabular}

\subsubsection{Field data collection}

At mature landforms, field data were collected at channel head locations. The initial plan was to survey entire streams by starting at the mouth and walking up the stream, but this was very 
difficult due to the terrain and vegetative cover of the mature landforms. For this reason, channel head locations were surveyed by walking down from the drainage divide until a channel head was apparent. To limit the amount of subjectivity in defining the location of each channel head, constant criteria were held for channel characteristics, multiple surveyors were always present for consensus, and field photographs were documented for future reference. The channel head was defined as the location nearest to the drainage divide where channeled morphology occurred (Montgomery and Dietrich, 1988), resulting in concentrated flow and sediment transport (Henkle et al., 2011). These characteristics were present when overland sheet flow became more concentrated and exposed subsurface bed material composed of sands, gravels, and cobbles. For each headwater channel site in the watersheds of mature landforms, the channel head and associated ridge point upstream of the channel head were surveyed using a Topcon Positioning Systems HiPer Lite GPS receiver (Tokyo, Japan). Due to the dense canopy cover, horizontal and vertical errors were $1 \mathrm{ft}$ and $3 \mathrm{ft}$, respectively.

Channel/bank properties documented were left bank slope, right bank slope, texture of exposed left bank, texture of exposed right bank, left bank vegetation, right bank vegetation, channel width, upstream slope, downstream slope, left valley slope (looking downstream), and right valley slope (looking downstream). Channel/bank properties and pebble counts were completed at appropriate sites. Pebble counts were completed with a gravelometer in accordance with the modified Wolfman (1954) pebble count typically used in the field (Harrelson et al., 1994). At long-term reclaimed sites, data were collected on erosive characteristics. Data collection consisted of walking on the sloped face of the valley fill and surveying locations where erosion had initiated by exposing subsurface rock and soil. The same properties evaluated for the mature landforms were evaluated at these erosion sites.

\subsubsection{Geomorphic design criteria}

Critical design criteria of drainage length $\left(\mathrm{L}_{\mathrm{D}}\right)$ and drainage density (DD) were determined from the field and spatial GIS analysis. $\mathrm{L}_{\mathrm{D}}$ is the distance from the channel head to the ridge point upvalley of that channel (Dietrich and Dunne, 1993). For the purposes of this study, $L_{D}$ was calculated as the distance from ridgeline to channel head as required by the design software (Bugosh, 2006). DD is stream length per watershed area (Horton, 1932). Not all channel head 
locations were identified in the reference watersheds during the field work due to resource and accessibility restrictions. To complete the data set, channel head locations were modeled in the unsurveyed valleys by applying the mean drainage length of the watershed. The headwater streams were then delineated and added to the NHD. DD was then calculated for each reference watershed. DD values including headwater stream lengths to adjust total stream length were compared to DD values using only the available NHD data. This method of identifying channel head locations, delineating streams, and calculating drainage density was applied to additional watersheds within Twin Falls State Park and Cabwaylingo State Forest until calculated drainage density resulted in a constant standard deviation. This analysis led to the target drainage density and allowable variance used in design.

\subsubsection{GIS analysis}

GIS was used to describe hillslope, aspect, and vegetation. Hillslope described the slope (\%) of the areas contained within each watershed. Aspect $\left({ }^{\circ}\right)$ described the direction in which slopes were facing. Hillslope and aspect were both evaluated using digital elevation models (USGS, 2003b). Forest fragmentation data from WVGIS Technical Center (Strager and Maxwell, 2011) gave a distribution of the vegetation cover in each watershed. Watershed characteristics determined with GIS were compared to what was seen in the field.

\subsection{Results and discussion}

The data from this portion of research have since been published in conjunction with the findings of Chapter 4 (DePriest et al., 2015).

\subsubsection{Field site determination}

Two undisturbed reference landform locations in the same ecoregion as the surface mine design site (detailed in Section 4.3.1) were selected that exhibited steep terrain, temperate climate, and mature forests. The first reference landform location was Twin Falls State Park in Wyoming County, WV (Figure 3.2); the second was Cabwaylingo State Forest in Wayne County, WV (Figure 3.2). Twin Falls State Park (3,776 acres) was completed in the 1970s and is predominantly forested. Mean annual temperature is $53^{\circ} \mathrm{F}$ and mean annual precipitation is 46 in (NOAA, 2014a). The two selected reference watersheds (Dixon and Jackson watersheds) are 
forested with minimal anthropogenic disturbance (i.e. access road, recreational campground, and hiking trails). The mean slopes of Dixon and Jackson watersheds were $27 \%$ and $32 \%$, respectively. Cabwaylingo State Forest (8,123 acres) was completed in the 1930s and is heavily forested. The Wiley watershed was selected as a reference because it was minimally disturbed by roads and trails. Mean annual temperature is $54^{\circ} \mathrm{F}$, and mean annual precipitation is 47 in (NOAA, 2014a). The watershed has steep terrain with a spatial mean slope of $43 \%$. A reclaimed site in Summersville, WV was chosen for field data collection as a long-term reclaimed site (Figure 3.2). Four valley fills were present at the Summersville long-term reclaimed site. The southwest and northwest facing valley fills were suitable for field data collection, whereas the northeast and southeast facing valley fills were not due to accessibility limitations.

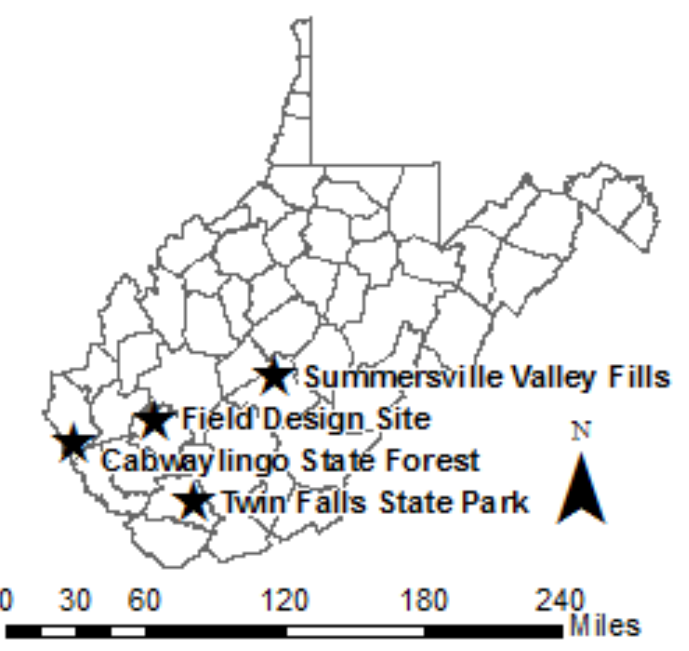

Figure 3.2. Location of reference landforms sites relative to design site for generation of geomorphic landforms.

\subsubsection{Field data}

Field data were collected from sites at Twin Falls State Park (Figure 3.3a), Cabwaylingo State Forest (Figure 3.3b), and Summersville, WV (Figure 3.3c). Eight sites in Dixon watershed, 11 sites in Jackson watershed, three sites in Wiley watershed, and five sites in Summersville were used to determine channel properties (Table 3.5) and watershed characteristics (Table 3.6). Additional reference landform data and field photographs are provided in Appendix B. 


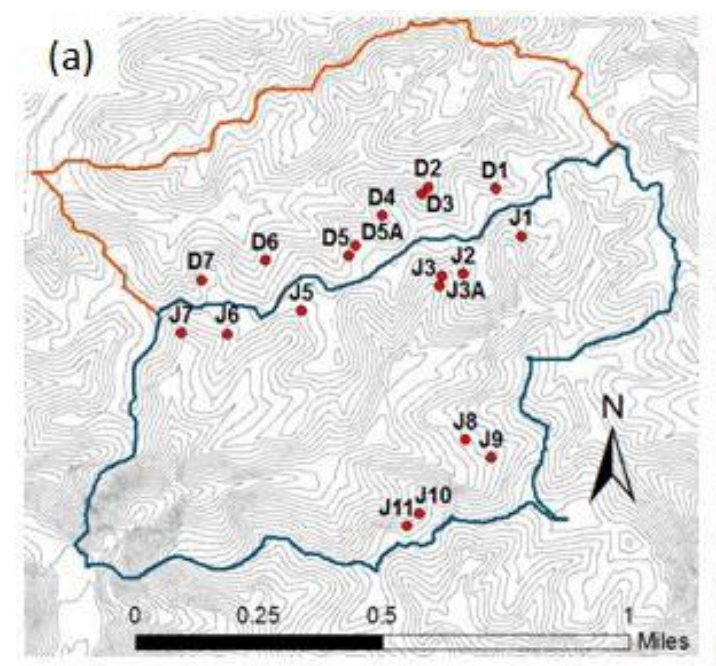

(b)

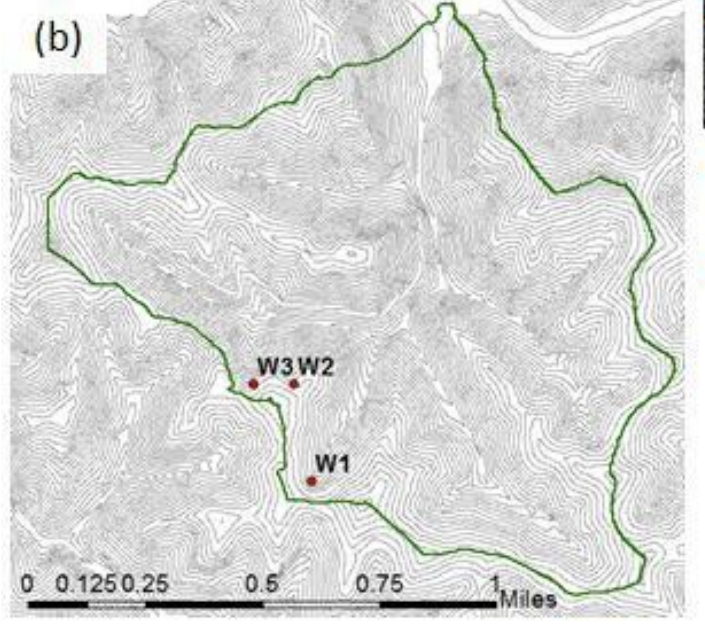

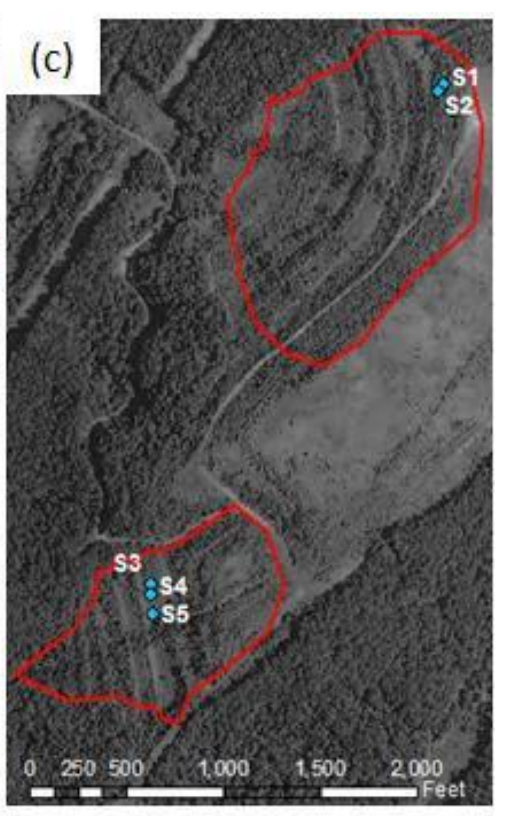

- Dixon watershed

- Jackson watershed

- Wiley watershed

- Valley fill boundaries

- $20 \mathrm{ft}$ contours

- Channelheads

Erosion sites

Figure 3.3. Channel heads and erosion sites at reference landforms: (a) Twin Falls State Park; (b) Cabwaylingo State Forest; and, (c) Summersville, WV long-term reclaimed site.

Table 3.5. Mean slope $\left(S_{c}\right)$, width $(B)$, median particle size $\left(D_{50}\right)$ and drainage length $\left(L_{D}\right)$ at channel head locations or erosion sites of reference landforms. Standard deviation of each mean value is reported in parentheses.

\begin{tabular}{cccccc}
\hline Watershed & $\begin{array}{c}\text { No. of } \\
\text { sites }\end{array}$ & $\mathbf{S}_{\mathbf{C}}(\boldsymbol{\%})$ & $\mathbf{B}(\mathbf{f t})$ & $\mathbf{D}_{\mathbf{5 0}}(\mathbf{i n})$ & $\mathbf{L}_{\mathbf{D}}(\mathbf{f t})$ \\
\hline Dixon & 8 & $18.1(4.2)$ & $3.2(1.1)$ & $0.03(0.004)$ & $429(43)$ \\
Jackson & 11 & $23.5(12.6)$ & $3.8(1.9)$ & $0.14(0.10)$ & $404(113)$ \\
Wiley & 3 & $46(7.2)$ & $4.1(0.8)$ & $0.03(0.003)$ & $330(29)$ \\
Summersville & 5 & $44(3.0)$ & $1.9(0.7)$ & $0.38(0.07)$ & NA \\
\hline
\end{tabular}


Table 3.6. Reference landform watershed characteristics $\left(S_{L}=\right.$ mean hillslope, $D D=$ drainage density).

\begin{tabular}{cccc}
\hline Watershed & $\begin{array}{c}\text { Area } \\
(\mathbf{a c})\end{array}$ & $\mathbf{S}_{\mathbf{L}}(\boldsymbol{\%})$ & $\begin{array}{c}\text { DD } \\
(\mathbf{f t} / \mathbf{a c})\end{array}$ \\
\hline Dixon & 235 & 27.2 & 69 \\
Jackson & 359 & 31.6 & 74 \\
Wiley & 574 & 43.0 & 62 \\
\hline
\end{tabular}

Channel head sites for mature landforms were found downslope of the transition point from convex to concave slopes, consistent with the findings of Dietrich and Dunne (1993). For all channel head locations and erosion sites, the majority of bed material was sand and gravel. Erosion sites had a higher percentage of gravels due to erosion of finer sand particles. Sampling sites at the mouths of streams had higher percentages of cobbles and boulders, indicative of the larger grain size of a stream bed at the mouth as compared to in its headwaters. Data for channel sinuosity was taken at the mouth of the Wiley watershed, as well as at the stream head for one site in the Dixon watershed and one site in the Wiley watershed. The mouth of the Wiley Branch had a sinuosity of 1.0. Site W1 in the Wiley watershed had a sinuosity of 1.0. Site D5 in the Dixon watershed had a sinuosity of 1.3 . All other sites were determined to have a sinuosity $\approx 1$ in the field due to straightness that could be visually determined and within the horizontal error of the surveying equipment.

For a given slope face at the long-term reclaimed site, erosion sites were found across the face of the slope at the same location between benches (Figure 3.3c). Essentially, erosion sites occurred parallel to the bench at a similar distance downslope from the bench (approximately halfway between benches). Preceding erosion sites was broad sheet flow. Areas downslope of erosion sites exhibited more defined and constricted sheet flow. Dense vegetation made it difficult to investigate erosive features on slope faces further downslope from the top of the fill.

\subsubsection{Geomorphic design criteria}

Mean drainage length and mean drainage density were calculated as $408 \mathrm{ft}$ and $62 \mathrm{ft} / \mathrm{ac}$, respectively. These mean values served as the critical geomorphic design criteria. For all three watersheds, a significant amount of additional stream length was added to the NHD data by including the headwater channels (Table 3.7). To allow for natural variability in designs, a range 
of acceptable drainage density values was created by applying a $\pm 23 \%$ variance (two standard deviations) to the mean drainage density value.

Table 3.7. Drainage densities calculated from varying stream lengths. Starting with the NHD streams first, the streams delineated from field mapped sites were added, and then the streams from GIS mapped sites were added.

\begin{tabular}{|c|c|c|c|c|c|c|c|}
\hline \multirow[b]{2}{*}{ Watershed } & \multirow[b]{2}{*}{$\begin{array}{c}\text { Watershed } \\
\text { Area (ac) }\end{array}$} & \multicolumn{3}{|c|}{ Stream Length (mi) } & \multicolumn{3}{|c|}{ Drainage Density (ft/ac) } \\
\hline & & $\begin{array}{l}\text { NHD } \\
\text { data } \\
\text { only }\end{array}$ & $\begin{array}{c}\text { Field } \\
\text { surveyed } \\
\text { streams }\end{array}$ & $\begin{array}{c}\text { GIS mapped } \\
\text { streams }\end{array}$ & $\begin{array}{l}\text { NHD } \\
\text { data } \\
\text { only }\end{array}$ & $\begin{array}{c}\text { Field } \\
\text { surveyed } \\
\text { streams }\end{array}$ & $\begin{array}{c}\text { GIS } \\
\text { mapped } \\
\text { streams }\end{array}$ \\
\hline Dixon & 235 & 1.062 & 2.126 & 3.060 & 24 & 48 & 69 \\
\hline Jackson & 359 & 1.732 & 3.744 & 5.018 & 26 & 55 & 74 \\
\hline Wiley & 574 & 4.906 & 5.085 & 6.692 & 45 & 47 & 62 \\
\hline
\end{tabular}

\subsubsection{GIS analysis}

Hillslope

The majority of hillslopes for mature sites (Dixon, Jackson, and Wiley watersheds) fell between $20-40 \%$ grade, but a moderate amount of slopes were greater than $40 \%$ grade (Table 3.8, Figure 3.4a, Figure 3.4b). This was indicative of the steep terrain of southern WV. The majority of hillslopes at the Summersville valley fills fell within 20-60\% grade (Figure 3.4c) due to the 2:1 slope design of conventional valley fills. Slope data from GIS were consistent with field observations. The difference in slope quantity and distribution between the mature landforms and the long-term reclaimed sites highlighted the difference that would be apparent between geomorphic reclaimed landforms and conventional reclaimed landforms.

Table 3.8. Percent by area of each slope range for each reference landform.

\begin{tabular}{cccccc}
\multirow{2}{*}{ Slope (\%) } & \multicolumn{5}{c}{ Percent by Area (\%) } \\
\cline { 2 - 5 } & Dixon & Jackson & Wiley & $\begin{array}{c}\text { Nortnwest } \\
\text { VF }\end{array}$ & $\begin{array}{c}\text { soutnwest } \\
\text { VF }\end{array}$ \\
\hline $0-20$ & 27.2 & 23.4 & 9.6 & 9.4 & 25.8 \\
$20-40$ & 59.4 & 52.8 & 61.8 & 59.2 & 53.3 \\
$40-60$ & 13.1 & 18.7 & 7.3 & 31.4 & 20.0 \\
$60-80$ & 0.3 & 3.6 & 20.1 & 0 & 0.9 \\
$80-100$ & 0 & 1.2 & 1.2 & 0 & 0 \\
$100-120$ & $\underline{0}$ & $\underline{0.3}$ & $\underline{0}$ & $\underline{0}$ & $\underline{0}$ \\
\hline
\end{tabular}



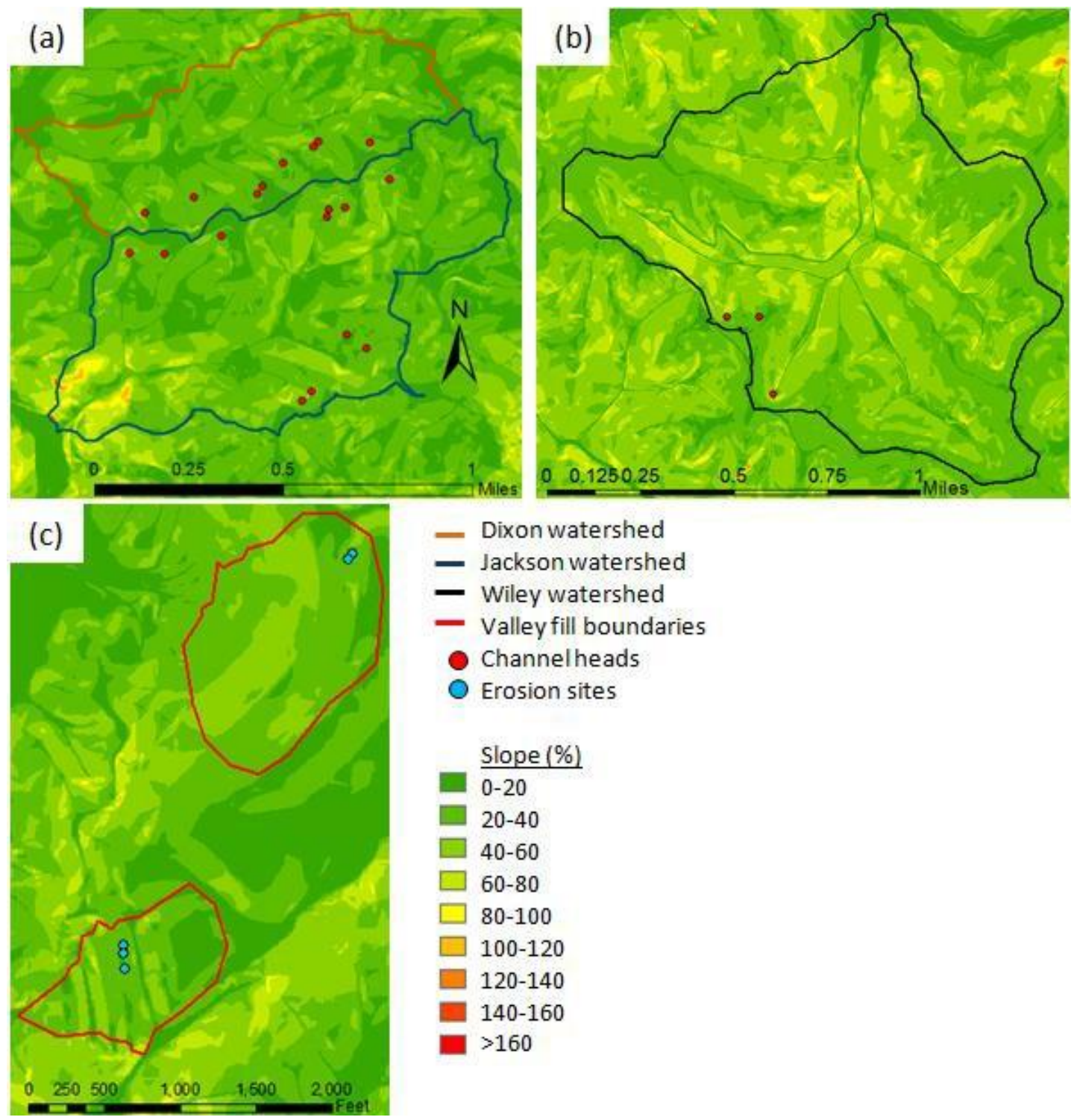

- Dixon watershed

- Jackson watershed

- Wiley watershed

- Valley fill boundaries

- Channelheads

- Erosion sites
Slope (\%)
$0-20$
20-40
40-60
60-80
$\square$ 80-100
- 100-120
- 120-140
- 140-160
$>160$

Figure 3.4. Slope distributions for reference landforms: (a) Twin Falls State Park; (b) Cabwaylingo State Forest; and, (c) Summersville, WV long-term reclaimed site.

\section{$\underline{\text { Aspect }}$}

For the mature landforms, aspect was well distributed among each direction (Table 3.9, Figure 3.5a, Figure 3.5b). No dominant aspect was found, but it was still useful to quantify the variability in aspect for mature landforms for future comparison of geomorphic designs. For the reclaimed sites, the majority of the slopes were in the direction that the valley fill was facing (northwest for the northwest facing fill; west for the southwest facing fill) (Figure 3.5c). This was due to the uniform slope construction of conventional valley fills. 
Table 3.9. Distribution of aspect for reference landform landforms.

\begin{tabular}{cccccc}
\hline \multirow{2}{*}{ Aspect ( $\left.{ }^{\circ}\right)$} & \multicolumn{5}{c}{ Percent by Area (\%) } \\
\cline { 2 - 6 } & Dixon & Jackson & Wiley & $\begin{array}{c}\text { Northwest } \\
\text { VF }\end{array}$ & $\begin{array}{c}\text { southwest } \\
\text { VF }\end{array}$ \\
\hline Flat (-1) & 0 & 0.2 & 0 & 0 & 0 \\
North (0-22.5,337.5-360) & 19 & 10.6 & 11.3 & 0.3 & 4.7 \\
Northeast (22.5-67.5) & 7.5 & 2.3 & 16.6 & 0.1 & 1.6 \\
East (67.5-112.5) & 4.4 & 7.2 & 13.9 & 0 & 2.5 \\
Southeast (112.5-157.5) & 10.6 & 14.5 & 6.9 & 0.8 & 10.2 \\
South (157.5-202.5) & 13.7 & 15.6 & 14.3 & 0.9 & 2.0 \\
Southwest (202.5-247.5) & 13.3 & 14.3 & 12.9 & 3.2 & 8.6 \\
West (247.5-292.5) & 17.1 & 15.3 & 12.7 & 38.1 & 59.2 \\
Northwest (292.5-337.5) & 14.4 & 20 & 11.4 & 56.7 & 11.2 \\
\hline
\end{tabular}
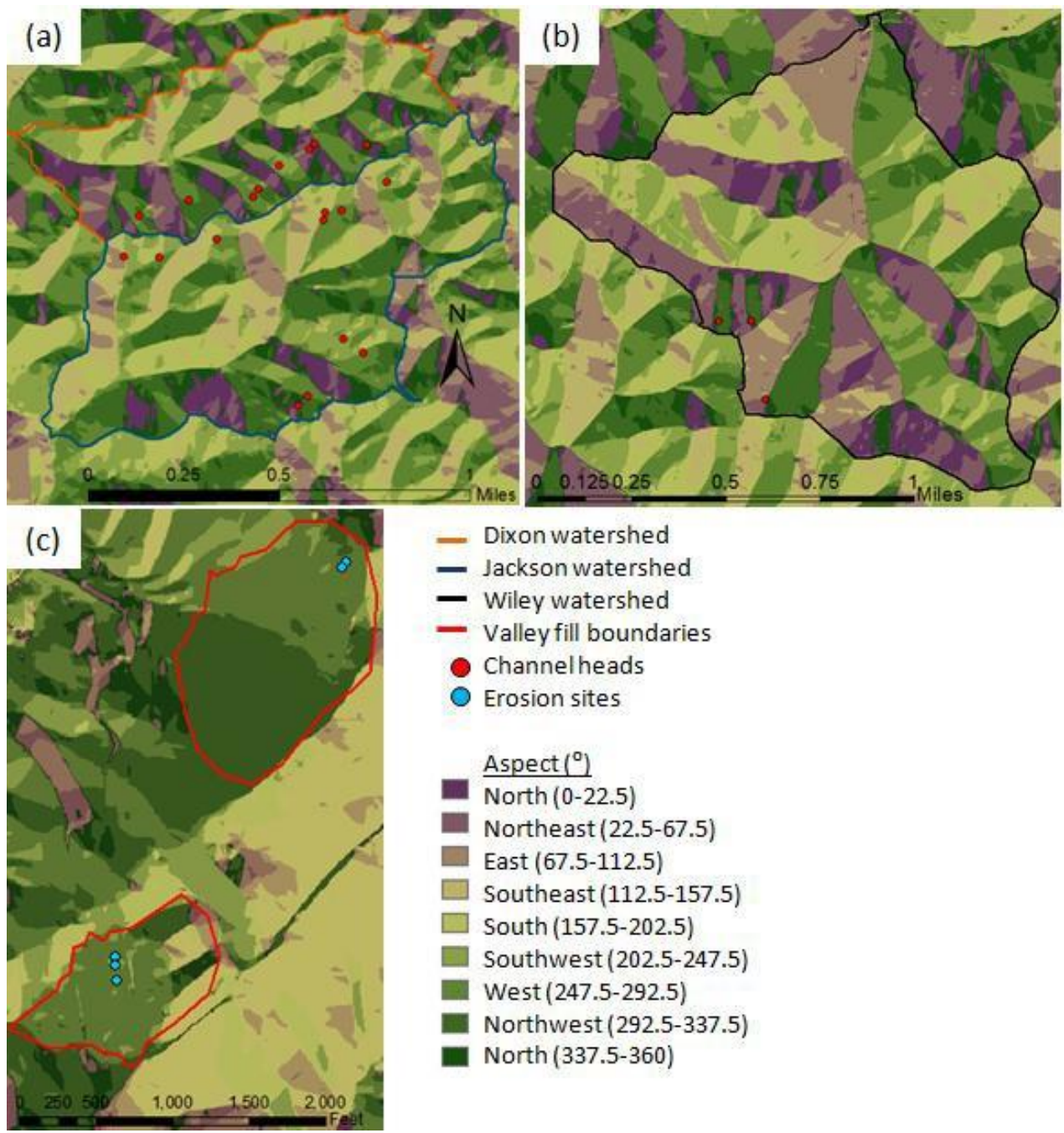

- Dixon watershed

- Jackson watershed

- Wiley watershed

- Valley fill boundaries

- Channelheads

Erosion sites

Aspect $\left({ }^{\circ}\right)$

North (0-22.5)

Northeast (22.5-67.5)

East (67.5-112.5)

$\square$ Southeast (112.5-157.5)

$\square$ South (157.5-202.5)

- Southwest (202.5-247.5)

West (247.5-292.5)

northwest (292.5-337.5)

North (337.5-360)

Figure 3.5. Aspect distributions for reference watersheds: (a) Twin Falls State Park; (b) Cabwaylingo State Forest; and, (c) Summersville, WV long-term reclaimed site. 
$\underline{\text { Vegetation }}$

For all locations, the vegetation consisted mostly of large core forests (Table 3.10, Figure 3.6), consistent with the characteristics considered when evaluating potential reference landforms. The valley fill sites had areas of perforated forest, as the fills had only been developing vegetation for 20-30 years. Although available GIS data suggested that vegetation was just as mature at the reclaimed sites as at mature sites, this was not consistent with what was observed in the field. Although long-term reclaimed sites had dense, developed vegetation (Figure 3.7a), it was not as mature as the vegetation seen at mature landform sites (Figure 3.7b).

Table 3.10. Percent by area coverage of vegetation types for each reference landform.

\begin{tabular}{cccccc}
\hline \multirow{2}{*}{ Vegetation Type } & \multicolumn{5}{c}{ Percent by Area (\%) } \\
\cline { 2 - 6 } & Dixon & Jackson & Wiley & Northwest VF & Southwest VF \\
\hline Perforated & 2.1 & 6.7 & 25.7 & 46.7 & 24.7 \\
Core (>500 acres) & 97.9 & 93.3 & 74.3 & 57.3 & 75.3 \\
\hline
\end{tabular}



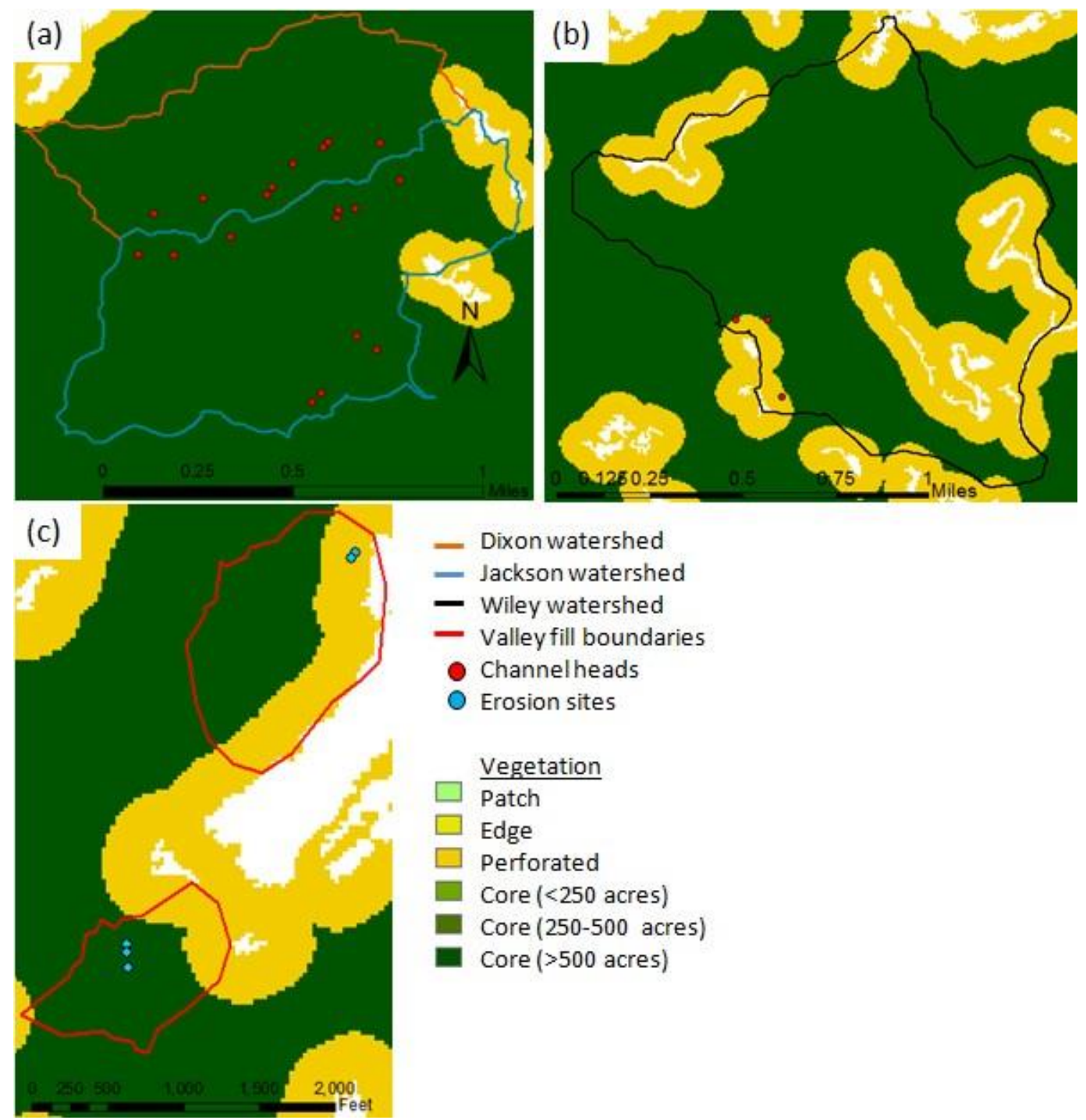

Figure 3.6. Vegetation distribution of reference landforms: (a) Twin Falls State Park; (b) Cabwaylingo State Forest; and, (c) Summersville, WV long-term reclaimed site.

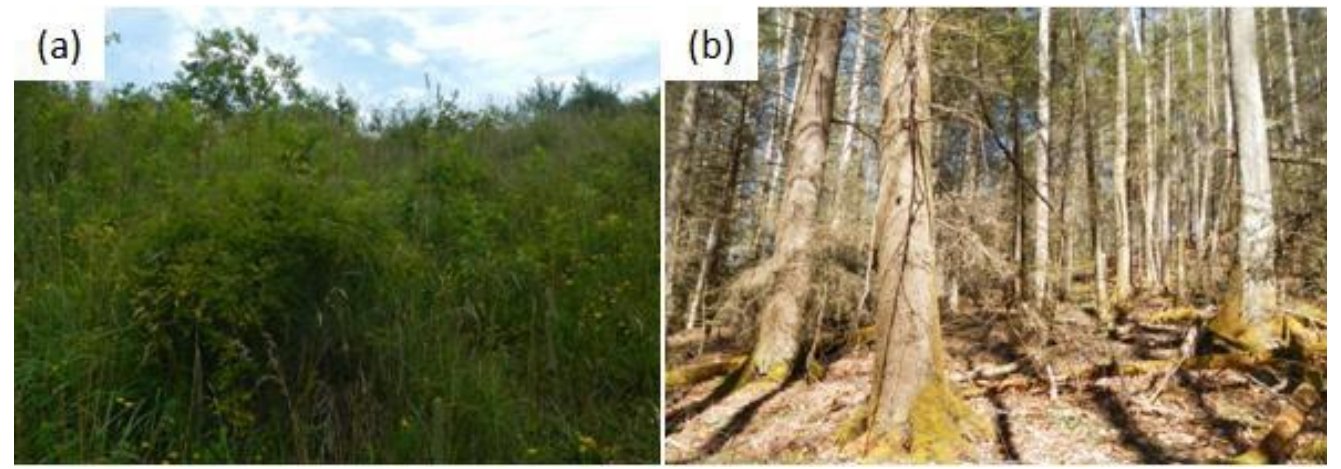

Figure 3.7. Vegetation at (a) long-term reclaimed site; and, (b) mature landform site. 


\subsubsection{Comparison to previous work}

Whereas the main intent of this research was to establish values for drainage length and drainage density specific to central Appalachia, much of the previous research completed with channel heads have investigated the effects of slope and drainage area on channel head location (Montgomery and Dietrich, 1988; Montgomery and Dietrich, 1989; Montgomery and Dietrich, 1992; Montgomery and Foufoula-Georgiou, 1993; Vogt et al., 2003; Heine et al., 2004; Benda et al., 2005; Hancock and Evans, 2005; McNamara et al., 2005; Henkle et al., 2011; Julian et al., 2012). The objective of these papers was to use slope-area relationships to perform large scale mapping of streams networks and investigate how they evolve over time. The data collected for the research presented in this chapter only either mapped channel heads in the field or used average drainage lengths to map channel heads. In the future, if more channel head sites are mapped in the field, a meaningful relationship between channel head location and contributing slope or area may be able to be developed, resulting in a larger database and possibly more accurate values for watershed properties such as drainage density.

\subsection{Conclusions and recommendations}

The overall objective of this portion of research was to define the properties of geomorphic landforms in central Appalachia, so that these properties could be used to complete geomorphic designs. Criteria were developed for the selection of mature, undisturbed landforms to serve as reference landforms for geomorphic designs. Long-term reclaimed sites were investigated to define the erosive characteristics that act on reclaimed landforms. Field data were collected from reference landforms and supplemented with spatial analysis to determine the geomorphic properties of undisturbed landforms in central Appalachia. The following conclusions are made from this research:

- A sufficient amount of field work is necessary to accurately define the geomorphic properties of mature landforms in central Appalachia.

- Surveying headwater stream locations provided a more accurate value for drainage density than if only available NHD data were used. Surveying headwater channels is necessary, as they are the channels typically buried in conventional valley fill reclamation. 
- From field data collection and spatial analysis of the reference landforms in this study, average drainage length was $408 \mathrm{ft}$ and average drainage density was $62 \mathrm{ft} / \mathrm{ac}$.

- For all channel head locations and erosion sites, the majority of bed material was sand and gravel.

- Mature landforms exhibited steep hillslopes, variable aspect, and vegetation consisting of dense core forest. Geomorphic landform design principles will attempt to replicate these features more effectively than does conventional reclamation.

The data collected through this research were limited by the number of field sites surveyed, as well as limited to application to central Appalachia. The methodology developed in this research can be used to perform additional field work in central Appalachia to supplement the current database, as well as be applied to other geographic areas where data on geomorphic properties are lacking. Mapping additional channel head sites in future studies may also allow a meaningful relationship between channel head location and contributing slope or area to be developed, reducing the amount of necessary field work in the long-term. To move forward with this research, however, the obtained values for geomorphic properties in central Appalachia, particularly drainage length and drainage density, are adequate. 


\section{CHAPTER 4. QUANTIFYING THE ISSUES ASSOCIATED WITH IMPLEMENTING GEOMORPHIC RECLAMTION IN CENTRAL APPALACHIA}

\subsection{Introduction}

The issues associated with the existing reclamation techniques in central Appalachia include long-term instability (Bell et al., 1989; Michael et al., 2010) and impaired water quality and habitat due to stream loss (Negley and Eshleman, 2006; Ferrari et al., 2009; Palmer et al., 2010; Bernhardt and Palmer, 2011; USEPA, 2011; Zipper et al., 2011; Miller and Zégre, 2014). These issues have prompted an analysis of unconventional reclamation methods, including geomorphic landform design (GLD). GLD is becoming more widely accepted by the scientific community as an alternative method for reclaiming disturbed landforms (Nicolau, 2003) and has been successful in the southwestern United States. Potential issues regarding stability, channel mitigation, and material placement exist, however, when implementing geomorphic design principles in central Appalachia (Michael et al., 2010). Conceptual geomorphic designs are necessary to quantify potential issues and assess the practicality of implementing geomorphic landform design in central Appalachia. Conceptual geomorphic designs have been completed in central Appalachia on a large scale (>200 acres) (Sears et al., 2013), but smaller scale conceptual geomorphic designs (for individual valley fills, 10-20 acres) are necessary to address sitespecific concerns and investigate the issues associated with implementing geomorphic reclamation on the scale at which initial projects will likely be constructed. The overall goal of this portion of research was to quantify potential issues and assess the practicality of implementing geomorphic reclamation on the scale of an individual valley fill. To accomplish this objective, the following tasks were completed:

1. Chose a surface mine reclamation site in southern WV to use as a design site and obtained necessary site data for use in geomorphic designs.

2. Defined the design criteria by which conceptual geomorphic landforms would be analyzed.

3. Generated a series geomorphic designs specific to southern WV to quantify the issues of landform stability, channel stability, and fill volume, and compare to the existing conventional reclamation. 


\subsection{Background}

Toy and Chuse (2005) gave a thorough overview of the geomorphic approach to disturbed land reclamation. A ten step process for geomorphic reclamation was developed: i) site characterization; ii) reclamation planning and engineering; iii) material management; iv) topographic reconstruction; v) replacement of topsoil or soil substitute; vi) surface manipulation; vii) addition of soil amendments; viii) revegetation; iv) irrigation; and, $\mathrm{x}$ ) site monitoring and maintenance. The four most important drainage-basin characteristics to consider in topographic reconstruction are as follows: i) drainage-basin relief; ii) drainage-basin area; iii) drainage density; and, iv) drainage pattern. The first step of the reclamation design process is locating the main channel. Drainage networks are then created using dendritic patterns with appropriate drainage densities. Hillslopes are preferred to be low gradient, short, and concave. Longitudinal channel profiles should be concave with no abrupt changes in gradient. The reclaimed landscape must merge with surrounding undisturbed basins to prevent degradation of undisturbed and reclaimed lands. It is expected that geomorphic reclamation will create higher initial construction costs, but will have lower long-term costs through reduced remedial treatment and maintenance.

Geomorphic reclamation is becoming widely accepted by the scientific and regulatory community as an alternative method for reclaiming disturbed landforms (Nicolau, 2003), and interest in the technique has been documented by the United States Office of Surface Mining Reclamation and Enforcement (OSMRE). Most applications of geomorphic reclamation to date have been in the southwestern United States (e.g. Measels and Bugosh, 2007; Bugosh, 2009; Robson et al., 2009). Additional geomorphic reclamation projects have been completed outside of the U.S. (e.g. Martin-Duque et al., 1998; Evans and Willgoose, 2000; Martin-Moreno et al., 2008; Martin-Duque et al., 2010). A patented method of design for geomorphically reclaimed landforms in the United States has been Natural Regrade with GeoFluv ${ }^{\mathrm{TM}}$ (Carlson Software and Bugosh, 2005). This method reproduces the mature state of a landform's evolution, creating stability and erosive equilibrium.

The success of geomorphic reclamation in the southwestern U.S. has prompted an analysis of the approach as an alternative reclamation method in the central Appalachian United States, where environmental impact issues associated with mountaintop mining and excess spoil fill (or valley 
fill) construction are common (e.g. Michael et al., 2010; Sears et al., 2013; Russell et al., 2014). Although geomorphic mine land reclamation is expected to have environmental benefits, Michael et al. (2010) documented potential issues associated with simultaneously ensuring slope stability, minimizing stream burial, and achieving desired fill volume when implementing geomorphic design principles in central Appalachia. Merging reclaimed hillslopes with surrounding undisturbed topography is a broad concern with geomorphic reclamation (Toy and Chuse, 2005) and is of particular concern in central Appalachia, where constructing artificial landforms that naturally blend in with the surrounding environment may not necessarily ensure stability due to steep natural landform slopes and the frequent occurrence of natural landslides. On the other hand, ensuring stability by constructing shallower, more stable landform slopes may require greater land area disturbance to maintain fill volumes as compared to a conventional design. These issues have been recognized but not quantified.

An additional cause of the issues associated with implementing the geomorphic approach in central Appalachia that has not been documented in literature (e.g. Michael et al., 2010) is the difference in mining and reclamation strategies between central Appalachia and regions where the geomorphic approach has been successful (particularly the southwestern U.S.). In the Southwest, surface coal mines are typically open pit mines. For a given area, the surface is excavated to the coal seam, the coal is extracted, and the overburden is placed back into the excavated pit area. Reclaiming within the mined area allows for definition of the drainage boundary and creation of a drainage network that is not restricted by the drainage network and drainage divide of the pre-mined pit. This freedom in defining the drainage boundary and network facilitates the application of geomorphic principles. In central Appalachia, however, mountaintop mining involves mining in one area, and incorporating reclamation in additional, undisturbed valleys. The pre-mined topography of the mined area typically consists of a mountaintop draining in multiple directions, while the undisturbed valley exhibits a prereclaimed topography draining to one point, often with only one channel. The drainage boundary and drainage network of the reclaimed landform are confined by the boundary and drainage of the valley that is being filled. The restricted drainage divide and network associated with valley fill reclamations in central Appalachia makes successful geomorphic reclamation more difficult than in other surface mining regions. 


\subsection{Methods}

\subsubsection{Field design site}

The field site for the generation of geomorphic reclamation designs was a surface mine in Boone Co., WV, USA in the same ecoregion as the reference landform sites (Figure 3.2). Two valley fills (VF1, 10.11 acres; VF2, 29.7 acres) with an existing conventional reclamation plan were used within the permit boundary for geomorphic designs (Figure 4.1). A third valley fill was evaluated but later excluded because applying geomorphic design principles would have resulted in a valley fill that impacted multiple drainage basins.

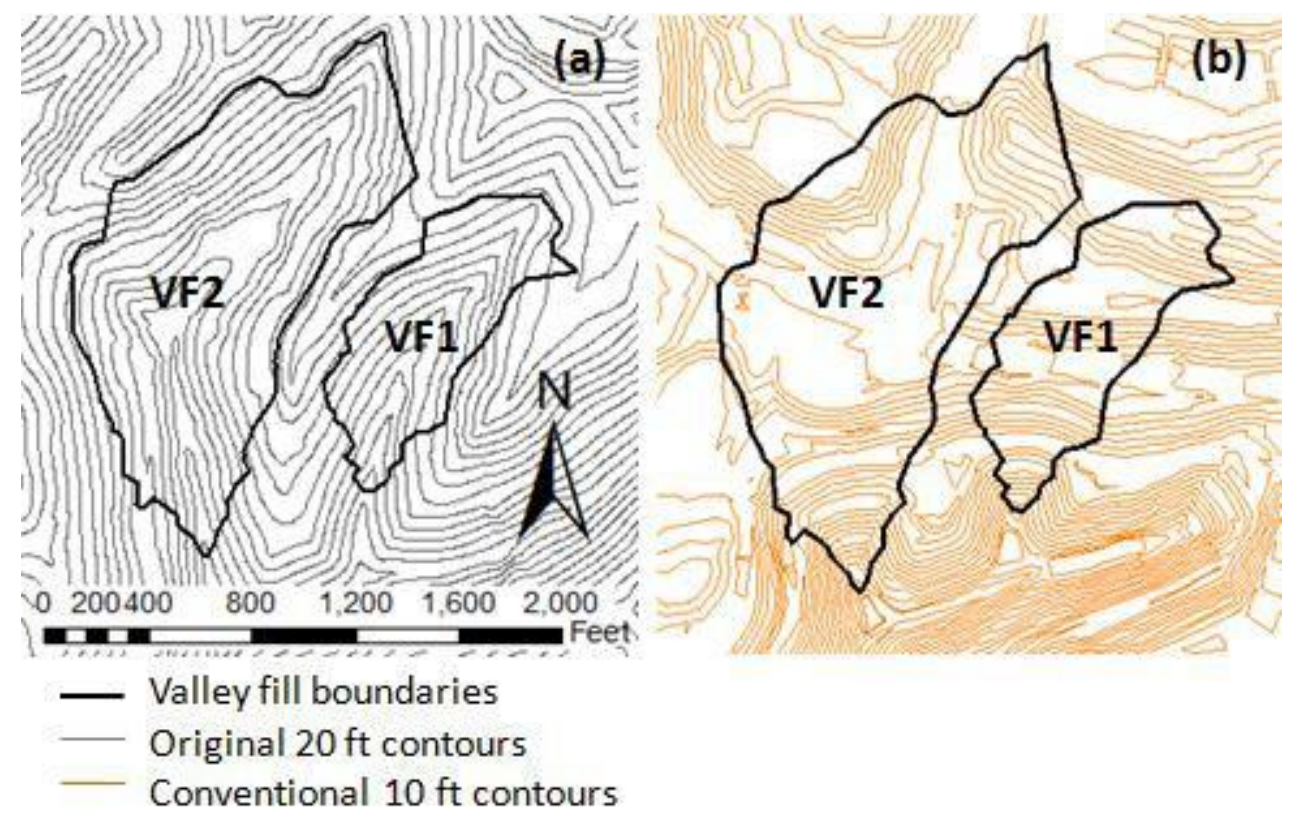

Figure 4.1. VF1 and VF2 locations on (a) original contours; and, (b) conventional reclamation contours.

The site is located in the central Appalachian ecoregion (USEPA, 2013) and has a temperate climate (average annual precipitation $=48$ in, average annual temperature $\left.=55^{\circ} \mathrm{F}\right)(\mathrm{NOAA}$, 2014a). The pre-mined terrain was steep with a spatial mean slope of 41\%; $90 \%$ of the hillslopes fell within the range of 20-70\% grade. Hillslopes exceeding $20 \%$ grade are considered steep as classified by West Virginia Department of Environmental Protection (WVDEP) (1999). The geology is dominated by gray shale and sandstone. Pre-mining vegetation was predominantly dense core forest. The pre-mining landuse of the design site was forestland, and the planned post-mining landuse was a return to forestland. 


\subsubsection{Design of geomorphic reclamation landforms}

Geomorphic landforms were generated using Carlson's Natural Regrade with GeoFluv ${ }^{\mathrm{TM}}$ (Figure 4.2).

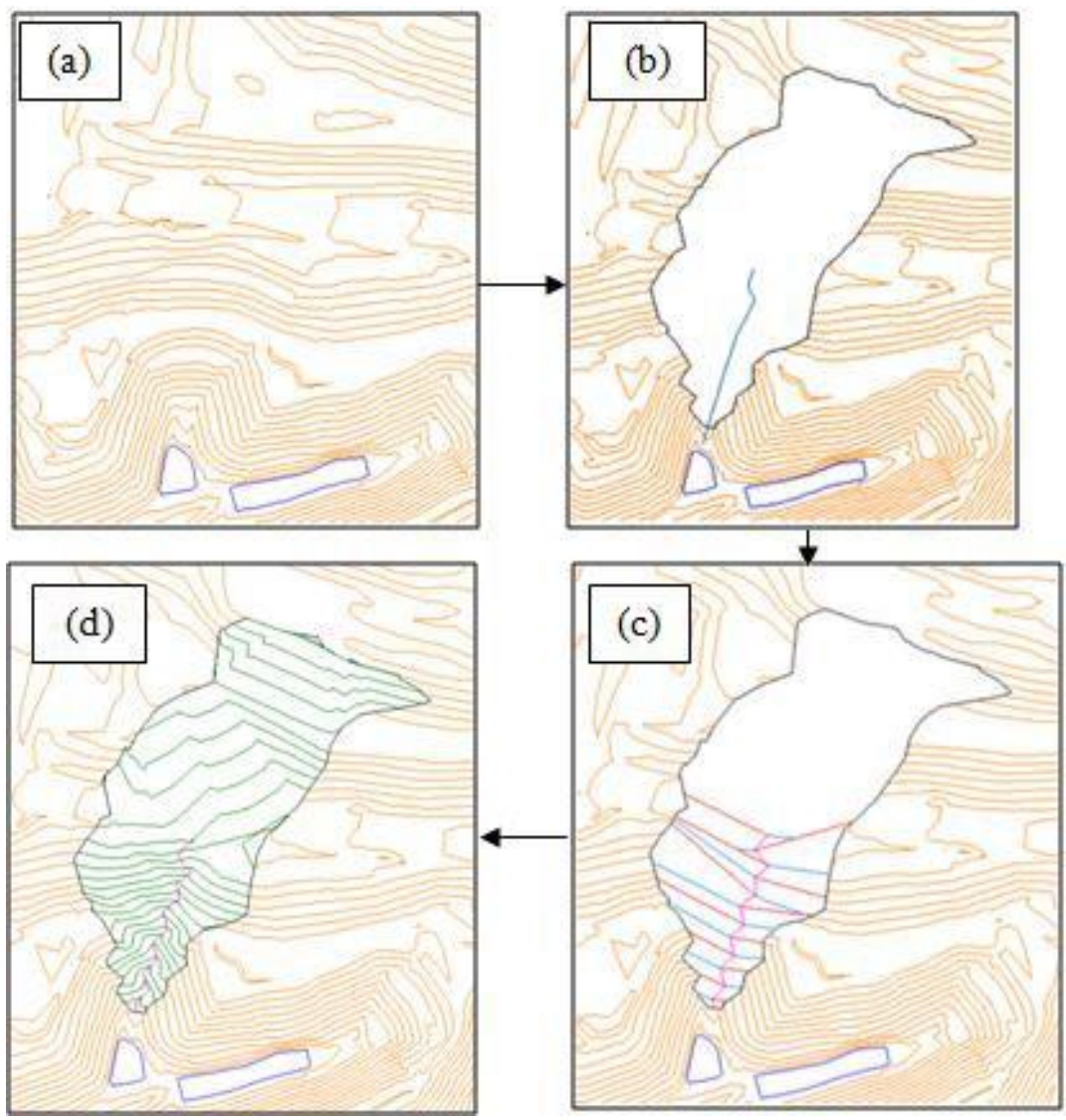

Figure 4.2. Natural Regrade design process for generating geomorphic landforms: (a) Given an existing topography; (b) User defines landform boundary and creates a polyline which satisfies geomorphic input parameters from which to generate a stream; (c) Software generates a stream and corresponding ridges and valleys; (d) Software triangulates and contours geomorphic landform that ties into surrounding topography.

For the purposes of this study, the existing topography was the conventional reclamation, which was provided by the surface mine officials. The pre-mined topography was investigated when calculating cut/fill volumes of the geomorphic designs and comparing them to the cut/fill of the conventional reclamation. Valley fill boundaries from the available WVDEP mining permit boundaries GIS data were used as the boundaries for geomorphic designs. The polylines used to generate streams followed the path of the streams in the pre-mined topography that were being buried in valley fill reclamation. Due to valley fill boundaries being taken from available GIS 
data, there were areas that did not match up well with the topographic data obtained from the surface mine officials. Designing with the original fill boundaries created an area of concern in which geomorphic designs drained to different watersheds than the watershed associated with the fill outlet structure. To prevent this issue, fill boundaries were altered so that the boundary tied into the highest possible elevation of the conventional reclamation surrounding the fill while still draining towards the toe of the fill and not incorporating more than one valley. Fills created were smaller in area than the original fill boundaries, but an effort was made to maintain the original boundary as closely as possible. Geomorphic designs attempted to create a stable landform that either mitigated or preserved the existing stream without expanding the footprint of the conventional valley fill. Channel placement replicated the pre-mining landscape. If these levels of volume and stability were not reached, the effect of expanding the valley fill footprint was investigated.

\section{$\underline{\text { Criteria for landform analysis }}$}

The criteria for analysis of designs were channel stability, landform stability, and fill volume. Channel stability was evaluated considering the design of a threshold channel; minimal bed material movement was desired. Shields (1936) diagram was used to determine median bed material size required to resist incipient motion. Channels requiring large bed material to limit movement (i.e. boulders, $\geq 10.1$ in) were not considered stable. Channel dimensions were determined conservatively by using a high runoff coefficient $(0.89)$ and intense storms (2-yr, 1 hr storm for bankfull discharge; $50 \mathrm{yr}$, 6-hr storm for flood prone discharge). The storm durations and intervals used to classify bankfull and flood prone discharges and dimensions were provided by Natural Regrade ${ }^{\mathrm{TM}}$ and varied from the WVDEP (1993) $100 \mathrm{yr}, 24-\mathrm{hr}$ design storm. Bankfull and flood prone channel dimensions were defined by Natural Regrade ${ }^{\mathrm{TM}}$ as the dimensions of a trapezoidal channel with $25 \%$ side slopes $(4: 1 \mathrm{H}: \mathrm{V})$ necessary to convey the respective peak flows.

Hillslopes adjacent to the channel were evaluated for geotechnical engineering stability to identify regions of potential slope failure. A stability analysis was performed on the mine spoil to determine at what grade hillslopes fell below the WVDEP design standard factor of safety of 1.5 (WVDEP, 1999) (Table 4.1). Factor of safety is the ratio of available shear resistance to the 
applied loads on a slope and quantifies the risk of failure (USACE, 2003). The software tool used for this analysis was SLOPE/W developed by GeoStudio®. Material strength properties of internal friction angle $\left(\phi=40^{\circ}\right)$, cohesion ( $\left.c=0 \mathrm{psf}\right)$, and unit weight $(\gamma=129.7 \mathrm{pcf})$ were obtained from the surface mine permit file. Constant slope profiles with no piezometric surface were modeled, and slope was increased until factor of safety fell below 1.5. Modeled hillslopes above $50 \%$ grade fell below the standard. This $50 \%$ grade threshold was consistent with the WVDEP design standard of a maximum 2:1 H:V slope for a valley fill face (WVDEP, 1999). The areas of hillslopes above $50 \%$ grade in each geomorphic design were investigated, with a fully stable design having no landforms above $50 \%$ grade. Another challenge associated with the application of geomorphic landform principles to the design of valley fills is the expected increased area of impact for a stable design (Michael et al., 2010). To address this concern, the volume of fill of each alternative design generated in this research was compared to the fill volume of the conventional fill design. To maintain a mass balance, the geomorphic design needed to reach $100 \%$ of the fill volume used to construct the conventional reclamation.

\section{$\underline{\text { Design iterations }}$}

Designs were completed systematically to determine the best possible design for the analyzed fill with respect to fill volume, channel stability, and landform stability. Designs were completed to optimize individual landform characteristics, and then altered to find a compromise among all characteristics through the following steps (Table 4.1):

1. Varying drainage density: First, the effect of drainage density on fill volume was investigated. For each fill, three cases of drainage density were investigated while leaving stream elevation and location constant. The first design generated a landform with a stream length that resulted in a drainage density value as close to the target drainage density as possible. The target drainage density was calculated using the reference data information. The second and third designs generated landforms with stream lengths that resulted in drainage density values at the upper and lower ends of the target drainage density variance, respectively.

2. Maximizing channel stability: The second set of designs attempted to maximize channel stability by preserving the existing channel. Preserving the existing channel created a 
design with the shallowest sloped channel possible. The geomorphic landform was created around the existing valley bottom without burying the existing channel. A design was completed for each fill.

3. Maximizing fill volume and hillslope stability: The third set of designs attempted to maximize fill volume and hillslope stability by generating a new channel at the highest elevation possible. The drainage density value associated with the highest fill volume from the first set of designs was used. A design was completed for each fill.

4. Compromise of stability and fill volume: The next designs investigated compromises among channel stability, fill volume, and hillslope stability. These designs were only completed with one fill, choosing the valley fill that showed the most promise with respect to application from initial designs. Channel stability was optimized by decreasing the channel head elevation until the maximum applied shear stress on the channel resulted in a required median bed particle size of cobble (10.1 in) or smaller at either bankfull or flood prone discharges; this corresponded to a maximum applied shear stress of 4.33 psf. One design ensured channel stability at bankfull flow, while two designs ensured channel stability at both bankfull and flood prone flows with low and high drainage densities.

5. Expanded impact area: Similar design cases were completed with an expanded valley fill footprint to investigate the effect of expanding the impacted area on the ability to meet all analysis criteria. The toe of the valley fill was extended to the downstream edge of the valley fill toe pond, the maximum area before additional valleys were impacted (Figure 4.3). First, channel stability was maximized by preserving the existing channel. Next, channel stability at bankfull flow was ensured. The final design ensured channel stability at both bankfull and flood prone flows.

6. Using default design criteria: A design for VF1 was completed using the default inputs in Natural Regrade to investigate the differences between a design using default values and a design using design criteria measured at the reference sites. 


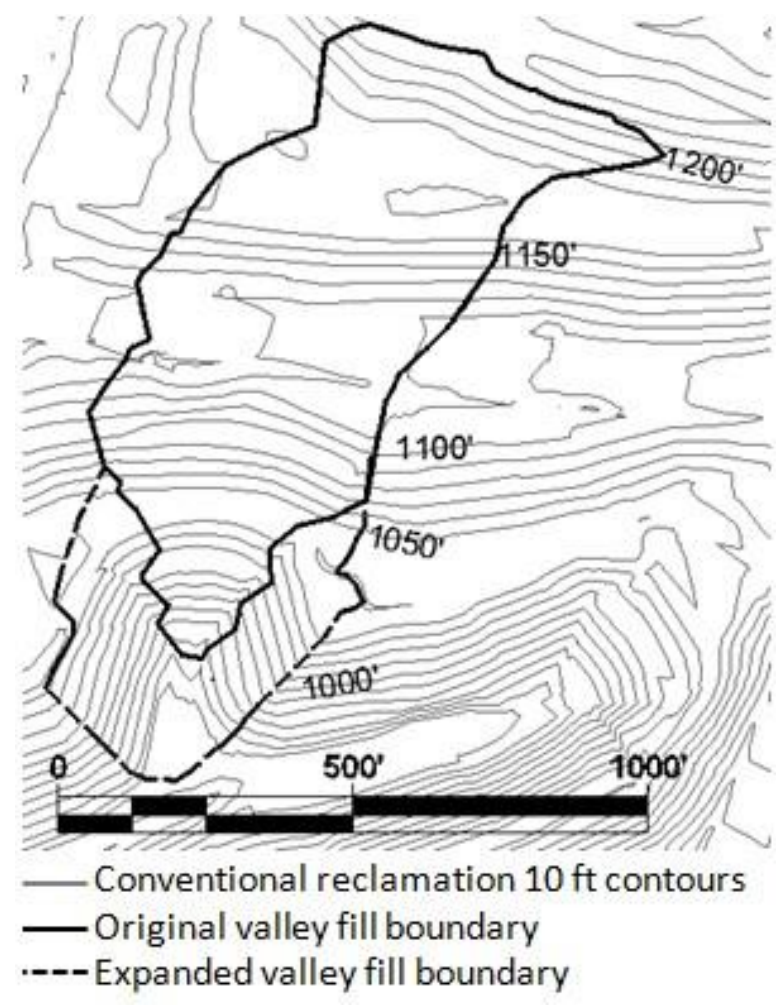

Figure 4.3. Expanded impact area of VF1 compared to the original valley fill footprint. 
Table 4.1. Summary of geomorphic valley fill design iterations

\begin{tabular}{|c|c|c|c|c|c|c|}
\hline $\begin{array}{c}\text { Design } \\
\text { number }\end{array}$ & $\begin{array}{c}\text { Valley } \\
\text { Fill }\end{array}$ & $\begin{array}{c}\text { Drainage } \\
\text { Density }\end{array}$ & Channel & $\begin{array}{l}\text { Channel } \\
\text { Stability }\end{array}$ & $\begin{array}{c}\text { Fill } \\
\text { volume }\end{array}$ & $\begin{array}{c}\text { Impact } \\
\text { Area }\end{array}$ \\
\hline \multicolumn{7}{|c|}{ Varying Drainage Density } \\
\hline 1 & 1 & Low & Constructed & & & Permittec \\
\hline 2 & 1 & Target & Constructed & & & Permittec \\
\hline 3 & 1 & High & Constructed & & & Permittec \\
\hline 4 & 2 & Low & Constructed & & & Permittec \\
\hline 5 & 2 & Target & Constructed & & & Permittec \\
\hline 6 & 2 & High & Constructed & & & Permittec \\
\hline \multicolumn{7}{|c|}{ Maximize Channel Stability } \\
\hline 7 & 1 & Low & Preserve & Maximum & & Permittec \\
\hline 8 & 2 & Low & Preserve & Maximum & & Permittec \\
\hline \multicolumn{7}{|c|}{ Maximize fill volume and hillslope stability } \\
\hline 9 & 1 & Low & Constructed & & Maximum & Permittec \\
\hline 10 & 2 & Low & Constructed & & Maximum & Permittec \\
\hline \multicolumn{7}{|c|}{ Compromise of stability and fill volume } \\
\hline 11 & 1 & Low & Constructed & Stable (BF) & & Permittec \\
\hline 12 & 1 & Low & Constructed & Stable (FP) & & Permittec \\
\hline 13 & 1 & High & Constructed & Stable (FP) & & Permittec \\
\hline \multicolumn{7}{|c|}{ Expanded impact area } \\
\hline 14 & 1 & Low & Preserve & Maximum & & Expandec \\
\hline 15 & 1 & Low & Constructed & Stable (BF) & & Expandec \\
\hline 16 & 1 & Low & Constructed & Stable (FP) & & Expandec \\
\hline \multicolumn{7}{|c|}{ Default design criteria } \\
\hline 17 & 1 & Default & Constructed & & & Permittec \\
\hline
\end{tabular}

Note: $\mathrm{BF}=$ bankfull, FP=floodprone

\subsubsection{Slope stability analysis}

For the designs closest to meeting the requirements for channel stability, landform stability, and fill volume, the slopes above $50 \%$ grade were further investigated to assess the critical areas of potential slope instability for each design. The distribution of landform slopes between 50\% and $60 \%$ grade was investigated to identify the potential for manual correction of unstable slopes. The steepest longitudinal profile for each design was analyzed with a two-dimensional finite element slope stability model to define the factor of safety against a failure using the same soil strength parameters as the initial stability analysis ( $\phi=40^{\circ}, \mathrm{c}=0 \mathrm{psf}, \gamma=129.7 \mathrm{pcf}$ ). Failure planes were generated for shallow failures at the steepest portion of the profile and for deep failures along the entire profile to investigate the minimum factor of safety. 


\subsection{Results and discussion}

The findings of this portion of the research, in conjunction with data from Chapter 3 , have since been published (DePriest et al., 2015).

\subsubsection{Channel design}

For a given impacted area and drainage density, channel length and dimensions were constant. Channel slopes varied among designs, impacting applied shear stress. When using the permitted area and low drainage density, reclaimed channel length was $612 \mathrm{ft}$. Bankfull width increased from $0.30 \mathrm{ft}$ at the channel head to $5.2 \mathrm{ft}$ at the mouth of the watershed. Bankfull depth ranged from $0.030 \mathrm{ft}$ to $0.52 \mathrm{ft}$. Within the permitted area and with high drainage density, channel length increased to $881 \mathrm{ft}$. Bankfull width increased from $0.89 \mathrm{ft}$ at the channel head to $5.2 \mathrm{ft}$ at the mouth of the watershed. Bankfull depth ranged from $0.090 \mathrm{ft}$ to $0.52 \mathrm{ft}$. Peak flows for both drainage density cases were calculated as $12.0 \mathrm{cfs}$ at bankfull and $32.5 \mathrm{cfs}$ at flood prone. The channel length for the designs using the expanded impact area was $746 \mathrm{ft}$. Bankfull width and depth ranges were 0.35-5.90 ft and 0.30-0.59 ft, respectively. Peak discharges were $15.6 \mathrm{cfs}$ at bankfull and $42.4 \mathrm{cfs}$ at flood prone. Increasing the impact area resulted in a slightly larger channel cross-section due to higher peak flows. Because channels were designed using the rational method, and the intensity of the $100 \mathrm{yr}, 24-\mathrm{hr}$ storm $(0.22 \mathrm{in} / \mathrm{hr})$ used by WVDEP is lower than the intensity of the $50 \mathrm{yr}, 6$-hr storm $\left(0.60 \mathrm{in} / \mathrm{hr}\right.$ ) used by Natural Regrade ${ }^{\mathrm{TM}}$ (NOAA, 2014b), the channel should be properly designed to meet the WVDEP regulations.

Although the channel dimensions were based on the user defined storm event, they could be manually redesigned to accommodate any storm with minimal effect on the landform. Manually altering channel dimensions would not change the longitudinal stream profile or the curvilinear shapes of contributing slopes. The design would remain compliant with the specific geomorphic design principles held by the GeoFluv ${ }^{\mathrm{TM}}$ method. Each design consisted of one channel due to the small size of the fill. Larger scale designs would have the potential to incorporate multiple channels and subbasins and could be investigated in future studies. 


\subsubsection{Alternative valley fill designs}

Varying drainage density

For both fills, the ratio of geomorphic design fill volume to conventional fill volume decreased as drainage density increased (Table 4.2, Figure 4.4, Figure 4.5). Increasing the stream length created less area in which fill material could be placed. Designs 1-6 were the first designs completed with Natural Regrade and resulted in errors in the generation of geomorphic contours (e.g. drastic changes in slope at the boundary). Due to these errors, additional information on landform and channel stability was not recorded, but the relationship between fill volume and drainage density was evident. While a reclaimed landform with a higher drainage density value would minimize the likelihood of long-term channel maintenance being required, the minimum acceptable drainage density value was used in all proceeding designs (excluding Design 13) in order to maximize fill volume.

Table 4.2. Characteristics of landforms developed to investigate drainage density (DD): ratio of design fill volume to conventional fill volume $\left(V_{G L D} / V_{C V}\right)$. Three designs created for each valley fill, 1 and 2.

\begin{tabular}{cccc}
\hline Design & Valley fill & $\begin{array}{c}\mathbf{D D} \\
(\mathbf{f t} / \mathbf{a c})\end{array}$ & $\mathbf{V}_{\mathbf{G L D}} / \mathbf{V}_{\mathbf{C V}}(\boldsymbol{\%})$ \\
\hline 1 & 1 & 48.2 & 83 \\
2 & 1 & 60.8 & 73 \\
3 & 1 & 74.8 & 66 \\
4 & 2 & 48.3 & 77 \\
5 & 2 & 60.7 & 63 \\
6 & 2 & 72.4 & 49 \\
\hline
\end{tabular}



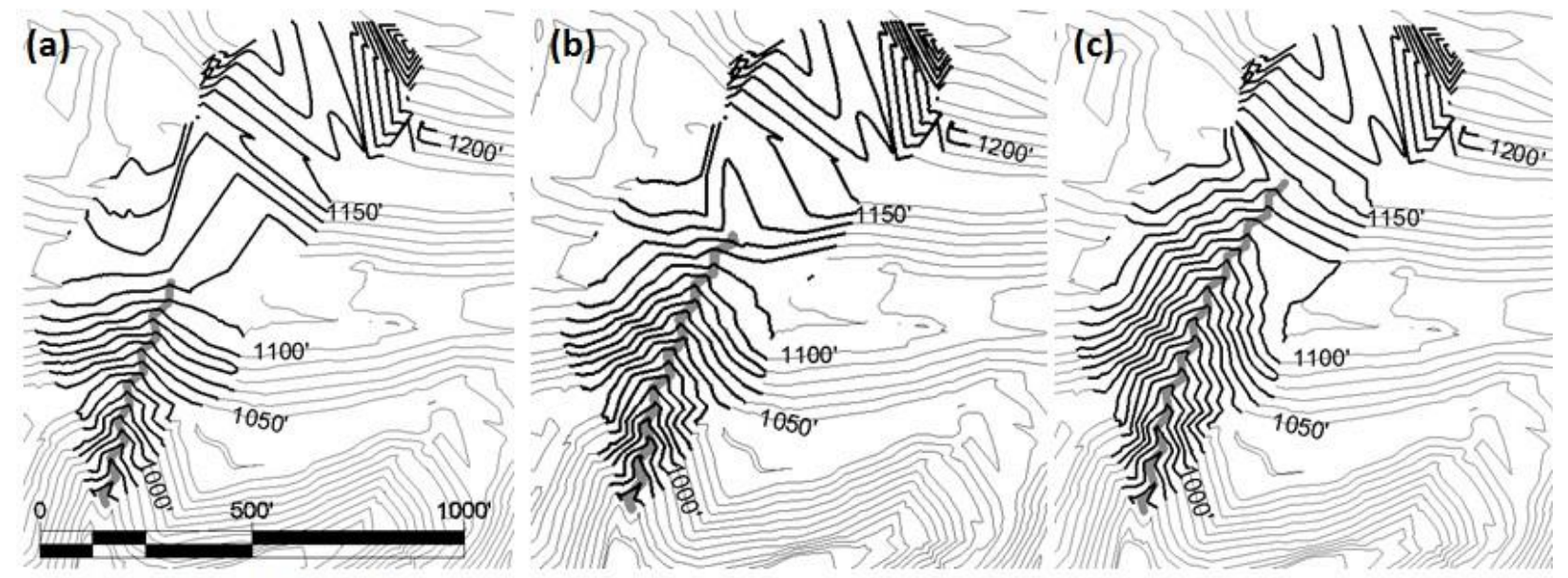

-Conventional $10 \mathrm{ft}$ contours

- Geomorphic $10 \mathrm{ft}$ contours

Channel

Figure 4.4. Geomorphic designs for VF1 with varying drainage density: (a) low drainage density (Design 1); (b) target drainage density (Design 2); and, (c) high drainage density (Design 3).
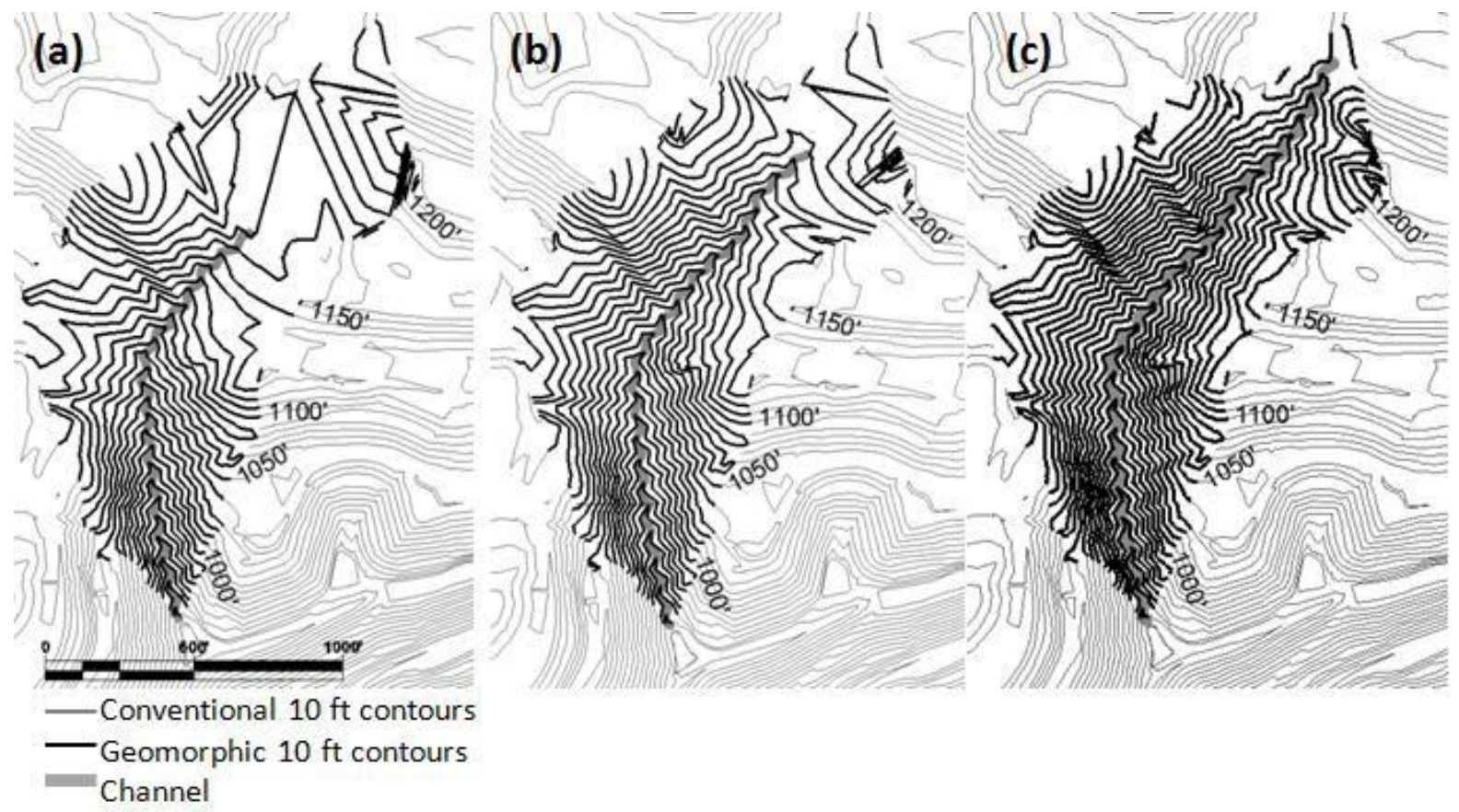

Figure 4.5. Geomorphic designs for VF2 with varying drainage density: (a) low drainage density (Design 4); (b) target drainage density (Design 5); and, (c) high drainage density (Design 6).

\section{Maximizing channel stability}

To maximize channel stability, the natural channel was preserved and a design was created for valley fills 1 and 2 (Table 4.3, Figure 4.6). 
Table 4.3. Characteristics of landforms developed to maximize channel stability: range in channel slopes $\left(\mathbf{S}_{\mathbf{c}}\right)$, maximum shear stress at bankfull $\left(\tau_{b}\right)$, maximum shear stress at flood prone $\left(\tau_{\mathrm{f}}\right)$, percent of unstable hillslopes by area $(>50 \%)\left(\mathrm{P}_{\mathrm{HS}}\right)$, ratio of design fill volume to conventional fill volume $\left(V_{\mathrm{GLD}} / \mathrm{V}_{\mathrm{CV}}\right)$. One design was created for each valley fill, 1 and 2.

\begin{tabular}{ccccccc} 
Design & Valley fill & $\mathbf{S}_{\mathbf{C}}(\boldsymbol{\%})$ & $\tau_{\mathbf{b}}(\mathbf{p s f})$ & $\tau_{\mathbf{f}}(\mathbf{p s f})$ & $\mathbf{P}_{\mathbf{H S}}(\boldsymbol{\%})$ & $\mathbf{V}_{\mathbf{G L D}} / \mathbf{V}_{\mathbf{C V}}(\boldsymbol{\%})$ \\
\hline 7 & 1 & $6.7-12$ & 2.84 & 3.67 & 33 & 65 \\
8 & 2 & $6.7-12$ & 4.09 & 5.28 & 26 & 53 \\
\hline
\end{tabular}
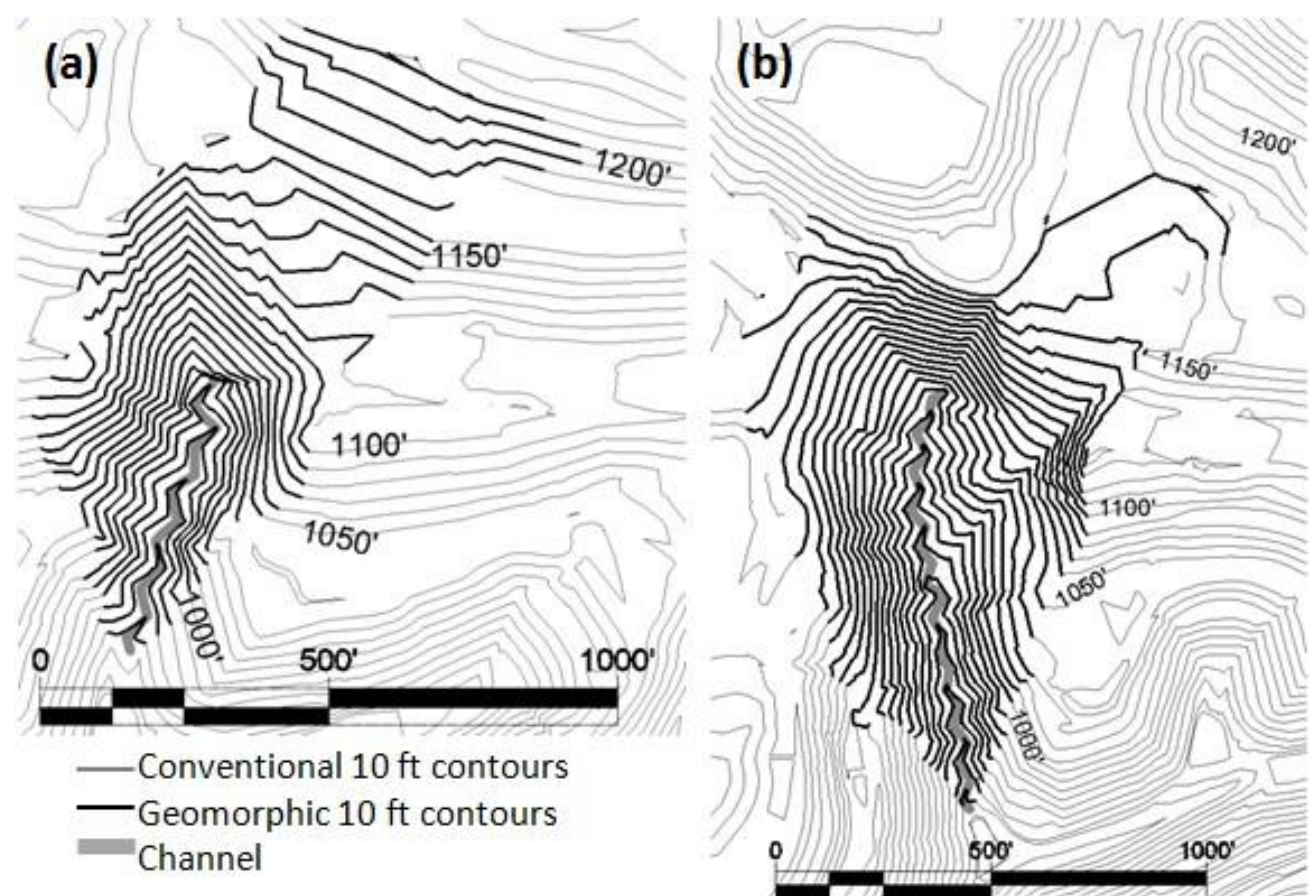

Figure 4.6. Geomorphic designs in permitted with maximum channel stability for (a) valley fill 1 (Design 7); and, (b) valley fill 2 (Design 8).

The reclaimed landforms were characterized by a channel profile that mimicked the existing topography to the channel head location, followed by a steep hillslope (Figure 4.7). Channel slopes remained moderate, and stream power remained low. The range in shear stress values suggest that bed material composed of cobble sized particles would result in a threshold channel. While the channels were likely stable, a substantial portion of hillslopes were greater than the $50 \%$ grade (2:1) threshold for stability, suggesting that these portions would not meet the WVDEP design standard. These steep hillslopes were due to the large elevation differences between the channel and watershed boundary (landform relief of $256 \mathrm{ft}$ and $245 \mathrm{ft}$ for VF1 and VF2, respectively) and would be difficult to both construct and maintain. 


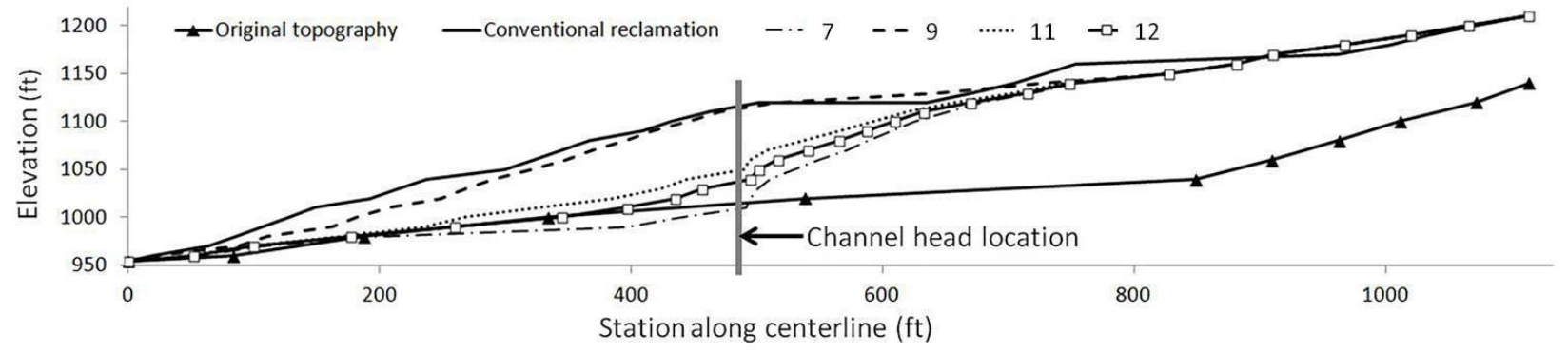

Figure 4.7. Centerline profiles of geomorphic designs for valley fill 1 compared to original and conventional reclaimed topography.

Maximizing fill volume and hillslope stability

Designs 9 and 10 maximized fill volume and hillslope stability for valley fills 1 and 2 (Table 4.4, Figure 4.8).

Table 4.4. Characteristics of landforms developed to maximize fill volume and hillslope stability: range in channel slopes $\left(S_{c}\right)$, maximum shear stress at bankfull $\left(\tau_{b}\right)$, maximum shear stress at flood prone $\left(\tau_{\mathrm{f}}\right)$, percent of unstable hillslopes $(>50 \%)\left(\mathbf{P}_{\mathrm{HS}}\right)$, ratio of design fill volume to conventional fill volume $\left(\mathrm{V}_{\mathrm{GLD}} / \mathrm{V}_{\mathrm{CV}}\right)$. One design created for each valley fill, 1 and 2.

\begin{tabular}{ccccccc}
\hline Design & Valley fill & $\mathbf{S}_{\mathbf{C}}(\boldsymbol{\%})$ & $\tau_{\mathbf{b}}(\mathbf{p s f})$ & $\tau_{\mathbf{f}}(\mathbf{p s f})$ & $\mathbf{P}_{\mathbf{H S}}(\boldsymbol{\%})$ & $\mathbf{V}_{\mathbf{G L D}} / \mathbf{V}_{\mathbf{C V}}(\boldsymbol{\%})$ \\
\hline 9 & 1 & $9.7-35$ & 8.24 & 10.64 & 6.1 & 99 \\
10 & 2 & $8.5-24$ & 8.09 & 10.45 & 4.4 & 85 \\
\hline
\end{tabular}



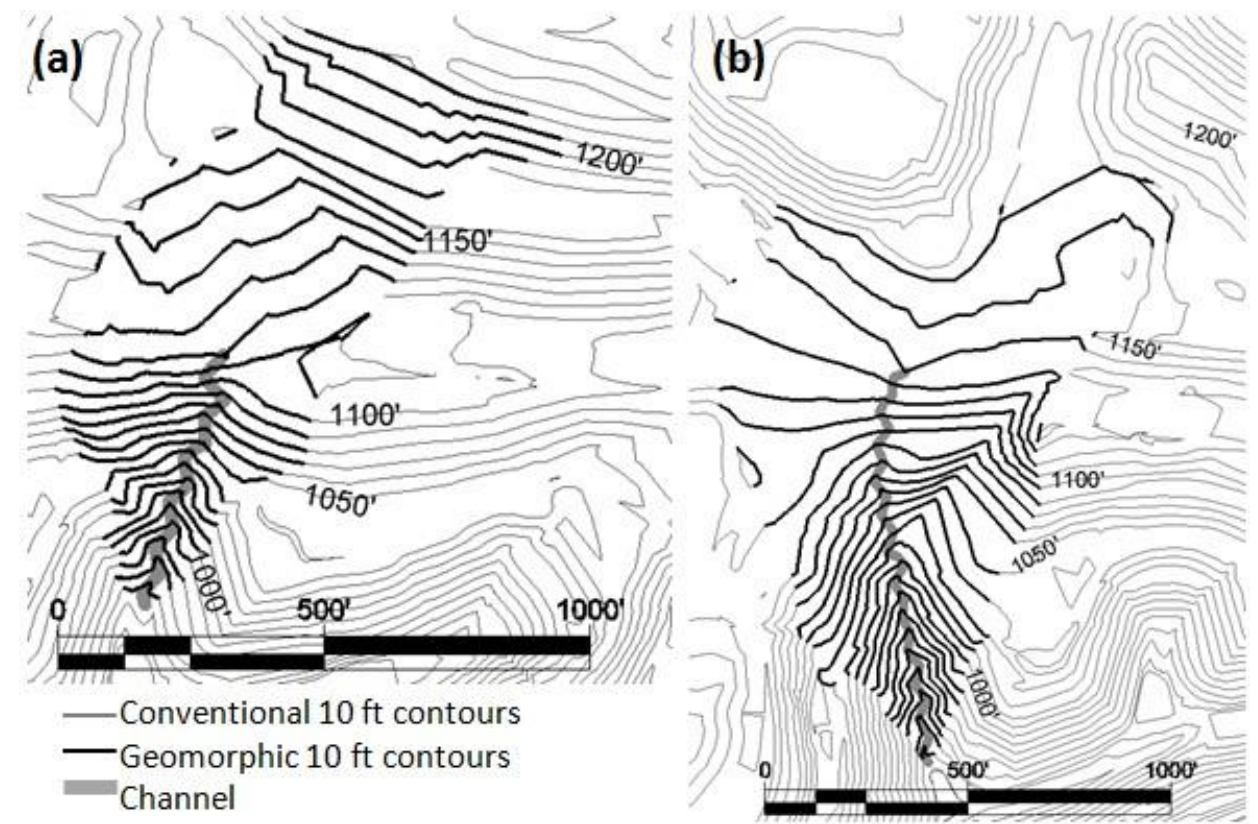

Figure 4.8. Geomorphic designs in permitted with maximum fill volume and hillslope stability for (a) valley fill 1 (Design 9); and, (b) valley fill 2 (Design 10).

VF1 met fill volume requirements and VF2 was closer to the requirements than when channel stability was maximized. Although hillslope stability was maximized, potentially unstable slopes remained as a small portion of the total design. While meeting volume and landform stability goals, this reclamation design failed in channel stability requirements. The large elevation change from the channel head to channel mouth (166 ft for VF1, $224 \mathrm{ft}$ for VF2) resulted in steep channel slopes (e.g. VF1 valley slope $=33 \%$; Channel slope $>30 \%$ for approximately $52 \%$ of the channel length; maximum slope $=35 \%$ ). Increased slopes elevated stream power such that applied shear stresses were too high to result in practical bed particle sizes. These designs also highlighted the difficulty that would be faced in attempting to place a channel on the face of a conventional valley fill, as the centerline profiles were very similar to a conventional reclamation (Figure 4.7).

\section{Compromise of channel and landform stability}

Designs 11, 12, and 13 had varying levels of channel stability and landform stability (Table 4.5, Figure 4.9). Designs were completed for VF1 because it was closer than VF2 to meeting stability and fill volume requirements in initial designs. 
Table 4.5. Characteristics of landforms developed to compromise stability and fill volume for VF1: range in channel slopes $\left(S_{c}\right)$, maximum shear stress at bankfull $\left(\tau_{b}\right)$, maximum shear stress at flood prone $\left(\tau_{\mathrm{f}}\right)$, percent of unstable hillslopes $(>50 \%)\left(\mathrm{P}_{\mathrm{HS}}\right)$, ratio of design

fill volume to conventional fill volume $\left(\mathrm{V}_{\mathrm{GLD}} / \mathrm{V}_{\mathrm{CV}}\right)$. $\mathrm{BF}=$ bankfull, $\mathbf{F P}=$ floodprone, DD=drainage density. Designs were completed for three cases of channel stability.

\begin{tabular}{ccccccc}
\hline Design & Channel & $\mathbf{S}_{\mathbf{C}}(\boldsymbol{\%})$ & $\tau_{\mathbf{b}}(\mathbf{p s f})$ & $\tau_{\mathbf{f}}(\mathbf{p s f})$ & $\begin{array}{c}\mathbf{P}_{\mathbf{H S}} \\
(\boldsymbol{\%})\end{array}$ & $\begin{array}{c}\mathbf{V}_{\mathbf{G L D}} / \mathbf{V}_{\mathbf{C V}} \\
(\boldsymbol{\%})\end{array}$ \\
\hline 11 & Stable at BF & $8.6-18$ & 4.30 & 5.56 & 14 & 78 \\
12 & Stable at FP & $8.0-14$ & 3.33 & 4.30 & 21 & 72 \\
13 & Stable at FP with high DD & $8.2-13$ & 3.33 & 4.30 & 39 & 54 \\
\hline
\end{tabular}
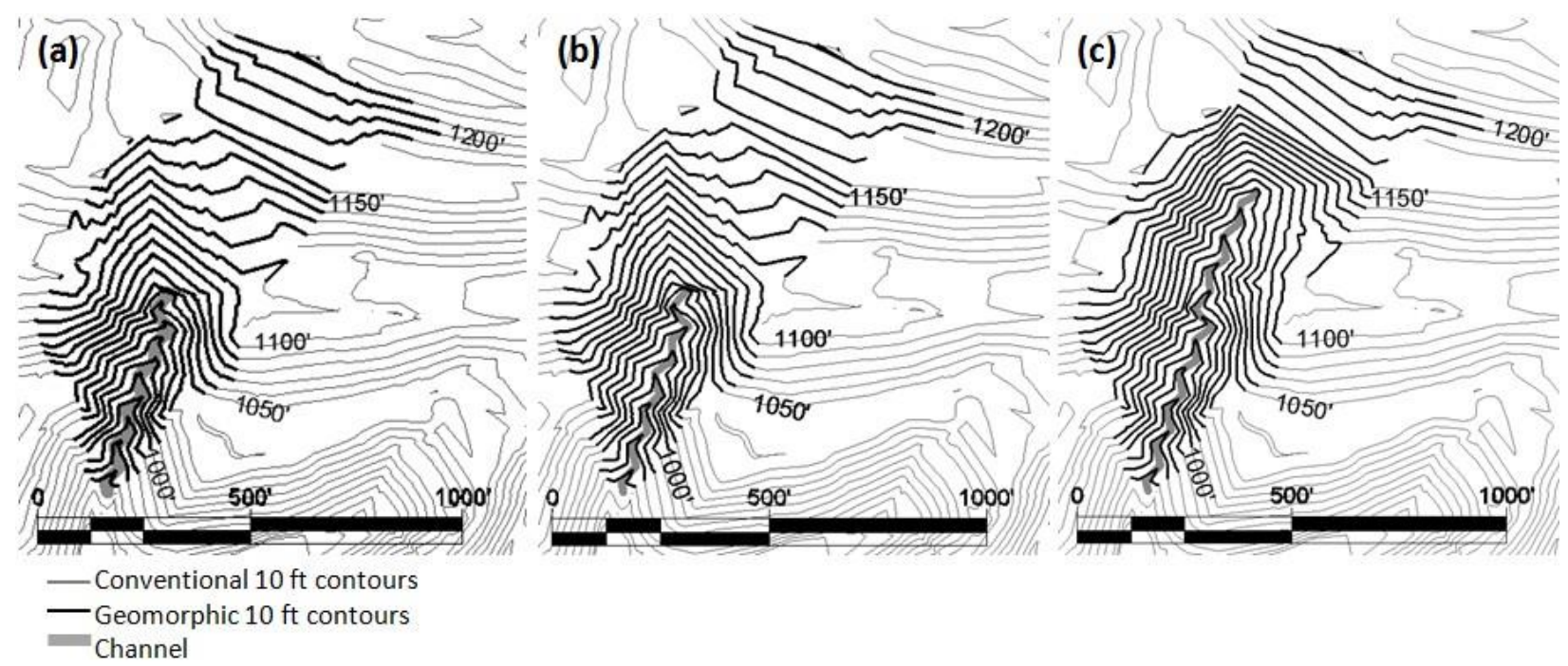

Figure 4.9. Geomorphic designs for VF1 in permitted area with (a) stable channel at bankfull flow (Design 11); (b) stable channel at flood prone flow (Design 12); and, (c) stable channel at flood prone flow and high drainage density (Design 13).

Design 11 created a stable channel under bankfull flow conditions while considering overall landform stability (Figure 4.9a). The channel was more stable than Design 9 but less stable than the Design 7, with a longitudinal profile between designs 7 and 9 (Figure 4.7). Calculated bankfull shear stresses suggest that cobbles could resist motion. The applied shear stress at flood prone discharge (maximum of $5.56 \mathrm{psf}$ ) required bed particle sizes of larger than cobble to resist motion for $46 \%$ of the channel length (maximum median bed particle size of 13 in). The occurrence of stable hill slopes did increase as compared to Design 7, but the fill volume requirement was not met.

Design 12 created a stable channel under both bankfull and flood prone flow conditions (Figure 4.9b). Calculated shear stresses suggest that cobbles could resist motion at both bankfull and 
flood prone flows. To reach this level of channel stability, the channel head elevation was reduced an additional $18.5 \mathrm{ft}$ from Design 11 (Figure 4.7). Landform stability, however, was compromised to reach this desired level of channel stability, with a higher percentage of hillslopes being above the $50 \%$ threshold. These potentially unstable gradients were located towards the middle of the longitudinal profile of hillslopes contributing to the main channel (at the transition point from concave to convex slope profiles) (Figure 4.10c). Above the slope increase at the head of the channel, slopes were lower and more closely resembled the conventional reclamation (Figure 4.10b). Unstable slopes and low fill volumes suggest that landform stability and material volumes are limiting factors in reaching a high level of channel stability. When drainage density was increased and the same channel stability requirements were held (Design 13, Figure 4.9c), hillslopes became more unstable and more fill volume was compromised. This design confirmed that using a low drainage density value provided the most promise in meeting stability and fill volume requirements.

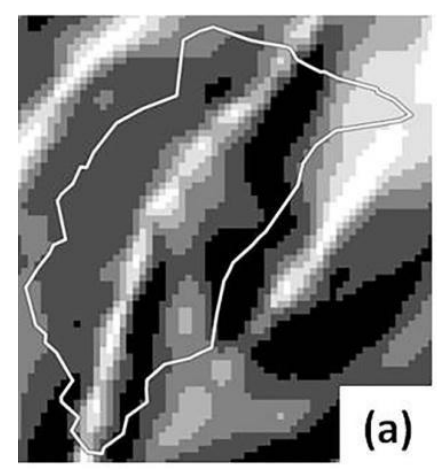

= Design boundary

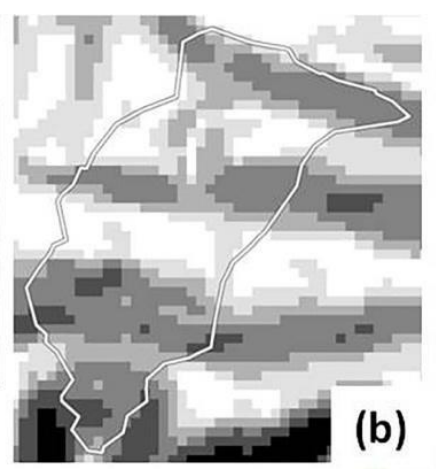

Slope (\%) $\square 0-10$

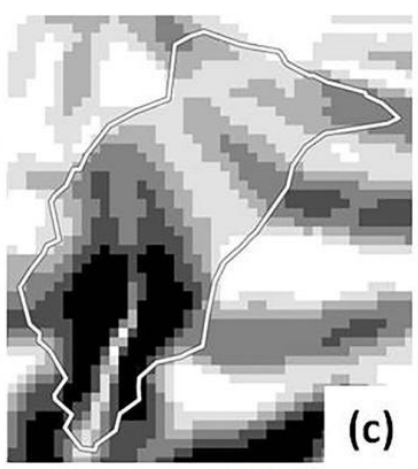

$10-20 \square 20-30$

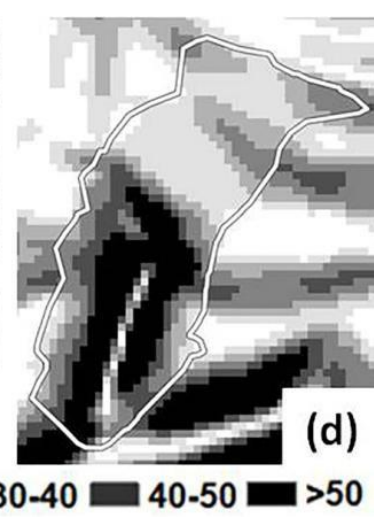

(d)

Figure 4.10. Slope distribution of (a) pre-mined topography; (b) conventional reclamation; (c) geomorphic design 12; and, (d) geomorphic design 16.

\section{Expanding impact area}

Varying levels of channel stability, landform stability, and fill volume were reached when expanding the impacted area of the fill (Table 4.6, Figure 4.11). 
Table 4.6. Characteristics of landforms developed with an expanded impact area for VF1: range in channel slopes $\left(\mathbf{S}_{c}\right)$, maximum shear stress at bankfull $\left(\tau_{b}\right)$, maximum shear stress at flood prone $\left(\tau_{\mathrm{f}}\right)$, percent of unstable hillslopes $(>50 \%)\left(\mathbf{P}_{\mathrm{HS}}\right)$, ratio of design fill volume to conventional fill volume $\left(\mathrm{V}_{\mathrm{GLD}} / \mathbf{V}_{\mathrm{CV}}\right)$. BF=bankfull, $\mathbf{F P}=$ floodprone. Designs were completed for three cases of channel stability.

\begin{tabular}{ccccccc}
\hline Design & Channel & $\mathbf{S}_{\mathbf{C}}(\boldsymbol{\%})$ & $\tau_{\mathbf{b}}(\mathbf{p s f})$ & $\tau_{\mathbf{f}}(\mathbf{p s f})$ & $\begin{array}{c}\mathbf{P}_{\mathbf{H S}} \\
(\boldsymbol{\%})\end{array}$ & $\begin{array}{c}\mathbf{V}_{\mathbf{G L D}} / \mathbf{V}_{\mathbf{C V}} \\
(\boldsymbol{\%})\end{array}$ \\
\hline 14 & Preserved & $6.7-12$ & 3.25 & 4.19 & 27 & 79 \\
15 & Stable at BF & $8.2-24$ & 4.33 & 5.60 & 9 & 114 \\
16 & Stable at FP & $8.2-12$ & 3.35 & 4.32 & 17 & 102 \\
\hline
\end{tabular}
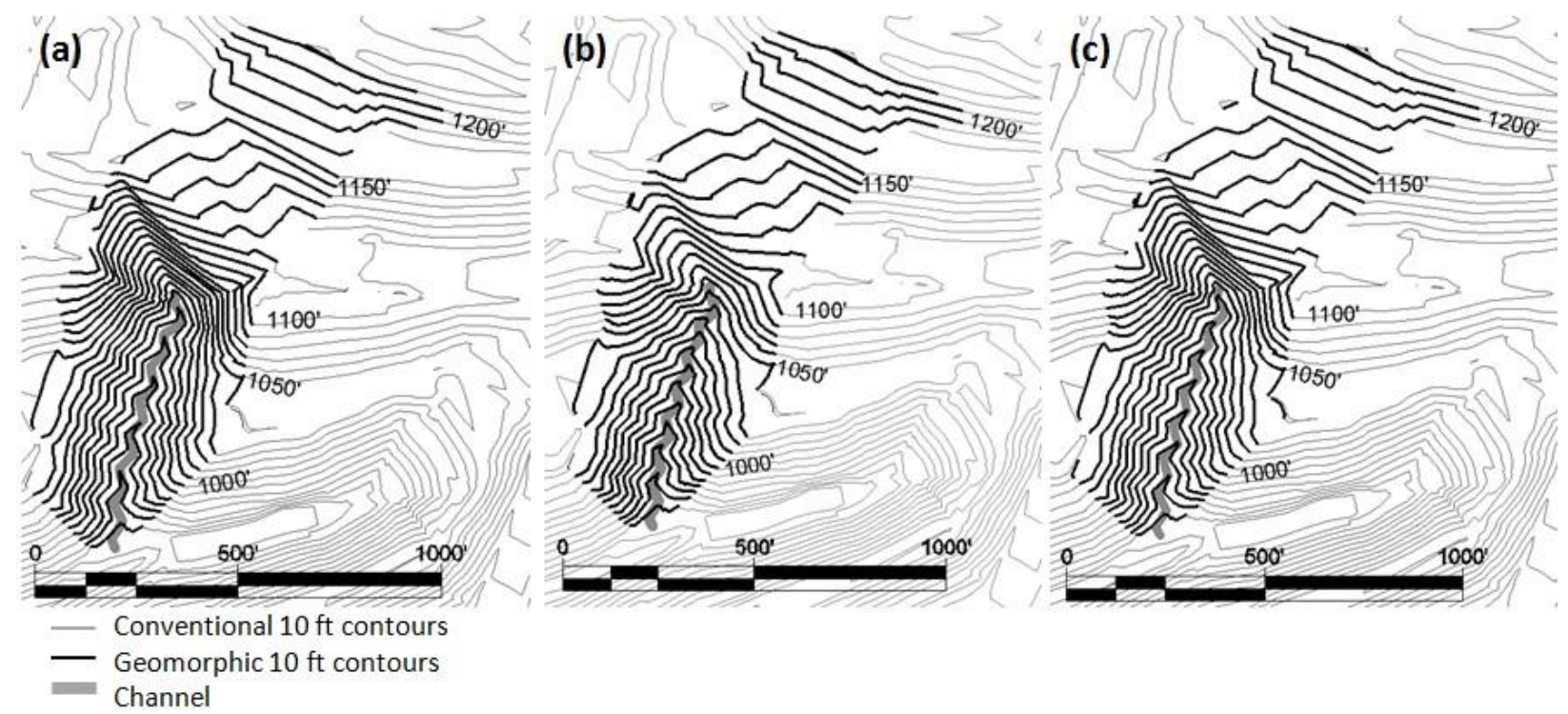

Figure 4.11. Geomorphic designs for VF1 in expanded area with (a) preserved channel (Design 14); (b) stable channel at bankfull flow (Design 15); and, (c) stable channel at flood prone flow (Design 16).

Extending the toe of the valley fill created a $31 \%$ increase in impacted area to 13.2 ac. (Figure 4.3). When the impacted area was expanded and the existing stream was preserved (Design 14, Figure 4.11a), hillslopes were not as steep as the preserved channel design for the permitted area (Design 7), but the risk of landform instability was still evident. The most common slope range was $10-20 \%$ grade, but a large portion of hillslopes were distributed in higher slope ranges (e.g. $18 \%$ of slopes from $40-50 \%$ grade; $15 \%$ of slopes from $50-60 \%$ grade). The channel was stable; the required mean bed particle size was not larger than cobble for any point in the channel. However, fill volume requirements were not met. Despite expanding the impacted area of the fill, a geomorphic design attempting to preserve the existing channel was not possible. 
If channel stability at bankfull flow was targeted with an expanded impact area (Design 15, Figure 4.11b), target fill volume was met. As was the case for the designs within the permitted area, this design had more stable hillslopes than the preserved channel design, but potentially unstable slopes still existed. The channel slopes in this design were higher than the slopes in the stable bankfull channel design for the permitted area (Design 11), with $61 \%$ of the channel requiring larger than cobble bed particle sizes at flood prone discharge (maximum required median bed particle size of 13 in). This design would not meet the regulations with respect to impact area.

For Design 16 (Figure 4.11c), fill volume and channel stability requirements were met. To reach this level of channel stability, the channel head was lowered an additional $41 \mathrm{ft}$ from the previous design. The higher flows associated with the increased impact area required decreasing the elevation of the channel head substantially to ensure full channel stability. Calculated shear stresses suggest that cobbles could resist motion at both bankfull and flood prone flows. Landform stability, however, was compromised to reach this desired level of channel stability, with a greater percentage of slopes exceeding the $50 \%$ threshold. Hillslope distribution was similar to the fully stable channel design in the permitted area (Figure 4.10d). As was the case with the previous design, this design did comply with area of impact regulations.

\section{Using default input values}

Using the design software's default input values resulted in a design with the same issues with respect to stability and fill volume requirements (Table 4.7, Figure 4.12). Increased drainage density and decreased drainage length resulted in more stream length, lower fill volume, and less stable slopes. Due to a drainage density value that was not applicable to the site, the landform was not in erosive equilibrium. The design created a more undulating surface with more ridges/valleys than the geomorphic designs using site-specific parameters, and it did not as closely mimic the drainage pattern of the original topography. The generated stream was longer, more meandering at the mouth, and steeper at the mouth. These stream features would not connect well with the existing valley and channel at the toe of the fill. This design reinforced that using site-specific design criteria is necessary for accurate geomorphic reclamation. 
Table 4.7. Characteristics of landforms developed using default software parameters for VF1: range in channel slopes $\left(S_{c}\right)$, maximum shear stress at bankfull $\left(\tau_{b}\right)$, maximum shear stress at flood prone $\left(\tau_{f}\right)$, percent of unstable hillslopes $(>50 \%)\left(\mathbf{P}_{\mathrm{HS}}\right)$, ratio of design fill volume to conventional fill volume $\left(\mathrm{V}_{\mathrm{GLD}} / \mathrm{V}_{\mathrm{CV}}\right)$.

\begin{tabular}{cccccc}
\hline Design & $\mathbf{S}_{\mathbf{C}}(\boldsymbol{\%})$ & $\tau_{\mathbf{b}}(\mathbf{p s f})$ & $\tau_{\mathbf{f}}(\mathbf{p s f})$ & $\mathbf{P}_{\mathbf{H S}}(\boldsymbol{\%})$ & $\begin{array}{c}\mathbf{V}_{\mathbf{G L D}} / \mathbf{V}_{\mathbf{C V}} \\
(\boldsymbol{\%})\end{array}$ \\
\hline 17 & $2.1-25$ & 6.02 & 7.77 & 22 & 60 \\
\hline
\end{tabular}

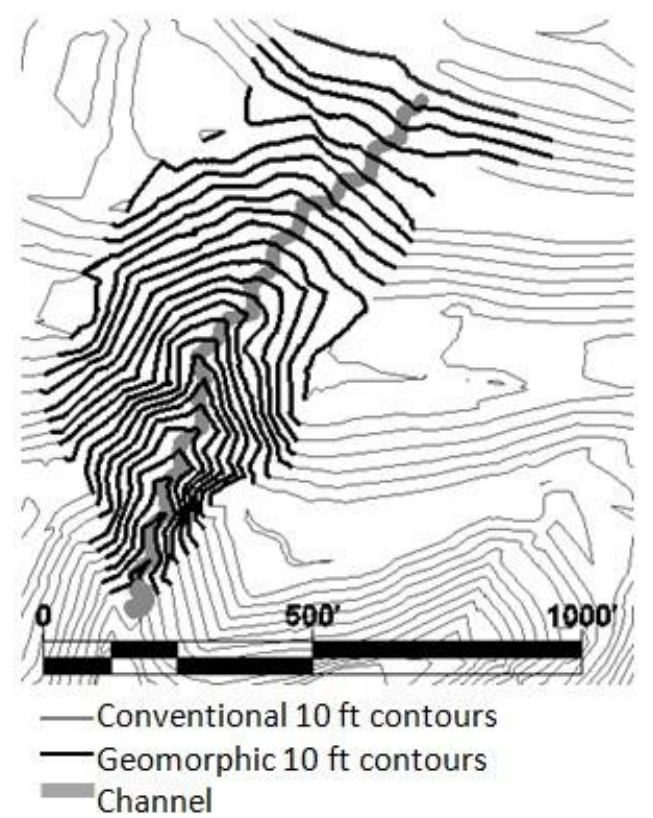

Figure 4.12. Geomorphic design for VF1 using software's default input values (Design 17).

\subsubsection{Slope stability analysis}

Slope stability analyses were performed on designs 11 (permitted area, stable channel at bankfull flow), 12 (permitted area, stable channel at floodprone flow), 15 (expanded area, stable channel at bankfull flow), and 16 (expanded area, stable channel at floodprone flow), as they were the designs for each area of impact that were closest to satisfying the criteria of fill volume, landform stability, and channel stability (Table 4.8). 
Table 4.8. Distribution of slope ranges between 50-60\% grade and minimum Factor of Safety for critical slope profile of geomorphic designs.

\begin{tabular}{|c|c|c|c|c|}
\hline \multirow{2}{*}{$\begin{array}{c}\text { Slope range } \\
(\%)\end{array}$} & \multicolumn{4}{|c|}{ Coverage by area $(\%)$} \\
\hline & 11 & $1 \angle$ & 12 & 10 \\
\hline $50-52$ & 2.2 & 3 & 2 & 2.9 \\
\hline $52-54$ & 1.9 & 3.3 & 1.9 & 2.5 \\
\hline $54-56$ & 1.5 & 2.1 & 1.9 & 1.9 \\
\hline $56-58$ & 1.6 & 1.9 & 1.2 & 1.3 \\
\hline $58-60$ & 1.6 & 1.5 & 1 & 1.3 \\
\hline$>60$ & 4.9 & 9.1 & 1.4 & 7.6 \\
\hline Factor of Safety & 1.02 & 0.93 & 1.46 & 1.40 \\
\hline
\end{tabular}

For the designs with stable channels at bankfull flows (11 and 15), the majority of potentially unstable slopes fell below $60 \%$ grade. For the slopes between $50 \%$ and $60 \%$ grade, a higher percentage of slopes were distributed closer to $50 \%$, which is promising when investigating manual correction of steep slopes. For the designs with completely stable channels (12 and 16), a higher percentage of slopes were above $60 \%$ gradient, posing a greater risk for instability and increasing the difficulty in manually correcting unstable areas. For the critical profile of each design, the factor of safety against failure was below the WVDEP standard of 1.5 (Table 4.8). This result was consistent with the findings of the initial stability analysis on the mine spoil. Critical profiles for the designs with an expanded area of impact were shown to be stable (FS $>1.0)$ and were closer to reaching the design standard factor of safety than designs in the permitted area. These stability analyses did not account for the sudden rise in groundwater table that would result from a large magnitude or duration storm event; groundwater table rise would increase pore pressure within the fill, thereby reducing factor of safety to values lower than those reported in this research. Expanding the area of impact was necessary to produce a stable geomorphic design, but the WVDEP regulations for maximum slope and impacted area were not met.

\subsubsection{Practicality of geomorphic designs}

If all designs are judged according to the criteria of fill volume, landform stability, and channel stability, it is apparent that compromises must be considered for application of this technique in steep terrain and that landform stability is a limiting factor (Table 4.9). This confirmed the potential issues documented by Michael et al. (2010). 
Table 4.9. Analysis of design criteria for geomorphic designs for VF1.

\begin{tabular}{cccc}
$\begin{array}{c}\text { Design } \\
\text { case }\end{array}$ & $\begin{array}{c}\text { Fill } \\
\text { volume }\end{array}$ & $\begin{array}{c}\text { Landform } \\
\text { stability }\end{array}$ & $\begin{array}{c}\text { Channel } \\
\text { stability }\end{array}$ \\
\cline { 1 - 3 } 7 & $\mathrm{x}$ & $\mathrm{x}$ & $\mathrm{V}$ \\
9 & $\mathrm{~V}$ & + & $\mathrm{x}$ \\
11 & + & + & + \\
12 & + & $\mathrm{x}$ & $\mathrm{V}$ \\
13 & $\mathrm{x}$ & $\mathrm{x}$ & $\mathrm{V}$ \\
14 & + & $\mathrm{x}$ & $\mathrm{V}$ \\
15 & $\mathrm{~V}$ & + & + \\
16 & $\mathrm{~V}$ & + & $\mathrm{V}$ \\
\cline { 1 - 2 } $\mathrm{x}$ & Criteria not met & \\
+ & Criteria moderately met & \\
$\mathrm{V}$ & Criteria met &
\end{tabular}

Met, not met, and moderately met are defined for each criterion as follows:

- Fill volume (as a percentage of conventional fill volume): Met if $\geq 100 \%$ : moderately met if between 70-100\%; and, not met if $<70 \%$.

- Landform stability (as a percentage, by area, of hillslopes above 50\% grade): Met if 0\%; moderately met if between $0-20 \%$; and, not met if $>20 \%$.

- Channel stability: Met if stable at both bankfull and flood prone flows; moderately met if stable at bankfull flow but not flood prone flow; and, not met if unstable at bankfull flow.

When the permitted area was used, target fill volume was reached with a moderate level of landform stability but with low channel stability (impractical bed particle size). If channel stability was ensured, landform stability and/or fill volume requirements could be not reached. A moderate level of all criteria could be met simultaneously within the permitted area. This design (design 11), however, had critical unstable slope profiles and would require manual adjustment to hillslopes and additional stabilizing measures to the channel. The issues associated with the designs in the permitted area suggest that expanding the impact area of the fill is necessary (but not necessarily sufficient) in meeting design criteria.

If the toe of the fill was extended to expand the impacted area, target fill volume was reached with moderate landform stability and full channel stability (design 16). The critical slopes were 
shown to be stable (FS >1.0), but they did not comply with existing reclamation standards (FS $\geq$ 1.5 , slope $\leq 2: 1$ ). To alter the design so that hillslopes meet regulations, either additional stabilizing measures for the channel or manual hillslope adjustment would be required. Expanding the impact area increased the likelihood of satisfying the criteria, but designs still exhibited unstable and/or noncompliant landform slopes, created additional issues by not complying with the regulations of fill placement, and created additional stream burial. Manual adjustments by the reclamation designer may be necessary for geomorphic principles to be successfully applied to valley fill reclamation. The landform may not strictly follow the GeoFluv $^{\mathrm{TM}}$ method and would have to be independently tested for stability, erosive equilibrium, and compliance with broad geomorphic design principles.

Aesthetically, the geomorphic designs created a much more natural looking landform, but not a landform that completely recreated the original valley. The geomorphic designs had more ridges and valleys than the pre-mined topography, which is typically one smooth, two-sided valley with a channel at the bottom. This difference between pre-mined and post-reclamation topography highlights that geomorphic reclamation aims to create a landform in erosive equilibrium, not to purely recreate the original, undisturbed topography. Accurately recreating the pre-mined topography is impossible due to differences in consolidation of materials, especially in the steep topography of Appalachia. These results are specific to the study site in this research, but it is expected that a design for a different valley fill location would experience the same relationships among channel stability, landform stability, and fill volume. While it is unknown if a design for another valley fill would have higher or lower levels of channel stability, landform stability, and fill volume, it is expected that the most feasible design would require an expanded impact area.

Additional issues have been documented (Michael et al., 2010) that were not addressed in this study and would have to be addressed before implementing geomorphic design principles in central Appalachia. Aspects of geomorphic reclamation do not coincide with methods allowable under the Federal Surface Mining Control and Reclamation Act regulations which result in broad plateaus, lack of curvilinear shapes, and steep drainage control systems. Cost increases in initial construction have not been quantified and could discourage industry collaboration. Also, more complex and time-consuming earthwork could delay reclamation completion and would require additional training for operators. 


\subsubsection{Benefits to geomorphic design}

The ecological benefits of geomorphic designs will likely result from recreated stream length. The pre-mined topography had $951 \mathrm{ft}$ of intermittent stream length that was being buried and not recreated by the conventional construction of the fill. The geomorphic reclamation within the permitted area with a stable channel, however, created $612 \mathrm{ft}$ of new stream length. When the area was expanded, 1,300 ft of stream length was buried and $746 \mathrm{ft}$ of new stream length was generated. Created headwater channels can provide essential ecological services that are otherwise lost in conventional reclamation. Benefits provided by headwater channels include transporting sediment (Milliman and Syvitski, 1992), processing nutrients (Freeman et al., 2007), and providing habitat diversity (Meyer and Wallace, 2001; Gomi et al., 2008). The amount of stream length generated by a geomorphic fill could be increased by increasing the drainage density of the design to the target drainage density, albeit at the potential cost of reduced fill volume and landform stability.

As compared to the conventional design, the proposed geomorphic designs better mimicked conditions of mature topography. Slopes of the pre-mined topography ranged from shallow slopes along the longitudinal profile of the channel to steep slopes in the areas contributing to the channel (Figure 4.10a). This slope distribution was mimicked by the geomorphic designs (Figure 4.10c and Figure 4.10d), while the slopes of the conventional reclamation were uniform along the face and shallow/flat above the crest (Figure 4.10b). The pre-mined topography exhibited stable slopes that were steeper than could be achieved in geomorphic designs due to more mature vegetation and more sound rock than that associated with reclaimed landforms. More variability in the slopes of the geomorphic designs could be obtained by increasing the drainage density to create more ridges and valleys contributing to the main channel, but the amount of fill volume and landform stability would again be compromised.

For the pre-mined topography, slope aspect was approximately evenly split between south/southeast on one side of the valley and west/northwest on the opposite side of the valley (Figure 4.13a); the channel flowed southwest. This distribution was similar to the aspect distributions of the geomorphic designs (Figure 4.13c and Figure 4.13d); the two sides of the contributing valley faced in mirrored directions, and the area above the channel head faced in the 
same direction as the channel. Aspect variability supports variation in vegetation, an important factor in habitat diversity (Churchill, 1982). As with slope, the variability in the distribution of aspect for the geomorphic designs could even more closely resemble mature topography if the length of the stream was increased. The aspect distribution of the conventional fill lacked variability, with the majority of slopes facing south (Figure 4.13b).
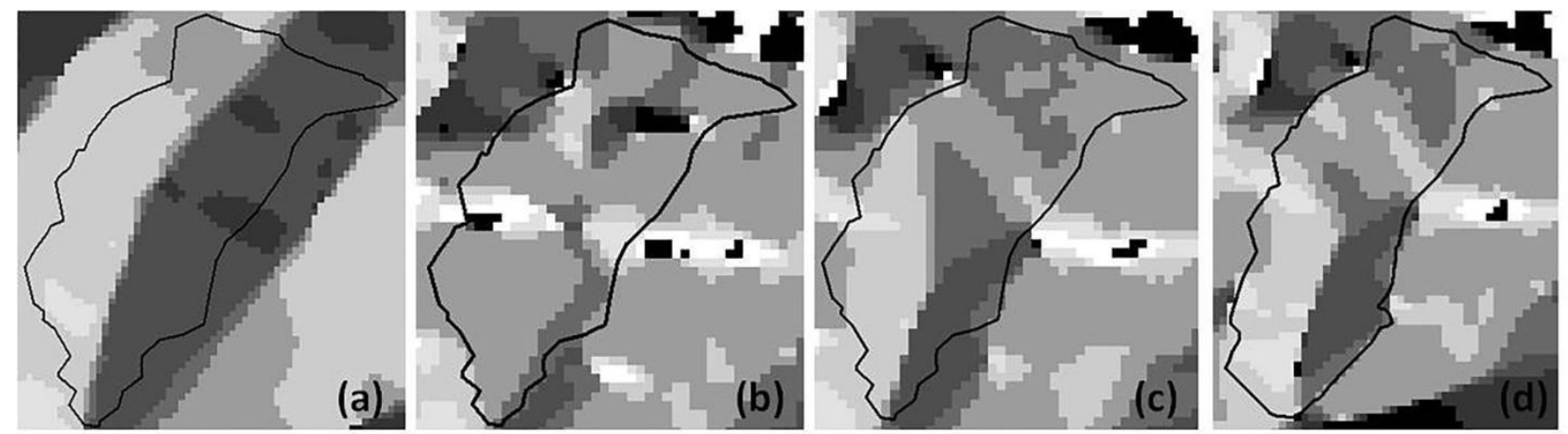

-Design boundary

Aspect

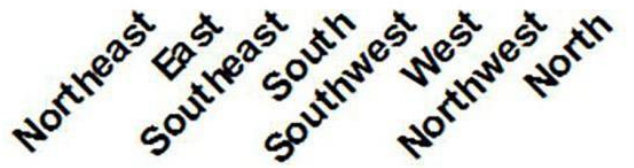

Figure 4.13. Aspect distribution of (a) pre-mined topography; (b) conventional reclamation; (c) geomorphic design 12; and, (d) geomorphic design 16.

Additional potential benefits to geomorphic reclamation not investigated in this portion of research study are lower erosion rates (Bugosh, 2009), improved management of surface water and groundwater, and enhanced downstream water quality through reduced contaminant loading from mine spoil.

\subsection{Conclusions and recommendations}

The objective of this portion of research was to quantify the issues that have been documented with respect to implementing geomorphic design principles in central Appalachia valley fill reclamation. A series of geomorphic designs for two valley fills in southern WV were completed and have confirmed that the issues associated with the steep slope topography, stability, and stream recreation are valid, especially if minimizing the area of impact is a priority. The following conclusions were made from this research:

- Fill volume decreased with increasing drainage density. 
- The existing stream of the pre-mined topography could not be preserved through geomorphic reclamation due to unstable constructed slopes around the channel.

- A geomorphic reclamation could mitigate the burial of the existing channel by creating a stable channel at a higher elevation.

- When the area of impact of the conventional reclamation was maintained, a geomorphic design for the locations studied could not simultaneously meet the requirements of channel stability, landform stability, and fill volume.

- Expanding the area of impact of the fill allowed a geomorphic design to better satisfy all three criteria for a successful design, but did not comply with regulations in central Appalachia for the placement of fill and maximum grade of constructed hillslopes. It is expected that a potentially successful design would require an expanded area of impact.

- Benefits of geomorphic designs are increased variability in slope and aspect and newly generated stream length. These benefits may result in improved habitat and biodiversity, decreased erosion, and improved management of surface water, groundwater, and mine spoil contaminants.

This work quantified the challenges related to applying geomorphic landform design principles to valley fills in central Appalachia. While another valley fill may be slightly more or less successful in meeting the design analysis criteria, it is not expected for the overall results of this study to change if other individual, small scale valley fills were investigated. The valley fill investigated in this study provides a valuable model from which the next necessary steps in applying geomorphic reclamation in central Appalachia can be analyzed. Future work should include field experiments to confirm the input parameters drainage length and drainage density. Modeling studies should address groundwater flow, contaminant transport, and hydrologic response. A pilot study is needed to address constructability and cost issues. 


\section{CHAPTER 5. GROUNDWATER MODELING AND SELENIUM DESORPTION COMPARISON OF GEOMORPHIC AND CONVENTIONAL VALLEY FILL ALTERNATIVES}

\subsection{Introduction}

Several studies have scrutinized the consequences of conventional reclamation methods with respect to altered watershed hydrology (e.g. Negley and Eshleman, 2006; Ferrari et al., 2009; Miller and Zégre, 2014) and impaired downstream water quality (e.g. Palmer et al., 2010; Bernhardt and Palmer, 2011; USEPA, 2011). Impaired water quality with elevated contaminant loads is attributed to groundwater contact with and desorption of contaminants (selenium) from the blasted rock overburden used to construct fills (USEPA, 2005, 2011). It is expected that the curvilinear slopes and reclaimed hydrology associated with geomorphic reclaimed landforms would exhibit increased runoff and reduced groundwater infiltration as compared to the flat and planar slopes associated with conventional valley fill surfaces. Reducing the quantity of water that comes in contact with high contaminant (e.g. selenium) concentration rock could reduce contaminant loads in water discharging from fills. The potential benefits to geomorphic reclamation with respect to groundwater movement and contaminant desorption has not been sufficiently investigated. Research has shown that various methods of chemical treatment can be effective in the removal of selenium (Se) (e.g. Baur and Johnson, 2003; Ziemkiewicz et al., 2011), but research has not been performed to determine if Se concentrations can be reduced through physical means, specifically ground surface modifications limiting water infiltration.

The overall goal of this portion of research was to compare groundwater movement and selenium desorption in conventional and geomorphic reclamation alternatives for a southern West Virginia surface mine to quantify any benefits to using geomorphic landform design as an alternative to conventional surface mine reclamation. To complete this analysis, the following tasks were completed:

1. Performed two-dimensional and three-dimensional numerical groundwater modeling of reclamation alternatives using finite element method.

2. Calculated selenium desorption by coupling groundwater modeling results with laboratory selenium leaching test data. 


\subsection{Background}

Previous work completed in groundwater modeling provides insight into the necessary steps of the modeling process and the most effective tools to use for a given application. The objectives of seepage modeling should be to predict the future volumetric flow of seepage during operation, the future contaminant release to the ecosystem during operation and post-closure, and the reduction in groundwater from alternative seepage mitigation strategies (Brixel et al., 2012). The basic components of the groundwater model should include bedrock of low permeability, colluvial/alluvial soils of higher permeability, a groundwater table located somewhere in the more permeable soils, and a waterway to which groundwater discharges.

In valley fills, saturated thicknesses are small and the majority of flow is through unsaturated rock; steep pit floors cause water to migrate to the bottom of the fills and flow toward the toe through the fill-valley interface (Hawkins, 2004). When modeling behavior of groundwater and contaminants under these conditions, it is essential to be able to estimate the hydraulic properties of unsaturated soils (Pham, 2005). Under variably-saturated conditions, changes in matric suction (difference in air pressure and pore pressure) result in subsequent changes in soil hydraulic properties (Fredlund et al., 2012). When matric suction exceeds what is called the "air entry value," saturated volumetric water content and saturated hydraulic conductivity cease to govern groundwater flow. Beyond the air entry value, water content and permeability decrease until they reach minimum residual conditions. The distribution of hydraulic properties above residual matric suction is not well known. Fredlund and Xing's (1994) equation for the soilwater characteristic curve (SWCC) (volumetric water content versus matric suction), along with saturated soil hydraulic conductivity, can be used to estimate the permeability function (soil hydraulic conductivity versus matric suction) (Fredlund et al., 1994). Fitting parameters for the Fredlund and Xing (1994) equation for SWCC can be estimated from soil grain size data (e.g. Zapata, 1999; Chin et al., 2010; Torres, 2011). Torres (2011) provided the most appropriate method for granular soils. Finite element models appear to be the most well suited for modeling unsaturated soils and transient conditions associated with reclaimed landforms (e.g. Fredlund et al., 1998; Chapuis and Aubertin, 2001; Abdelghani et al., 2009). 
A contaminant of particular concern when analyzing reclaimed landforms in central Appalachia mining regions is selenium (Se), a naturally occurring element in the coal seams and surrounding strata of southern WV (Vesper et al., 2008) that can be toxic in excessive concentrations (Swaine, 1990; Frankenberger and Engberg, 1998). For WV coal mines, selenium discharges must meet the chronic freshwater aquatic life standard of $5 \mu \mathrm{g} / \mathrm{L}$ (USEPA, 1999); updated criteria for lentic and lotic freshwater systems of $1.2 \mu \mathrm{g} / \mathrm{L}$ and $3.1 \mu \mathrm{g} / \mathrm{L}$, respectively, are currently under review (USEPA, 2015). Many surface mines and tailings facilities have selenium discharges in excess of this standard and require post-construction treatment due to the leaching of Se from mine spoil (USEPA, 2005, 2011). Limited studies have investigated the leaching of Se specifically from materials associated with coal mining (e.g. Sharmasarkar and Vance, 2002; Roy, 2005; Wang et al., 2007; Pumure et al., 2009; Pumure et al., 2010; Ziemkiewicz et al., 2011). The relationship between Se and groundwater movement in reclaimed landforms, particularly how selenium partitions between liquid and solid phases in response to groundwater seepage, has not been quantified with modeling studies.

\subsection{Methods}

Groundwater movement for reclamation alternatives was modeled using SoilVision Systems Ltd. (Saskatoon, Saskatchewan, Canada, 2009) SVOffice Geotechnical Software Suite. SVOffice models groundwater in one, two, or three dimensions using the finite element method. Primary features of SVOffice include the following: fully automatic mesh generation; fully automatic mesh refinement based on any model variable; seepage face boundary conditions; fully implicit approach to solve difficult models with convergence issues; fluid mass-balance tracking; axisymmetric and plan analysis formulations; 3, 6, or 9 noded triangles as elements for 2D analysis; 4, 10, 20 noded for 3D analysis; adaptive time stepping with automatic generation and control of time steps; Newton-Raphson convergence iteration schemes; matrix preconditioning in conjugate-gradient solutions. Groundwater movement was modeled using the SVflux packages. SVOffice was selected due to the ability of the software to model unsaturated soil flow conditions. SVOffice did not have the capability to model desorption from contaminated soil, so selenium desorption was calculated using a mass-balance approach by coupling groundwater results with unsaturated soil selenium leaching laboratory data. 


\subsubsection{Conceptual groundwater model}

The field site case being modeled (Figure 5.1) consisted of the following features: foundation rock comprised of the existing valley; fill material consisting of free-draining blasted rock overburden with certain groundwater and contaminant properties; infiltration into the surface of the fill material; phreatic water table with variable elevations within the fill material; and, settling pond structure at toe of fill with specified head level. The fill material surface profile varied depending on the reclamation technique (planar for conventional fill, curvilinear for geomorphic fill). Infiltration into the fill also varied depending on hydrologic inputs, reclamation technique, slope angles, and soil properties. The fill material was unsaturated with a phreatic water table due to unconfined aquifer conditions. The interface between the fill material and foundation rock was impermeable due to a drastic decrease in permeability. Groundwater seepage was assumed to be governed by porous media flow and did not account for macropore or conduit flow.

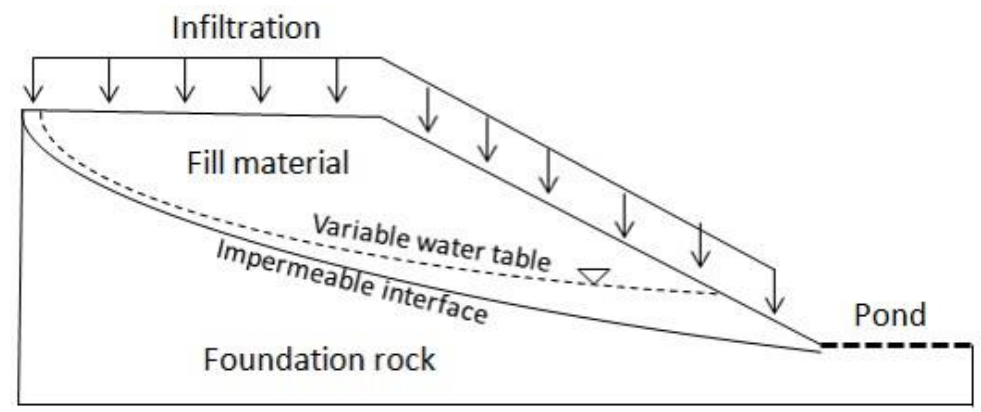

Figure 5.1. Conceptual groundwater model of valley fill

\subsubsection{Material properties}

A critical review was conducted on studies involving groundwater and contaminant modeling of waste rock, as well as the surface mine permit file and laboratory testing, to obtain the necessary properties of the fill material (tabulated in Appendix C). Groundwater soil properties included saturated hydraulic conductivity $\left(\mathrm{K}_{\text {sat }}\right)$, anisotropy ratio $\left(\mathrm{K}_{\mathrm{H}} / \mathrm{K}_{\mathrm{V}}\right)$, porosity $(\mathrm{n})$, and specific gravity $\left(\mathrm{G}_{\mathrm{s}}\right)$. Required soil properties for calculation of selenium desorption were bulk density $(\rho), n$, contaminant starting concentration $\left(\mathrm{C}_{0}\right)$, and a characterization of selenium desorption from blasted rock. Based on the review of soil properties, expected soil properties and upper and lower bound soil properties were determined (Table 5.1). 
Table 5.1. Expected and range of values for fill material properties

\begin{tabular}{ccc}
\hline Property & Expected value & Range \\
\hline Saturated hydraulic conductivity $(\mathrm{m} / \mathrm{d})$ & 1.47 & $0.86-46.7$ \\
Anisotropy ratio & 10 & $2.0-20$ \\
Porosity & 0.30 & $0.30-0.43$ \\
Specific gravity & 2.69 & $\mathrm{~N} / \mathrm{A}$ \\
Bulk density $\left(\mathrm{kg} / \mathrm{m}^{3}\right)$ & 2002 & $\mathrm{~N} / \mathrm{A}$ \\
Se starting concentration $(\mathrm{mg} / \mathrm{kg})$ & 1.26 & $0.00-4.84$ \\
\hline urces: Soil testing; Mine permit file; Peterson et al. (2004); Wels et al. (2012); Abdelghani et
\end{tabular}

Sources: Soil testing; Mine permit file; Peterson et al. (2004); Wels et al. (2012); Abdelghani et al. (2009); Mao et al. (2006), Ataie-Ashtiani (2007), Fredlund et al. (1998); Domenico and Schwartz (1990); Russell (2012); Russell et al. (2014)

Unsaturated soil property functions were determined using the Fredlund and Xing (1994)

equation for the soil-water characteristic curve (SWCC) (Equation 5.1) (Figure 5.2):

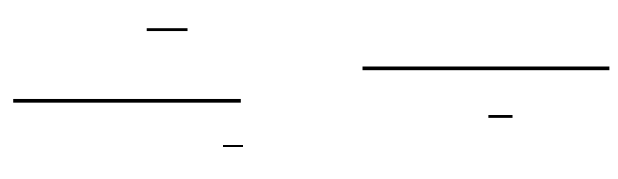

where, 


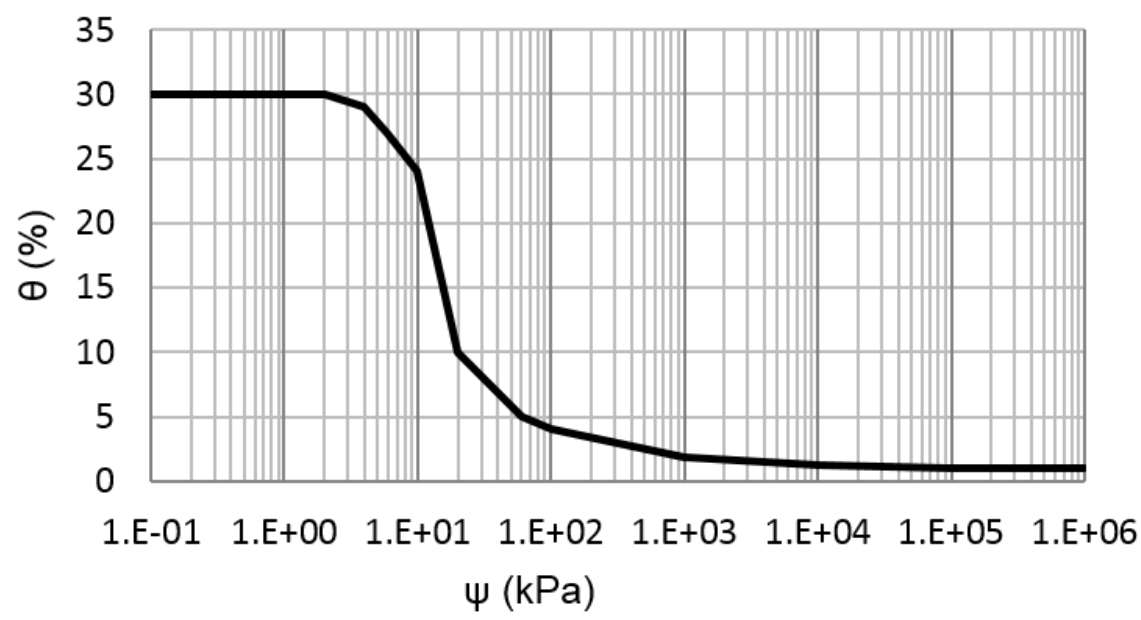

Figure 5.2. Soil-water characteristic curve for mine spoil developed from Fredlund and Xing (1994) equation and Torres (2011) curve fitting parameters. Volumetric water content $(\theta)$ versus matric suction $(\psi)$.

Saturated volumetric water content was assumed to be equal to porosity (30\%). Volumetric water content exhibited a sharp decrease once the air entry value $(7.1 \mathrm{kPa})$ was exceeded and until residual matric suction (>100 $\mathrm{kPa}$ ) and water content $(4.0 \%)$ conditions were reached. Empirically developed fitting parameters $\mathrm{a}, \mathrm{n}, \mathrm{m}$, and $\mathrm{h}_{\mathrm{r}}$ were estimated using the Torres (2011) model for granular materials (Equations 5.2-5.5) using laboratory data on grain size distribution of valley fill overburden (Russell et al., 2014). A $\mathrm{D}_{10}$ particle diameter of $0.11 \mathrm{~mm}$ resulted in the following fitting parameters: $\mathrm{a}=9.62, \mathrm{n}=4.72, \mathrm{~m}=0.79, \mathrm{~h}_{\mathrm{r}}=100$. Parameter " $\mathrm{a}$ " was related to and approximately the air entry value; " $n$ " controlled the slope of the curve at its inflection point; "m" was related to residual water content; "hr" corresponded to matric suction under residual water content conditions.

where, 
The permeability function was estimated according to Fredlund et al. (1994) (Equation 5.6) (Figure 5.3) using the developed SWCC. Integration was performed within the finite element groundwater modelling tool.

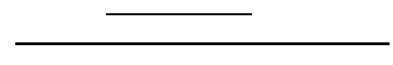

where,

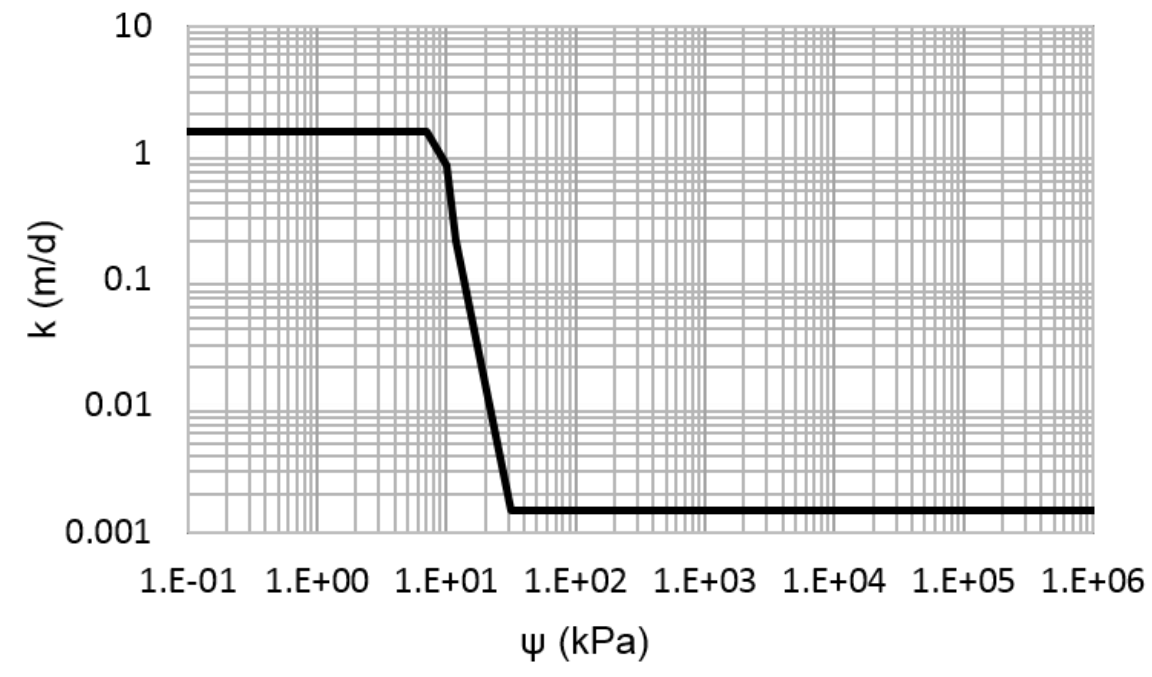

Figure 5.3. Unsaturated permeability function for mine spoil estimated according to Fredlund et al. (1994). Soil hydraulic conductivity $(k)$ versus matric suction $(\psi)$.

Saturated hydraulic conductivity was set to $1.47 \mathrm{~m} / \mathrm{d}$ and governed flow until the air entry value was exceeded. Saturated hydraulic conductivity can be highly variable and is difficult to define with an accurate field condition value, but $1.47 \mathrm{~m} / \mathrm{d}$ provided an appropriate value for model comparison purposes. Hydraulic conductivity then decreased approximately linearly with 
increasing matric suction until minimum hydraulic conductivity $(0.00147 \mathrm{~m} / \mathrm{d})$ was reached. Fredlund et al. (2012) reported that a large magnitude difference in saturated and minimum hydraulic conductivity creates model convergence issues, and that data on minimum hydraulic conductivity (minimum value hydraulic conductivity can reach under residual water content conditions) are lacking. Therefore, the minimum hydraulic conductivity was assumed to be three orders of magnitude less than saturated hydraulic conductivity.

\subsubsection{Numerical groundwater model}

\section{Model geometry}

An additional geomorphic design was completed for valley fill 1 from the previous chapter (Chapter 4, Section 4.3.1) for the specific purpose of modeling (Figure 5.4c) with the following characteristics: i) maximum drainage length (distance from watershed boundary to reclaimed channel head) of $124 \mathrm{~m}$; ii) target drainage density (stream length per watershed area) of 4.7 $\mathrm{km}^{-1}$; and, iii) reclaimed channel designed to be stable at floodprone flow (channel dimensions required to accommodate $50 \mathrm{yr}, 6-\mathrm{hr}$ storm). The geomorphic fill consisted of approximately $250,000 \mathrm{~m}^{3}$ of blasted rock. The surface area of the geomorphic fill was $23,212 \mathrm{~m}^{2}, 398 \mathrm{~m}^{2}$ of which was covered by the reclaimed stream. Five percent of hillslopes were above the West Virginia Department of Environmental Protection (WVDEP) maximum slope standard of 50\% grade (WVDEP, 1999); the majority of hillslopes were less than $20 \%$ grade. The reclaimed stream length was $171 \mathrm{~m}$.

The existing reclamation was used for the geometry of the conventional valley fill face (Figure 5.4 b). Approximately $358,000 \mathrm{~m}^{3}$ of blasted rock overburden were used to construct the existing valley fill through conventional techniques. The fill face consisted of slopes ranging mostly from $40 \%-50 \%$ grade, with flat slopes along the crest. The total area of the fill surface was $25,881 \mathrm{~m}^{2}$; $15,733 \mathrm{~m}^{2}$ of the surface was the flat crest, $10,148 \mathrm{~m}^{2}$ was the sloped face. The undisturbed, premining valley defined the lower boundary of each model (Figure 5.4a). 

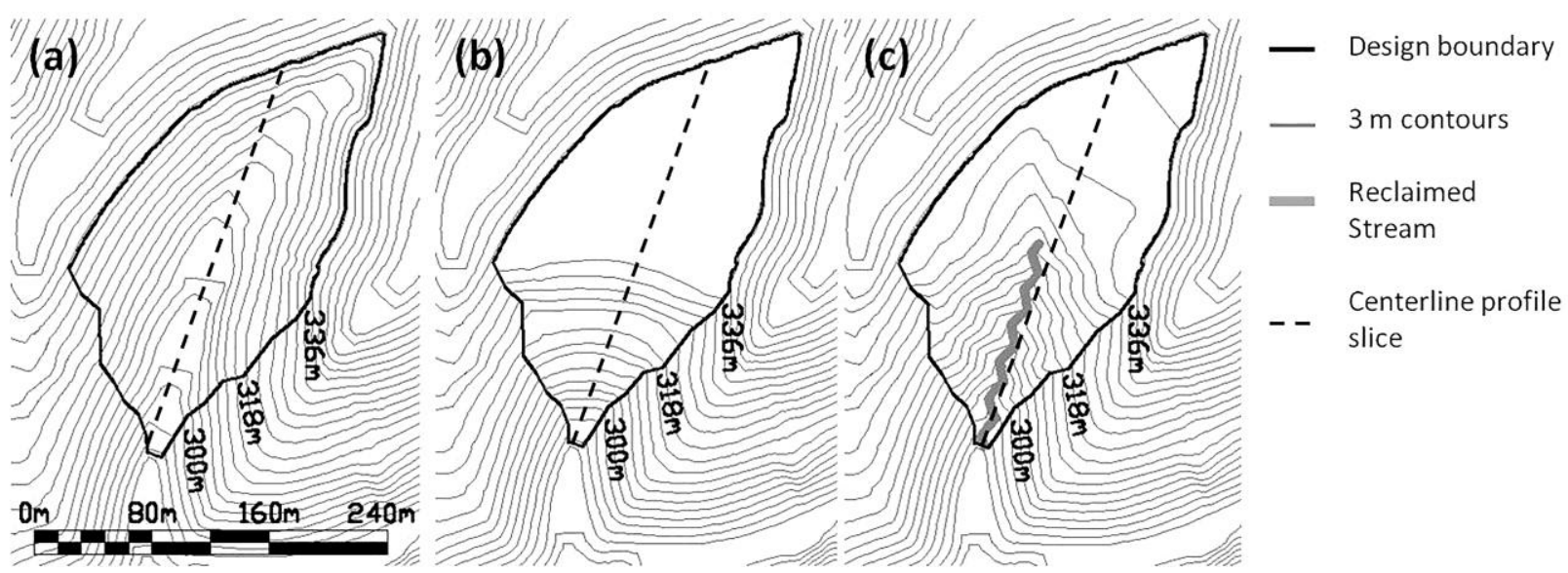

Figure 5.4. Contours used for geometry of two-dimensional and three-dimensional models with location of two-dimensional profile slice for (a) original valley; (b) conventional valley fill reclamation; and, (c) geomorphic design.

For two-dimensional modeling, centerline slices were defined at the same location in each surface to produce two dimensional profiles and capture the area or the geomorphic fill with the reclaimed stream (Figure 5.4, Figure 5.5). For all three profiles, the elevation extent was $290 \mathrm{~m}$ to $335 \mathrm{~m}$ and the longitudinal extent was $0 \mathrm{~m}$ to $273 \mathrm{~m}$. The reclaimed stream in the geomorphic design began at a longitudinal station of $128 \mathrm{~m}$ and an elevation of $323 \mathrm{~m}$ (Figure 5.5). Model volumes (considering a unit width) of the conventional and geomorphic profiles were $4,725 \mathrm{~m}^{3}$ and $3,009 \mathrm{~m}^{3}$, respectively. For three-dimensional modeling, each entire fill volume was modeled. Model volumes of the three-dimensional conventional and geomorphic fills were $343,253 \mathrm{~m}^{3}$ and $229,739 \mathrm{~m}^{3}$, respectively.

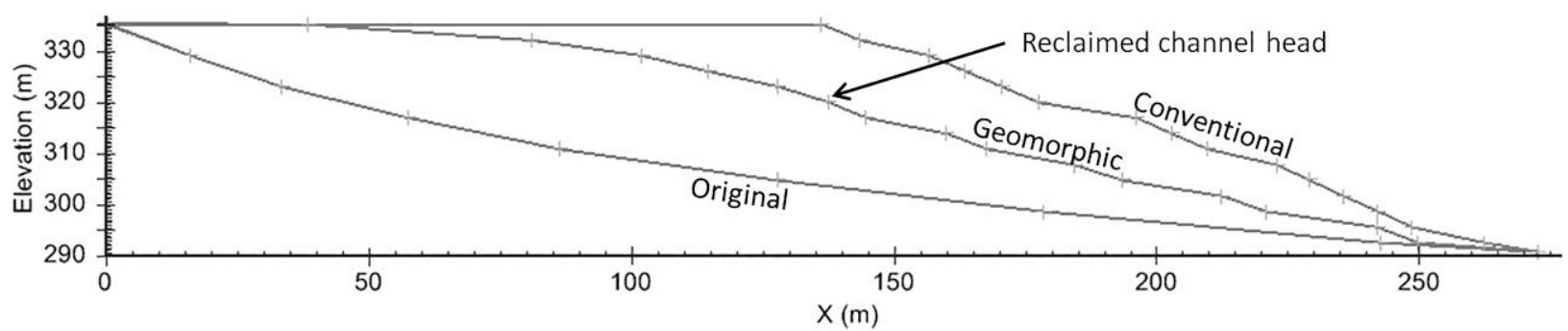

Figure 5.5. Two-dimensional profiles along centerline slice for original valley, conventional valley fill reclamation, and geomorphic design.

$\underline{\text { Boundary conditions - two-dimensional groundwater models }}$

Hydrologic data were obtained from the National Oceanic and Atmospheric Administration (NOAA) Precipitation Frequency Data Server (PFDS) and used to determine the normal flux boundary condition applied to the surface of each fill profile (Figure 5.6). The closest weather 
station to the field design site was Madison (Site ID: 46-5563) (NOAA, 2014b). Twenty years of precipitation data (1993-2012) were used to calculate an average precipitation rate of 0.0039 $\mathrm{m} / \mathrm{d}$. Published data on infiltration rates are variable and take multiple landform and hydrologic factors into consideration (e.g. Jorgensen and Gardner, 1987; Ritter and Gardner, 1993; Isabel, 1994; Meek et al., 2012; Wels et al., 2012). To simplify model conditions and because published data on infiltration into reclaimed slopes are limited, infiltration rate was defined only as a percentage of precipitation. Infiltration boundary conditions were applied uniformly over time.

For the two-dimensional model of the conventional fill, infiltration into the surface was calculated as $55 \%$ of total precipitation $(0.0022 \mathrm{~m} / \mathrm{d})$, as that percentage fell in the ranges determined by Ritter and Gardner (1993), Meek et al. (2012), and Wels et al. (2012). For the two-dimensional model of the geomorphic fill, infiltration varied by location along the slope profile. For the portion of the profile without a stream, infiltration was equal to the rate applied to the conventional fill. A range of infiltration rates (from $0 \%$ infiltration to an infiltration equal to the uncovered portion of the profile) were modeled for the portion of the profile with stream coverage, because infiltration rate for the stream bed was unknown. As $55 \%$ of precipitation infiltrating into the uncovered portion of the fill resulted in an infiltration rate of $0.0022 \mathrm{~m} / \mathrm{d}$, the material used to construct the stream bed would need to have a hydraulic conductivity low enough to prevent infiltration at that rate. According to United States Department of Agriculture (USDA) (2007), an infiltration rate below $0.0022 \mathrm{~m} / \mathrm{d}$ corresponded to a consolidated bed material with high silt-clay content. The infiltration rate for this type of bed material (0.0006 $\mathrm{m} / \mathrm{d}$ ) was closest to an infiltration rate of $10 \%$ of the total precipitation.

A review boundary condition was modeled near the toe of each fill (Figure 5.6). Due to the sharp convergence of the profile at the toe of the slope, applying a specified head at the toe pond resulted in the water table elevation being forced lower at the toe than it would in the field. Due to these convergence issues, the model was cut vertically near the toe (at a location where each fill height was approximately $3 \mathrm{~m}$ ) and a review boundary condition was applied to solve for the location at which the water table would exit. This fill height occurred at a horizontal station of $249 \mathrm{~m}$ and $242 \mathrm{~m}$ for the conventional fill and geomorphic fill, respectively. For the purposes of modeling, the flow rate coming out of the modeled face represented the drainage through the toe of the fill. 

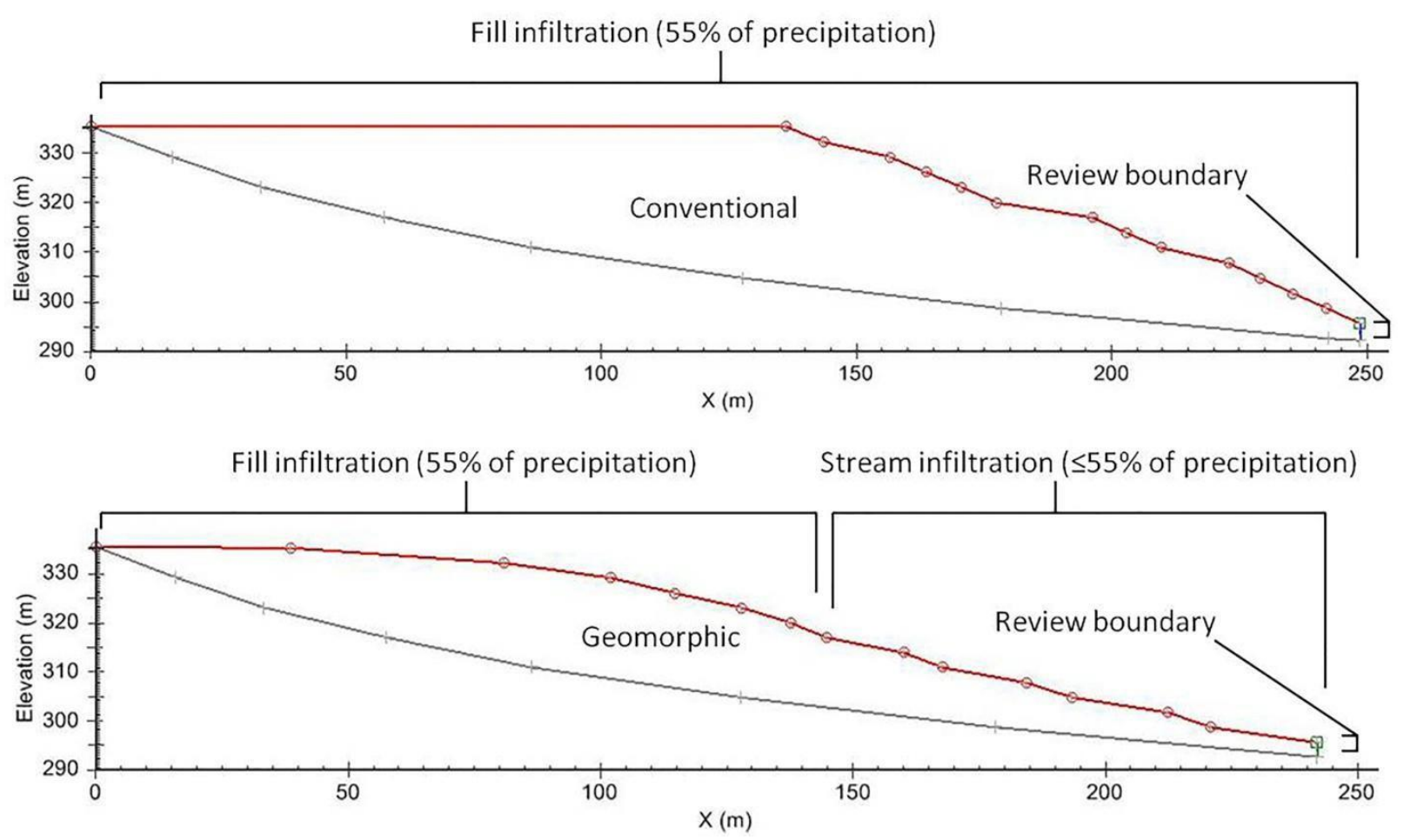

Figure 5.6. Groundwater boundary conditions applied to two-dimensional profiles of conventional and geomorphic fills.

$\underline{\text { Boundary conditions - three-dimensional groundwater models }}$

In three-dimensional models, boundary conditions varied based on slope and landform shape (Figure 5.7). For the conventional fill, infiltration into the valley fill face was calculated as 55\% of total precipitation (0.0022 m/d) (Ritter and Gardner, 1993; Meek et al., 2012; Wels et al. 2012). Infiltration into the flat crest area of the conventional valley fill was calculated as $85 \%$ of total precipitation (Sharma et al., 1983). Higher infiltration into the crest of the fill was due to flat slope. For the geomorphic fill, the 55\% infiltration rate was applied to the entire surface, as the entire geomorphic surface was sloped, and 55\% was the rate applied to the sloped portion of the conventional valley fill. In actuality, infiltration into the geomorphic fill would vary spatially with respect to slope, but a uniformly applied 55\% infiltration rate was assumed based on data limitations and model convergence issues, and to compare results to the conventional fill. A unique infiltration rate into the stream was not considered because the stream accounted for less than $2 \%$ of the total fill surface area and created mesh refinement issues. 

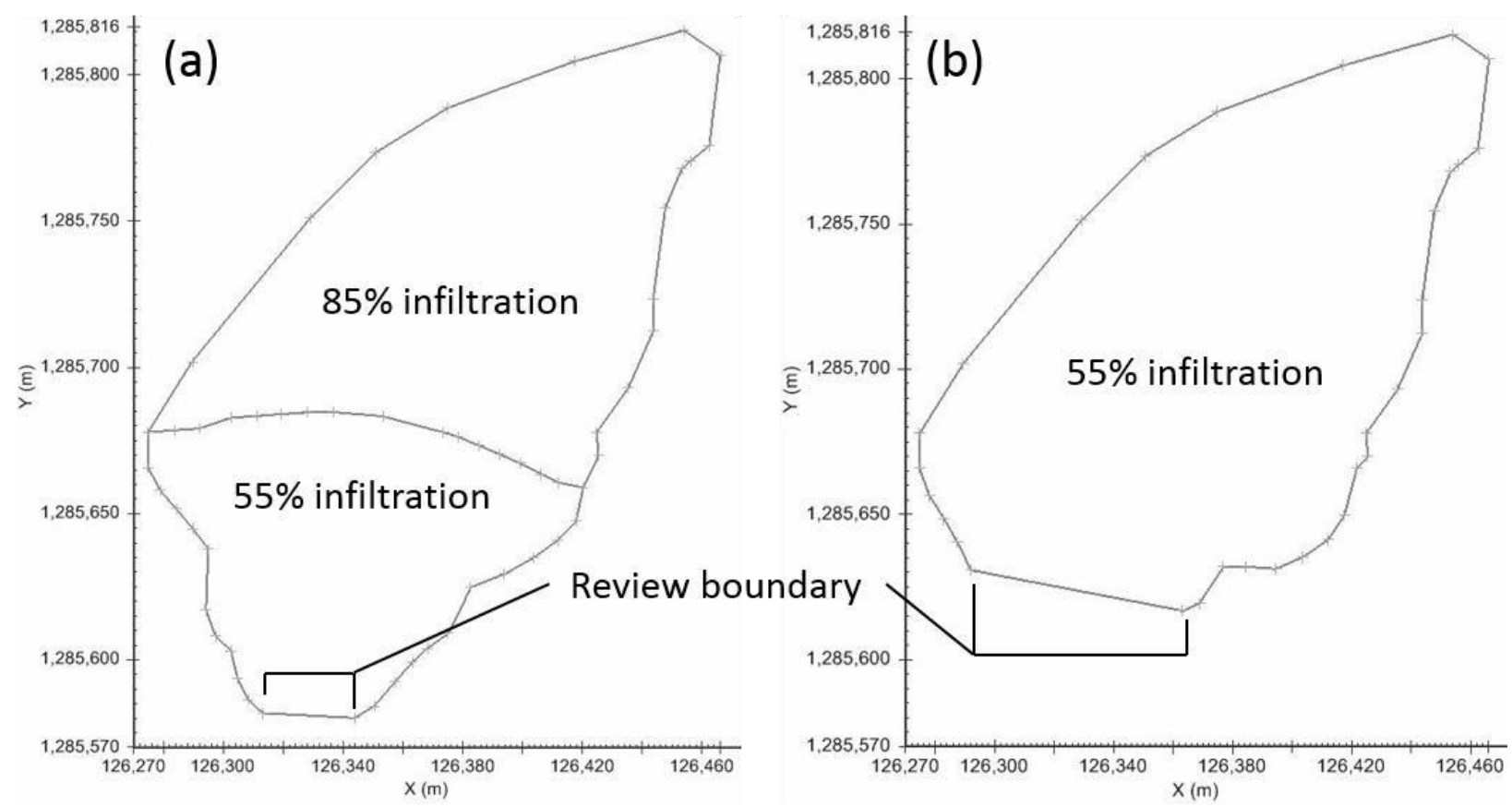

Figure 5.7. Groundwater boundary conditions applied (as shown in plan view) to threedimensional models of (a) conventional fill, and (b) geomorphic fill. Infiltration boundary conditions (as a percentage of precipitation) applied on the XY plane; review boundary conditions applied on the $\mathrm{XZ}$ plane (into page).

Similar to two-dimensional modeling, the toe of each fill was modeled as a review boundary and cut to a depth as to allow the groundwater table to not be affected by the converging fill surface at the toe. The surface areas of the cut review boundaries were $206 \mathrm{~m}^{2}$ and $207 \mathrm{~m}^{2}$ for the conventional and geomorphic fills, respectively. The geomorphic fill had to be cut at location further in from the toe than in the conventional fill due to shallower fill depths near the toe (Figure 5.7). The outer boundary of each fill was drawn in to the point that the difference in the elevation of the fill surface and original valley was approximately $3 \mathrm{~m}$; a thickness of this magnitude minimized mesh refinement issues along the model boundaries.

$\underline{\text { Two-dimensional groundwater modeling process }}$

The purpose of two-dimensional groundwater models was to confirm unsaturated seepage conditions, investigate the most appropriate soil property conditions, and investigate the effect of a reduced infiltration reclaimed stream. Models compared the conventional fill with constant infiltration to the geomorphic fill with varied stream infiltration. Particular analysis was given to the geomorphic fill with a $10 \%$ infiltration stream due to its potential application in stream bed 
design (USDA, 2007). Models were first completed in steady-state conditions (tabulated in Appendix C, Table C.4). Models considered both saturated and unsaturated conditions. Saturated soils were only used in initial models, as the flow conditions were governed by unsaturated soil property functions in the field. Fill profiles were modeled using homogeneous soils; the distribution of heterogeneous layers was unknown. Both isotropic and anisotropic soil properties were modeled. The results of the steady-state modeling considering unsaturated and isotropic conditions for each fill and infiltration case were used as the initial conditions for transient models. Transient, unsaturated conditions were modeled over ten years, considering only unsaturated, isotropic soils (tabulated in Appendix C, Table C.5). Anisotropy resulted in difficulty reaching convergence in transient models.

\section{$\underline{\text { Three-dimensional groundwater modeling process }}$}

The purpose of three-dimensional groundwater models was to investigate the effect of reduced infiltration into the entire geomorphic fill. Models compared the conventional fill with variable infiltration into the crest and face to the geomorphic fill with a constant infiltration rate applied to the entire surface. Groundwater models were first completed in steady-state conditions and were used as initial conditions for transient modeling. Transient models were run for ten years. Fill volumes were modeled using unsaturated, isotropic, homogeneous soils, as these were the most appropriate conditions with confident results from two-dimensional groundwater models.

\section{Groundwater flow path tracking}

Transient groundwater particle tracking was used to calculate the volume of fill material that had been contacted by a single pass through of water over time. A "pass through" was defined as uniformly spaced individual particles of water that infiltrated into the fill surface at the same time and flowed through the fill until discharging through the toe; one "pass through" corresponded to one infiltration event. For two-dimensional models, particle flow paths were documented for the conventional fill and for the geomorphic fill with a $10 \%$ infiltration stream. Flow paths were spaced uniformly at $10 \mathrm{~m}$ across each fill surface and tracked for the duration of the 10 year transient groundwater model in 100 time steps (36.5 days each); 36.5 days was the discretization limit for model memory capabilities. The area affected by each flow path over time was calculated as the sum of the areas affected on either side of that flow path. The area affected 
on either side of each flow path was an irregular quadrilateral that extended half the distance between the flow path of interest and the adjacent flow path (Figure 5.8).

a)

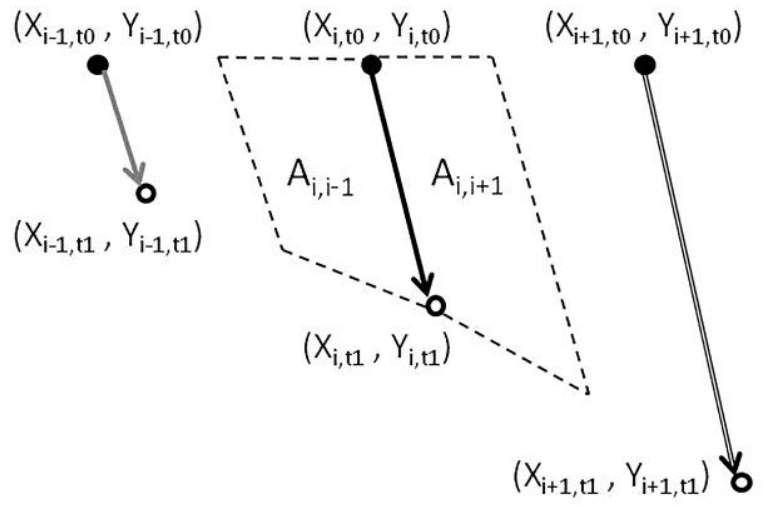

b)

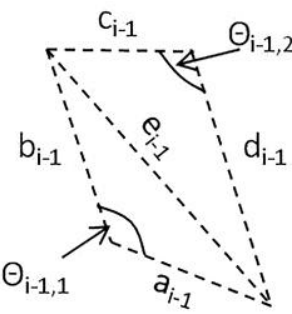

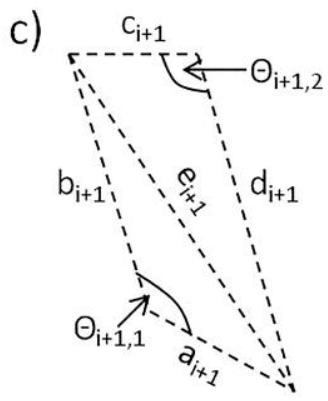

$\longrightarrow$ Flow path "i"

$\longrightarrow$ Flow path "i-1"

$\Longrightarrow$ Flow path "i+1"

- Particle location at $t_{0}$

- Particle location at $t_{1}$

Figure 5.8. Geometry of fill area affected by an individual flow path "i": a) coordinates and total area $\left(A_{i}\right)$ affected by flow path of interest with respect to adjacent flow paths; $b$ ) geometry of left portion of area affected by flow path of interest $\left(A_{i, i-1}\right)$; and, c) geometry of right portion of area affected by flow path of interest $\left(A_{i, i+1}\right)$.

Irregular quadrilateral areas were calculated according to Coolidge (1939) form of

Bretschneider's Formula (Bretschneider, 1854) (Equation 5.7).

where, 
As an example, for the specific case of the left-side area affected by an individual flow path (Figure 5.8b), the calculation was as follows:

where,

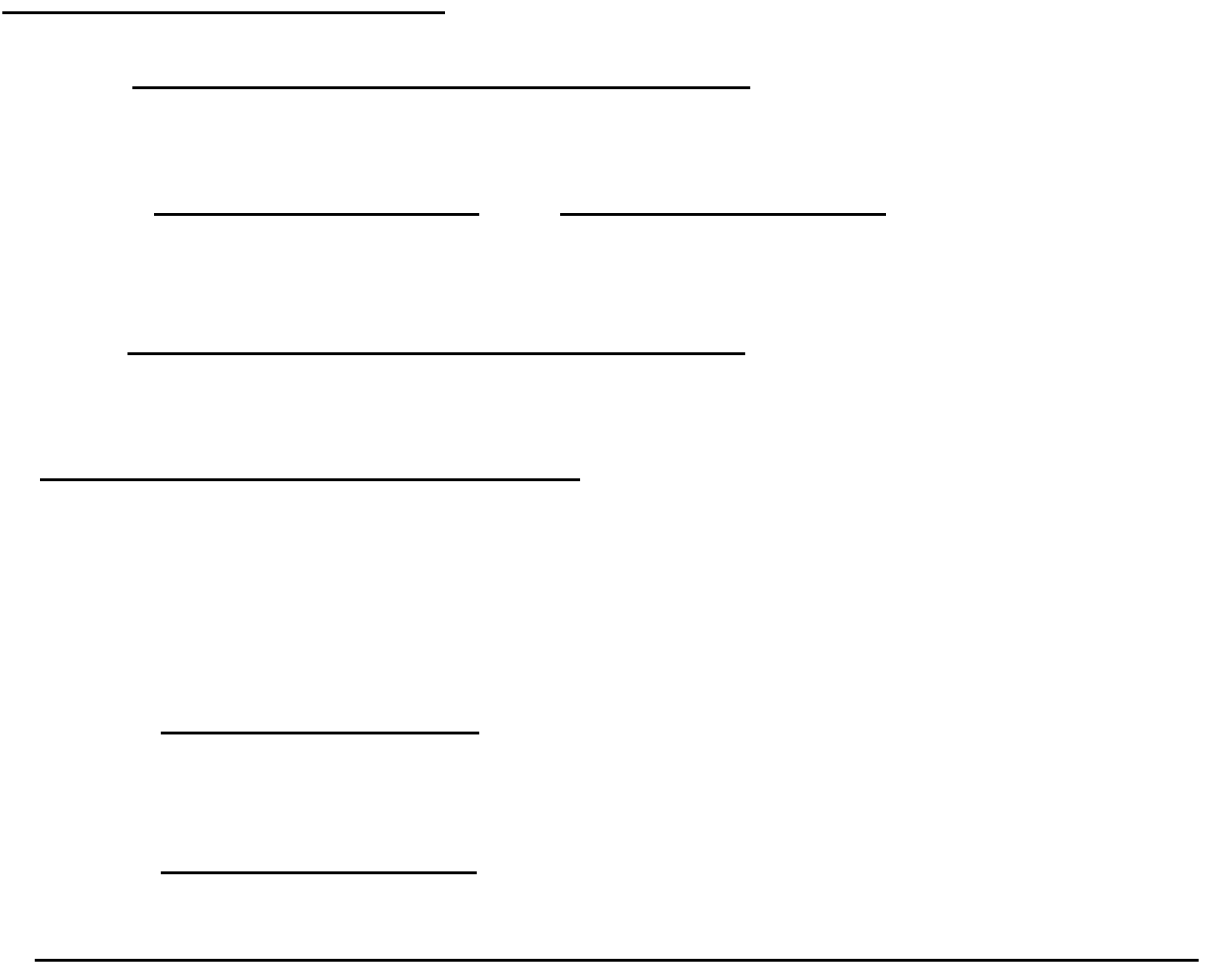

This calculation process was repeated for the right-side area affected by an individual flow path to obtain total affected area. Area calculations were completed for every flow path at every time step to document the fraction of fill area affected by each flow path over time for the duration of the two-dimensional groundwater model (Equation 5.8). Total residence time of each particle flow path was also recorded as the time needed for an individual particle to infiltrate and reach the toe of the fill. 
where,

Transient particle tracking was also documented in three-dimensional groundwater models. Particle tracking was applied to each fill surface at a uniform spacing of $15.75 \mathrm{~m} \mathrm{x} 15.75 \mathrm{~m}$ for the duration of the ten year transient model; this was the most discrete spacing possible without surpassing the memory capabilities of the computing software. Unlike in the particle tracking method used for two-dimensional models, the total area affected by each flow path was only calculated once the flow path has exited the fill. The volume affected by each individual flow path over time was not tracked because time-dependent, irregular, three-dimensional volumes were computationally demanding. Instead, a direct relationship was developed between flow path length and fill volume affected. The length of each flow path once it had exited the fill, as well as the residence time of that flow path within the fill, were recorded. For each flow path, the ratio of that flow path length to the total length of all flow paths was used to calculate the fraction of total fill volume affected by that flow path (Equation 5.9). Through this calculation, the volume of fill contacted by discharging water with a given residence time was recorded. Time steps at which fill volumes contacted by water were recorded corresponded to the consecutive times at which individual flow paths reached the toe of the fill.

where,

$\underline{\text { Normalization and comparison of groundwater results }}$

The following outputs were documented in both two-dimensional and three-dimensional groundwater models: infiltration volume, discharge rate and volume, groundwater flux rate, 
volume of water in the fill, degree of saturation, pore-water pressure, and total head. As fill alternatives were constructed with different surface areas and fill volumes, results were normalized to provide a basis from which to compare conventional and geomorphic models. Normalizing results consisted of dividing the raw groundwater results for each fill alternative by the fill property that corresponded to that groundwater property in the respective fill. Infiltration volume was normalized by fill profile length in two-dimensional models and by fill surface area in three-dimensional models. Groundwater volumes within the fill were normalized by fill volume. Groundwater discharge rates and volumes through the toe of each fill were not normalized, as they discharged through a constant height in two-dimensional models and constant cross-sectional area in three-dimensional models. Normalized results were then compared using percent change, which represented the relative change between the original value (normalized result for the conventional fill) and the new value (normalized result for the geomorphic fill) (Equation 5.10).

where,

Model calibration and stability

Because historical data on groundwater depth or discharge in small scale, steep pit floor valley fills were not available, numerical groundwater models were not calibrated to quantitative field results. The steady-state groundwater condition of each model, however, was compared to what would be expected to occur in the field; expected field conditions consisted of a deep groundwater table and small saturated thickness (Hawkins, 2004). Steady-state models that met this condition were considered to be appropriate to serve as the initial conditions of transient models. Confidence was not placed in the individual quantitative results of each individual transient model, but in the comparison (as a percentage change) in quantitative results among fill alternatives modeled under consistent material property and boundary conditions. To investigate the stability of the numerical groundwater model and determine which, if any, model conditions 
resulted in model instability, a multitude of models with varying soil properties and boundary conditions were completed. The steady-state conditions and transient groundwater relationships were compared among all models. These model conditions represented the variation in maximum (worst case) and minimum (best case) conditions to which the model would reasonably be subjected within the context of the conceptual model. The maximum condition to which the groundwater model would be subjected would be infiltration equal to $100 \%$ of precipitation, hydraulic conductivity at its minimum value, and isotropic soil. This condition would result in the highest influx to the groundwater system and the lowest flow rates through the fill. The minimum condition to which the groundwater model would be subjected would be infiltration equal to one percent of precipitation, hydraulic conductivity at its maximum value, and anisotropic soil. This condition would result in the lowest influx to the groundwater system and the highest flow rates through the fill.

\subsubsection{Selenium desorption calculation}

Desorbed mass of selenium was calculated, normalized, and compared between the conventional fill and the geomorphic fill in both two and three dimensions under transient, unsaturated, homogeneous, isotropic conditions. These groundwater models exhibited results with the most confidence and provided a stark comparison between reclamation alternatives. As the contaminant transport modeling package in SVOffice did not have the ability to model desorption of contaminants from mine rock, selenium desorption was manually calculated by coupling selenium laboratory leaching data with transient numerical groundwater modeling results through a four step process: 1) laboratory testing of unsaturated selenium desorption; 2) combining Se desorption data with two-dimensional groundwater modeling results; 3) combining Se desorption data with three-dimensional groundwater modeling results; and, 4) normalizing and comparing Se desorption results.

\section{Step 1: Laboratory testing of unsaturated selenium desorption}

Unsaturated column leaching tests were performed on recently uncovered blasted rock overburden samples from an additional surface mine site in the same county as the study site. Overburden consisted of gray sandstone, the type of blasted rock expected in the constructed valley fill. Duplicate columns were constructed in which $5 \mathrm{~kg}$ of overburden was placed. A series 
of 14 infiltrations were performed on each column with surrogate rainwater used as the permeant to match the acidity of typical Appalachian precipitation ( $\mathrm{pH} ~ 5.2)$. A 2-yr, 12-hr storm of 5.5 $\mathrm{cm}$ for Madison, West Virginia (NOAA, 2014b) was simulated; this volume of infiltration also ensured sufficient permeant was collected to perform the lab testing. A total of $1,010 \mathrm{~mL}$ was infiltrated approximately twice per week for each column. The effluent was then filtered and sent to REIC Consultants (Beaver, WV, USA) to be analyzed for selenium (SM3114B). Values less than the detection limit were recorded as half of the detection limit (USEPA, 1998).

Initial concentration of total selenium in the overburden samples was $1.26 \mathrm{mg} / \mathrm{kg}$. Thirty percent of total Se was considered mobile (Ziemkiewicz et al., 2011). For selenium, equilibrium was reached by a leached volume of 10.1 L (Figure 5.9). The percent of mobile Se that was desorbed decreased with consecutive infiltrations, with the highest percentage of mobile Se being desorbed within the first infiltrations (Table 5.2). 


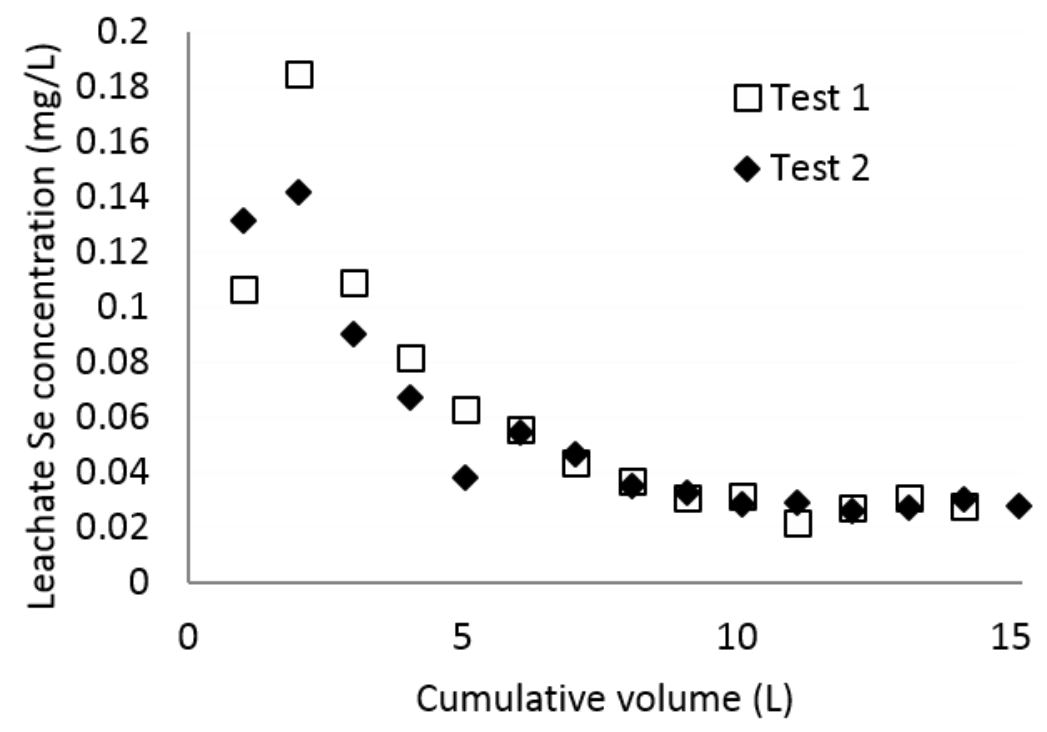

Figure 5.9. Concentration of selenium in leachate of duplicate unsaturated column tests.

Table 5.2. Percent of mobile Se desorbed from individual consecutive infiltrations through an unsaturated sandstone soil column.

\begin{tabular}{cc}
\hline Infiltration event & Percent mobile Se desorbed $(\%)$ \\
\hline 1 & 6.66 \\
2 & 7.84 \\
3 & 5.53 \\
4 & 5.32 \\
5 & 3.62 \\
6 & 1.49 \\
7 & 1.42 \\
8 & 1.35 \\
9 & 2.41 \\
10 & 2.43 \\
11 & 1.96 \\
12 & 1.94 \\
13 & 2.11 \\
14 & 1.75 \\
\hline
\end{tabular}

$\underline{\text { Step 2: Combining selenium laboratory desorption data and two-dimensional groundwater results }}$

For two-dimensional models, mass of Se desorbed from each fill alternative during and as a result of passes of water was calculated, as well as cumulatively from all 14 passes tested in the laboratory. Each laboratory infiltration event was representative of a "pass through" documented in transient groundwater modeling. The Se concentration present in the laboratory soil sample 
$(1.26 \mathrm{mg} / \mathrm{kg})$ was assumed to be distributed uniformly throughout the two-dimensional conventional and geomorphic fill models and used in conjunction with overburden density (2002 $\mathrm{kg} / \mathrm{m}^{3}$ ) (Russell et al., 2014) and percentage of Se that was mobile (30\%) (Ziemkiewicz et al., 2011) to calculate total mobile Se in the two-dimensional profile of each reclamation alternative (Table 5.3).

Table 5.3. Mass, volume, and Se properties of two-dimensional models of reclamation alternatives using column leaching lab data.

\begin{tabular}{cccc}
\hline & Total volume $\left(\mathrm{m}^{3}\right)$ & Soil mass $(\mathrm{kg})$ & Total mobile Se $(\mathrm{g})$ \\
\hline Column leaching & 0.0042 & 5 & 0.0019 \\
Conventional fill & 4725 & $9.46 \times 10^{6}$ & 2503 \\
Geomorphic fill & 3009 & $6.02 \times 10^{6}$ & 1594 \\
\hline
\end{tabular}

At each time step, the mass of Se available in the volume of fill being contacted by water (Equation 5.11) was directly proportional to the fraction of fill volume contacted (Equation 5.8). The fraction of mobile Se desorbed during each consecutive pass through (14 total) was assumed to increase linearly over time up to the fraction desorbed in the laboratory leaching study (e.g. $6.66 \%$ for the first pass through), with longer residence times resulting in a higher fraction of $\mathrm{Se}$ being desorbed (Equation 5.12). Mass of Se desorbed during each pass through was calculated based on the fraction of mobile Se desorbed during that pass through and the available Se mass (Equation 5.13). The total Se desorbed as a result of an individual pass through was calculated as the sum of Se desorbed after each time step (Equation 5.14). The total mass of available $\mathrm{Se}$ in each fill volume for the proceeding pass through was calculated as the difference between $\mathrm{Se}$ mass available before the previous pass through and the mass of Se desorbed in that pass through (Equation 5.15).

where, 
Se desorption was calculated based on residence time of individual passes of water rather than on pore volume; the ratio of volume of water to pore volume of soil was much higher in the column leaching study than in the groundwater models, making scaling from lab to model difficult. This method of calculation resulted in Se desorption as a function of number of passes of water through the fill as opposed to Se desorption over time, and assumed that an individual total pass of water took the same time to travel through each fill. Despite the limitations in this method of calculation, it was the most appropriate method with available data and modeling capabilities.

Step 3: Combining selenium laboratory desorption data and three-dimensional groundwater $\underline{\text { results }}$

For three-dimensional models, desorbed Se mass was calculated for each fill alternative as a result of all 14 infiltration events tested in the laboratory, both individually and cumulatively. Se desorption within each pass through was not calculated, as seepage particle tracking only accounted for total residence time of each flow path, not transient lengths of each flow path. The Se concentration present in the laboratory soil sample $(1.26 \mathrm{mg} / \mathrm{kg})$ was assumed to be distributed uniformly throughout the three-dimensional conventional and geomorphic fill models and used in conjunction with overburden density $\left(2,002 \mathrm{~kg} / \mathrm{m}^{3}\right)$ (Russell et al., 2014) and percentage of Se that is mobile (30\%) (Ziemkiewicz et al., 2011) to calculate total mobile Se in the three-dimensional volume of each reclamation alternative (Table 5.4). 
Table 5.4. Mass, volume, and Se properties of three-dimensional models of reclamation alternatives using column leaching lab data.

\begin{tabular}{cccc}
\hline & Total volume $\left(\mathrm{m}^{3}\right)$ & Soil mass $(\mathrm{kg})$ & Total mobile Se $(\mathrm{kg})$ \\
\hline Column leaching & 0.0042 & 5 & 0.0000019 \\
Conventional fill & 343253 & $4.81 \times 10^{8}$ & 1818 \\
Geomorphic fill & 229739 & $3.22 \times 10^{8}$ & 1212 \\
\hline
\end{tabular}

Se desorption as a result of consecutive passes of water was then calculated in the same manner as the two-dimensional calculation (Equations 5.11-5.15), using fill volume fraction as calculated by Equation 5.9 .

Step 4: Normalizing and comparing selenium desorption results

For all two-dimensional and three-dimensional models, desorbed Se as a result of each pass through of water (Equation 5.14) was normalized by the initial available Se in each fill (Table 5.3, Table 5.4) in order compare between fills (Equation 5.16). Normalized results were compared between the geomorphic and conventional fill based on percent change (Equation 5.10).

where,

\subsection{Results and discussion}

\subsubsection{Two-dimensional groundwater models}

$\underline{\text { Steady-state models }}$

Generally, two-dimensional steady-state degree of saturation was not highly variable between fill types (conventional fill: range of 27.6-34.7\%; geomorphic fill: range of 26.5-39.1\%). (Table

5.5). Maximum storage (1,417 and $902.5 \mathrm{~m}^{3}$, respectively, for conventional and geomorphic fill) was reached in each fill under saturated, steady-state conditions. For a given unsaturated modeling case, anisotropic seepage conditions allowed water to drain from the fill at a faster rate 
due to higher horizontal hydraulic conductivity. The steady-state groundwater level was lower than in anisotropic models, resulting in lower discharge rates and volumes of water within the fill. Anisotropic models for the geomorphic fill with varying stream infiltration rates required increasing minimum hydraulic conductivity one to two orders of magnitude from the initial value of $0.0147 \mathrm{~m} / \mathrm{d}$ in order to reach convergence. For this reason, while anisotropic conditions were more indicative of field conditions, a higher level of stability was present in the results of the isotropic models (Figure 5.10). Steady-state models confirmed that fills exhibit small saturated thickness $(<3 \mathrm{~m})$ and that the majority of flow is through unsaturated material due to high hydraulic conductivity of the soil and steep valley fill floors. The shape of the groundwater table surface was controlled by the shape of the existing valley.

Table 5.5. Steady-state results for conventional and geomorphic fills: volume of infiltrating water $\left(V_{i}\right)$, degree of saturation $(S)$, flow rate at toe $\left(Q_{t}\right)$, and total volume of water in fill $\left(V_{w}\right)$. Models conditions varied as follows: saturated (Sat), unsaturated (US), isotropic (I), anisotropic (A), stream infiltration rate (Infil) from $0 \%$ to $50 \%$ of total precipitation rate or equal to uncovered infiltration rate.

\begin{tabular}{|c|c|c|c|c|c|c|}
\hline Fill & Model & & $V_{i}\left(m^{3} / d\right)$ & $\mathrm{S}(\%)$ & $\mathrm{Q}_{\mathrm{t}}\left(\mathrm{m}^{3} / \mathrm{d}\right)$ & $\mathrm{V}_{\mathrm{w}}\left(\mathrm{m}^{3}\right)$ \\
\hline \multirow{9}{*}{ Conventional } & Sat_I & & 0.5947 & 100 & 0.5469 & 1417 \\
\hline & Sat A & & 0.5947 & 100 & 0.4882 & 1417 \\
\hline & US_I & & 0.5947 & 34.7 & 0.4770 & 492.0 \\
\hline & US_A & & $\underline{0.5947}$ & 27.6 & $\underline{0.5176}$ & $\underline{391.1}$ \\
\hline & Sat_I & & 0.5612 & 100 & 0.6124 & 902.5 \\
\hline & Sat_A & & 0.5612 & 100 & 0.4811 & 902.5 \\
\hline & US_I & & 0.5612 & 39.1 & 0.5112 & 353.3 \\
\hline & US_A & & 0.5612 & 28.9 & 0.4736 & 261.3 \\
\hline & US_I_Il il0 & & 0.2537 & 34.6 & 0.2556 & 312.1 \\
\hline \multirow{11}{*}{ Geomorphic } & US_I_Infil10 & & 0.3096 & 35.5 & 0.3008 & 320.3 \\
\hline & US_I_Infil20 & & 0.3655 & 36.4 & 0.3492 & 328.8 \\
\hline & US_I_Infil30 & & 0.4214 & 37.3 & 0.3487 & 336.9 \\
\hline & US_I_Infil40 & & 0.4773 & 38.1 & 0.4410 & 343.5 \\
\hline & US_I_Infil50 & & 0.5333 & 38.8 & 0.4876 & 350.5 \\
\hline & US_A_Infil0 & & 0.2537 & 26.5 & 0.2530 & 239.1 \\
\hline & US_A_Infil10 & & 0.3096 & 19.1 & 0.2521 & 172.4 \\
\hline & US_A_Infil20 & \multirow{4}{*}{98} & 0.3655 & 27.9 & 0.3343 & 252.2 \\
\hline & US_A_Infil30 & & 0.4214 & 28.2 & 0.3744 & 254.9 \\
\hline & US_A_Infil40 & & 0.4773 & 28.5 & 0.4144 & 257.6 \\
\hline & US_A_Infil50 & & $\underline{0.5333}$ & 28.8 & $\underline{0.4539}$ & 260.1 \\
\hline
\end{tabular}




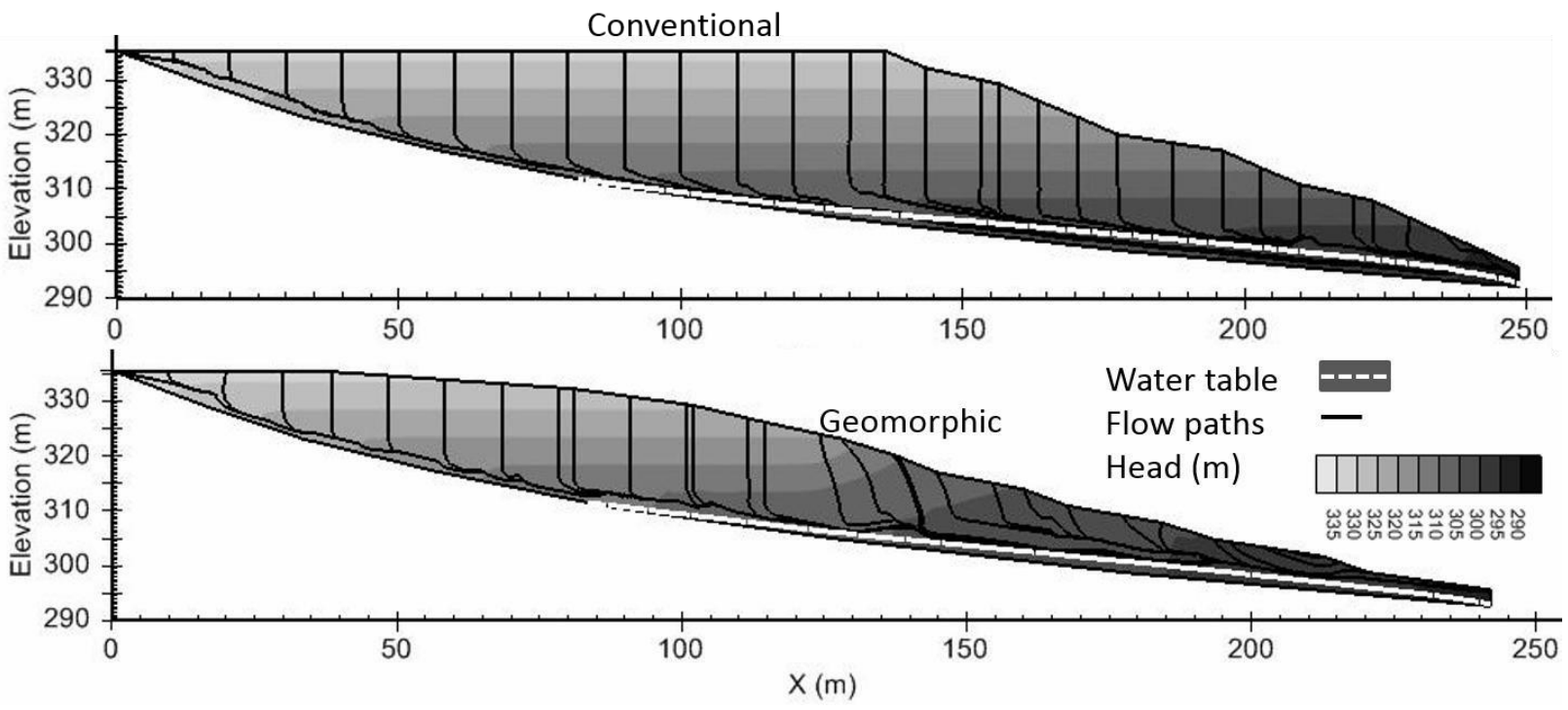

Figure 5.10. Steady-state groundwater flow paths and hydraulic head for conventional fill and geomorphic fill with $\mathbf{1 0 \%}$ stream infiltration. Both models are unsaturated, homogeneous, and isotropic.

When comparing normalized steady-state groundwater results under unsaturated, homogenous, isotropic conditions, the degree of saturation in the geomorphic fill was closest to the degree of saturation of the conventional fill if a $10 \%$ infiltration stream was established on the geomorphic fill surface (Figure 5.11). As stream infiltration rate decreased, percent reductions in infiltration volume and flow rate at the toe increased. Lower groundwater discharge rate at the toe of the fill corresponded to lower water table depth. A slight variation was present in the geomorphic fill with a $30 \%$ infiltration stream because minimum hydraulic conductivity was increased to reach model convergence. Groundwater movement was not improved when a low infiltration stream was not established on the geomorphic fill (infiltration percentage between 50\% and 55\%). 


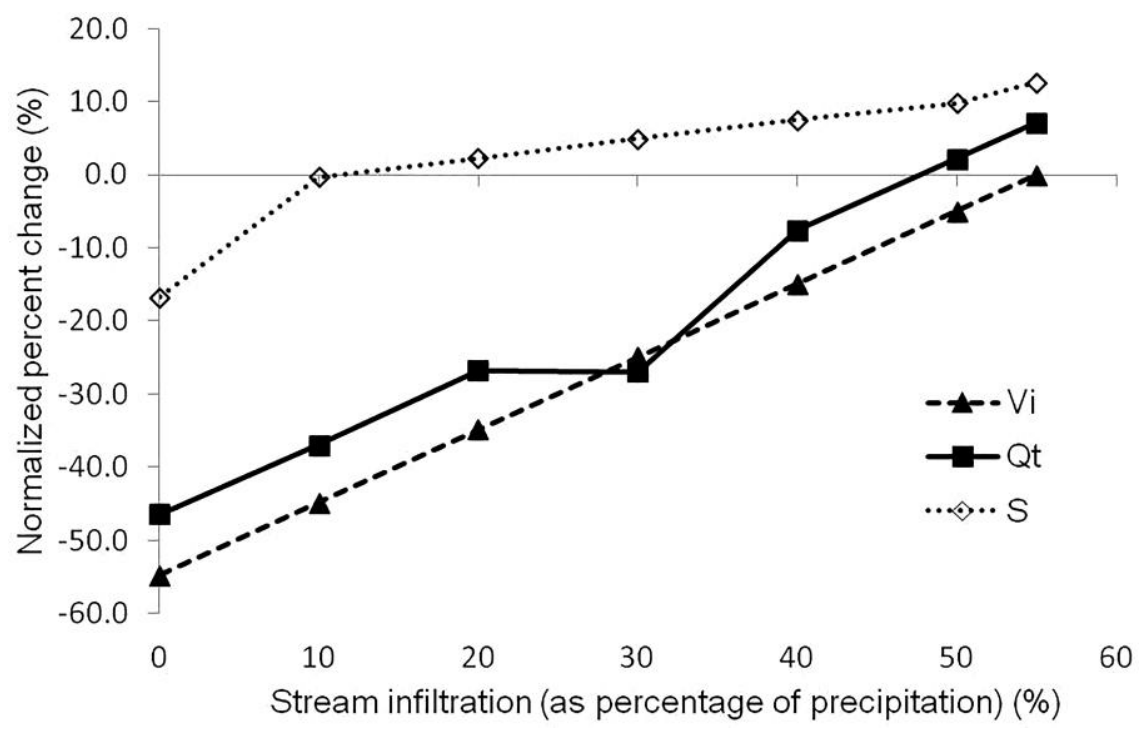

Figure 5.11. Normalized percent change of two-dimensional, steady-state groundwater results from conventional fill to geomorphic fill with stream infiltration rate varying from $0 \%$ to $55 \%$ of precipitation: volume of infiltrating water $\left(V_{i}\right)$, flow rate at toe $\left(Q_{t}\right)$, and degree of saturation $(\mathrm{S})$.

\section{$\underline{\text { Transient models }}$}

Analysis of transient groundwater models focused on the conventional fill, the geomorphic fill with no reclaimed stream, and the geomorphic fill with a stream infiltration equal to $10 \%$ of precipitation. These models were compared because of their similar steady-state conditions and the $10 \%$ stream infiltration rate corresponding to consolidated bed material (USDA, 2007). Degree of saturation was similar among the three fill alternatives; infiltration volume, discharge rate, and discharge volume were lower in geomorphic models; groundwater results were lowest for the geomorphic fill with a reduced infiltration stream (Table 5.6). A steady-state was reached for all fills between four and ten years. 
Table 5.6. Two-dimensional transient groundwater modeling results for the conventional fill and geomorphic fill with or without a stream under unsaturated isotropic conditions: volume of infiltrating water $\left(V_{i}\right)$, flow rate at toe $\left(Q_{t}\right)$, cumulative volume of water that has discharged through toe $\left(V_{0}\right)$, total volume of water in fill $\left(V_{w}\right)$, degree of saturation $(S)$, and difference in infiltration and discharge volumes $\left(V_{i}-V_{0}\right)$.

\begin{tabular}{ccccccc}
\hline Time $(\mathrm{d})$ & 0 & 5 & 180 & 365 & 1460 & 3650 \\
\hline Conventional (Infil55) & & & & & & \\
$\mathrm{V}_{\mathrm{i}}\left(\mathrm{m}^{3}\right)$ & 0 & 3.0 & 107.0 & 217.1 & 868.2 & 2170.5 \\
$\mathrm{Q}_{\mathrm{t}}\left(\mathrm{m}^{3} / \mathrm{d}\right)$ & 0.477 & 0.786 & 0.590 & 0.534 & 0.493 & 0.493 \\
$\mathrm{~V}_{\mathrm{o}}\left(\mathrm{m}^{3}\right)$ & 0 & 3.7 & 101.9 & 206.8 & 751.1 & 1830.0 \\
$\mathrm{~V}_{\mathrm{w}}\left(\mathrm{m}^{3}\right)$ & 492 & 517.2 & 505.2 & 491.4 & 486.5 & 486.5 \\
$\mathrm{~S}(\%)$ & 34.7 & 36.5 & 35.6 & 34.7 & 34.3 & 34.3 \\
$\mathrm{~V}_{\mathrm{i}}-\mathrm{V}_{\mathrm{o}}\left(\mathrm{m}^{3}\right)$ & 0 & -0.7 & 5.2 & 10.3 & 117.1 & 340.5 \\
\hline Geomorphic without stream $($ Infil55) & & & & & \\
$\mathrm{V}_{\mathrm{i}}\left(\mathrm{m}^{3}\right)$ & 0 & 2.8 & 101.0 & 204.8 & 819.4 & 2048.5 \\
$\mathrm{Q}_{\mathrm{t}}\left(\mathrm{m}^{3} / \mathrm{d}\right)$ & 0.511 & 0.506 & 0.576 & 0.479 & 0.443 & 0.443 \\
$\mathrm{~V}_{\mathrm{o}}\left(\mathrm{m}^{3}\right)$ & 0 & 2.5 & 92.9 & 189.5 & 678.1 & 1649.6 \\
$\mathrm{~V}_{\mathrm{w}}\left(\mathrm{m}^{3}\right)$ & 353.3 & 386.2 & 370.8 & 354.2 & 350.1 & 350.1 \\
$\mathrm{~S}(\%)$ & 39.1 & 42.8 & 41.1 & 39.2 & 38.8 & 38.8 \\
$\mathrm{~V}_{\mathrm{i}}-\mathrm{V}_{\mathrm{o}}\left(\mathrm{m}^{3}\right)$ & 0 & 0.3 & 8.2 & 15.4 & 141.3 & 398.9 \\
$\mathrm{~V}_{\mathrm{i}}-\mathrm{V}_{\mathrm{o}}\left(\mathrm{m}^{3}\right)$ & 0.301 & 0.303 & 0.449 & 0.344 & 0.301 & 0.301 \\
\hline $\mathrm{V}_{\mathrm{i}}\left(\mathrm{m}^{3}\right)$ & 0 & 1.4 & 66.2 & 139.8 & 474.5 & 1133.2 \\
$\mathrm{Q}_{\mathrm{t}}\left(\mathrm{m}^{3} / \mathrm{d}\right)$ & 320.3 & 357.5 & 341.9 & 324.14 & 318.9 & 318.9 \\
$\mathrm{~V}_{\mathrm{o}}\left(\mathrm{m}^{3}\right)$ & 39.6 & 37.9 & 35.9 & 35.3 & 35.3 \\
$\mathrm{~V}_{\mathrm{w}}\left(\mathrm{m}^{3}\right)$ & 0.2 & -10.5 & -26.8 & -22.5 & -3.3 \\
$\mathrm{~S}_{\text {Geomorphic with stream (Infillo) }}$ & 0 & 1.5 & 55.7 & 113.0 & 452.0 & 1130.0 \\
\hline & 0.30 .5 & & & & & \\
\hline
\end{tabular}

It was apparent from the normalized percent change in transient groundwater results that the most significant reductions in the geomorphic fills were with respect to infiltration volume and the difference between infiltration and discharge volumes, and that the geomorphic fill with a stream was more effective in exhibiting these reductions (Table 5.7, calculated from Table 5.6). Infiltration volume was only reduced if a stream was recreated (45\% reduction). The difference between infiltration and discharge volumes was reduced by over $100 \%$ for the duration of the 
geomorphic model with a stream (100-362\% reduction), but was only reduced early in the model when no stream was present. Reduction in discharge rate and volume was also greater when a reduced infiltration stream was modeled.

Table 5.7. Normalized percent change in two-dimensional groundwater modeling results from conventional fill to geomorphic fills: volume of infiltrating water $\left(V_{i}\right)$, flow rate at toe

$\left(Q_{t}\right)$, cumulative volume of water that has discharged through toe $\left(V_{o}\right)$, total volume of water in fill $\left(V_{w}\right)$, and difference in infiltration and discharge volumes $\left(V_{i}-V_{0}\right)$.

\begin{tabular}{cccccc}
\hline Time $(\mathrm{d})$ & 5 & 180 & 365 & 1460 & 3650 \\
\hline Geomorphic & without & stream (Infil55) & & \\
$\mathrm{V}_{\mathrm{i}}\left(\mathrm{m}^{3}\right)$ & 0 & 0 & 0 & 0 & 0 \\
$\mathrm{Q}_{\mathrm{t}}\left(\mathrm{m}^{3} / \mathrm{d}\right)$ & -48 & 5.6 & -12 & -18 & -19 \\
$\mathrm{~V}_{\mathrm{o}}\left(\mathrm{m}^{3}\right)$ & -50 & -13 & -7.8 & -15 & -17 \\
$\mathrm{~V}_{\mathrm{w}}\left(\mathrm{m}^{3}\right)$ & 6 & 4.2 & 1.5 & 0.15 & 0.14 \\
$\mathrm{~V}_{\mathrm{i}}-\mathrm{V}_{\mathrm{o}}\left(\mathrm{m}^{3}\right)$ & -100 & 58 & 50 & 21 & 17 \\
\hline Geomorphic & with stream $($ Infillo) & & & \\
$\mathrm{V}_{\mathrm{i}}\left(\mathrm{m}^{3}\right)$ & -45 & -45 & -45 & -45 & -45 \\
$\mathrm{Q}_{\mathrm{t}}\left(\mathrm{m}^{3} / \mathrm{d}\right)$ & -61 & -24 & -36 & -39 & -39 \\
$\mathrm{~V}_{\mathrm{o}}\left(\mathrm{m}^{3}\right)$ & -63 & -35 & -32 & -37 & -39 \\
$\mathrm{~V}_{\mathrm{w}}\left(\mathrm{m}^{3}\right)$ & 8.5 & 6.3 & 3.6 & 3.0 & 3.0 \\
$\mathrm{~V}_{\mathrm{i}}-\mathrm{V}_{\mathrm{o}}\left(\mathrm{m}^{3}\right)$ & -123 & -304 & -362 & -119 & -101 \\
\hline
\end{tabular}

The geomorphic fill with a stream was the quickest to reach a condition in which water was discharging from the fill at or higher than the rate at which water was infiltrating (Figure 5.12), resulting in the least contact with internal fill materials. Infiltration volume was only greater than discharge volume for the first month of the model; cumulative discharge volume throughout the model was as much $24 \%$ greater than infiltration volume (time $=1$ year). For the conventional fill and geomorphic fill without a stream, infiltration volume remained greater than discharge volume throughout the transient modeling period. 


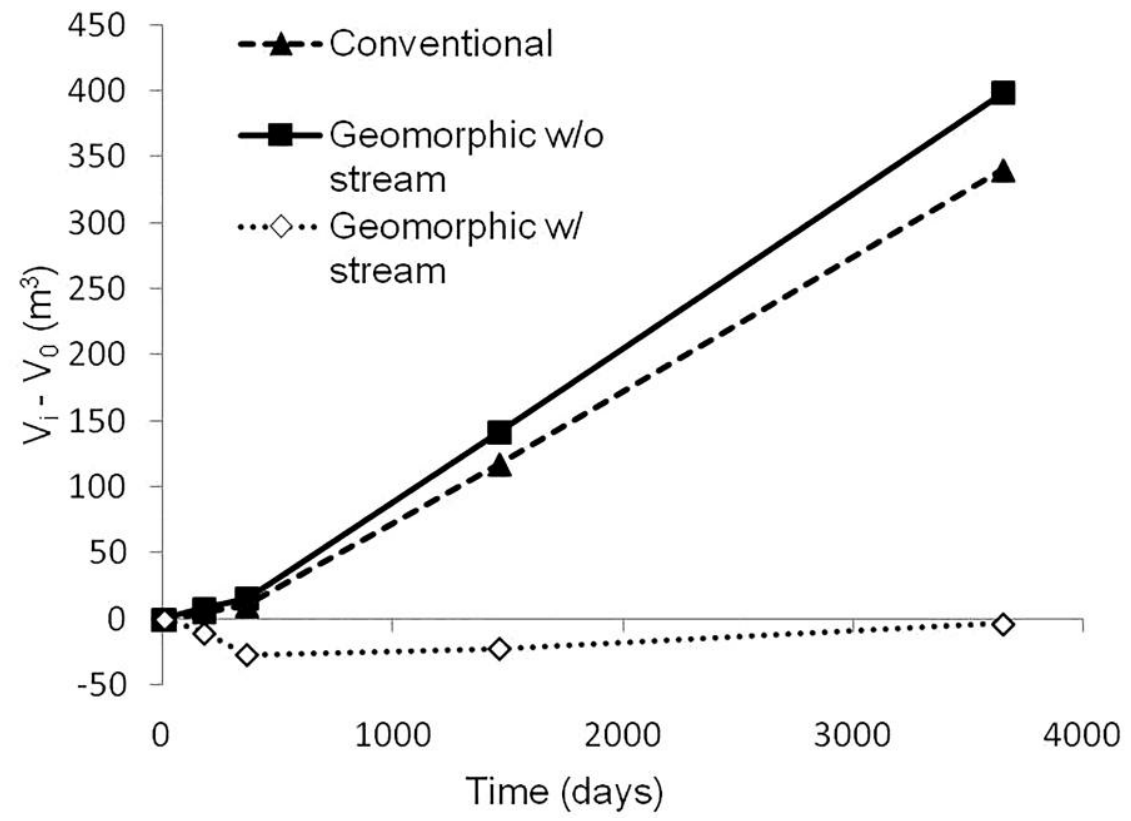

Figure 5.12. Difference in infiltration volume $\left(V_{i}\right)$ and discharge volume $\left(V_{0}\right)$ among twodimensional models of reclamation alternatives. Region above $x$-axis represents infiltration greater than discharge; region below $x$-axis represents infiltration less than discharge.

The volume of fill contacted by water over time steadily increased in the conventional fill, but exhibited a sharp increase earlier in the geomorphic fill (41.7\% increase at $\sim$ five years) (Figure 5.13). This sharp increase was because the longest flow paths (those furthest from the toe and corresponding to the largest affected fill volumes) had shorter residence times in the geomorphic fill than in the conventional fill. The flow path accounting for the largest percentage of fill volume in the geomorphic fill (41.7\%) exhibited a residence time of approximately five years, while the flow path contacting the largest percentage of fill volume in the conventional fill (25.0\%) required the duration of the model (10 years) to travel through the fill. Halfway through the transient model, two thirds of the geomorphic fill had been contacted by discharged water, but discharged water had contacted only a quarter of the conventional fill. The water that infiltrated into the upper portions of the geomorphic fill without stream coverage was able to quickly infiltrate to the bottom of the fill and exit freely without being choked off by water infiltrating into the shallower portions of the fill. Water that infiltrated into the upper portions of the conventional fill required increasingly long to discharge as distance from the toe increased. Shorter residence times could possibly be attributed to a lower geomorphic fill volume. This issue was accounted for by normalizing by the different available masses of Se in the two fills (same ratio as difference in fill volumes) after residence times were used to calculate $\mathrm{Se}$ 
desorption. Differences in fill volume contacted by water over time are tabulated and represented in Appendix C (Table C.6, Figure C.1).

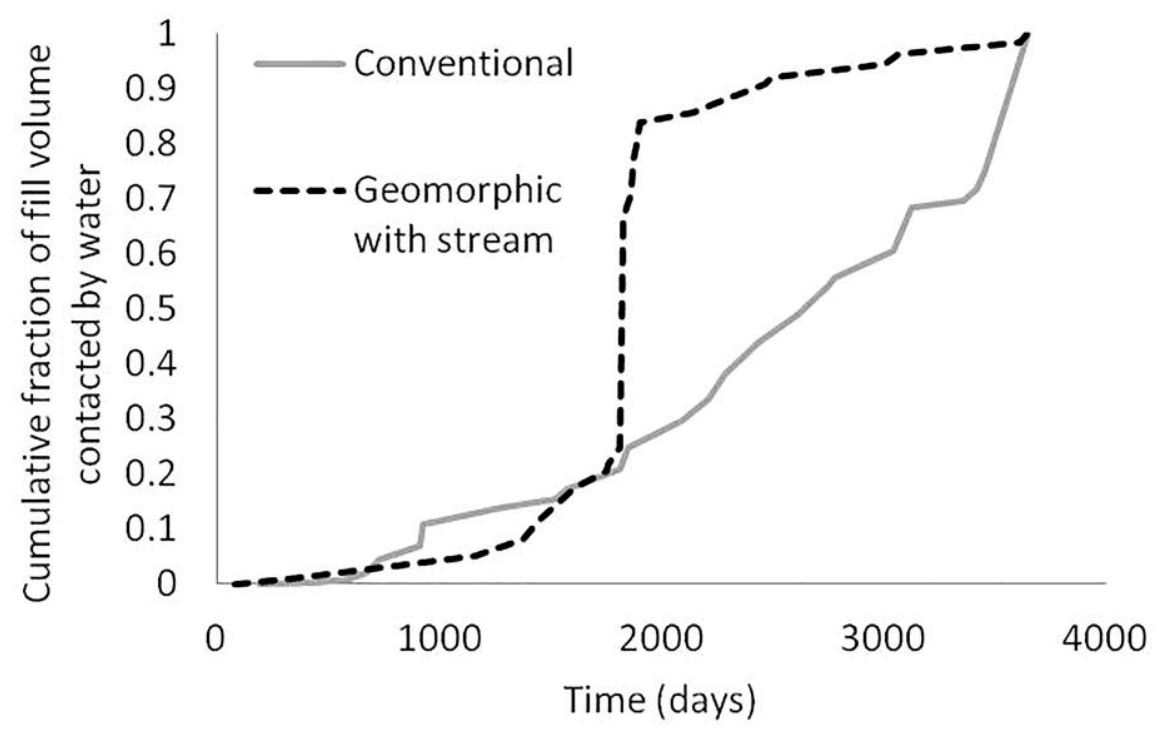

Figure 5.13. Cumulative fraction of fill volume contacted by discharging water over time in two-dimensional models of reclamation alternatives.

Constructing a stream on the surface of a geomorphic fill had a significant impact on groundwater movement. Less water infiltrated into the geomorphic fill and exhibited shorter residence times. Simply altering the two-dimensional profile to be curvilinear as opposed to planar without establishing a stream had less or insignificant impact on groundwater movement. Low infiltration capacity streams must either consist of consolidated bed material with high siltclay content (USDA, 2007) using the fine fraction of overburden or implement the use of geosynthetic materials in order to reduce infiltration.

\subsubsection{Three-dimensional groundwater models}

The steady-state, three-dimensional geomorphic groundwater model exhibited lower normalized infiltration volume than the conventional fill ( $23 \%$ reduction), lower normalized discharge rate ( $11 \%$ reduction), and comparable degree of saturation (1.7\% increase). Saturated thicknesses were small, and the majority of flow was through unsaturated blasted rock (Figure 5.14). These findings were consistent with steady-state two-dimensional groundwater results. 

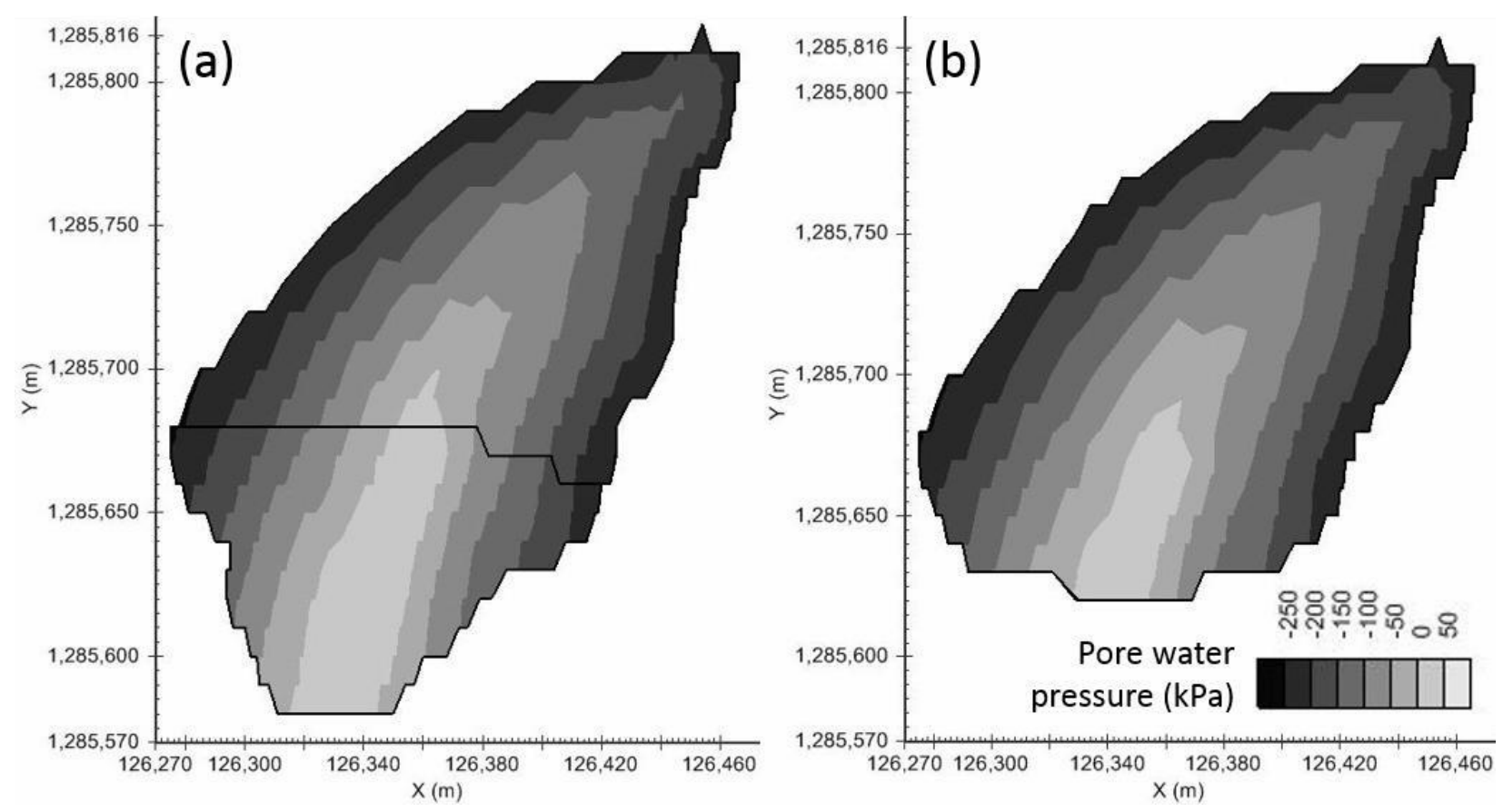

Figure 5.14. Pore pressure distribution in three-dimensional models of reclamation alternatives: (a) conventional fill; and, (b) geomorphic fill. Lightest shade in distribution corresponds to positive pore pressure (location of groundwater table).

The transient geomorphic groundwater model exhibited reductions in infiltration volume, discharge rate and volume, and difference between infiltration and discharge volumes as compared to the conventional fill (Table 5.8). The most significant reduction was in the difference between infiltration and discharge volumes. Reducing the magnitude by which infiltration volume exceeded discharge volume resulted in a condition with reduced groundwater contact time with internal fill materials. The change in groundwater results between the two fills was less dramatic than in two-dimensional modeling due to a lower magnitude reduction in infiltration volume. Two-dimensional models analyzed only the portion of fill covered by a stream, whereas three-dimensional models analyzed the geomorphic landform as a whole. 
Table 5.8. Normalized percent change in three-dimensional transient groundwater modeling results from conventional fill to geomorphic fill: volume of infiltrating water $\left(V_{i}\right)$, instantaneous flow rate at toe $\left(Q_{t}\right)$, cumulative volume of water that has discharged through toe $\left(V_{0}\right)$, total volume of water in fill $\left(V_{w}\right)$, and difference in infiltration and discharge volumes $\left(\mathbf{V}_{\mathbf{i}}-\mathbf{V}_{\mathbf{0}}\right)$.

\begin{tabular}{cccccc}
\hline Time $(\mathrm{d})$ & 5 & 180 & 365 & 1460 & 3650 \\
\hline $\mathrm{V}_{\mathrm{i}}\left(\mathrm{m}^{3}\right)$ & -23 & -23 & -23 & -23 & -23 \\
$\mathrm{Q}_{\mathrm{t}}\left(\mathrm{m}^{3} / \mathrm{d}\right)$ & -14 & -25 & -22 & -28 & -28 \\
$\mathrm{~V}_{\mathrm{o}}\left(\mathrm{m}^{3}\right)$ & -12 & -21 & -23 & -26 & -27 \\
$\mathrm{~V}_{\mathrm{w}}\left(\mathrm{m}^{3}\right)$ & -0.9 & -4.0 & -2.4 & -1.3 & -1.3 \\
$\mathrm{~V}_{\mathrm{i}}-\mathrm{V}_{\mathrm{o}}\left(\mathrm{m}^{3}\right)$ & -88 & -68 & -60 & -48 & -44 \\
\hline
\end{tabular}

Similar to two-dimensional models, the geomorphic three-dimensional model exhibited shorter residences times for groundwater that affected larger fill volumes (Figure 5.15). Groundwater contacting large fill volumes required approximately twice as long to travel through and discharge from the conventional fill. The conventional fill exhibited a consistent increase in the volume of fill contacted by discharging water over time due to the steady infiltration and discharge of groundwater flow paths; the amount of time needed for a flow path to travel through the fill and discharge through the toe steadily increased with increased distance between the infiltration point and the toe. The geomorphic fill exhibited an initial sharper increase in fill volume contacted by discharging water, followed by a shallower, steady increase. The sharp increase was due to longer flow paths associated with larger fill volumes traveling through the fill and discharging from the toe at a faster rate than the conventional fill. Differences in fill volume contacted by water over time are tabulated and represented in Appendix C (Table C.7, Figure C.2). 


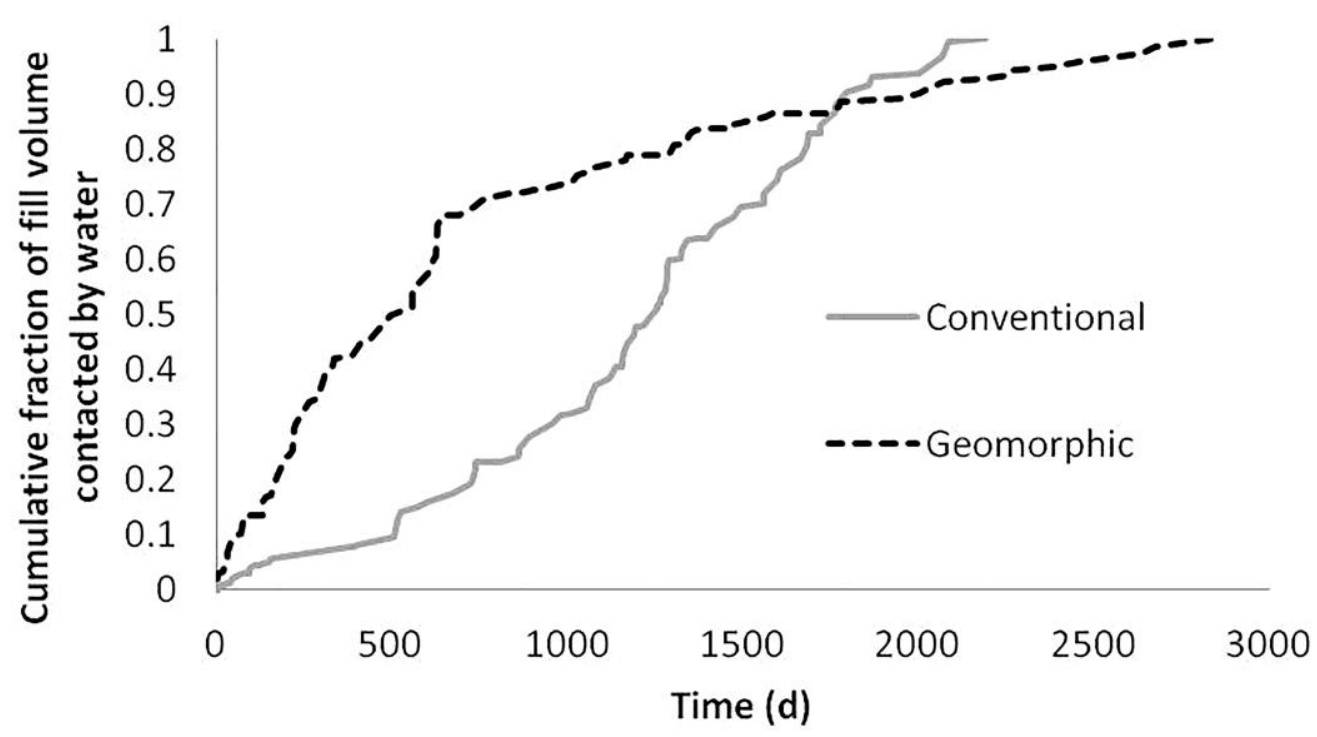

Figure 5.15. Cumulative fraction of three-dimensional fill volume contacted by discharging water over time in fill alternatives.

As in two-dimensional models, the improvement in groundwater movement can be directly attributed to reduced infiltration. In two-dimensional models, infiltration was reduced along the fill centerline through the creation of a low-infiltration capacity stream. When investigating the three-dimensional volume, however, it is apparent that infiltration must be reduced along the entire fill surface through sloped design with minimal flat, high infiltration capacity areas. Ideally, constructing slopes with geomorphic orientation will reduce infiltration volumes without having to use low permeability materials on the fill surface. Constructing variable slopes on the entire reclaimed surface generates a runoff condition similar to the face of the conventional valley fill, which occupies only a fraction of the fill surface in conventional reclamation practice. The recreated stream on the geomorphic fill must be designed not only to prevent infiltration from direct rainfall, but to prevent infiltration due to increased runoff from geomorphic landform slopes.

\subsubsection{Groundwater model calibration and stability}

Varying infiltration rate, surface profile shape, or material properties had little to no effect on steady-state groundwater conditions in the fills investigated. With the exception of fully saturated models, which are not reasonable field conditions, steady-state degree of saturation was relatively constant among all two-dimensional or three-dimensional models. Saturated thicknesses were also small $(<3 \mathrm{~m})$ in all models. Worst case conditions (maximum infiltration 
and minimum flow) resulted in increased saturated thickness $(\sim 10 \mathrm{~m})$. Best case conditions (minimum infiltration and maximum flow) resulted in very small, almost nonexistent saturated thickness. These conditions represent the extremes of groundwater flow and are not expected to occur in the field, but were still able to reach convergence quickly. In the absence of historical groundwater depth and/or discharge data, the steady-state models completed in this research were considered indicative of expected field conditions. To obtain these expected steady-state conditions and convergence in all models, groundwater model geometries of blasted rock fills with steep pit floors required a review boundary at the location of groundwater discharge and no sharp convergences along boundaries. The relationships of variation in groundwater properties over time were consistent among transient models, with the quantitative values associated with each relationship varying according to the respective material and boundary conditions. Specific conditions which caused model instability were anisotropic soils, variation in infiltration rates applied along the fill surface, and sharp geometry convergences at boundaries. Model instabilities associated with these conditions were typically related to mesh refinement.

Completing models for comparison, as opposed to for individual prediction, allowed for assumptions such as homogeneous and isotropic soils and uniform infiltration rates. While it is expected that larger particles migrate to the bottom of blasted rock fills (either through suffusion or by gravity), the effect of heterogeneity cannot be analyzed until layering data become available. Data on infiltration into reclaimed soils are lacking, but uniform infiltration rates are appropriate in comparative models. Overall, the modeling results of this research provided a valid comparison of groundwater and selenium desorption in reclamation alternatives based on the software used, available software capabilities, available soil property data, and assumptions made. To obtain accurate predictive groundwater results in future studies, individual models must be calibrated based on either historical groundwater depth or discharge.

\subsubsection{Selenium desorption}

$\underline{\text { Two-dimensional calculation for desorbed Se mass }}$

In two-dimensional analysis, the geomorphic fill with a $10 \%$ infiltration stream exhibited reduced selenium desorption compared to the conventional fill (Table 5.9). The highest desorption of Se occurred within the first five passes of water and decreased steadily throughout 
consecutive passes. During individual passes of water, Se desorption in the geomorphic fill initially increased more sharply than in the conventional fill, but ended at a lower peak (Figure 5.16). The relationship of Se desorption over time was similar for each pass through of water through each fill, with a generally decreasing peak Se desorption. Higher desorption of Se in the laboratory corresponded to a more significant difference in Se desorption between fill alternatives. When the laboratory desorption of Se was highest (in the first few passes), the shorter residence times in the geomorphic groundwater model had a greater effect on the percentage of Se desorbed. The percentage of mobile Se desorbed in the lab reduced from $6.7 \%$ after the first pass through to $1.8 \%$ after the final pass through (Table 5.2), and the percent reduction in Se desorption in the geomorphic fill compared to the conventional fill decreased from $27 \%$ to $18 \%$. After all passes of water, however, the cumulative reduction in Se desorption only decreased from $27 \%$ to $23 \%$ (Table 5.9).

Table 5.9. Percent change in normalized selenium desorption in two-dimensional model of geomorphic fill with stream compared to conventional fill as a result of consecutive passes of water, both individually and cumulatively.

\begin{tabular}{ccccc}
\hline \multirow{2}{*}{$\begin{array}{c}\text { Pass } \\
\text { through }\end{array}$} & \multicolumn{2}{c}{ Normalized desorbed Se } & \multicolumn{2}{c}{ Percent change $(\%)$} \\
\cline { 2 - 5 } & Conventional & Geomorphic with stream & Individual & Cumulative \\
\hline 1 & 0.04748 & 0.03484 & -26.6 & -26.6 \\
2 & 0.05290 & 0.03948 & -25.4 & -26.0 \\
3 & 0.03497 & 0.02663 & -23.9 & -25.4 \\
4 & 0.03216 & 0.02483 & -22.8 & -24.9 \\
5 & 0.02096 & 0.01639 & -21.8 & -24.6 \\
6 & 0.00838 & 0.00661 & -21.1 & -24.4 \\
7 & 0.00789 & 0.00625 & -20.8 & -24.3 \\
8 & 0.00742 & 0.00589 & -20.6 & -24.2 \\
9 & 0.01310 & 0.01044 & -20.3 & -23.9 \\
10 & 0.01296 & 0.01039 & -19.8 & -23.7 \\
11 & 0.01026 & 0.00827 & -19.4 & -23.5 \\
12 & 0.00999 & 0.00810 & -19.0 & -23.4 \\
13 & 0.01070 & 0.00871 & -18.6 & -23.2 \\
14 & 0.00873 & 0.00714 & -18.2 & -23.0 \\
\hline
\end{tabular}




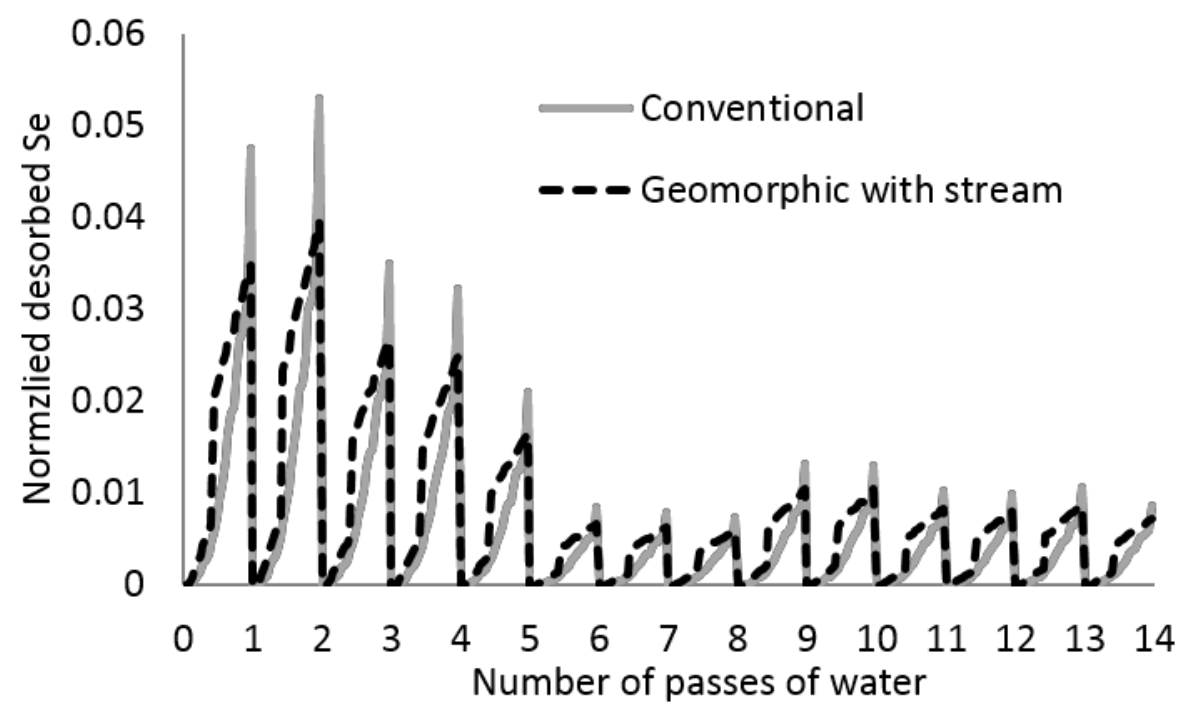

Figure 5.16. Normalized desorption of selenium from individual passes of water assuming passes occur in succession in two-dimensional models of reclamation alternatives.

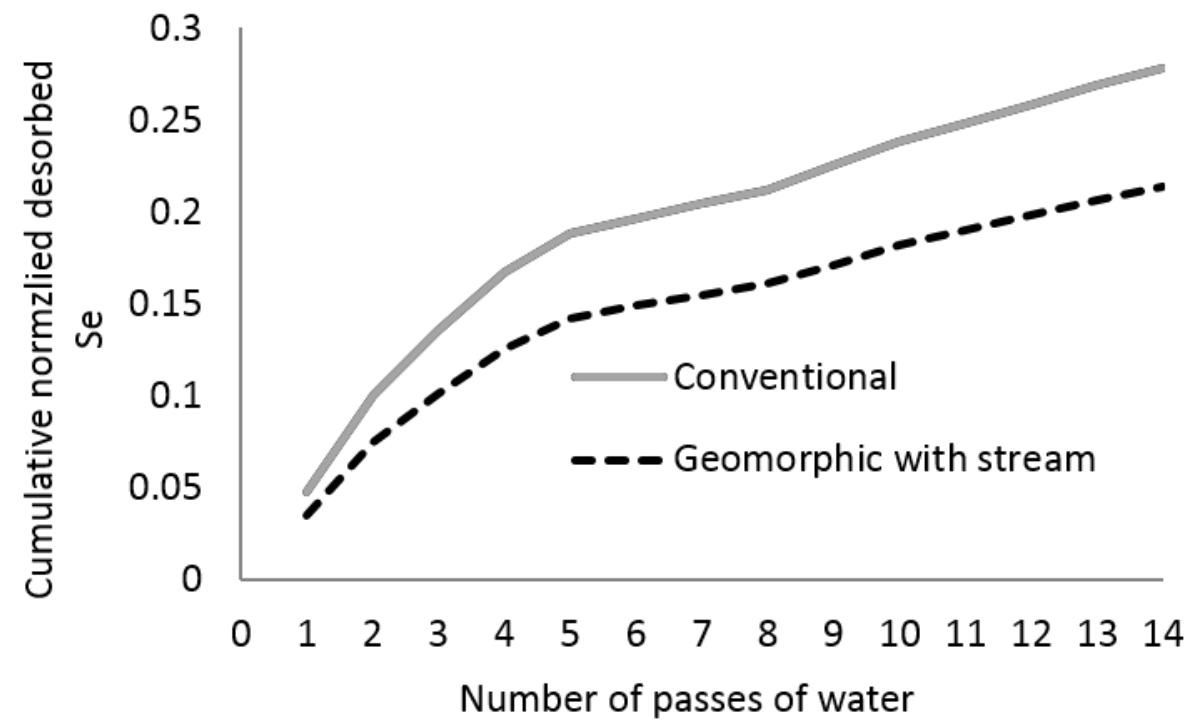

Figure 5.17. Cumulative normalized desorbed selenium from consecutive passes of water in two-dimensional models.

The reduction in Se desorption can be attributed to improved groundwater movement through the geomorphic fill, both in reduced volume and reduced residence time. For reclamation design, a geomorphic fill was effective in reducing Se desorption through physical means by the creation of a low infiltration capacity stream. Decrease in infiltration volume reduced the amount of water that came in contact with internal fill materials. Additionally, infiltrating water that affected large 
volumes of fill resided within the fill for shorter periods of time, resulting in a lower percentage of Se being desorbed from the fill material.

The critical locations with respect to Se desorption appeared to be fill volumes furthest from the toe and closest to the valley bottom. The water contacting these fill volumes required the longest time to travel through and discharge from the fill, resulting in the highest Se desorption. While the geomorphic fill was more effective in reducing the groundwater residence times associated with these large fill volumes, care should be taken not to place overburden with high concentration of Se or other contaminants in these areas of the fill.

\section{$\underline{\text { Three-dimensional calculation for desorbed Se mass }}$}

Desorption of Se based on three-dimensional groundwater models followed a similar trend as two-dimensional models (Table 5.10) (Figure 5.18) (Figure 5.19). Se desorption was reduced in the geomorphic fill, and the highest desorption of Se occurred in the first few passes of water. A slight increase in Se desorption occurred after the ninth pass through, and was attributed to the slight increase in Se desorption in the laboratory study. In general, Se desorbed from reclamation alternatives decreased in correspondence with decreased Se desorption rates in the laboratory study. Despite a less significant reduction in infiltration volume, the reduction in Se desorption in the geomorphic fill was more significant than in two-dimensional models and remained constant throughout consecutive passes. The higher and constant reduction in Se desorption was attributed to the larger volumes analyzed in three dimensions; each two-dimensional profile accounted for less than $2 \%$ of its total respective fill volume. Also, the calculation for fill volume affected by each flow path was less refined than in the two-dimensional calculation. The three-dimensional calculation did not take into account that the area affected by each flow path changed over time, and that multiple flow paths eventually became common flow paths, both of which could have resulted in a more significant reduction in Se desorption for the geomorphic fill. 
Table 5.10. Percent change in normalized selenium desorption in three-dimensional model of geomorphic fill compared to conventional fill as a result of consecutive passes of water, both individually and cumulatively.

\begin{tabular}{ccccc}
\hline \multirow{2}{*}{$\begin{array}{c}\text { Pass } \\
\text { through }\end{array}$} & \multicolumn{2}{c}{ Normalized desorbed Se } & \multicolumn{2}{c}{ Percent change (\%) } \\
\hline 1 & 0.02190 & 0.01344 & -38.6 & -38.6 \\
2 & 0.02520 & 0.01546 & -38.7 & -38.6 \\
3 & 0.01717 & 0.01053 & -38.7 & -38.6 \\
4 & 0.01616 & 0.00991 & -38.7 & -38.7 \\
5 & 0.01077 & 0.00660 & -38.7 & -38.7 \\
6 & 0.00437 & 0.00268 & -38.7 & -38.7 \\
7 & 0.00414 & 0.00254 & -38.7 & -38.7 \\
8 & 0.00392 & 0.00240 & -38.7 & -38.7 \\
9 & 0.00695 & 0.00426 & -38.7 & -38.7 \\
10 & 0.00695 & 0.00426 & -38.7 & -38.7 \\
11 & 0.00555 & 0.00340 & -38.7 & -38.7 \\
12 & 0.00545 & 0.00334 & -38.7 & -38.7 \\
13 & 0.00589 & 0.00361 & -38.6 & -38.7 \\
14 & 0.00484 & 0.00297 & -38.6 & -38.7 \\
\hline
\end{tabular}

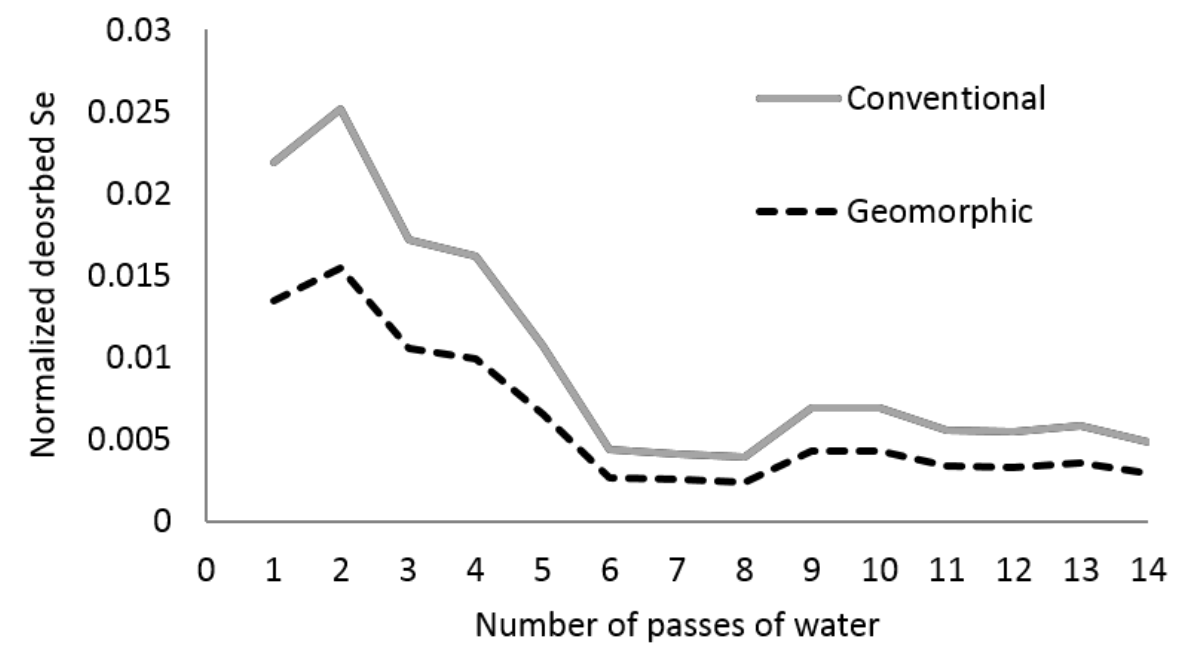

Figure 5.18. Normalized desorption of selenium from individual passes of water assuming passes occur in succession in three-dimensional models of reclamation alternatives. 


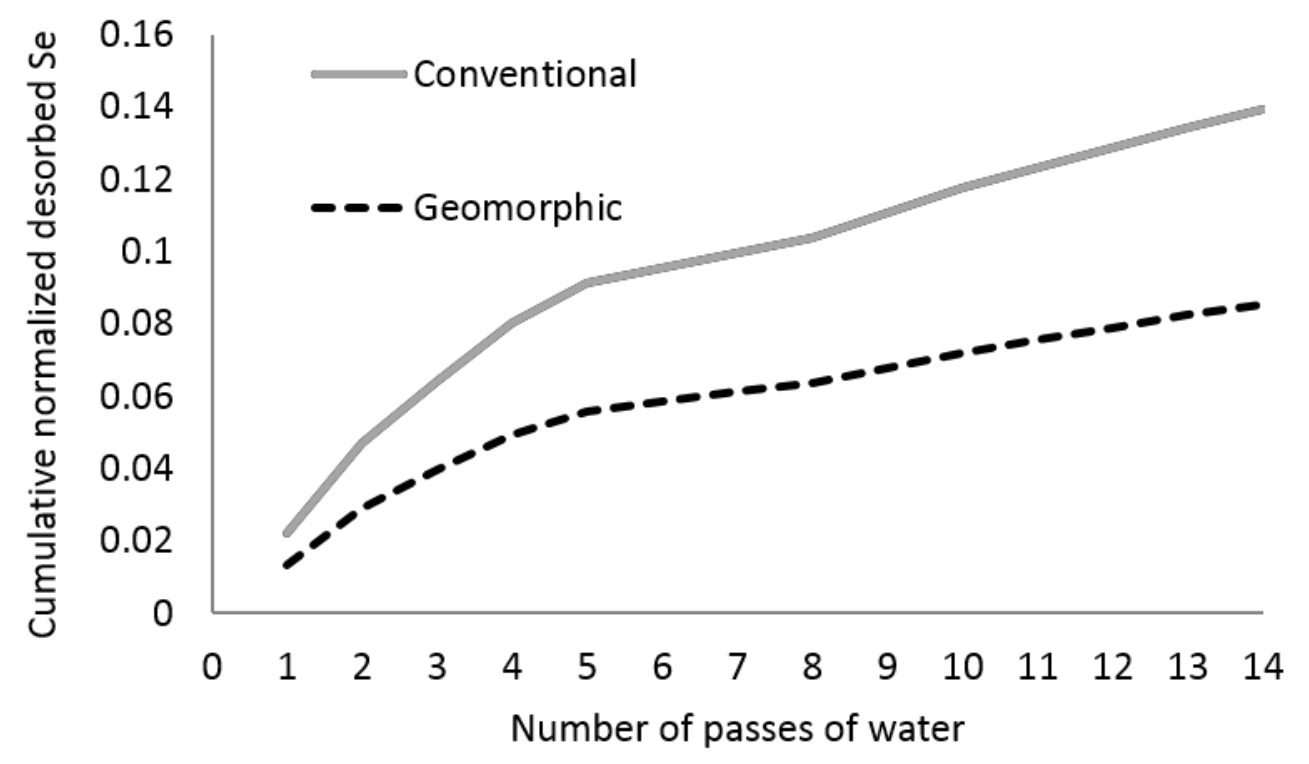

Figure 5.19. Cumulative normalized desorbed selenium from consecutive passes of water in three-dimensional models or reclamation alternatives.

Similar to two-dimensional analysis, the reduction in Se desorption for the geomorphic fill in three-dimensional analysis can be directly attributed to two characteristics of geomorphic reclamation apparent from groundwater modeling: decreased infiltration and decreased groundwater residence time. Decreased infiltration and groundwater residence times were possible through the application of geomorphic slopes to the entire fill surface and minimal construction of shallow sloping, high infiltration areas.

\subsection{Conclusions and recommendations}

The objective of this research was to compare groundwater movement and selenium transport in conventional and geomorphic reclamation alternatives for a southern West Virginia surface mine, and investigate if groundwater and selenium desorption could be improved through physical means. Two-dimensional and three-dimensional groundwater modeling of reclamation alternatives was completed using a finite element method tool. Selenium desorption was calculated manually by coupling groundwater modeling results with laboratory leaching test data. Two-dimensional modeling investigated the effect of a reclaimed stream on a geomorphic fill, while three-dimensional modeling investigated reduced infiltration into the entire geomorphic fill surface. Geomorphic landforms were superior to conventional valley fills 
through decreased infiltration and discharge volumes, water residence time, and desorption of selenium. The following conclusions were made from this research:

- Unsaturated soil property functions are vital in modeling seepage through blasted rock fills and can be developed through laboratory soil testing data and empirically developed equations. Saturated volumetric water content of $30 \%$ and saturated hydraulic conductivity of $1.47 \mathrm{~m} / \mathrm{d}$ both reduce sharply when unsaturated soil conditions govern groundwater flow.

- For two-dimensional, steady-state groundwater models, the degree of saturation in the geomorphic fill was closest to the degree of saturation of the conventional fill if a $10 \%$ infiltration stream was established on the geomorphic fill surface. As stream infiltration rate decreased, percent reduction in infiltration volume and flow rate at the toe increased. Groundwater movement was not improved when a low infiltration stream was not established on the geomorphic fill. Steady-state models confirmed that fills exhibit small saturated thickness $(<3 \mathrm{~m})$ and that the majority of flow is through unsaturated material due to high hydraulic conductivity of the soil and steep valley fill floors.

- In two-dimensional, transient groundwater models, infiltration volume, discharge rate, and discharge volume were lower in geomorphic models by $45 \%, 39-61 \%$, and $39-63 \%$, respectively; the geomorphic fill with a reduced infiltration stream was the most effective in exhibiting these reductions. The geomorphic fill with a stream was also the quickest to reach a condition in which water was discharging from the fill at or higher than the rate at which water was infiltrating (up to $24 \%$ higher discharge than infiltration), resulting in the least contact with internal fill materials. The longest flow paths (those furthest from the toe and corresponding to the largest affected fill volumes) had shorter residence times in the geomorphic fill (42\% of fill volume contacted within $\sim 5$ years) than in the conventional fill ( $25 \%$ of fill volume contacted within $\sim 10$ years).

- When analyzing fill alternatives in two dimensions, groundwater movement can be improved through physical means if infiltration is reduced. Along centerline profiles of reclamation alternatives, infiltration must be reduced through the design of low infiltration capacity soils on the fill surface, particularly for the bed material of the reclaimed stream. 
- The three-dimensional transient geomorphic groundwater model exhibited reductions in infiltration volume, discharge rate, discharge volume, and difference between infiltration and discharge volumes of $23 \%, 12-27 \%, 14-28 \%$, and 44-88\%, respectively, as compared to the conventional fill. Reducing the difference between infiltration and discharge volumes minimized water contact with internal fill materials. Groundwater contacting large fill volumes required approximately twice as long to travel through and discharge from the conventional fill as compared to the geomorphic fill. Improvement in groundwater movement can be directly attributed to reduced infiltration through curvilinear surface design and minimal flat, high infiltration capacity areas. The recreated stream on the geomorphic fill must be designed not only to prevent infiltration from direct rainfall, but to prevent infiltration from increased runoff off of geomorphic landform slopes.

- Geomorphic fills exhibited lower selenium desorption than conventional fills (23-27\% reduction in two-dimensional models, 39\% reduction in three-dimensional models). Reduction in Se desorption for the geomorphic fill can be directly attributed to two characteristics of geomorphic reclamation apparent from groundwater modeling: decreased infiltration and decreased water residence time. Reduced groundwater quantity and contact time with high Se concentration blasted rock was key in reducing Se loads in discharging groundwater. Desorption based on laboratory leaching studies is highest during initial infiltration events.

- The critical locations for Se desorption appeared to be fill volumes furthest from the toe and closest to the valley bottom. The water contacting these fill volumes required the longest time to travel through and discharge from the fill, resulting in the highest Se desorption. Care should be taken not to place overburden with high concentration of Se or other contaminants in these areas of the fill.

The quantified benefits of geomorphic reclamation developed in this study can be used by regulatory and decision-making agencies to inform the next step of application of geomorphic reclamation in central Appalachia. Future studies should further investigate the leaching of Se from unsaturated soils over a longer time period and in water-soil ratios more similar to those seen in the field. A pilot construction and monitoring project should be completed to confirm the 
conceptual findings with respect to infiltration, groundwater movement, and contaminant loading, to calibrate future groundwater models, and to investigate geomorphic slope and channel design. The method developed for manual calculation of contaminant desorption based on laboratory data should be incorporated into a tool that can be used in direct conjunction with finite element numerical groundwater models. 


\section{CHAPTER 6. CONCLUSIONS}

This work evaluated the potential of applying geomorphic landform design (GLD) principles to valley fill reclamation in central Appalachia through three major objectives: 1) defined the geomorphic characteristics off mature reference landforms in southern West Virginia;2) quantified the issues associated with implementing geomorphic reclamation on the scale of an individual valley fill; and, 3) compared groundwater movement and desorption of selenium in reclamation alternatives for a southern WV surface mine to quantify potential benefits of geomorphic reclamation. The findings of this research will be used to provide recommendations on the practicality of implementing geomorphic reclamation as an alternative to conventional valley fill reclamation in central Appalachia.

\subsection{Objective 1: Quantify characteristics of mature landforms in central Appalachia}

The goal of this portion of research was to define the geomorphic properties of mature reference landforms in central Appalachia, so that these properties could be used to complete geomorphic designs and inform future geomorphic reclamation in central Appalachia. Criteria for selection of field sites for collection of geomorphic data were developed. Field characteristics of reference landforms were measured in three watersheds. Critical design parameters (drainage density and drainage length) were quantified for these locations. Additional channel and landform characteristics were measured: bed slope, bed material grain size, width, hillslope, vegetation, and aspect. The variability of channel and landform characteristics was recorded to inform design and evaluation of the geomorphic valley fills. Results confirmed that geomorphic properties of landforms vary regionally and that a sufficient amount of field work is necessary to accurately define the geomorphic properties of mature landforms in central Appalachia. Surveying headwater stream locations provided a more accurate value for drainage density than if only available National Hydrography Dataset (NHD) data were used. Surveying headwater channels was necessary, as they are the channels typically buried in conventional valley fill reclamation. For all channel head locations and erosion sites, the majority of bed material was sand and gravel. Mature landforms exhibited steep hillslopes, variable aspect, and vegetation consisting of dense core forest. Geomorphic landform design principles will attempt to replicate 
these features more effectively than does conventional reclamation. Investigation of long-term reclaimed sites confirmed that conventional valley fills were not in erosive equilibrium.

\subsection{Objective 2: Quantify the issues associated with implementing geomorphic reclamation in central Appalachia}

The goal of this portion of research was to quantify potential issues associated with implementing geomorphic reclamation in central Appalachia on the scale of a small valley fill. Using reference design parameters, a series of alternative valley fill designs were completed, considering two permitted valley fills. The designs were analyzed with respect to fill volume, channel stability, and landform stability. The following conditions were investigated: 1) varying drainage density; 2) maximizing channel stability; 3) maximizing fill volume and hillslope stability; 4) compromise of stability and fill volume; 5) expanded impact area; and, 6) using default design criteria. Geomorphic designs confirmed that the issues associated with the steep slope topography, stability, and stream recreation are valid, especially if minimizing the area of impact is a priority. Fill volume decreased with increasing drainage density. The existing stream of the pre-mined topography could not be preserved through geomorphic reclamation due to unstable constructed slopes around the channel, but a geomorphic reclamation could mitigate the burial of the existing channel by creating a stable channel at a higher elevation. When the area of impact of the conventional reclamation was maintained, a geomorphic design for the locations studied could not simultaneously meet the requirements of channel stability, landform stability, and fill volume. Expanding the area of impact of the fill allowed a geomorphic design to better satisfy all three criteria for a successful design, but did not comply with regulations in central Appalachia for the placement of fill and maximum grade of constructed hillslopes. It is expected that a potentially successful design would require an expanded area of impact. While another valley fill may be slightly more or less successful in meeting the design analysis criteria in this study, overall results of this study are not expected to change if other individual, small scale valley fills were investigated. Benefits of geomorphic designs were increased variability in slope and aspect and newly generated stream length. These benefits may result in improved habitat and biodiversity, decreased erosion, and improved management of surface water, groundwater, reduced loads from mine spoil contaminants. 


\subsection{Objective 3: Compare groundwater movement and selenium desorption in geomorphic and conventional valley fill alternatives}

The goal of this portion of research was to compare groundwater movement and selenium desorption in conventional and geomorphic reclamation alternatives for a southern West Virginia surface mine to quantify any benefits to using geomorphic landform design as an alternative to conventional surface mine reclamation. Groundwater movement in reclamation alternatives was analyzed with finite element geotechnical modeling software. A landform designed using geomorphic design principles was compared to a conventional valley fill for the same area. Soil properties and hydrologic inputs were compiled from the surface mine permit file, laboratory soil testing, and additional modeling literature. Unsaturated soil property functions (soil-water characteristic curve and hydraulic conductivity function) were developed from soil testing data and literature. Models assumed homogenous and isotropic soils and uniform infiltration rates. Groundwater models were compared in two-dimensional profiles and three-dimensional landforms. Steady-state models confirmed that the majority of groundwater flow in valley fills is through unsaturated media. Geomorphic landforms were superior to conventional valley fills through decreased infiltration and water residence time. When investigating entire reclaimed landforms, it is apparent that infiltration must be reduced along the entire fill surface through sloped design with minimal flat, high infiltration capacity areas. The recreated stream on the geomorphic fill must be designed not only to prevent infiltration from direct rainfall, but to prevent infiltration due to increased runoff off from geomorphic landform slopes.

Desorbed mass of selenium was compared by coupling groundwater modeling results with laboratory selenium leaching data. Groundwater residence times and fill volumes contacted by water over time were documented from two-dimensional and three-dimensional groundwater modeling. The percentage of mobile selenium leached from consecutive passes of water in unsaturated soil column laboratory tests was defined. For both two-dimensional and threedimensional models, desorption of Se was reduced in geomorphic fills. Reduction in Se desorption for the geomorphic fill can be directly attributed to two characteristics of geomorphic reclamation apparent from groundwater modeling: decreased infiltration and decreased groundwater residence time. In all models, infiltrating water that affected large volumes of fill resided within the fill for shorter periods of time, resulting in a lower percentage of Se being 
desorbed from the fill material. The critical locations with respect to Se desorption appeared to be fill volumes furthest from the toe and closest to the valley bottom. The water contacting these fill volumes required the longest time to travel through and discharge from the fill, resulting in the highest Se desorption.

\subsection{Implications of the study}

The goal of this research was to improve our understanding of implementing geomorphic reclamation in the central Appalachian region of the United States. To date, geomorphic reclamation in central Appalachia has been analyzed on a broad scale (Michael et al., 2010; Sears et al., 2013; Sears et al., 2014; Russell et al., 2014). This study quantitatively investigated the individual issues and benefits associated with geomorphic reclamation on a scale at which potential pilot construction projects would be implemented. Comprehensively, these findings can inform the next step of analysis of geomorphic reclamation in central Appalachia. The following contributions to the body of knowledge resulted from this research:

1. Field work and spatial analysis were used to compile a dataset of geomorphic properties of undisturbed landforms in central Appalachia, including drainage lengths, drainage densities, slopes, aspects, vegetation, and headwater channel properties. These data can be used to generate future geomorphic landform designs in central Appalachia and compare designs to existing, undisturbed geomorphology. Data can also serve as the basis for future field work and spatial analysis of the geomorphology of central Appalachia. The methodology developed can be applied to additional areas in Appalachia, as well as other areas of the United States. Evaluation criteria for mature and long-term reclaimed landforms can be used for any future selection of field data collection sites.

2. A series of conceptual geomorphic designs quantified and confirmed the potential issues associated with GLD with respect to landform stability, channel mitigation, and material volumes. Conceptual designs provided recommendations on the practicality of implementing a small scale geomorphic design as an alternative to a conventional valley fill. The criteria for analysis of geomorphic reclaimed landforms can continue to be used for analysis of future geomorphic designs in central Appalachia. The characteristics of the most successful geomorphic reclamation design for an individual valley fill have been 
defined, and the compromises that must be considered with respect to current reclamation regulations have been made apparent. Potential benefits with respect to landform shape and function have been highlighted. These findings can inform decision-making agencies, such as the Office of Surface Mining Reclamation and Enforcement (OSMRE), as to the next step in analyzing geomorphic reclamation in central Appalachia. The methodology and results of conceptual geomorphic designs from this research can also be applied to other regions in which steep slopes are a reclamation concern.

3. A quantitative comparison of the groundwater movement and desorption of selenium between traditional and geomorphic reclamation strategies confirmed the potential benefits of geomorphic reclamation. Appropriate unsaturated soil property functions were determined and can be used in future groundwater modeling. A methodology was developed for pairing groundwater modeling results with contaminant leaching data to obtain a comparison in desorption from valley fill alternatives that is not available through existing finite element modeling techniques. This method can be used in future modeling studies on desorption from contaminated rock and serve as the basis for a desorption modeling tool. Quantified benefits of geomorphic landform design with respect to groundwater and selenium loads may be used when determining the practicality of applying geomorphic principles compared to the quantified drawbacks.

\subsection{Limitations of the study and future research recommendations}

Field work and spatial analysis of geomorphic properties in this study was limited by the number and location of field sites surveyed. The methodology developed in this research can be used to perform additional field work in central Appalachia to supplement the current database of geomorphic properties, as well as be applied to other geographic areas where data on geomorphic properties are lacking. Specifically in central Appalachia, additional landforms and watersheds should be evaluated using the evaluation tools developed in this research. Further evaluations can determine appropriate sites for additional field data collection and spatial analysis, as well as iteratively correct any misconceptions in the developed evaluation criteria. Additional field work should be performed to confirm headwater drainage basin characteristics. By mapping additional channel head sites in the field and collecting the landform properties associated with those channel head sites through spatial analysis (e.g. slope, aspect, contributing 
area, climate, rainfall, geology), a quantitative relationship between channel head location and landform properties can be developed. Using this quantitative relationship and an understanding of its geographic limitations, the amount of field work necessary to accurately define the geomorphic properties of central Appalachian landforms can be reduced in the long-term. On an individual basis, reduced field work can increase the resources allotted to other aspects of the geomorphic reclamation design process while still maintaining confidence in the reference parameters used.

The series of geomorphic designs that have confirmed the issues associated with implementing geomorphic reclamation in central Appalachia were limited by the number and type of fills investigated, the level of analysis, and the software utilized. In this study, two fills were investigated. Future work should investigate a large sample of valley fills in central Appalachia. The characteristics of the most successful design from this research can be applied to a design for each of these additional valley fills. Results of these designs can be used to confirm the findings of this research. The ability of each individual geomorphic design to satisfy the analysis criteria for stability and fill volume developed in this research can be compared to the properties of the area in which the fill is being placed (e.g. fill area, slope of existing ground, valley length). This comparison can be used to determine the characteristics of an individual valley fill reclamation area with the highest potential for successful implementation of a geomorphic design.

Slope stability was analyzed for only critical profiles, but a more comprehensive slope stability analysis should be performed on entire landforms. A pilot construction project is needed to assess constructability and cost issues. Monitoring of the pilot construction project can be used to confirm input design parameters and the criteria used for stability and fill volume analyses, as well as assess the appropriateness of the GeoFluv ${ }^{\mathrm{TM}}$ method. Successful design may involve a compromise between the geomorphic principles that govern the GeoFluv ${ }^{\mathrm{TM}}$ method and manual adjustments by the designer.

The comparison of groundwater modeling and selenium desorption in this research was limited by the assumptions made in groundwater modeling, the available selenium leaching data, and the software used. The purpose of groundwater modeling in this research was to compare results among fill alternatives, rather than to obtain predictive results for individual fills. For this reason, 
models were simplified as to run smoothly and provide a multitude of comparative results. No historical data were available on surface infiltration, groundwater table location, or discharge for the fills modeled to calibrate two-dimensional or three-dimensional models. Instead, a critical review of soil properties was completed to obtain expected values. Groundwater models assumed homogeneous, isotropic soils and uniform infiltration due to these data limitations and model convergence issues. Future studies should test overburden specific to central Appalachian surface mines to obtain all necessary soil properties for accurate groundwater modeling. A fill with historical data on groundwater levels should be used to calibrate individual predictive models. If necessary, models should be constructed with heterogeneous and anisotropic soils, as well as infiltration boundary conditions that reflect seasonal variations in groundwater recharge. Infiltration and groundwater monitoring of a pilot construction project can be used to confirm the results of this research and to calibrate future high accuracy predictive models.

Unsaturated leaching data were limited to 14 consecutive samples, which provided a small snapshot of leaching behavior compared to the life of a valley fill and the amount of time needed to completely desorb a contaminant such as selenium. Future studies should investigate longterm leaching of Se from mine overburden, both in saturated and unsaturated conditions. The finite element modeling software SVOffice, like other modeling software, did not have the ability to model desorption of contaminants from soil. In comparison to solid volume, the volumes of water within groundwater models were also much lower than in laboratory testing. For these reasons, Se desorption was calculated manually based on residence time of water and percentage of Se leached by consecutive passes of water in the laboratory. Tracking groundwater flow length and solid volumes affected by that water over time was very time consuming and complex. Future studies should use the methodology for Se desorption calculation developed in this research to develop a tool that can be used in conjunction with finite element groundwater models to more efficiently and accurately calculate desorption over time.

\subsection{Acknowledgements}

Research pertaining to the geomorphic properties of central Appalachia and conceptual geomorphic reclamation designs was supported by Grant/Cooperative Agreement Number S12AC20029 from the Office of Surface Mining Reclamation and Enforcement (OSMRE). Its 
contents are solely the responsibility of the author and do not necessarily represent the official views of the OSMRE. Research pertaining to groundwater modeling and selenium desorption and transport was supported by Grant/Cooperative Agreement Number G12AP20156 from the United States Geological Survey (USGS). Its contents are solely the responsibility of the author and do not necessarily represent the official views of the USGS. 


\section{REFERENCES}

Abdelghani, F.B., Simon, R., Aubertain, M., Molson, J. and Therrien, R. (2009). "Use of the HydroGeosphere code to simulate water flow and contaminant transport through mining wastes disposed in a symmetric open pit within fractured rock." Proc., Tailings and Mine Waste, University of Alberta, Edmonton, AB, 601-611.

Ataie-Ashtiani, B. (2007). "MODSharp: Regional-scale numerical model for quantifying groundwater flux and contaminant discharge into the coastal zone." Environmental Modeling and Software, 22, 1307-1315. DOI:10.1016/j.envsoft.2006.07.005

Balistrieri, L.S., and Chao, T.T. (1987). "Selenium adsorption by goethite." Soil Science Society of America Journal, 51, 1145-1151. DOI: 10.2136/sssaj1987.03615995005100050009x

Balistrieri, L.S., and Chao, T.T. (1990). "Adsorption of selenium by amorphous iron oxyhydroxide and manganese dioxide." Geochimica et Cosmochimica Acta, 54, 739-751. DOI: 10.1016/0016-7037(90)90369-V

Baur, I., and Johnson, C. (2003). "Sorption of selenite and selenate to cement minerals." Environmental Science and Technology, 37, 3442-3447. DOI: 10.1021/es020148d

Bell, J.C., Daniels, W.L., and Zipper, C.E. (1989). "The practice of "approximate original contour" in the central Appalachians. I. Slope stability and erosion potential." Landscape and Urban Planning, 18, 127-138. DOI: 10.1016/0169-2046(89)90004-2

Benda, L., Hassan, M.A., Church, M., and May, C.L. (2005). "Geomorphology of steepland headwaters: the transition from hillslopes to channels." Journal of the American Water Resources Association, 41(4), 835-951. DOI: 10.1111/j.1752-1688.2005.tb03773.x

Bernhardt, E.S., and Palmer, M.A. (2011). "The environmental costs of mountaintop mining valley fill operations for aquatic ecosystems of the central Appalachians." Annals of the New York Academy of Sciences, 1223, 39-57. DOI: 10.1111/j.1749-6632.2011.05986.x

Blaylock, M.J., Tawfic, T.A., and Vance, G.F. (1995). "Modeling selenium sorption in reclaimed coal mine soil materials." Soil Science, 159, 43-48. DOI: 10.1097/00010694-199501000-00005

Bretschneider, C.A. (1842). "Untersuchung der trigonometrischen Relationen des geradlinigen Viereckes." Archiv der Mathematik und Physik, 2, 225-261.

Brixel, B., Caldwell, J., and Wels, C. (2012). "Groundwater issues in the design, operation and closure of tailings, waste rock, and heap leach facilities." Proc., Tailings and Mine Waste, University of British Columbia, Vancouver, BC, Canada, 347-348.

Brooks, R.H., and Corey, A.T. (1964). "Hydraulic properties of porous media." Colorado State University Hydrology Paper No. 3, Colorado State University, Fort Collins, CO, 27 p. 
Buckley, C., Hopkinson, L., Quaranta, J.D., Mack, B., and Ziemkiewicz, P. (2013).

"Investigating regional design parameters in the design of West Virginia valley fills to support application of geomorphic landform design principles." Environmental Considerations in Energy Production, J.R. Canyon, ed., SME, Englewood, CO, 405-414.

Bugosh, N. (2006). Basic manual for fluvial geomorphic review of landform designs. United States Department of the Interior Office of Surface Mining Reclamation and Enforcement (OSMRE), Denver, CO, 36 p.

Bugosh, N. (2009). "A summary of some land surface and water quality monitoring results for constructed GeoFluv landforms." Proc., Joint Conference of the $26^{\text {th }}$ Annual Meetings of the American Society of Mining and Reclamation (ASMR) and $11^{\text {th }}$ Billings Land Reclamation Symposium, ASMR, Lexington, KY, 153-175.

Carlson Software Inc., and Bugosh, N. (2005). Fluvial Geomorphic Landscape Design Computer Software. US Patent Office, publication number WO/2005/036331, international application number PCT/US2004/02995.

Chapuis, R.P., and Aubertin, M. (2001). "A simplified method to estimate saturated and unsaturated seepage through dikes under steady-state conditions." Canadian Geotechnical Journal, 28, 1321-1328. DOI: 10.1139/cgj-38-6-1321

Chin, K.B., Leong, E.C., and Rahardojo, H. (2010). "A simplified method to estimate the soilwater characteristic curve." Canadian Geotechnical Journal, 20(4), 661-672. DOI: 10.1139/T10033

Churchill, R.R. (1982). "Aspect-induced differences in hillslope processes.” Earth Surface Processes and Landforms, 7, 171.172. DOI: 10.1002/esp.3290070209

Coolidge, J.L. (1939) “A historically interesting formula for the area of a quadrilateral." The American Mathematical Monthly, 46, 345-347. DOI: 10.2307/2302891

DePriest, N.C., Hopkinson, L.C., Quaranta, J.D., and Ziemkiewicz, P.F. (2015). “Geomorphic landform design alternatives for an existing valley fill in central Appalachia, USA: Quantifying the key issues.” Ecological Engineering, 81, 19-29. DOI: 10.1016/j.ecoleng.2015.04.007.

Dietrich, W.E., and Dunne, T. (1993). "The channel head.” Channel Network Hydrology, K. Beven and M.J. Kirby, eds., John Wiley and Sons, Chichester, UK, 175-219.

Domenico, P.A., and Schwartz, F.W. (1990). Physical and chemical hydrogeology, John Wiley \& Sons, New York, NY, 528 p.

Eckels, R., and Bugosh, N. (2010). "Natural approach to mined land rehabilitation." Proc., FIG Congress 2010, International Federation of Surveyors, Copenhagen, Denmark, 17 p. 
Elrashidi, M.A., Adriano, D.C.,Workman, S.M., Lindsey,W.L. (1987). "Chemical equilibria of selenium in soils: a theoretical development." Soil Science, 144(2), 141-152.

DOI: 10.1097/00010694-198708000-00008

Elrashidi, M.A., Adriano, D.C., and Lindsay, W.L. (1989). "Solubility, speciation and transformations of selenium in soils." Selenium in agriculture and the environment, L.W. Jacobs, ed., Soil Science Society of America, Inc., Madison, WI, 51-63.

Evans, K.G. and Willgoose, G.R. (2000). "Post-mining landform evolution modeling: 2. Effects of vegetation and surface ripping." Earth Surface Processes and Landforms, 25, 803-823. DOI: 10.1002/1096-9837(200008)25:8<803::AID-ESP96>3.0.CO;2-4

Ferarri, J.R., Lookingbill, T.R., McCormick, B., Townsend, P.A., and Eshleman, K.N. (2009). "Surface mining and reclamation effects on flood response of watersheds in the central Appalachian Plateau region." Water Resources Research, 45, 1-11. DOI: 10.1029/2008WR007109

Fevrier, L., Martin-Garin, A., and Leclerc, E. (2007). "Variation of the distribution coefficient $(\mathrm{Kd})$ of selenium in soils under various microbial states." Journal of Environmental Radioactivity, 97, 189-205. DOI: 10.1016/j.jenvrad.2007.04.005

Frankenberger, W.T.J., and Engberg, R.A. (1998). Environmental chemistry of selenium, Marcel Dekker, Inc., New York, NY, 713 p.

Fredlund, D.G., Rahardjo, H., and Fredlund, M.D. (2012). Unsaturated soil mechanics in engineering practice, John Wiley \& Sons, Hoboken, NJ, 944 p.

Fredlund, D.G., and Xing, A. (1994). "Equations for the soil-water characteristic curve." Canadian Geotechnical Journal, 31(3), 521-532. DOI: 10.1139/t94-061

Fredlund, D.G., Xing, A., and Huang, S.Y. (1994). "Predicting the permeability function for unsaturated soils using the soil-water characteristic curve." Canadian Geotechnical Journal, 31(4), 533-546. DOI: 10.1139/t94-062

Fredlund, M.D., Wilson, G.W., and Fredlund, D.G. (1998). "Estimation of hydraulic properties of an unsaturated soil us.ing a knowledge-based system." Proc., $2^{\text {nd }}$ International Conference on Unsaturated Soils, International Academic Publishers, Beijing, China, 479-484.

Fredlund, M.D., Wilson, G.W., and Fredlund, D.G. (2002). "Use of the grain-size distribution for estimation of the soil-water characteristics curve." Canadian Geotechnical Journal, 39, 10031117. DOI: 10.1139/T02-049

Freeman, M.C., Pringle, C.M., and Jackson, C.R. (2007). "Hydrologic connectivity and the contribution of stream headwaters to ecological integrity at regional scales." Journal of the American Water Resources Association, 43(1), 5-14. DOI: 10.1111/j.1752-1688.2007.00002.x 
Freeze, R.A. and Cherry, J.A. (1979). “Ch. 9: Groundwater contamination.” Groundwater, Prentice Hall, Englewood Cliffs, NJ, 383-462.

Fritz, K.M., Johnson, B.R., Walters, D.M. (2008). "Physical indicators of hydrologic permanence in forested headwater streams." Journal of the North American Benthological Society, 27(3), 690-704. DOI: 10.1899/07-117.1

Gardner, W.R. (1958). "Some steady state solutions of the unsaturated moisture flow equation with application to evaporation from a water-table." Soil Science Journal, 85(4), 228-232. DOI: 10.1097/00010694-195804000-00006

Gomi, T., Sidle, R.C., Miyata, S., Kosugi, and Ken'ichirou, Onda, Y. (2008). "Dynamic runoff connectivity of overland flow on steep forested hillslopes: Scale effects and runoff transfer." Water Resources Research, 44(8), 1-16. DOI: 10.1029/2007WR005894

Hancock, G. R., and Evans, K.G. (2005). "Channel head location and characteristics using digital elevation models." Earth Surface Processes and Landforms, 31(1), 809-824. DOI:

10.1002/esp. 1285

Harrelson, C.C., Rawling, C.L., and Potyondy, J.P. (1994). "Stream channel reference sites: an illustrated guide to field technique." Report RM-245, Rocky Mountain Research Station, Forest Service, United States Department of Agriculture, Fort Collins, CO, 61 p.

Hawkins, J.W., and Aljoe, W.W. (1992). "Psuedokarst groundwater hydrologic characteristics of a mine spoil aquifer." Mine Water and the Environment, 11(2), 37-52. DOI:

10.1007/BF02919585

Hawkins, J.W. (1994). "Modeling of a reclaimed surface coal mine spoil aquifer using MODFLOW." Proc., International Land Reclamation and Mine Drainage Conference and the Third International Conference on the Abatement of Acidic Drainage, 1, ASMR, Lexington, KY, 20-29.

Hawkins, J.W. (1995). "Impacts on ground-water hydrology from surface coal mining in northern Appalachia.” Proc., International Mine Water Association Symposium, American Institute of Hydrology, Denver, CO, 32-54.

Hawkins, J.W. (2004). "Predictability of surface mine spoil hydrologic properties in the Appalachian Plateau." Ground Water, 42(1), 119-125. DOI: 10.1111/j.17456584.2004.tb02457.x

Heine, R.A., Lant, C.L., and Sengupta, R.R. (2004). "Development and comparison of approaches for automated mapping of stream channel networks." Annals of the Association of American Geographers, 94(3), 477-790. DOI: 10.1111/j.1467-8306.2004.00409.x 
Henkle, J.E., Wohl, E., and Beckman, N. (2011). "Locations of channel heads in the semiarid Colorado Front Range, USA." Geomorphology, 129, 309-319. DOI:

10.1016/j.geomorph.2011.02.026

Horton, R.E. (1932). "Drainage basin characteristics.” Trans., American Geophysical Union, 13(1), 350-361. DOI: 10.1029/TR013i001p00350

Isabel, D., Gelinas, P.J., Bourque, E., Nastev, M. and Precourt, S. (1994). "Water budget for waste rock dump at La Mine Doyon, Quebec." MEND Report 1.14.2d, Département de géologie et de génie géologique, Université Laval, Quebec, Canada, 50 p.

James, L.A., Watson, D.G., and Hansen, W.F. (2006). "Using LiDAR data to map gullies and headwater streams under forest canopy: South Carolina, USA." Catena, 1-13. DOI: 10.1016/j.catena.2006.10.010

Johnson, E.A., Rudin, M.J., Steinberg, S.M., and Johnson, W.H. (2000). “The sorption of selenite on various cement formulations." Waste Management, 20, 509-516. DOI:

10.1016/S0956-053X(00)00024-6

Jorgenson, D.W., and Gardner, T.W. (1987). "Infiltration capacity of disturbed soils: temporal change and lithologic control." Journal of the American Water Resources Association, 23(6). DOI: $10.1111 /$ j.1752-1688.1987.tb00868

Julian, J.P., Elmore, A.J., and Guinn, S.M. (2012). "Channel head locations in forested watersheds across the mid-Atlantic United States: a physiographic analysis." Geomorphology, 177-188, 194-203. DOI: 10.1016/j.geomorph.2012.07.029

Kaplan, D.I., and Serne, R.J. (1995). "Distribution coefficient values describing iodine, neptunium, selenium, technetium, and uranium sorption to Hanford sediments." $P N L-10379$, Pacific Northwest Laboratory, Richland, Washington, 25 p.

Langbein, W.B., and Iseri, K.T. (1960). "General introduction and hydrologic definitions. Manual of Hydrology: Part 1. General surface-water techniques.” U.S. Geological Survey WaterSupply Paper 1541-A, USGS, Washington, D.C., 33 p.

Maher, T.P., and Dovovan, J.J. (1995). "Hydrogeologic characterization of local scale hydraulic properties in a weathered acidic minespoil." Proc., National Meeting of the American Society for Surface Mining and Reclamation, ASMR, Lexington, KY, 741-753.

Mao, X., Prommer, H., Barry, D.A., Langevin, C.D., Panteleit, B., and Li, L. (2006). 'Threedimensional model for multi-component reactive transport with variable density groundwater flow." Environmental Modeling and Software, 21, 615-628. DOI: 10.1016/j.envsoft.2004.11.008

Mark, D.M. (1983). "Relations between field-surveyed channel networks and map-based geomorphometric measures, Inez, Kentucky." Annals of the Association of American Geographers, 73(3), 35-372. DOI: 10.1111/j.1467-8306.1983.tb01422.x 
Martin-Duque, J.F., Pedraza, J., Diez, A., Sanz, M.A., and Carrasco, R.M. (1998). “A geomorphological design for the rehabilitation of an abandoned sand quarry in central Spain." Landscape and Urban Planning, 42(1), 1-14. DOI: 10.1016/S0169-2046(98)00070-X

Martin-Duque, J.F., Sanz, M.A., Bodoque, J.M., Lucia, A., and Martin-Moreno, C. (2010). "Restoring earth surface processes through landform design. A 13-year monitoring of a geomorphic reclamation model for quarries on slopes." Earth Surface Processes and Landforms, 35(5), 531-548. DOI: 10.1002/esp. 1950

Martin-Moreno, C., Martin-Duque, J.F., Nicolau, J.M., Sanchez, L., Ruiz, R., Sanze, M.A., Lucia, A., and Zapico, I. (2008). "A geomorphic approach for the ecological restoration of kaolin mines at the Upper Tagus Natural Park (Spain)." Proc., $6^{\text {th }}$ European Conference on Ecological Restoration, Research Institute for Nature and Forest (INBO), Brussels, Belgium, 1-4.

McNamara, J.P, Ziegler, A.D., Wood, S.H., and Vogler, J.B. (2005). "Channel head locations with respect to geomorphologic thresholds derived from a digital elevation model: a case study in northern Thailand." Forest Ecology and Management, 224, 147-156. DOI:

10.1016/j.foreco.2005.12.014

Measles, D., and Bugosh, N. (2007). "Making and building a fluvial geomorphic reclamation design at an active draggling mine using the GeoFluv ${ }^{\mathrm{TM}}$ design method." Proc., Joint Conference of the 24th Annual Meetings of the American Society of Mining and Reclamation, ASMR, Lexington, KY, 449-456.

Meek, A., O’dell, K., and Faulkner, B. (2012). "Selenium Treatment Arch-Eastern, Birch Mine." Proc., West Virginia Mine Drainage Task Force Symposium. West Virginia Mine Drainage Task Force, Morgantown, WV.

Meyer, J.L., and Wallace, J.B. (2001). "Lost linkages and lotic ecology: rediscovering small streams.” Ecology: Achievement and Challenge, M. Press, N. Huntly, and S. Levin, eds., Blackwell Science, Oxford, UK, 295-317.

Michael, P., Superfesky, M., and Uranoswki, L. (2010). “Challenges of applying geomorphic and stream reclamation methodologies to mountaintop mining and excess spoil fill construction in steep slope topography (e.g. central Appalachia)." Proc., Joint Conference of the $27^{\text {th }}$ Annual Meetings of the American Society of Mining and Reclamation, $12^{\text {th }}$ Annual Pennsylvania Abandoned Mine Reclamation Conference, and $4^{\text {th }}$ Annual Appalachian Regional Reforestation Initiative Mined Land Reforestation Conference, ASMR, Lexington, KY, 610-634.

Miller, A.J., and Zegre, N.P. (2014). "Mountaintop removal mining and catchment hydrology." Water, 6, 472-499. DOI: 10.3390/w6030472

Milliman, J.D., and Syvitsi, J.P.M. (1992). “Geomorphic/tectonic control of sediment discharge to the ocean: the importance of small mountain rivers." Journal of Geology, 100(5), 525-544. DOI: $10.1086 / 629606$ 
Montgomery, D.R., and Dietrich, W.E. (1988). "Where do channels begin?" Nature, 336(6196), 232-234. DOI: $10.1038 / 336232 \mathrm{a} 0$

Montgomery, D.R., and Dietrich, W.E. (1989). "Source areas, drainage density, and channel initiation." Water Resources Research, 25(8), 1907-1918. DOI: 10.1029/WR025i008p01907

Montgomery, D.R., and Dietrich, W.E. (1992). "Channel initiation and the problem of landscape scale." Science, 255, 826-255. DOI: 10.1126/science.255.5046.826

Montgomery, D.R., and Foufoula-Georgiou, E. (1993). "Channel network source representation using digital elevation models." Water Resources Research, 29(12), 3925-3934. DOI:

10.1029/93WR02463

Morris, D.A., and A.I. Johnson, (1967). "Summary of hydrologic and physical properties of rock and soil materials as analyzed by the Hydrologic Laboratory of the U.S. Geological Survey." Water-Supply Paper 1839-D, U.S. Geological Survey, Washington, D.C., 42 p.

Mualem, Y. (1976). "A new model for predicting hydraulic conductivity of unsaturated porous media." Water Resources Research, 12, 513-522. DOI: 10.1029/WR012i003p00513

National Oceanic and Atmospheric Administration (NOAA). (2014a). "National Weather Service." < http://hdsc.nws.noaa.gov> (Jul. 29, 2014).

NOAA. (2014b). "Precipitation Frequency Data Server (PFDS)." Hydrometeorological Design Studies Center. <http://hdsc.nws.noaa.gov> (Nov. 20, 2013).

Negley, T.L., and Eshleman, K.N. (2006). "Comparison of stormflow responses on surfacemined and forested watersheds in the Appalachian Mountains, USA.” Hydrological Processes, 20, 3467-3483. DOI: 10.1002/hyp.6148

Nicolau, J.M. (2003). "Trends in relief design and construction in opencast mining reclamation." Land Degradation and Development, 14, 215-226. DOI: 10.1002/ldr.548

Oiller, C.D. (1967). "Landform description without stage names." Australian Geographical Studies, 5, 73-80. DOI: 10.1111/j.1467-8470.1967.tb00751.x

Palmer, M.A., Bernhardt, E.S., Schlesinger, W.H., Eshleman, K.N., Foufoula-Georgiou, E., Hendryx, M.S., Lemly, A.D., Likens, G.E., Loucks, O.L., Power, M.E., White, P.S. and Wilcock, P.R. (2010). "Mountaintop mining consequences.” Science, 327, 148-149. DOI: 10.1126/science. 1180543

Paybins, K.S. (2003). "Flow origin, drainage area, and hydrologic characteristics of headwater streams in the mountaintop coal-mining region of southern West Virginia, 2000-01." Water Resources Investigation Report 02-4300, USGS, Charleston, WV, 20 p. 
Peterson, D.M., Kautskey, M., Karp, K.E., Wright, T., and Metzler, D.R. (2004). "Modeling of density-dependent groundwater flow and transport at the uranium mill tailings site near Moab, Utah." Proc., Tailings and Mine Waste, Taylor \& Francis Group, London, UK, 185-194.

Pham, H.Q. (2005). "A volume-mass constitutive model for unsaturated models." Ph.D. Thesis, University of Saskatchwan, Saskatoon, SK, Canada, 532 p.

Pumure, I., Renton, J.J., and Smart, R.B. (2009). "Accelerated aqueous leaching of selenium and arsenic from coal associated rock samples with selenium speciation using ultrasound extraction." Environmental Geology, 56, 985-991. DOI: 10.10007/s00254-008-1200-9

Pumure, I., Renton, J.J., Smart, R.B. (2010). "Ultrasonic extraction of arsenic and selenium from rocks associated with mountaintop removal/valley fills coal mining: estimation of bioaccessible concentrations." Chemosphere, 78, 1295-1300. DOI: 10.1016/j.chemosphere.2010.01.020

Ritter, J.R., and Gardner, T.W. (1993). "Hydrologic evolution of drainage basins disturbed by surface mining, central Pennsylvania." Geological Society of America Bulletin, 105(1), 101-115. DOI: 10.1130/0016-7606(1993)105<0101:HEODBD>2.3.CO;2

Robson, M. Spots, R., Wade, R., and Erickson, W. (2009). “A case history: Limestone quarry reclamation using fluvial geomorphic design techniques." Proc., Joint Conference of the $26^{\text {th }}$ Annual Meetings of the American Society of Mining and Reclamation and $11^{\text {th }}$ Billings Land Reclamation Symposium, ASMR, Lexington, KY, 1166-1175.

Rosgen, D.L. (1994). “A classification of natural rivers.” Catena, 22(3), 169-199. DOI: 10.1016/0341-8162(94)90001-9

Roy, M. (2005). “A detailed sequential extraction study of selenium in coal and coal-associated strata from a coal mine in West Virginia." M.S. Thesis, West Virginia University, Morgantown, WV, 83 p.

Rudin, M.J. (1996). "Leaching of selenium from cement-based matrices." Waste Management, 16(4), 305-311. DOI: 10.1016/S0956-053X(96)00073-6

Russell, H.B. (2012). "Soil and slope stability study of geomorphic landform profiles versus approximate original contour for valley fill designs." M.S. Thesis, West Virginia University, Morgantown, WV, $238 \mathrm{p}$.

Russell, H., DePriest, N., and Quaranta, J.D. (2014). "Stability analysis comparison of conventional valley-fill to geomorphic landform designs." Trans., Society of Mining Metallurgy and Exploration, 336, 414-420.

Sayler, K.L. (2008). "Land cover trends: central Appalachians." United States Department of the Interior, U.S. Geological Survey, Washington, D.C. <http://landcovertrends.usgs.gov/east/eco69Report.html> (Nov, 20, 2013) 
Schor, H.J., and Gray, D.H. (2007). Landforming: an environmental approach to hillside development, nine Reclamation and watershed restoration, John Wiley \& Sons, Hoboken, NJ, $368 \mathrm{p}$.

Sears, A.E., Bise, C.J., Quaranta, J.D., and Hopkinson, L.C. (2013). "Methodology for geomorphic landform design of valley-fills in Appalachia surface mine reclamation." Environmental Considerations in Energy Production, J.R. Canyon, ed., SME, Englewood, CO, 397-404.

Sears, A.E., Bise, C.J., Quaranta, J.D., and Hopkinson, L.C. (2014). "Field and modeling study for stream mitigation on surface mine sites in West Virginia." Mining Engineering, 66(5), 48-53.

Sharma, K.D., Singh, H.P., and Pareek, O.P. (1983). "Rainwater infiltration into a bare loamy sand." Hydrological Sciences Journal, 28(3), 417-424. DOI: 10.1080/02626668309491980

Sharmasarkar, S., and Vance, G.F. (2002). "Selenite-selenate sorption in surface coal mine environment." Advances in Environmental Research, 7, 87-95. DOI: 10.1016/S10930191(01)00110-1

Sheppard, M.I., and Thibuault, D.H. (1990). "Default soil solid/liquid partition coefficients, Kds for four major soil types: a compendium.” Health Physics, 59(4), 471-82. DOI:

Shields, A. (1936). "Anwendung der Aehnlichkeitsmechanik und der Turbulenzforschung auf die Geschiebebewgung." Mitteilungen der Preussische Versuchanstalt für Wasserbau und Schiffbau Berlin, Eigenverl, 26 p.

Sparks, D.L. (1989). Kinetics of soil chemical processes, Academic Press, San Diego, CA, 210 p.

Strager, M., and Maxwell, A. (2011). Forest fragmentation of WV. West Virginia Wetland Inventory and Modeling Project Phase III. <http://wvgis.wvu.edu/data/dataset.php?ID=453> (Nov. 30, 2013)

Svec, J.R., Kolka, R.K., and Stringer, J.W. (2005). "Defining perennial, intermittent, and ephemeral channels in Eastern Kentucky: Application to forestry best management practices." Forest Ecology and Management, 214(1-3), 170-182. DOI: 10.1016/j.foreco.2005.04.008

Swaine, D.J. (1990). Trace elements in coal. Butterwork \& Co., Ltd., London, England, 292 p.

Torres, G.H. (2011). "Estimating the soil-water characteristic curve using grain-size analysis and plasticity index.” M.S. Thesis, Arizona State University, Tempe, AZ, 257 p.

Townsend, P.A., Helmers, D.P., Kingdon, C.C., McNeil, B.E., de Beurs, K.M., and Eshleman, K.N. (2009). "Changes in the extent of surface mining and reclamation in the central Appalachians detected using a 1976-2006 Landsat time series." Remote Sensing of Environment, 113, 62-72. DOI: 10.1016/j.rse.2008.08.012 
Toy, T.J., and Chuse, W.R. (2005). "Topographical reconstruction: a geomorphic approach." Ecological Engineering, 24, 29-35. DOI: 10.1016/j.ecoleng.2004.12.014

U.S. Army Corps of Engineers (USACE). (2003). "Engineering design - slope stability." EM No. 1110-2-1902. USACE, Washington, DC, 205 p.

U.S. Department of Agriculture (USDA). (2007). "Ch. 19 - Transmission losses." National Engineering Handbook. USDA, Washington, D.C., 36 p.

U.S. Environmental Protection Agency (USEPA). (1999). Chronic aquatic life criterion selenium. United States Environmental Protection Agency - National Recommended Water Quality Criteria.

<http://water.epa.gov/scitech/swguidance/standards/criteria/current/index.cfm\#R> (Nov. 30, 2013).

USEPA. (2005). Final Programmatic Environmental Impact Statement (PEIS) on Mountaintop Mining/Valley Fills in Appalachia (EPA 9-03-R-05002), U.S. Environmental Protection Agency. $<$ http://www.epa.gov/region03/mtntop/eis2005.htm> (July 14, 2014).

USEPA. (2011). "The Effects of Mountaintop Mines and Valley Fills on Aquatic Ecosystems of the Central Appalachian Coalfields." 2011 Final Report, EPA/600/R-09/138F, USEPA, Washington, DC, $137 \mathrm{p}$.

USEPA. (2013). "Level III ecoregions of the continental United States: Corvallis, Oregon, U.S. EPA - National Health and Environmental Effects Research Laboratory, map scale 1:7,500,000." <http://www.epa.gov/wed/pages/ecoregions/level_iii_iv.htm> (July 14, 2014).

USEPA. (2015). "Draft aquatic life ambient water quality criterion for selenium - freshwater." EPA 822-P-15-001, USEPA Office of Water, Washington, D.C., 740 p.

United States Geological Survey (USGS). (2003a). Streams - National Hydrography Dataset (NHD - 24k). The National Map. <http://wvgis.wvu.edu/data/dataset.php?ID=235> (Nov. 30, 2013).

USGS. (2003b). Digital elevation models (USGS 3-meter). USGS Seamless Data Distribution System, $1 / 9^{\text {th }}$ Arc Second, National Elevation Dataset.

<http://wvgis.wvu.edu/data/dataset.php?ID=261> (Nov. 30, 2013).

van Genuchten, M.T. (1980). "A closed-form equation for predicting the hydraulic conductivity of unsaturated soils." Journal of Soil Science Society of America, 44, 892-898. DOI:

10.2136/sssaj1980.03615995004400050002x

Vereecken, H., Maes, J., Feyen, J., and Darius, P. (1989). "Estimation the soil moisture retention characteristics from texture, bulk density, and carbon content." Soil Science Journal, 148(6), 389-403. DOI: 10.1097/00010694-198912000-00001 
Vesper, D.J., Roy, M., and Rhoads, C.J. (2008). "Selenium distribution and mode of occurrence in the Kanawha Formation, southern West Virginia, U.S.A." International Journal of Coal Geology, 73(3), 237-249. DOI: 10.1016/j.coal.2007.06.003

Villines, J.A. (2013). "Using GIS to delineate headwater stream origins in the Appalachian coalbelt region of Kentucky.” M.S. Thesis, University of Kentucky, Lexington, KY, 134 p.

Vogt, J.V., Colombo, R., and Bertolo, F. (2003). "Deriving drainage networks and catchment boundaries: a new methodology combining digital elevation data and environmental characteristics." Geomorphology, 53, 281-298. DOI: 10.1016/S0169-555X(02)00319-7

Wang, T., Wang, J., and Burken, J.G. (2007). "The leaching characteristics of selenium from coal fly ashes." Journal of Environmental Quality, 36(6), 1794-1792. DOI: $10.2134 /$ jeq2007.0143

Wels, C., Ferguson, P.R., and Fawcett, M. (2012). "Numerical groundwater flow modeling at the historic Rum Jungle mine site, Northern Territory, Australia." Proc., International Mine Water Association (IMWA) Annual Conference, C.D. McCullough, M.A. Lund, and L. Wyse, eds., IMWA, Bunbury, Australia, 309-315.

West Virginia Department of Environmental Protection (WVDEP). (1993). Technical handbook: Standards and specifications for erosion and sediment control excess spoil disposal haulages. WVDEP, Division of Mining and Reclamation (DMR), Charleston, WV, 320 p.

WVDEP. (1999). "Section 29: AOC and excess spoil disposal." Permit Handbook: Policies and Procedures for Permit Applications. WVDEP, DMR, Charleston, WV, 8 p.

Wiley, J.B., Evaldi, R.D., Eychaner, J.H., and Chambers, D.B. (2001). "Reconnaissance of stream geormorphology, lower stream flow, and stream temperature in the mountaintop coalmining region, southern West Virginia," Water-Resources Investigations Report 01-4092, USGS, 1999-2000, 34 p.

Wilson, L.G., Decook, K.J., and Neuman, S.P. (1980). "Final report: Regional recharge research for Southwest alluvial basins." Water Resources Research Center, Department of Hydrology and Water Resources, University of Arizona, Tuczon, AZ, 370 p.

Wolfman, M.G. (1954). “A method of sampling coarse-river bed material.” Transactions, American Geophysical Union, 35(6), 951-956. DOI: 10.1029/TR035i006p00951

Zapata, C.E. (1999). "Uncertainty in soil-water characteristic curve and impacts on unsaturated shear strength predictions.” Ph.D. These, Arizona State University, Tempe, AZ.

Zhang, P., and Sparks, D.L. (1990). "Kinetics of selenate and selenite adsorption/desorption at the goethite/water interface." Environmental Science and Technology, 24, 1848-1856. DOI: $10.1021 / \mathrm{es} 00082 \mathrm{a} 010$ 
Ziemkiewicz, P., O'Neal, M., and Lovett, R. (2011). "Selenium leaching kinetics and in-situ control." Mine Water \& the Environment, 30(2), 141-150. DOI: 10.1007/s10230-011-0154-4

Zipper, C.E., Daniels, W.L., and Bell, J.C. (1989a). "Approximate original contour reclamation: an alternative in steep slope terrains." Journal of Soil and Water Conservation, 44(4), 279-283.

Zipper, C.E., Daniels, W.L., and Bell, J.C. (1989b). "The practice of "approximate original contour" in the central Appalachians. II. Economic and environmental consequences of an alternative." Landscape Urban Planning, 18, 139-152. DOI: 10.1016/0169-2046(89)90005-4

Zipper, C.E., Burger, J.A., Skousen, J.G., Angel, P.N., Barton, C.D., Davis, V., and Franklin, J.A. (2011). "Restoring forests and associated ecosystem services on Appalachian coal surface mines." Environmental Management, 47, 751-765. DOI: 10.1007/s00267-011-9670-z 


\section{APPENDIX A. REFERENCE LANDFORM SELECTION}

$\underline{\text { Mature landforms }}$

The regional (Table A.1 - Table A.6) and watershed (Table A.7 - Table A.9) evaluations for the potential mature landform field data collection locations are presented in the following tables. Locations that passed the Regional Evaluation Phase were Twin Falls State Park, Cabwaylingo State Forest, East Lynn Lake Wildlife Management Area, Laurel Lake Wildlife Management Area, and R.D. Bailey Lake. Ultimately, Jackson and Dixon watersheds at Twin Falls State Park and Wiley watershed at Cabwaylingo State Forest were selected for field data collection.

Table A.1. Regional evaluation matrix for Twin Falls State Park.

\begin{tabular}{|c|c|c|c|c|}
\hline Property & Weight & Score & $\begin{array}{l}\text { Weighted } \\
\text { Score }\end{array}$ & Comments \\
\hline Landuse & 1 & 4 & 4 & Forested, southern WV, slightly disturbed \\
\hline Topography & 1 & 5 & 5 & Steep slopes, forested \\
\hline History & 3 & 3 & 9 & $\begin{array}{c}\text { Completed in } 1970 \text { s, slightly disturbed from roads } \\
\text { and recreational areas }\end{array}$ \\
\hline $\begin{array}{l}\text { GIS data } \\
\text { availability }\end{array}$ & 5 & 5 & 25 & GIS data readily available \\
\hline Access potential & 5 & 5 & 25 & $\begin{array}{c}\text { State park, readily accessible, road system } \\
\text { throughout park }\end{array}$ \\
\hline Total & & & 68 & $\begin{array}{c}\text { Score adequate to move to Watershed } \\
\text { Evaluation Phase }\end{array}$ \\
\hline
\end{tabular}

Note: $1=$ Poor, $5=$ Excellent

Score of $60 / 75$ is adequate for further consideration 
Table A.2. Regional evaluation for Cabwaylingo State Forest.

\begin{tabular}{|c|c|c|c|c|}
\hline Property & Weight & Score & $\begin{array}{l}\text { Weighted } \\
\text { Score }\end{array}$ & Comments \\
\hline Landuse & 1 & 5 & 5 & Mature forest, southern WV \\
\hline Topography & 1 & 5 & 5 & Steep terrain, forested \\
\hline History & 3 & 4 & 12 & Undisturbed, completed in 1930s \\
\hline $\begin{array}{l}\text { GIS data } \\
\text { availability }\end{array}$ & 5 & 5 & 25 & GIS data readily available \\
\hline Access potential & 5 & 5 & 25 & $\begin{array}{c}\text { State forest, readily accessible, roads and trails } \\
\text { throughout park }\end{array}$ \\
\hline Total & & & 72 & $\begin{array}{l}\text { Score adequate to move to Watershed } \\
\text { Evaluation Phase }\end{array}$ \\
\hline
\end{tabular}

Note: $1=$ Poor, 5 = Excellent

Score of $60 / 75$ is adequate for further consideration 
Table A.3. Regional evaluation for East Lynn Lake Wildlife Management Area.

\begin{tabular}{|c|c|c|c|c|}
\hline Property & Weight & Score & $\begin{array}{l}\text { Weighted } \\
\text { Score }\end{array}$ & Comments \\
\hline Landuse & 1 & 5 & 5 & Mature forest, southern WV, not disturbed \\
\hline Topography & 1 & 5 & 5 & $\begin{array}{c}\text { Steep, forested, } 90 \% \text { covereage by oak-hickory } \\
\text { forest }\end{array}$ \\
\hline History & 3 & 4 & 12 & $\begin{array}{c}\text { Lake completed in } 1970 \text { s, owned by USACE, } \\
\text { managed by DNR, little disturbance }\end{array}$ \\
\hline $\begin{array}{l}\text { GIS data } \\
\text { availability }\end{array}$ & 5 & 5 & 25 & GIS data readily available \\
\hline Access potential & 5 & 5 & 25 & $\begin{array}{l}\text { Readily accessible, decent network of roads } \\
\text { throughout park }\end{array}$ \\
\hline Total & & & 72 & $\begin{array}{l}\text { Score adequate to move to Watershed } \\
\text { Evaluation Phase }\end{array}$ \\
\hline
\end{tabular}

Note: $1=$ Poor, 5 = Excellent

Score of $60 / 75$ is adequate for further consideration 
Table A.4. Regional evaluation for Laurel Lake Wildlife Management Area.

\begin{tabular}{|c|c|c|c|c|}
\hline Property & Weight & Score & $\begin{array}{l}\text { Weighted } \\
\text { Score }\end{array}$ & Comments \\
\hline Landuse & 1 & 3 & 3 & Mostly mature forest but disturbed \\
\hline Topography & 1 & 5 & 5 & Steep terrain and narrow valleys, forested \\
\hline History & 3 & 1 & 3 & $\begin{array}{c}\text { Constructed in } 1960 \text { s, active mining, slides, valley } \\
\text { fills }\end{array}$ \\
\hline $\begin{array}{l}\text { GIS data } \\
\text { availability }\end{array}$ & 5 & 5 & 25 & GIS data readily available \\
\hline Access potential & 5 & 5 & 25 & $\begin{array}{l}\text { Wildlife Management Area so readily accessible, } \\
\text { network of trails throughout park }\end{array}$ \\
\hline Total & & & 61 & $\begin{array}{l}\text { Score adequate to move to Watershed } \\
\text { Evaluation Phase }\end{array}$ \\
\hline
\end{tabular}

Note: $1=$ Poor, $5=$ Excellent

Score of $60 / 75$ is adequate for further consideration 
Table A.5. Regional evaluation for R.D. Bailey Lake.

\begin{tabular}{|c|c|c|c|c|}
\hline Property & Weight & Score & $\begin{array}{l}\text { Weighted } \\
\text { Score }\end{array}$ & Comments \\
\hline Landuse & 1 & 3 & 3 & Mostly mature forest but disturbed \\
\hline Topography & 1 & 5 & 5 & Forested, steep slopes \\
\hline History & 3 & 1 & 3 & Completed in 1970 s, much active mining in area \\
\hline $\begin{array}{l}\text { GIS data } \\
\text { availability }\end{array}$ & 5 & 5 & 25 & GIS data readily available \\
\hline Access potential & 5 & 5 & 25 & Readily accessible \\
\hline Total & & & 61 & $\begin{array}{c}\text { Score adequate to move to Watershed } \\
\text { Evaluation Phase }\end{array}$ \\
\hline
\end{tabular}

Note: $1=$ Poor, $5=$ Excellent

Score of $60 / 75$ is adequate for further consideration

Table A.6. Regional evaluation for Beech Fork State Park.

\begin{tabular}{|c|c|c|c|c|}
\hline Property & Weight & Score & $\begin{array}{l}\text { Weighted } \\
\text { Score }\end{array}$ & Comments \\
\hline Landuse & 1 & 5 & 5 & Mature forest, southern WV, not disturbed \\
\hline Topography & 1 & 3 & 3 & Forested but not very steep \\
\hline History & 3 & 3 & 9 & $\begin{array}{l}\text { Lake completed in 1970s, owned by USACE, } \\
\text { disturbance from construction of lakefront } \\
\text { properties }\end{array}$ \\
\hline $\begin{array}{l}\text { GIS data } \\
\text { availability }\end{array}$ & 5 & 5 & 25 & GIS data readily available \\
\hline Access potential & 5 & 3 & 15 & $\begin{array}{l}\text { Access around lake area but not to less disturbed } \\
\text { areas }\end{array}$ \\
\hline Total & & & 57 & $\begin{array}{c}\text { Score not adequate to move to Watershed } \\
\text { Evaluation Phase }\end{array}$ \\
\hline
\end{tabular}

Note: $1=$ Poor, $5=$ Excellent

Score of $60 / 75$ is adequate for further consideration 
Table A.7. Dixon watershed evaluation.

\begin{tabular}{|c|c|c|c|c|}
\hline Property & Weight & Score & Weighted Score & Comments \\
\hline Accessibility & 5 & 5 & 25 & Majority of watershed is easily accessible \\
\hline Watershed Size & 5 & 5 & 25 & $\begin{array}{l}\text { Watershed size is appropriate for } \\
\text { applying to geomorphic landform design }\end{array}$ \\
\hline Streams/Channels & 5 & 3 & 15 & $\begin{array}{c}\text { Some channels affected by trails } \\
\text { throughout slope but majority are } \\
\text { undisturbed }\end{array}$ \\
\hline Vegetation & 3 & 5 & 15 & Mature forest with thick cover \\
\hline History & 3 & 2 & 6 & $\begin{array}{c}\text { Some areas of watershed disturbed by } \\
\text { park trails throughout slope }\end{array}$ \\
\hline Total & & & 86 & Score adequate for field data collection \\
\hline
\end{tabular}

Note: $1=$ Poor, $5=$ Excellent

Score of $84 / 105$ is adequate for further consideration

Table A.8. Jackson watershed evaluation.

\begin{tabular}{|c|c|c|c|c|}
\hline Property & Weight & Score & Weighted Score & Comments \\
\hline Accessibility & 5 & 5 & 25 & Majority of watershed is easily accessible \\
\hline Watershed Size & 5 & 5 & 25 & Watershed size is appropriate for \\
applying to geomorphic landform design
\end{tabular}

Note: $1=$ Poor, $5=$ Excellent

Score of $84 / 105$ is adequate for further consideration

Table A.9. Wiley watershed evaluation.

\begin{tabular}{|c|c|c|c|c|}
\hline Property & Weight & Score & Weighted Score & $\begin{array}{c}\text { Comments } \\
\text { Accessibility }\end{array}$ \\
\hline inaccessible by road or lie within private \\
property
\end{tabular}

Note: $1=$ Poor, $5=$ Excellent

Score of $84 / 105$ is adequate for further consideration 
$\underline{\text { Long-term reclaimed sites }}$

The regional (Table A.10) and watershed (Table A.11 - Table A.14) evaluations for the potential long-term reclaimed field data collection locations are presented in the following tables. A longterm reclaimed site in Summersville, WV passed the regional evaluation. Ultimately, the northwest and southwest facing valley fills were selected for field data collection.

Table A.10. Regional evaluation for Summersville long-term reclaimed site.

\begin{tabular}{|c|c|c|c|l|}
\hline Property & Weight & Score & Weighted Score & \multicolumn{1}{c|}{ Comments } \\
\hline Reclaimed Landuse & 3 & 5 & 15 & $\begin{array}{l}\text { Reclaimed landuse is woodland; only disturbance is } \\
\text { road to top of area and radio tower at top; } 4 \text { valley } \\
\text { fills in reclaimed area }\end{array}$ \\
\hline GIS data availability & 5 & 5 & 12 & $\begin{array}{l}\text { All fills in area have completed bond release } \\
\text { and have been completed for 15-20 years; no } \\
\text { information on stability was available }\end{array}$ \\
\hline Access potential & 5 & 5 & 25 & $\begin{array}{l}\text { All necessary GIS data for the area is } \\
\text { available }\end{array}$ \\
\hline Total & 5 & 25 & $\begin{array}{l}\text { A road to the top of the fill area provides } \\
\text { access to all fills in the area }\end{array}$ \\
\hline
\end{tabular}

Note: 1 = Poor, 5 = Excellent

Score of $64 / 80$ is adequate for further consideration

Table A.11. Watershed evaluation for northwest facing valley fill in Summersville, WV.

\begin{tabular}{|c|c|c|c|l|}
\hline Property & Weight & Score & Weighted Score & \multicolumn{1}{c|}{ Comments } \\
\hline Accessibility & 5 & 4 & 20 & $\begin{array}{l}\text { Access to fill from road; road slightly } \\
\text { disturbs fill; permission to access } \\
\text { obtained from landowner }\end{array}$ \\
\hline Watershed Size & 5 & 5 & 25 & $\begin{array}{l}\text { Watershed size is appropriate for } \\
\text { geomorphic landform design }\end{array}$ \\
\hline Vegetation & 3 & 5 & 15 & Mature vegetation \\
\hline History & 1 & 5 & 5 & $\begin{array}{l}\text { Fill's bonding process completed } \\
\text { between 1990 and 1996 }\end{array}$ \\
\hline Total & & & 65 & $\begin{array}{l}\text { Score adequate for field data } \\
\text { collection }\end{array}$ \\
\hline
\end{tabular}

Note: $1=$ Poor, $5=$ Excellent

Score of $56 / 70$ is adequate for further consideration 
Table A.12. Watershed evaluation for southwest facing valley fill in Summersville, WV.

\begin{tabular}{|c|c|c|c|l|}
\hline Property & Weight & Score & Weighted Score & \multicolumn{1}{c|}{ Comments } \\
\hline Accessibility & 5 & 5 & 25 & $\begin{array}{l}\text { Access to fill from road; permission to } \\
\text { access obtained from landowner }\end{array}$ \\
\hline Watershed Size & 5 & 3 & 15 & $\begin{array}{l}\text { Watershed is slightly smaller than } \\
\text { desired for GLD }\end{array}$ \\
\hline Vegetation & 3 & 5 & 15 & Mature vegetation \\
\hline History & 1 & 5 & 5 & $\begin{array}{l}\text { Fill's bonding process completed in } \\
1990\end{array}$ \\
\hline Total & & & 60 & $\begin{array}{l}\text { Score adequate for field data } \\
\text { collection }\end{array}$ \\
\hline
\end{tabular}

Note: 1 = Poor, 5 = Excellent

Score of $56 / 70$ is adequate for further consideration

Table A.13. Watershed evaluation for northeast facing valley fill in Summersville, WV.

\begin{tabular}{|c|c|c|c|l|}
\hline Property & Weight & Score & Weighted Score & \multicolumn{1}{c|}{ Comments } \\
\hline Accessibility & 5 & 1 & 5 & $\begin{array}{l}\text { Fill is accessible by road, but } \\
\text { landownder permission could not be } \\
\text { obtained }\end{array}$ \\
\hline Watershed Size & 5 & 3 & 15 & $\begin{array}{l}\text { Watershed size is slightly smaller } \\
\text { than needed for GLD }\end{array}$ \\
\hline Vegetation & 3 & 5 & 15 & Mature vegetation \\
\hline History & 1 & 5 & 5 & $\begin{array}{l}\text { Fill's bonding proccess completed } \\
\text { in 1990 }\end{array}$ \\
\hline Total & & & 40 & $\begin{array}{l}\text { Score not adequate for field data } \\
\text { collection }\end{array}$ \\
\hline
\end{tabular}

Note: $1=$ Poor, $5=$ Excellent

Score of $56 / 70$ is adequate for further consideration

Table A.14. Watershed evaluation for southeast facing valley fill in Summersville, WV.

\begin{tabular}{|c|c|c|c|l|}
\hline Property & Weight & Score & Weighted Score & \multicolumn{1}{c|}{ Comments } \\
\hline Accessibility & 5 & 1 & 5 & $\begin{array}{l}\text { Fill is accessible by road, but } \\
\text { landownder permission could not be } \\
\text { obtained }\end{array}$ \\
\hline Watershed Size & 5 & 5 & 25 & $\begin{array}{l}\text { Watershed size is appropriate for } \\
\text { GLD }\end{array}$ \\
\hline Vegetation & 3 & 5 & 15 & Mature vegetation \\
\hline History & 1 & 5 & 5 & $\begin{array}{l}\text { Fill's bonding proccess completed } \\
\text { in 1990 }\end{array}$ \\
\hline Total & & & 50 & $\begin{array}{l}\text { Score not adequate for field data } \\
\text { collection }\end{array}$ \\
\hline
\end{tabular}

Note: 1 = Poor, 5 = Excellent

Score of $56 / 70$ is adequate for further consideration 


\section{APPENDIX B. REFERENCE LANDFORM CHARACTERISTICS}

Table B.1. Site properties - Dixon watershed.

\begin{tabular}{|c|c|c|c|c|c|c|c|c|c|c|}
\hline \multirow[b]{2}{*}{ Site } & \multicolumn{5}{|c|}{ Channel Properties } & \multicolumn{4}{|c|}{ Bank Properties } & \multirow[b]{2}{*}{$\begin{array}{l}\text { Pebble } \\
\text { count? }\end{array}$} \\
\hline & $\begin{array}{l}\text { Width } \\
\text { (ft) }\end{array}$ & $\begin{array}{l}\text { Upstream } \\
\text { slope }(\%)\end{array}$ & $\begin{array}{c}\text { Downstream } \\
\text { slope }(\%)\end{array}$ & $\begin{array}{l}\text { Left } \\
\text { slope } \\
(\%)\end{array}$ & $\begin{array}{r}\text { Right } \\
\text { slope } \\
(\%)\end{array}$ & $\begin{array}{l}\text { Left } \\
\text { slope } \\
(\%)\end{array}$ & $\begin{array}{r}\text { Right } \\
\text { slope } \\
(\%)\end{array}$ & $\begin{array}{c}\text { Left } \\
\text { bank } \\
\text { veg. } \\
(\%)\end{array}$ & $\begin{array}{c}\text { Right } \\
\text { bank } \\
\text { veg. } \\
(\%)\end{array}$ & \\
\hline D1 & 4.6 & 19 & 14 & 14 & 22 & $0-3$ & $0-3$ & $60-80$ & $60-80$ & no \\
\hline D2 & 22 & 22 & 19 & 30 & 34 & $9-15$ & $9-15$ & $60-80$ & $60-80$ & yes \\
\hline D3 & 2.7 & 31 & 16 & 32 & 34 & $9-15$ & $9-15$ & $60-80$ & $60-80$ & yes \\
\hline D4 & 3.3 & 21 & 18 & 20 & 26 & $4-8$ & $4-8$ & $60-80$ & $60-80$ & yes \\
\hline D5 & 3 & 19 & 22 & 21 & 15 & $0-3$ & $0-3$ & $80-100$ & $80-100$ & no \\
\hline D5A & NA & NA & NA & NA & NA & NA & NA & NA & NA & no \\
\hline D6 & 3 & 29 & 12 & 30 & 40 & $4-8$ & $4-8$ & $40-60$ & $40-60$ & yes \\
\hline D7 & 2.1 & 21 & 19 & 26 & 24 & $0-3$ & $0-3$ & $40-60$ & $40-60$ & yes \\
\hline $\mathrm{DM}$ & 18.4 & 6 & 3 & 38 & 11 & 41532 & 41532 & $60-80$ & $60-80$ & yes \\
\hline DM-MF & 25.4 & 3 & 2 & 37 & 10 & $16-25$ & $9-15$ & $80-100$ & $80-100$ & yes \\
\hline $\begin{array}{l}\text { Dixon } \\
\text { Head }\end{array}$ & 5 & 18 & 25 & 17 & 14 & $4-8$ & $4-8$ & $60-80$ & $60-80$ & yes \\
\hline
\end{tabular}


Table B.2. Site properties - Jackson watershed.

\begin{tabular}{|c|c|c|c|c|c|c|c|c|c|c|}
\hline \multirow[b]{2}{*}{ C:to } & \multirow[b]{2}{*}{$\begin{array}{c}\text { Width } \\
\text { (ft) }\end{array}$} & \multicolumn{3}{|c|}{ Channel Properties } & \multicolumn{6}{|c|}{ Bank Properties } \\
\hline & & $\begin{array}{l}\text { Upstream } \\
\text { slope }(\%)\end{array}$ & $\begin{array}{l}\text { Downstream } \\
\text { slope }(\%)\end{array}$ & $\begin{array}{r}\text { Left } \\
(\%)\end{array}$ & $\begin{array}{c}\text { Right } \\
(\%)\end{array}$ & $\begin{array}{c}\text { Left slope } \\
(\%)\end{array}$ & $\underset{\text { Right }}{\text { Right }}$ & $\begin{array}{c}\text { Left } \\
\text { bank } \\
\text { veg. } \\
(\%)\end{array}$ & $\begin{array}{c}\text { Right } \\
\text { bank } \\
\text { veg. } \\
(\%)\end{array}$ & Daklont? \\
\hline $\mathrm{J} 1$ & 2.7 & 26 & 26 & 10 & 20 & $9-15$ & $9-15$ & $60-80$ & $60-80$ & yes \\
\hline $\mathrm{J} 2$ & 3 & 22 & 26 & 16 & 23 & $9-15$ & $9-15$ & $60-80$ & $60-80$ & yes \\
\hline $\mathrm{J} 3$ & NA & NA & NA & NA & NA & NA & NA & NA & NA & no \\
\hline $\mathrm{J} 3 \mathrm{~A}$ & 4.7 & vertical & 50 & 45 & 0 & $4-8$ & $4-8$ & $40-60$ & $40-60$ & yes \\
\hline $\mathrm{J} 4$ & 2.7 & 14 & 9 & 4 & 31 & $9-15$ & $9-15$ & $60-80$ & $60-80$ & yes \\
\hline $\mathrm{J} 5$ & 2.6 & 25 & 19 & 15 & 19 & $0-3$ & $0-3$ & $20-40$ & $20-40$ & yes \\
\hline J6 & 2.6 & 20 & 20 & 26 & 25 & $0-3$ & $0-3$ & $40-60$ & $40-60$ & no \\
\hline $\mathrm{J} 7$ & NA & NA & NA & NA & NA & NA & NA & NA & NA & no \\
\hline $\mathrm{J} 8$ & 2.4 & 21 & 15 & 8 & 22 & $9-15$ & $9-15$ & $40-60$ & $40-60$ & yes \\
\hline J9 & 9 & 25 & 5 & 31 & 27 & $9-15$ & $9-15$ & $60-80$ & $40-60$ & yes \\
\hline J10 & 5 & 35 & 35 & 15 & 10 & $9-15$ & $4-8$ & $80-100$ & $80-100$ & no \\
\hline $\mathrm{J} 11$ & 4 & 44 & 32 & 7 & 24 & $4-8$ & $4-8$ & $60-80$ & $60-80$ & no \\
\hline $\mathrm{J} 12$ & 3.5 & 26 & 21 & 16 & 17 & $4-8$ & $4-8$ & $40-60$ & $40-60$ & yes \\
\hline
\end{tabular}

Table B.3. Site properties - Wiley watershed.

\begin{tabular}{ccccccccccc}
\hline & \multicolumn{9}{c}{ Channel Properties } & \multicolumn{7}{c}{ Bank Properties } & \\
\cline { 2 - 7 } Site & $\begin{array}{c}\text { Width } \\
\text { (ft) }\end{array}$ & $\begin{array}{c}\text { Upstream } \\
\text { slope (\%) }\end{array}$ & $\begin{array}{c}\text { Downstream } \\
\text { slope (\%) }\end{array}$ & $\begin{array}{c}\text { Left } \\
\text { slope } \\
(\boldsymbol{\%})\end{array}$ & $\begin{array}{c}\text { Right } \\
\text { slope } \\
(\boldsymbol{\%})\end{array}$ & $\begin{array}{c}\text { Left slope } \\
(\boldsymbol{\%})\end{array}$ & $\begin{array}{c}\text { Right } \\
\text { slope } \\
(\boldsymbol{\%})\end{array}$ & $\begin{array}{c}\text { Left } \\
\text { bank } \\
\text { veg. } \\
(\boldsymbol{\%})\end{array}$ & $\begin{array}{c}\text { Right } \\
\text { bank } \\
\text { veg. } \\
(\boldsymbol{\%})\end{array}$ & $\begin{array}{c}\text { Pebble } \\
\text { count? }\end{array}$ \\
\hline W1 & 4 & 52 & 44 & 30 & 28 & $16-25$ & $16-25$ & $60-80$ & $60-80$ & yes \\
W2 & 3.4 & 44 & 40 & 30 & 19 & $16-25$ & $16-25$ & $40-60$ & $40-60$ & yes \\
W3 & 5 & 54 & 54 & 34 & 33 & $16-25$ & $16-25$ & $40-60$ & $40-60$ & no \\
WM & 7.9 & 3 & 2 & 5 & 5 & $16-25$ & $16-25$ & $80-100$ & $80-100$ & yes \\
\hline
\end{tabular}


Table B.4. Critical grain size distribution for pebble count collection sites.

\begin{tabular}{|c|c|c|c|c|c|c|c|}
\hline Site & $D_{50}$ (in) & $D_{84}$ (in) & $\%$ silt/clay & $\%$ sand & $\%$ gravel & $\%$ cobble & $\%$ boulder \\
\hline D2 & 0.03 & 0.75 & 0 & 73 & 22 & 5 & 0 \\
\hline D3 & 0.03 & 0.04 & 0 & 94 & 2 & 4 & 0 \\
\hline D4 & 0.03 & 0.37 & 0 & 63 & 36 & 1 & 0 \\
\hline D6 & 0.04 & 0.63 & 0 & 54 & 46 & 0 & 0 \\
\hline D7 & 0.03 & 0.04 & 0 & 90 & 10 & 0 & 0 \\
\hline DM & 3.23 & 7.87 & 0 & 0 & 36 & 51 & 13 \\
\hline DM-MF & 6.30 & 12.60 & 0 & 0 & 19 & 41 & 40 \\
\hline $\begin{array}{c}\text { Dixon } \\
\text { Head }\end{array}$ & 0.51 & 3.94 & 0 & 19 & 59 & 15 & 7 \\
\hline $\mathrm{J} 1$ & 0.04 & 1.34 & 0 & 59 & 35 & 5 & 1 \\
\hline $\mathrm{J} 2$ & 0.04 & 0.39 & 0 & 57 & 40 & 3 & 0 \\
\hline $\mathrm{J} 3 \mathrm{~A}$ & 0.14 & 0.30 & 0 & 36 & 64 & 0 & 0 \\
\hline $\mathrm{J} 4$ & 0.17 & 0.47 & 0 & 32 & 68 & 0 & 0 \\
\hline J5 & 0.04 & 0.30 & 0 & 57 & 43 & 0 & 0 \\
\hline J8 & 0.26 & 0.75 & 0 & 42 & 57 & 1 & 0 \\
\hline J9 & 0.20 & 2.87 & 0 & 48 & 34 & 15 & 3 \\
\hline $\mathrm{J} 12$ & 0.27 & 0.79 & 0 & 44 & 53 & 3 & 0 \\
\hline W1 & 0.03 & 0.39 & 0 & 61 & 36 & 3 & 0 \\
\hline W2 & 0.03 & 0.27 & 0 & 75 & 25 & 0 & 0 \\
\hline WM & 1.18 & 2.28 & 0 & 7 & 80 & 13 & 0 \\
\hline $\mathrm{S} 1$ & 0.43 & 0.79 & 0 & 23 & 76 & 1 & 0 \\
\hline S3 & 0.33 & 0.63 & 0 & 6 & 93 & 1 & 0 \\
\hline
\end{tabular}



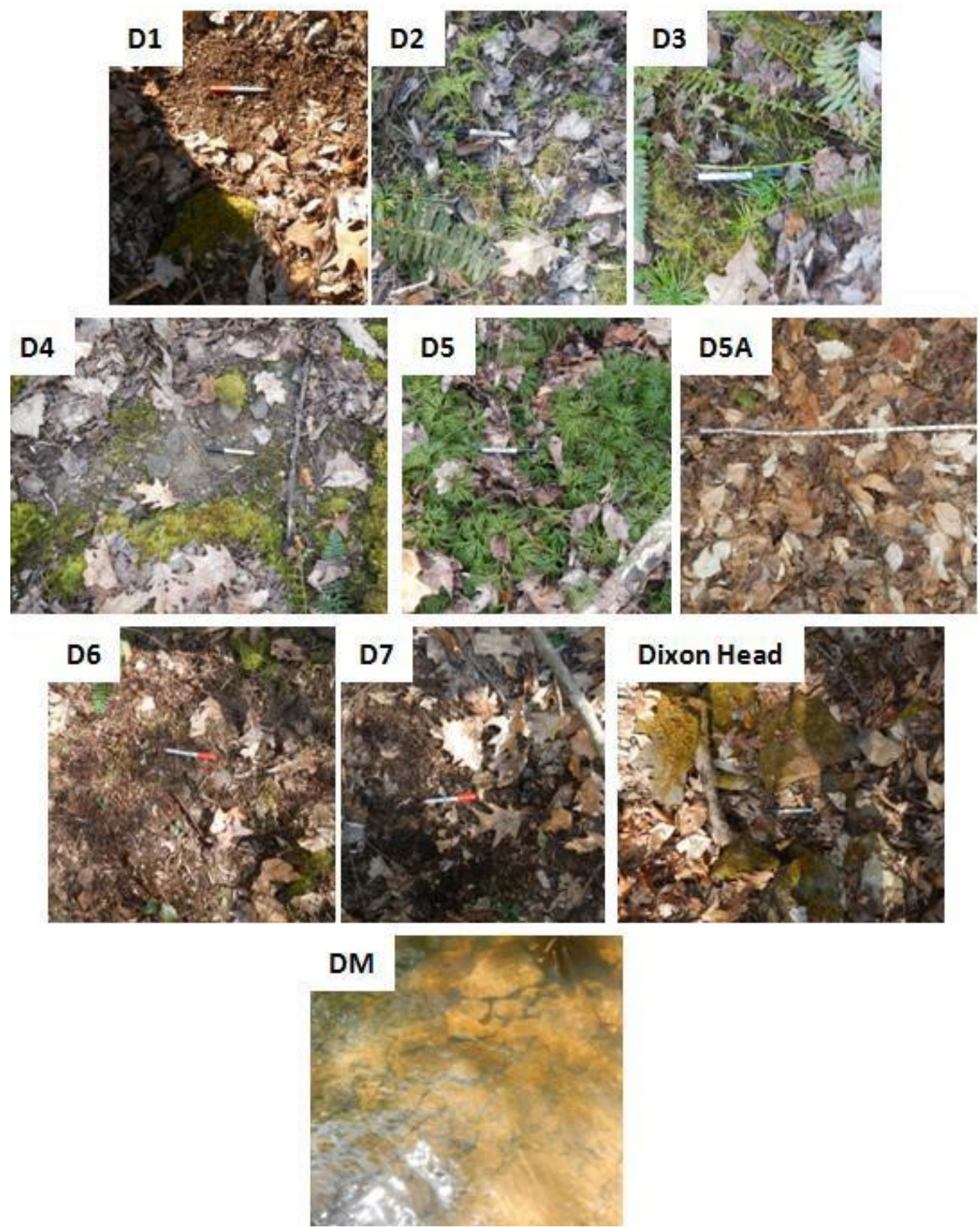

Figure B.1. Channel beds at channel heads and mouth of Dixon watershed. 

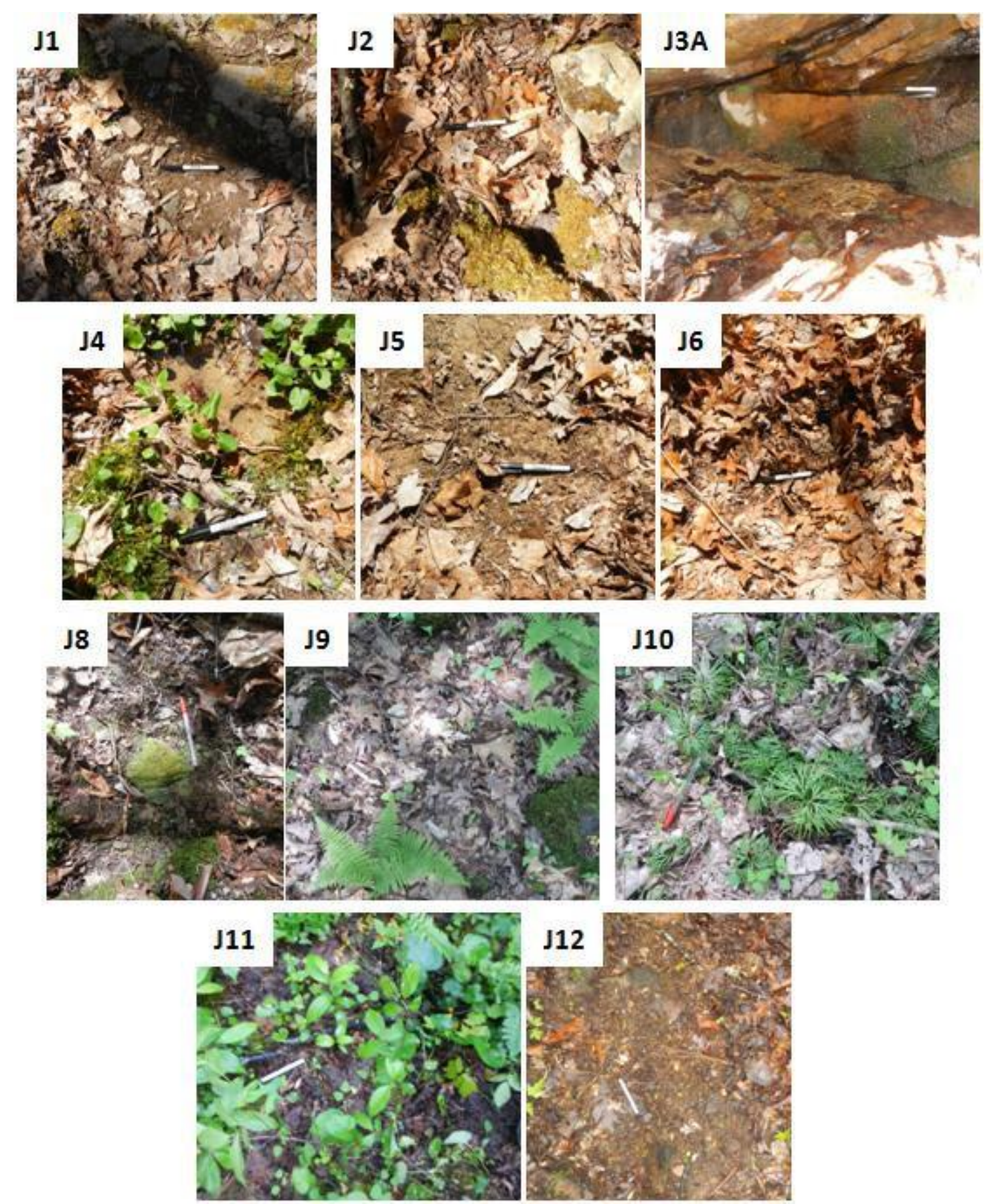

Figure B.2. Channel beds at channel heads in Jackson watershed. 

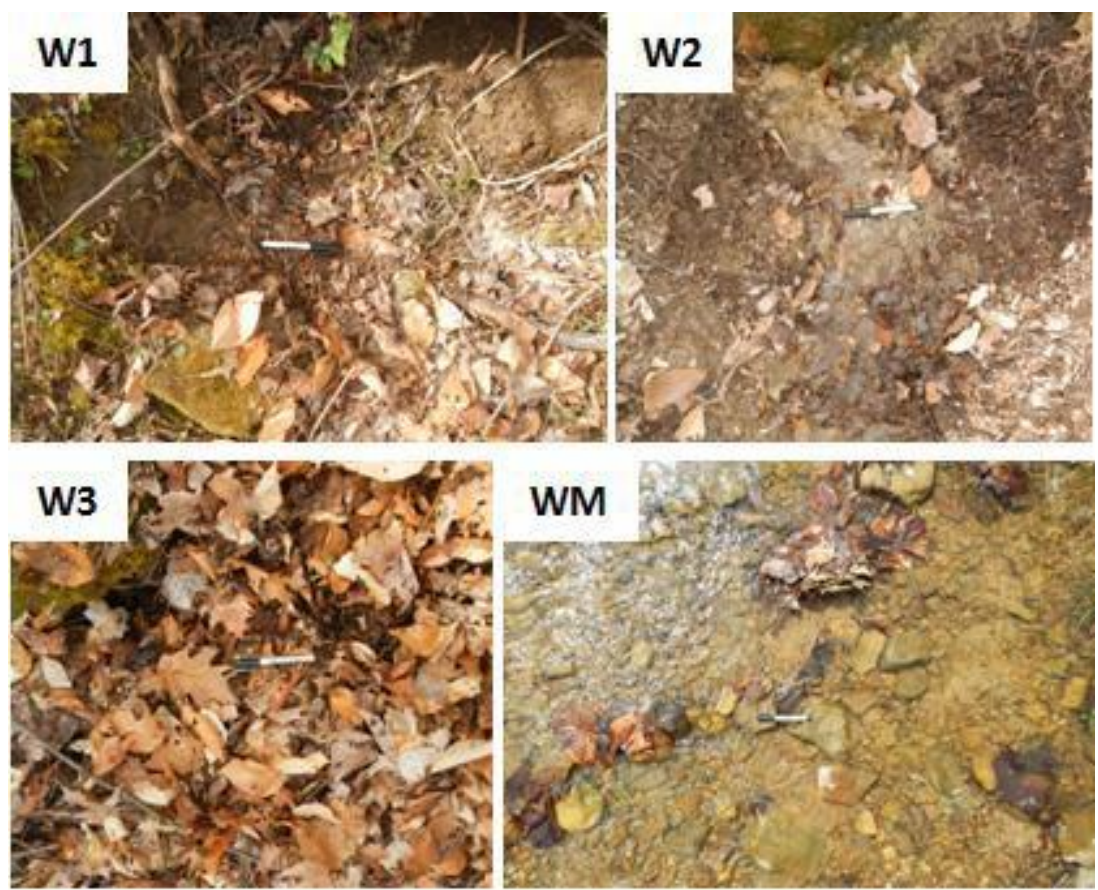

Figure B.3. Channel beds at channel heads and mouth of Wiley watershed.
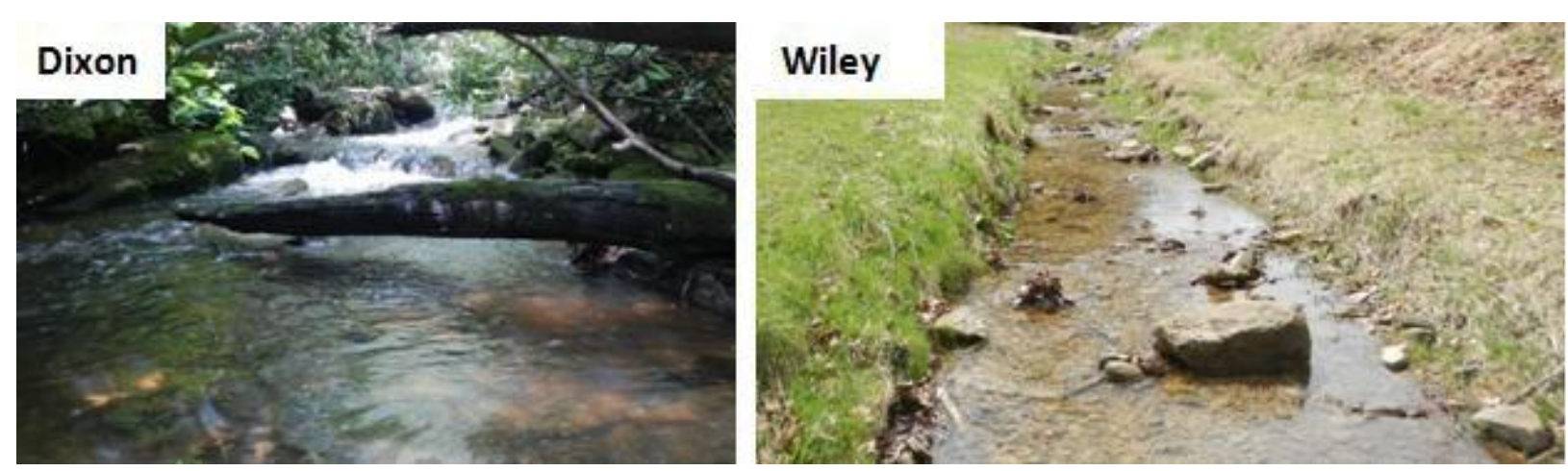

Figure B.4. Mouth (looking upstream) of Dixon and Wiley watersheds.
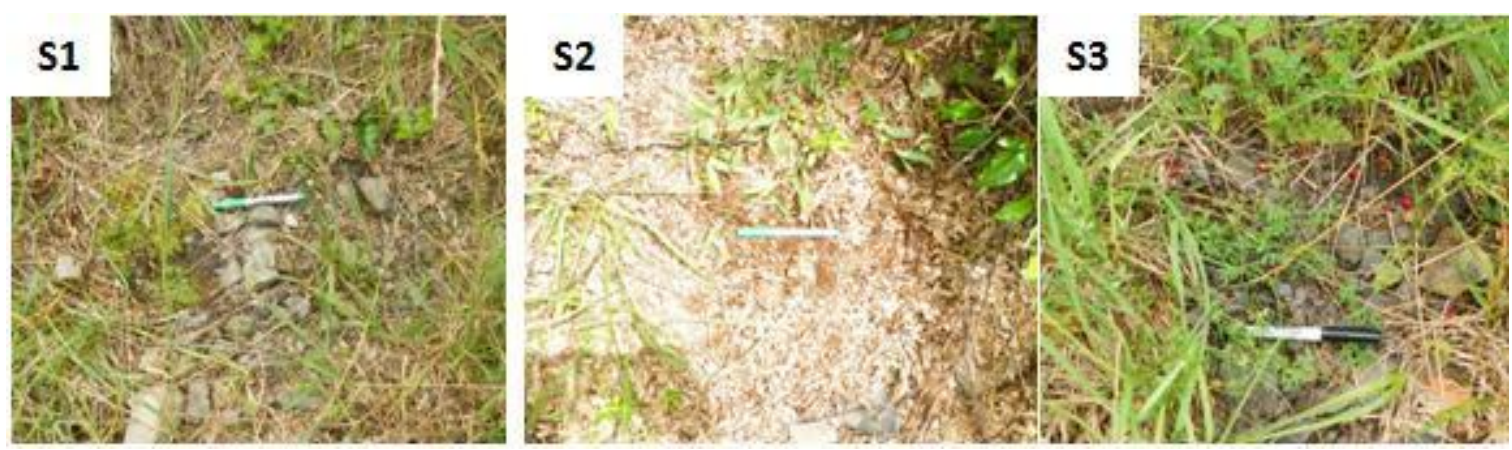

Figure B.5. Photos of erosion sites at Summersville valley fills. 

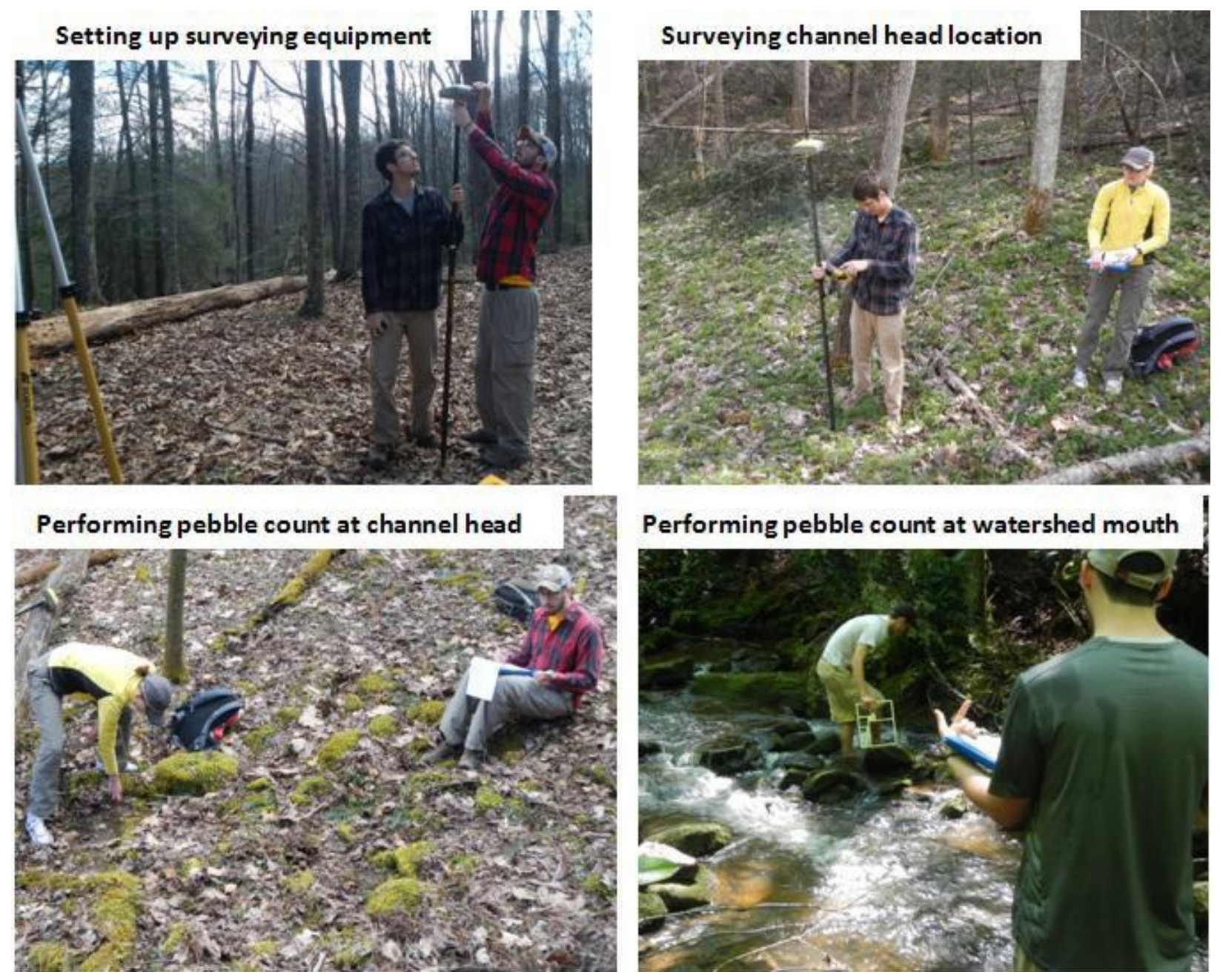

Figure B.6. Photos of field data collection. 


\section{APPENDIX C. GROUNDWATER MODELING AND SELENIUM DESORPTION CALCULATION}

Table C.1. Review of soil properties relevant to groundwater modeling based on literature: saturated hydraulic conductivity $\left(K_{\text {sat }}\right)$, anisotropy ration $\left(K_{H} / K_{v}\right)$, and porosity $(n)$.

\begin{tabular}{ccll}
\hline Property & Value & \multicolumn{1}{c}{ Source } & \multicolumn{1}{c}{ Material type } \\
\hline & 1.47 & Surface mine permit & Sandstone/shale \\
& 46.7 & Peterson et al. (2004) & Gravel/sand \\
& 4.32 & Wels et al. (2012) & Saturated fractured rock \\
$\mathrm{K}_{\mathrm{sat}}$ & 0.86 & Abdelghani et al. (2009) & Fine sand/gravel \\
$(\mathrm{m} / \mathrm{d})$ & 2.51 & Mao et al. (2006) & Waste rock \\
& 42.3 & Ataie-Ashtiani (2007) & Saturated fill material \\
\hline \multirow{3}{*}{$\mathrm{K}_{\mathrm{H}} / \mathrm{K}_{\mathrm{V}}$} & 0.95 & Fredlund et al. (1998) & Gravel/sand \\
& 10 & Peterson et al. (2004) & Sandstone \\
& $2.0-20$ & Domenico and Schwartz (1990) & Shale \\
\hline & 10 & Domenico and Schwartz (1990) & Gravel/sand \\
& 0.30 & Peterson et al. (2004) & Saturated fractured rock \\
& 0.34 & Abdelghani et al. (2009) & Fine sand/gravel \\
& 0.30 & Mao et al. (2006) & Waste rock \\
& 0.35 & Ataie-Ashtiani (2007) & Sandstone \\
& $0.14-0.49$ & Morris and Johnson (1967) & Waste rock \\
\hline
\end{tabular}


Table C.2. Review of soil properties relevant to selenium transport modeling based on literature, lab testing, and surface mine permit file: bulk density $(\rho)$, selenium starting concentration $\left(\mathbf{C}_{0}\right)$, and selenium distribution coefficient $\left(\mathrm{Se} \mathrm{K}_{\mathrm{d}}\right)$.

\begin{tabular}{|c|c|c|c|}
\hline Property & Value & Source & Material type \\
\hline \multirow{2}{*}{$\mathrm{P}\left(\mathrm{kg} / \mathrm{m}^{3}\right)$} & 2002 & Surface mine permit & Overburden \\
\hline & 2244 & Surface mine permit & Bedrock \\
\hline \multirow{14}{*}{$\begin{array}{c}\mathrm{C}_{0} \\
(\mathrm{mg} / \mathrm{kg})\end{array}$} & 1.33 & Surface mine permit & $0.8 \mathrm{ft}$ thick sandstone \\
\hline & 1.49 & Surface mine permit & $1.9 \mathrm{ft}$ thick sandstone \\
\hline & 4.73 & Surface mine permit & $2.6 \mathrm{ft}$ thick sandstone \\
\hline & 1.18 & Surface mine permit & $2.0 \mathrm{ft}$ thick sandstone \\
\hline & 1.84 & Surface mine permit & $2.0 \mathrm{ft}$ thick sandstone \\
\hline & $\begin{array}{l}1.22 \\
2.28\end{array}$ & $\begin{array}{l}\text { Surface mine permit } \\
\text { Surface mine permit }\end{array}$ & $\begin{array}{l}0.9 \mathrm{ft} \text { thick sandstone } \\
1.6 \mathrm{ft} \text { and } 3.0 \mathrm{ft} \text { sandstone }\end{array}$ \\
\hline & 1.12 & Surface mine permit & $5.0 \mathrm{ft}$ sandstone \\
\hline & 1.26 & Eddy, unpublished data & Sandstone \\
\hline & 4.84 & Eddy, unpublished data & Shale \\
\hline & 3.13 & Vesper et al. (2008) & Coal \\
\hline & 3.48 & Vesper et al. (2008) & Carbolith \\
\hline & 0.56 & Vesper et al. (2008) & Shale \\
\hline & 0.54 & Vesper et al. (2008) & Mudstone \\
\hline & 0.51 & Vesper et al. (2008) & Sandstone \\
\hline \multirow{14}{*}{$\begin{array}{l}\mathrm{Se} \mathrm{K}_{\mathrm{d}} \\
(\mathrm{L} / \mathrm{kg})\end{array}$} & $6.90-24.7$ & Eddy, unpublished data & Sandstone \\
\hline & $36.6-86.9$ & Eddy, unpublished data & Shale \\
\hline & 15.8 & Fevrier et al. (2007) & Silty clay \\
\hline & 380 & Baur and Johnson (2003) & Cement minerals; selenite \\
\hline & 2060 & Baur and Johnson (2003) & Cememt minerals; selenate \\
\hline & $350-1100$ & Johnson et al. (2000) & Cement formulations \\
\hline & 0.78 & Kaplan and Serne (1995) & Sand \\
\hline & 150 & Sheppard and Thibault (1990) & Sand \\
\hline & 500 & Sheppard and Thibault (1990) & Silt \\
\hline & 740 & Sheppard and Thibault (1990) & Clay \\
\hline & 1800 & Sheppard and Thibault (1990) & Organics \\
\hline & $7-657$ & Sharmasarkar and Vance (2002) & Mine overburden; selenite \\
\hline & $5-85$ & Sharmasarkar and Vance (2002) & Mine overburden; selenate \\
\hline & 530 & Ziemkiewicz et al (2011) & Coarse coal tailings \\
\hline
\end{tabular}


Table C.3. Review of boundary conditions based on precipitation, infiltration percentages, and infiltration capacities from literature: annual precipitation rate $(P)$, percentage of precipitation attributed to infiltration $\left(I_{P}\right)$, and infiltration rate based on capacity $\left(I_{C}\right)$

\begin{tabular}{|c|c|c|c|}
\hline $\begin{array}{l}\text { Boundary } \\
\text { Condition }\end{array}$ & Value & Source & $\begin{array}{c}\text { Details (location, condition, } \\
\text { material type) }\end{array}$ \\
\hline $\mathrm{P}(\mathrm{m} / \mathrm{d})$ & 0.0039 & NOAA (2014b) & Madison, WV, 1983-2012 \\
\hline \multirow{7}{*}{$\mathrm{I}_{\mathrm{P}}(\%)$} & 36 & Surface mine permit & Reclaimed condition \\
\hline & 10 & Wels et al. (2012) & Humid climate \\
\hline & $50-60$ & Wels et al. (2012) & Reclaimed condition \\
\hline & 58 & Meek et al. (2012) & Valley fill face \\
\hline & 37 & Isabel (1994) & Waste rock pile \\
\hline & $13-94$ & $\begin{array}{l}\text { Jorgensen and Gardner } \\
\text { (1987) }\end{array}$ & Disturbed mine spoil \\
\hline & $54-59$ & $\begin{array}{l}\text { Ritter and Gardner } \\
(1993)\end{array}$ & Reclaimed surface mine \\
\hline \multirow{7}{*}{$\mathrm{I}_{\mathrm{C}}(\mathrm{m} / \mathrm{d})$} & 3.0479 & USDA (2007) & \multirow{2}{*}{$\begin{array}{l}\text { Very clean gravel and large sand } \\
\text { Clean sand and gravel, field } \\
\text { conditions } \\
\text { Sand and gravel mixture with low silt- }\end{array}$} \\
\hline & $1.2191-3.0479$ & USDA (2007) & \\
\hline & $0.6096-1.8287$ & USDA (2007) & clay content \\
\hline & 0.1524-.6096 & USDA (2007) & $\begin{array}{l}\text { Sand and gravel mixture with high } \\
\text { silt-clay content }\end{array}$ \\
\hline & $0.0006-0.0601$ & USDA (2007) & $\begin{array}{l}\text { Consolidated bed material with high } \\
\text { silt-clay content }\end{array}$ \\
\hline & $0.6096-0.7620$ & Wilson et al. (1980) & Unlined canals, gravelly sandy soils \\
\hline & $0.9144-1.8287$ & Wilson et al. (1980) & Unlined canals, very gravelly soils \\
\hline
\end{tabular}


Table C.4. Two-dimensional steady-state models for each fill with varying model conditions: saturated (Sat), unsaturated (US), isotropic (I), anisotropic (A), and stream infiltration rate (Infil) from $0 \%$ to $50 \%$ of total precipitation rate or equal to uncovered infiltration rate.

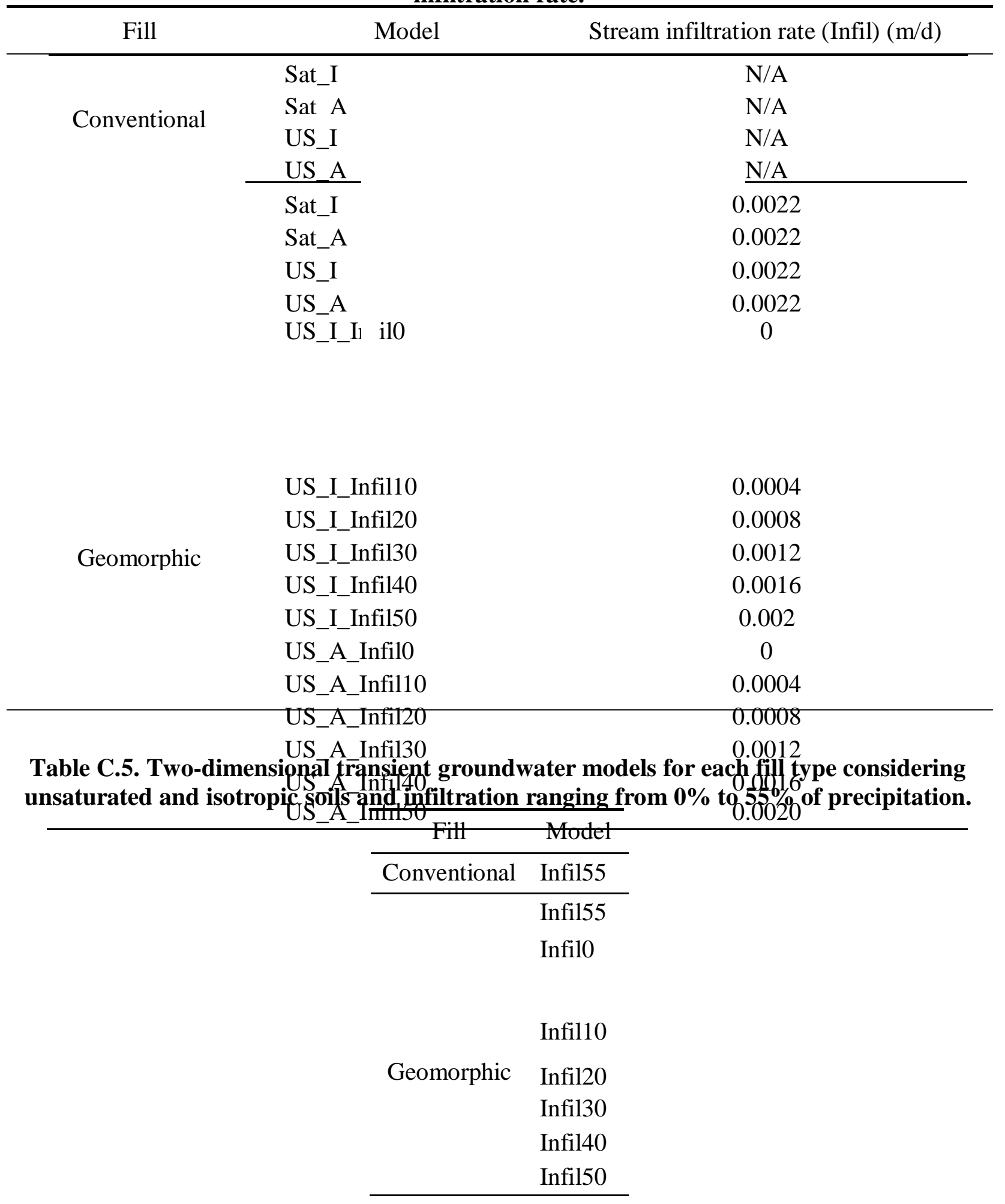


Table C.6. Two-dimensional groundwater particle tracking in conventional fill and geomorphic fill with $10 \%$ infiltration stream. Vs = additional percentage of fill volume contacted by discharging water.

\begin{tabular}{cccc}
\hline \multicolumn{2}{c}{ Conventional } & \multicolumn{2}{c}{ Geomorphic } \\
\hline Time $(\mathrm{d})$ & $\mathrm{V}_{\mathrm{s}}(\%)$ & Time $(\mathrm{d})$ & $\mathrm{V}_{\mathrm{s}}(\%)$ \\
\hline 190 & 0.02 & 77 & 0.10 \\
442 & 0.37 & 153 & 0.30 \\
586 & 0.50 & 372 & 0.91 \\
675 & 1.04 & 1161 & 3.73 \\
734 & 2.53 & 1380 & 3.09 \\
909 & 2.44 & 1445 & 3.47 \\
923 & 3.90 & 1518 & 2.54 \\
1278 & 3.10 & 1613 & 3.27 \\
1518 & 1.39 & 1752 & 3.11 \\
1573 & 2.03 & 1759 & 1.26 \\
1810 & 3.58 & 1810 & 2.97 \\
1851 & 3.78 & 1829 & 41.68 \\
2091 & 4.86 & 1862 & 3.73 \\
2208 & 3.92 & 1865 & 1.91 \\
2289 & 4.55 & 1872 & 4.75 \\
2438 & 5.94 & 1887 & 3.00 \\
2613 & 5.15 & 1902 & 4.06 \\
2748 & 5.00 & 2143 & 1.85 \\
2778 & 1.46 & 2230 & 1.34 \\
3044 & 4.88 & 2467 & 3.55 \\
3128 & 7.83 & 2497 & 1.19 \\
3359 & 1.14 & 3008 & 2.70 \\
3416 & 2.29 & 3070 & 1.75 \\
3460 & 3.30 & 3614 & 2.10 \\
3650 & 24.99 & 3650 & 1.66 \\
\hline & & &
\end{tabular}



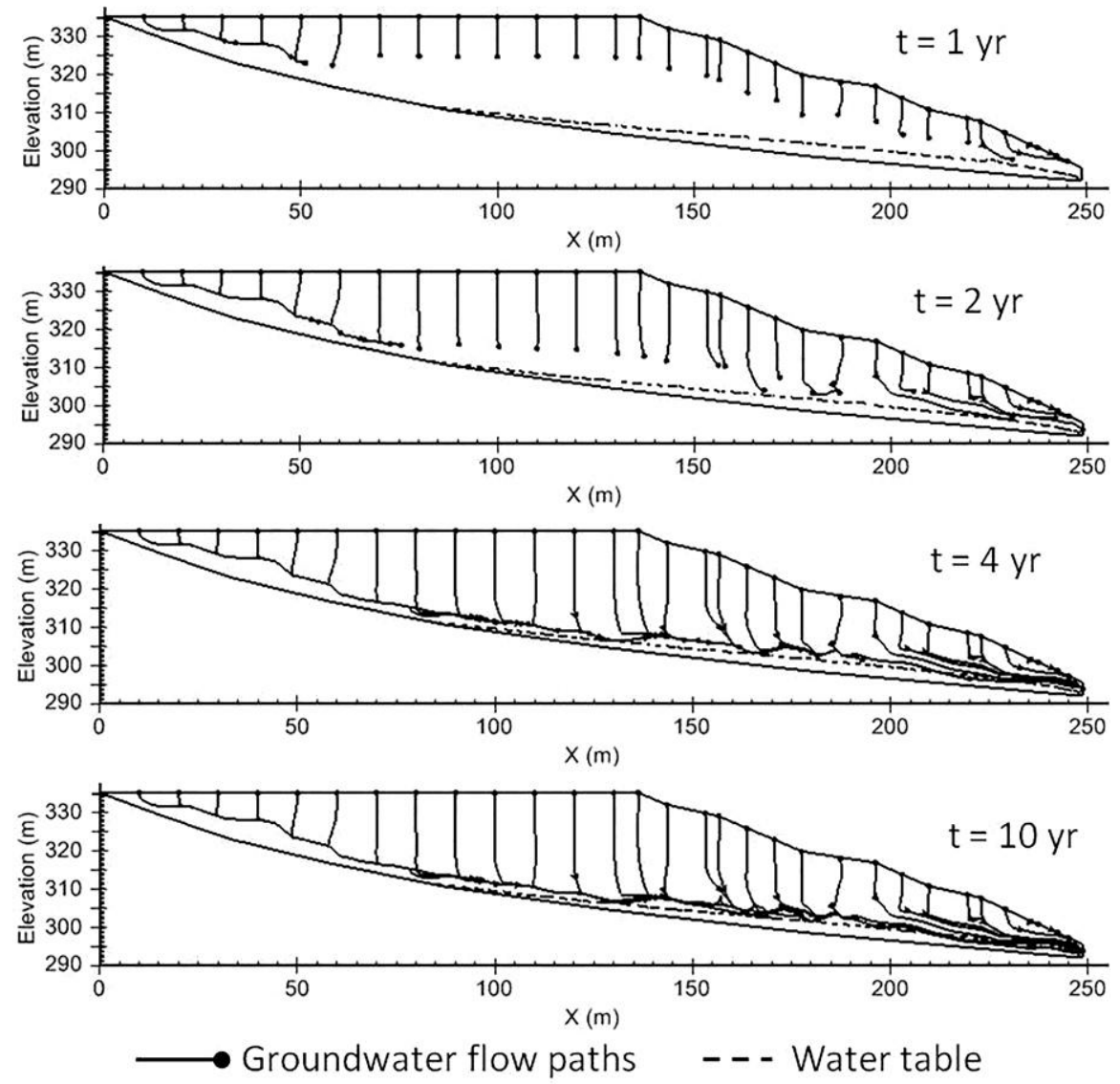

Figure C.1. Two-dimensional particle tracking of groundwater flow paths over time for conventional fill. 

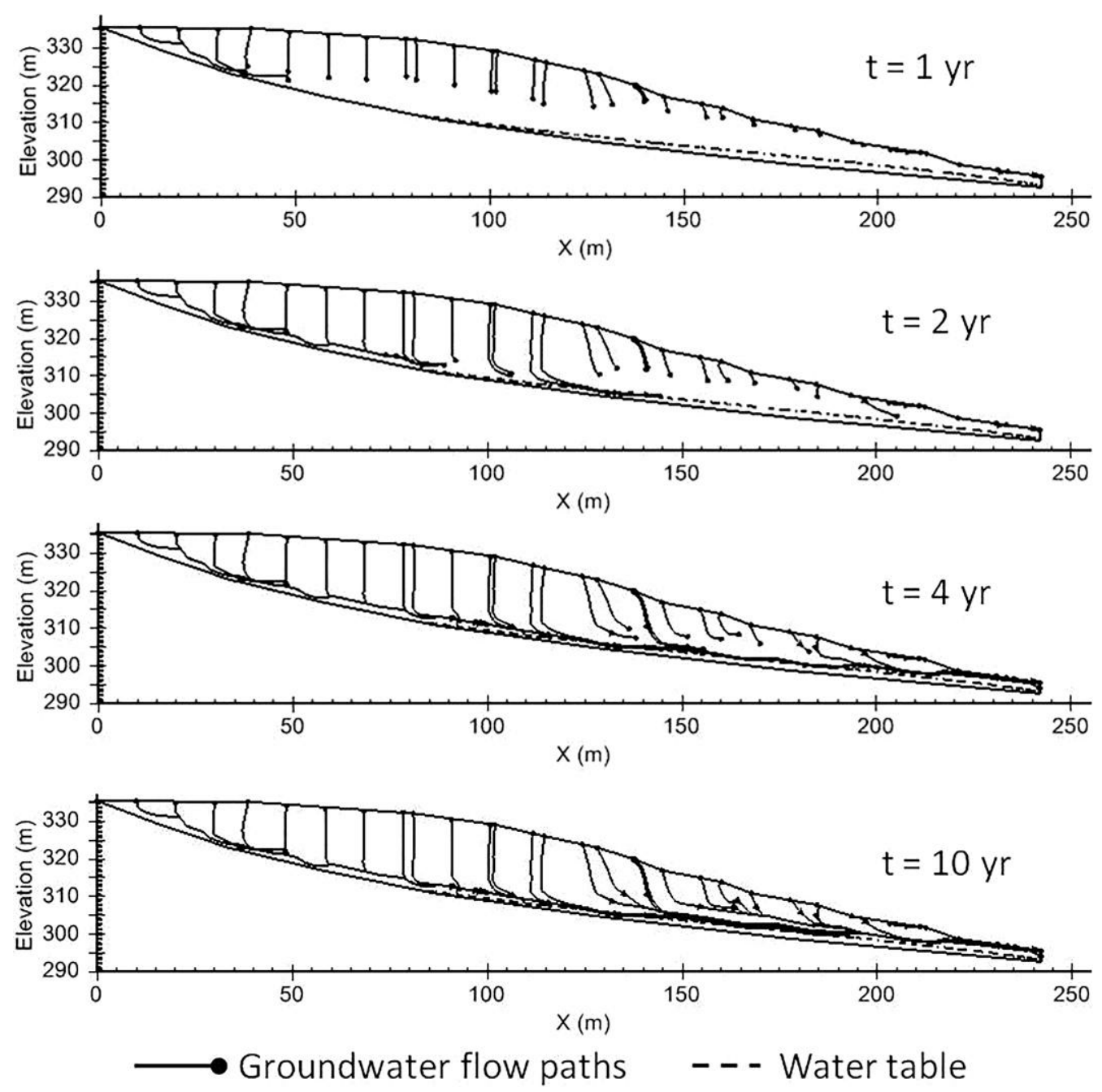

Figure C.2. Two-dimensional particle tracking of groundwater flow paths over time for geomorphic fill with reduced infiltration stream. 
Table C.7. Three-dimensional groundwater particle tracking in conventional fill and geomorphic fill. Vs = additional percentage of fill volume contacted by discharging water.

\begin{tabular}{|c|c|c|c|c|c|c|c|}
\hline \multicolumn{4}{|c|}{ Conventional } & \multicolumn{4}{|c|}{ Geomorphic } \\
\hline Time (d) & $\mathrm{V}_{\mathrm{s}}(\%)$ & Time (d) & $\mathrm{V}_{\mathrm{s}}(\%)$ & Time (d) & $\mathrm{V}_{\mathrm{s}}(\%)$ & Time (d) & $\mathrm{V}_{\mathrm{s}}(\%)$ \\
\hline 1 & 0.00 & 1062 & 1.31 & 3 & 2.15 & 834 & 0.43 \\
\hline 1 & 0.01 & 1069 & 1.28 & 4 & 0.79 & 850 & 0.07 \\
\hline 2 & 0.05 & 1079 & 1.20 & 16 & 0.36 & 882 & 0.21 \\
\hline 8 & 0.39 & 1100 & 0.85 & 30 & 2.22 & 901 & 0.43 \\
\hline 9 & 0.28 & 1118 & 0.33 & 34 & 1.50 & 940 & 0.29 \\
\hline 13 & 0.02 & 1127 & 0.96 & 40 & 1.72 & 975 & 0.64 \\
\hline 20 & 0.13 & 1136 & 1.21 & 45 & 0.72 & 1013 & 0.50 \\
\hline 25 & 0.09 & 1156 & 0.08 & 55 & 0.50 & 1030 & 1.29 \\
\hline 25 & 0.08 & 1158 & 1.25 & 71 & 0.36 & 1059 & 0.64 \\
\hline 28 & 0.02 & 1163 & 1.52 & 81 & 3.15 & 1069 & 0.64 \\
\hline 37 & 0.19 & 1171 & 1.38 & 132 & 0.21 & 1106 & 0.43 \\
\hline 38 & 0.09 & 1191 & 1.61 & 133 & 2.22 & 1145 & 0.79 \\
\hline 41 & 0.04 & 1193 & 1.50 & 143 & 1.07 & 1168 & 0.29 \\
\hline 42 & 0.22 & 1204 & 0.06 & 154 & 0.29 & 1173 & 0.86 \\
\hline 51 & 0.80 & 1219 & 0.13 & 176 & 3.58 & 1285 & 0.07 \\
\hline 56 & 0.05 & 1232 & 1.38 & 198 & 3.29 & 1297 & 0.43 \\
\hline 58 & 0.04 & 1255 & 1.70 & 207 & 0.29 & 1302 & 1.43 \\
\hline 60 & 0.07 & 1256 & 0.73 & 217 & 0.93 & 1335 & 0.07 \\
\hline 60 & 0.24 & 1264 & 0.24 & 222 & 4.08 & 1344 & 0.79 \\
\hline 76 & 0.02 & 1265 & 0.86 & 226 & 0.79 & 1344 & 0.86 \\
\hline 93 & 0.05 & 1281 & 1.51 & 265 & 3.86 & 1355 & 0.43 \\
\hline 94 & 1.11 & 1282 & 0.01 & 290 & 0.79 & 1367 & 0.57 \\
\hline 107 & 0.40 & 1284 & 2.41 & 311 & 4.72 & 1400 & 0.14 \\
\hline 121 & 0.07 & 1287 & 1.79 & 330 & 0.79 & 1465 & 0.02 \\
\hline 121 & 0.14 & 1291 & 1.17 & 336 & 1.79 & 1466 & 0.50 \\
\hline 129 & 0.09 & 1323 & 0.34 & 389 & 0.36 & 1567 & 1.65 \\
\hline 150 & 0.50 & 1328 & 1.82 & 417 & 2.93 & 1583 & 0.43 \\
\hline 156 & 0.61 & 1343 & 1.55 & 439 & 0.14 & 1742 & 0.21 \\
\hline 376 & 1.94 & 1366 & 0.30 & 497 & 4.44 & 1743 & 0.36 \\
\hline 391 & 0.11 & 1398 & 0.09 & 560 & 1.29 & 1771 & 0.79 \\
\hline 396 & 0.34 & 1422 & 1.98 & 561 & 3.08 & 1776 & 0.93 \\
\hline 506 & 1.36 & 1473 & 1.77 & 611 & 3.79 & 1952 & 0.43 \\
\hline 516 & 3.19 & 1493 & 2.07 & 612 & 0.50 & 2003 & 0.93 \\
\hline 528 & 1.31 & 1559 & 0.36 & 618 & 1.36 & 2030 & 1.07 \\
\hline 573 & 0.99 & 1561 & 2.01 & 625 & 0.36 & 2072 & 1.14 \\
\hline 599 & 1.05 & 1600 & 2.22 & 628 & 5.15 & 2192 & 0.72 \\
\hline 674 & 1.42 & 1605 & 1.99 & 632 & 0.72 & 2265 & 0.57 \\
\hline 726 & 1.96 & 1665 & 2.16 & 642 & 1.72 & 2274 & 1.00 \\
\hline
\end{tabular}




\begin{tabular}{cccccccc}
728 & 0.48 & 1685 & 2.21 & 693 & 0.04 & 2386 & 0.36 \\
737 & 2.16 & 1688 & 2.29 & 705 & 0.57 & 2457 & 0.86 \\
738 & 1.05 & 1719 & 0.08 & 734 & 0.86 & 2637 & 1.65 \\
812 & 0.04 & 1720 & 1.27 & 758 & 1.29 & 2674 & 1.07 \\
857 & 1.09 & 1764 & 2.44 & 788 & 0.72 & 2846 & 1.55 \\
861 & 0.08 & 1767 & 1.17 & & & \\
863 & 1.16 & 1795 & 2.50 & & & \\
892 & 2.18 & 1859 & 1.23 & & & \\
923 & 1.27 & 1868 & 1.44 & & & \\
957 & 1.22 & 2000 & 0.84 & & & \\
982 & 1.59 & 2066 & 2.76 & & & \\
1008 & 0.08 & 2087 & 2.89 & & & \\
1050 & 1.18 & 2192 & 0.46 & & & \\
1058 & 0.21 & & & & & \\
\hline
\end{tabular}

